\title{
The definition and policy relevance of monetary aggregates in the Netherlands : an inquiry into the measurement of monetary services
}

Citation for published version (APA):

Janssen, N. G. J. (1995). The definition and policy relevance of monetary aggregates in the Netherlands : an inquiry into the measurement of monetary services. [Doctoral Thesis, Maastricht University]. Datawyse / Universitaire Pers Maastricht. https://doi.org/10.26481/dis.19950922nj

Document status and date:

Published: 01/01/1995

DOI:

10.26481/dis.19950922nj

Document Version:

Publisher's PDF, also known as Version of record

Please check the document version of this publication:

- A submitted manuscript is the version of the article upon submission and before peer-review. There can be important differences between the submitted version and the official published version of record.

People interested in the research are advised to contact the author for the final version of the publication, or visit the DOI to the publisher's website.

- The final author version and the galley proof are versions of the publication after peer review.

- The final published version features the final layout of the paper including the volume, issue and page numbers.

Link to publication

\footnotetext{
General rights rights.

- You may freely distribute the URL identifying the publication in the public portal. please follow below link for the End User Agreement:

www.umlib.nl/taverne-license

Take down policy

If you believe that this document breaches copyright please contact us at:

repository@maastrichtuniversity.nl

providing details and we will investigate your claim.
}

Copyright and moral rights for the publications made accessible in the public portal are retained by the authors and/or other copyright owners and it is a condition of accessing publications that users recognise and abide by the legal requirements associated with these

- Users may download and print one copy of any publication from the public portal for the purpose of private study or research.

- You may not further distribute the material or use it for any profit-making activity or commercial gain

If the publication is distributed under the terms of Article 25fa of the Dutch Copyright Act, indicated by the "Taverne" license above, 


\section{THE DEFINITION AND POLICY RELEVANCE OF MONETARY AGGREGATES IN THE NETHERLANDS}

An Inquiry into the Measurement of Monetary Services

Norbert Janssen 
Janssen, Norbertus Gerirudis Jacobus

The definition and policy relevance of monetary aggregates in the Netherlands : an inquiry into the measurement of monetary services / Norbertus Gertrudis Jacobus Janssen.

- Maastricht : Universicaire Pers Maastricht. - III. Thesis Rijksuniversiteit Limburg Maastricht. - With ref. With summary in Dutch.

ISBN 90-5278-198-2

Subject headings: divisia / monetary policy; the Netherlands / monetary services; the Netherlands. 


\section{THE DEFINITION AND POLICY RELEVANCE OF MONETARY AGGREGATES IN THE NETHERLANDS}

An Inquiry into the Measurement of Monetary Services

\section{PROEFSCHRIFT}

ter verkrijging van de graad van doctor aan de Rijksuniversiteit Limburg

te Maastricht, op gezag van de Rector Magnificus, Prof. Mr. M.J. Cohen, volgens het besluit van het College

van Dekanen, in het openbaar te verdedigen op vrijdag

22 september 1995 om 14.00 uur

door

Norbertus Gertrudis Jacobus Janssen 


\section{Prondorit:}

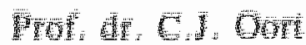

\section{Copromotor:}

DF. C, IM Mest

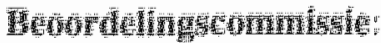

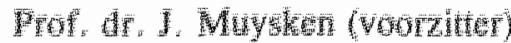

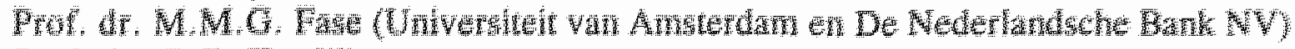
por.d. C.G. Soedik 
Preface

Chapter $\mathbb{1}$ Introduction

1.1 Background

1.2 Aim of this thesis

1.3 Outline of the thesis

Chapter 2 The measurement of monetary services: a survey 7

2.1 Introduction

2.2 Weak separability of monetary aggregates 7

2.2.1 Nonparametric tests of weak separability 8

2.2.2 Parametric tests of weak separability 9

2.2.3 Evaluation 10

$\begin{array}{lll}2.3 & \text { Substitution between financial assets } & 10\end{array}$

2.3.1 Single equation estimates of the degree of substitution 11

2.3.2 The microeconomic approach to financial substitution 11

2.3.2.1 An eclectic view of the substitution between liquid assets

2.3.2.2 The constant elasticity of substitution utility specification $\quad 12$

2.3.2.3 The translog utility specification $\quad 12$

2.3.2.4 The Fourier utility specification 14

$\begin{array}{lll}2.3 .3 & \text { Evaluation } & 15\end{array}$

$2.4 \quad$ Simple-sum versus weighted monetary aggregates 15

2.4.1 The indicator properties of simple-sum and weighted monetary aggregates 16

2.4.2 The demand for simple-sum and weighted monetary aggregates

$\begin{array}{lll}2.4 .3 & \text { Evaluation } & 20\end{array}$

2.5 Concluding summary of the empirical evidence 20

Chapter 3 Determination of weakly separable monetary aggregates 23

3.1 Introduction 23

3.2 Weak separability of utility functions 25

$\begin{array}{lll}3.2 .1 & \text { Theoretical foundations } & 25\end{array}$

$\begin{array}{ll}3.2 .2 & \text { The nonparametric test for weak separability } 28\end{array}$

3.2.2.1 Test for consistency of the data with GARP 28

3.2.2.2 Examples of the GARP testing procedure 29

3.2.2.3 Determination of weakly separable groups 31

3.2.3 Drawbacks and modifications of the NONPAR test 32 
3.2.3.I The bias towards rejection of the weak separability hypathesis

3.2.3.2 A new quantity normalisation in the

NONPAR test

3.3 Testing the separability of monetary assets from consumption goods 36

3.3.1 Data generation procedure

3.3.2 Results with aggregate data

3.3.3 Results for households

3.4 Weakly separable groups of financial assets

3.4.1 Weakly separable monetary aggregates for the economy as a whole

3.4.2 Weakly separable monetary aggregates for households

3.5 Conclusion

Chapter 4 The construction of economic indices of monetary services

4.1 Introduction

4.2 Historical background for the current interest in weighted monetary aggregates

4.3 The flow of liquidity measured by weighted monetary aggregates

4.4 Data description

4.5 Empirical results

4.5.1 Growth rates of simple-sum and Divisia monetary aggregates

4.5.2 Velocity behaviour of simple-sum and Divisia monetary aggregates

4.6 Conclusion

Chapter 5 Substitution between the components of harmonised M3 in the Netherlands

5.1 Introduction

5.2 The theoretical model 73

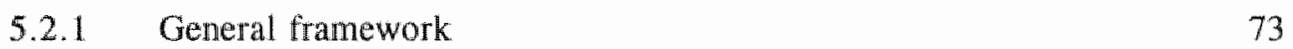

5.2.1.1 The Fourier flexible form $\quad 75$

5.2.1.2 The translog functional form 77

$\begin{array}{lll}5.2 .2 & \text { Determining substitution elasticities } & 78\end{array}$

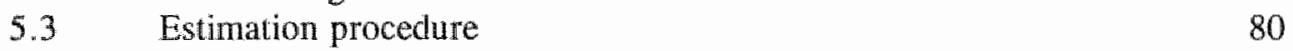

5.3.1 Method of estimation $\quad 80$

5.3.1.1 The static and dynamic Fourier demand system 80

5.3.1.2 The translog demand system 81

$\begin{array}{lll}5.3 .2 & \text { Data } & 82\end{array}$

5.4 Empirical results and interpretation at the aggregate level 85

5.4.1 Fourier model $\quad 85$

\begin{tabular}{lll}
5.4 .2 & Translog model & 88 \\
\hline & & 89
\end{tabular}

5.5 Empirical results and interpretation at the sectoral level 89 
5.5.1 Fourier model 90

5.5.1.1 The business sector 90

5.5.1.2 The household sector $\quad 92$

5.5.2 Translog model 93

5.5.3 Policy implications 95

5.6 Summary and conclusions 96

Chapter 6 Sum and weighted monetary aggregates as indicators for the Netheriands

6.1 Introduction 99

$\begin{array}{ll}6.2 \text { Dutch monetary policy: an overview } & 101\end{array}$

6.3 Description of the data 103

6.4 The performance of simple-sum and Divisia aggregates

$\begin{array}{lll}\text { 6.4.1 The St. Louis model } & 104\end{array}$

$\begin{array}{lll}6.4 .2 & \text { Results } & 107\end{array}$

6.5 Causality tests and long-run dynamics 110

$\begin{array}{ll}6.5 .1 & \text { Unit root and cointegration tests } \\ 6.5 .2 & 110\end{array}$

6.5.2 Causality test results, 1965-1993 113

6.5.3 Causality test results, 1979-1993 116

6.6 Out-of-sample forecasts of inflation and real income growth 123

6.7 Conclusion 125

Chapter 7 Do German monetary aggregates matter $\begin{array}{ll}\text { for the Dutch economy? } & 127\end{array}$

$\begin{array}{lll}7.1 & \text { Introduction } & 127\end{array}$

7.2 Impact of German monetary aggregates on the Dutch economy 128

7.3 Out-of-sample forecasts of Dutch inflation and real income growth with German monetary aggregates

7.4 The relative performance of Dutch and German monetary aggregates

7.5 Conclusion

Chapter 8 Summary and conclusions

8.1 Summary and evaluation 139

8.2 Directions for future research 144

$\begin{array}{lr}\text { References } & 145\end{array}$

$\begin{array}{ll}\text { Samenvatting } & 151\end{array}$

$\begin{array}{lr}\text { Curriculum vitae } & 155\end{array}$ 
" 


\section{Preface}

This dissertation is the result of four years of research while I was employed as a research assistant (AIO) at the Faculty of Economics and Business Administration of the University of Limburg in Maastricht. As almost all academic research, this thesis would not have been completed without discussions with and encouragements from many colleagues.

First of all, I would like to thank my supervisors Coen Oort and Clemens Kool for the stimulating discussions I had with them about this thesis and about related topics, and for their constructive comments on the various papers I wrote in the past four years. With Clemens as a co-author, I also learned how to write accessible scientific papers. His enthusiasm in supervising me proved to be a great help in finishing the thesis in time.

A special word of thanks is directed to Joan Muysken, who offered me a position at this faculty and who always remained interested in the progress of my research. As chairman of the examining committee he provided me with some useful comments to improve my thesis. I also thank Martin Fase for his critical remarks on parts of this thesis, although I could not include all of them in the final version of my dissertation. During the last two years Kees Koedijk continuously supported me to proceed on my dissertation.

Several other colleagues at the faculty provided useful comments on parts of the thesis and adviced me during my research. In particular, I would like to mention Erik de Regt, Huub Meijers, Maurice Oude Wansink and Geert Woltjer. My former officemates Kristian Kerckhoffs, François Nissen and Alex Lammertsma gave me the opportunity to discuss any problems in my research with them and proved to be good friends. I would also like to thank Tom van Veen for always being an interested colleague and for becoming a good friend at the faculty.

Lilian Raetsen and Tilly Loth contributed to this thesis by being always so kind to help me with any organisational or word-processing problems. They also gave me the opportunity to change my mind when I was stuck in my research and created a pleasant atmosphere to write this thesis.

Finally, I express my gratitude to my parents, who enabled me to follow my scientific interests and who encouraged me in everything in my life, and especially in finishing this thesis. I was able to finish this thesis in Maastricht, because my parents prepared my movement to London.

Maastricht, 25 April 1995 



\section{INTRODUCTION}

\subsection{Background}

After decades of dispute between Keynesians and monetarists on the issue of whether money influences real and/or nominal economic variables, there is widespread agreement among economists nowadays that money may indeed affect real growth as well as inflation. In other words, the idea that "money matters" has generally become accepted in economic science and policy.

Mainly two factors have contributed to the gradual incorporation of this insight into mainstream economics. A first explanation is formed by the empirical finding of a stable demand for money function over most of the postwar period. The stability of the demand for money led to a predictable relationship between money, interest rates and GNP in that time period. Many empirical studies have found evidence of a stable relation between changes in the money supply and changes in nominal national income or output in different countries until the early 1980s." Second, during the 1970s (and the early 1980s), inflation in most OECD countries was very high. The high and volatile inflation also had detrimental effects on the real economy, for example on unemployment and international trade. Keynesian theories were unable to explain the stagflation of the 1970s. Monetarist theory, on the other hand, argued that the stagflation was partly caused by monetary factors or by inadequate monetary policy. As a result, monetarism gained influence in economic theory and policy-making during the 1970s. Accordingly, the present consensus about the importance of money for steady economic development without serious shocks can mainly be attributed to the above two factors.

Acceptance of the view that money may affect the real economy implies that monetary policy may have a part to play in the stabilisation of the real economy and the price level. The recognition that excessive money growth causes inflation in the intermediate run has led many central banks to switch to a policy of targeting growth rates of monetary aggregates to control inflation in the $1970 \mathrm{~s}$.

Although the importance of money and monetary policy for the course of the real economy is generally acknowledged, there is no such agreement on what should comprise the concept of money and how money should be measured appropriately in order to achieve the ultimate policy targets.

See Judd and Scadding (1982) and Laider (1985) for an overview of the empirical evidence on the (in)stability of the demand for money 
Which definition of the money supply is appropriate in this respect depends partly on economic theory and partly on empirical evidence. The evaluation of the effects of monetary policy on real growth and inflation can be enhanced by distinguishing three elements in the transmission process between the monetary and the real sector of the economy. First, the transmission mechanism is considerably affected by the definition of the monetary aggregate used in policy making and by the decision which financial assets to include in this aggregate. The controllability of this money supply measure with the available central bank instruments is the second element in this process. Finally, the (stability of the) demand for all the assets that are included in the monetary aggregate determines the ultimate effects of monetary policy on the real economy. This thesis is mainly concerned with the first and the third element in the transmission process between money and the real economy.

\subsection{Aim of this thesis}

The research presented in this study is motivated by the following observations. During the $1970 \mathrm{~s}$, when the demand for money was relatively stable in most industrialised countries, including the Netherlands, many central banks adhered to a policy of targeting the growth rates of monetary aggregates to obtain price stability. Over the past decade, however, most central banks have abandoned monetary targeting, while maintaining inflation control as their most prominent policy objective. The principal reason for this policy shift appears to be the breakdown of demand for money functions in many countries during the late $1970 \mathrm{~s}$ and $1980 \mathrm{~s}^{2}$ These instabilities have seriously impeded the effectiveness of existing monetary targeting policies. Part of the problem may be due to measurement error in the official aggregates. The issue of what constitutes a good measure of money is, as yet, unresolved. Aggregates that are defined differently from the traditional ones may still be good candidates for a policy relying on monetary targets or indicators. Apart from theoretical considerations, the usefulness of a money supply measure in this respect also depends on the exact policy purposes involved and on the empirical performance of such an aggregate.

The aim of this study is to analyse whether a theoretically correct and policy relevant definition of the money supply can be constructed for the Netherlands, while taking into account that the Dutch central bank's ultimate policy objective is price stability. The existence nowadays of a large spectrum of financial assets with different characteristics seriously complicates the problem of finding a suitable measure of the money supply. Due to financial innovation, deregulation and other changes in financial systems this spectrum changes continuously. New financial assets are intro-

2 The formerly existing money demand function in the USA has shifted after 1973 (see Judd and Seadding, 1982 for a survey), whereas for the Netherlands and some other countries instabilities are found in the 1980s. Boughton (1991 and 1992) gives an overview of the literature on money demand instabilities in the 1980 s. 
duced and characteristics of existing assets change over time. These observations provide important impediments to a sharp distinction between assets that should be considered money $3^{3}$ and assets that should be excluded from the money supply measure.

Money definitions that are relevant for policy purposes should measure total liquidity in the economy, because liquidity is assumed to influence inflation in the longer run. Financial assets are considered to provide liquidity to their users if these assets are accepted as a means of exchange. Total transactions volume or spending in an economy is not determined by the stock of money, but rather by the total flow of monetary services from different financial assets. A correct money measure should give information about these monetary services. However, the degree to which financial assets provide monetary services to their holders differs and is likely to change over time. Traditional simple-sum monetary aggregates (no matter how broadly they are defined) cannot incorporate these obvious differences. The definition of such aggregates nevertheless presupposes that there is a clear distinction between liquid and illiquid financial assets.

This thesis deals with the question of how to take into account different degrees of moneyness of financial assets for an effective monetary policy directed at price stability. The objective is to analyse whether one or more monetary aggregates can be defined that are capable of measuring the flow of monetary services in the Dutch economy and that are also useful as an intermediate target or indicator of monetary policy, and more specifically of inflation. In order to be eligible as an indicator of monetary policy such aggregates must be closely related to the ultimate policy objeclives.

In contrast to the simple-sum aggregates, which are the result of one-for-one additions of the stocks of financial assets, aggregates that measure the fllow of monetary services correctly ${ }^{4}$ are based on both microeconomic theory of consumer behaviour and on index number theory. Ultimately, the degree of moneyness of a financial asset (or, alternatively, the flow of monetary services from that asset) is determined by the optimizing behaviour of individual economic agents.

The first question in the process of selecting useful monetary aggregates for the Netherlands is whether a proposed aggregate is viewed as one single good in the representative consumer"s decision process. This is equivalent to defining an aggregate whose composition is unaffected by the consumption of other financial assets or real goods. An empirical test will be used to shed more light on this question. Second, the theoretically correct aggregation method must be determined in order to measure the flow of monetary services derived from the component assets of monetary aggregates. The third question in the thesis deals with the substitutability between the main component assets of an aggregate that is, on empirical grounds, eligible for

3 Financial assets should be considered money if they can be used as a means of exchange. Such assets are assumed to provide monetary services. 
monetary policy purposes. The elasticities of substitution give an indication of the degree of liquidity of different monetary assets. Finally, the empirical performance of simple-sum and weighted monetary aggregates as indicators of inflation and real growth is compared for the case of the Netherlands. The third and fourth problem analysed are related insofar that both the substitution approach and weighted monetary aggregates are designed to deal appropriately with differences in the degree of moneyness between several financial assets.

\subsection{Outline of the thesis}

The structure of this study is as follows. Chapter 2 presents an overview of the relevant literature for the topic of this thesis. Broadly speaking, all of this research deals with issues related to the measurement of money, with the aim of finding a definition of money that enables monetary authorities to achieve their ultimate policy objectives. Some of these studies investigate the causes of observed failures in policies of monetary targeting, while others foeus on the performance of monetary aggregates that are defined differently from the ones that have been used by central banks so far. Most of the literature presented in chapter 2 is based on the view that money provides positive value to utility maximising economic agents. The survey, however, mainly discusses the empirical part of the literature on the measurement of monetary services in different countries in order to show whether this research direction has practical relevance. The underlying theory is presented in more detail in the subsequent chapters in order to better understand the argument of this thesis. While generally accepting the existing theories, we show some fruitful new approaches in this research area and add to the literature by providing new empirical evidence for the Netherlands.

In chapter 3 the concept of weak separability of monetary aggregates is presented. What we are looking for in this chapter is a monetary aggregate that behaves as if it was an elementary good and that is, as such, consistent with consumer demand theory. Using Varian's (1982 and 1983) nonparametric test, we first analyse whether the composition of a portfolio consisting of eight financial assets is independent of the consumption of goods and then investigate whether the existing monetary aggregates M1, M2 and harmonised M3 in the Netherlands are weakly separable from other financial assets. In other words, this test is used to determine the admissible components of monetary aggregates, which forms the first necessary step in the process of selecting useful monetary aggregates for the Netherlands. Since this test is sensitive to the steady increase of the money supply and of income over time we introduce a new quantity normalisation for goods and assets that is able to take into account this income effect on consumption decisions.

Chapter 4 explains a large part of the index number and microeconomic theory that is at the basis of a correct measurement of the flow of monetary services in an economy (see Barnet, 1978, 1980a and 1981 and Diewert, 1976). The main subject of this chapter is to discuss the theoretical foundations for an appropriate aggregation method for financial assets with different characteristics. Based on consumers' opti- 
mizing behaviour, the true aggregator function that measures the flow of monetary services can be approximated by weighted monetary aggregates. Such aggregates internalise pure substitution effects between their components. The Divisia index, which is the most prominent example among these aggregates, is analysed in more detail. The monetary aggregates used so far for policy purposes have been obtained by simple summation over the component assets, but the results of this policy have been relatively disappointing in the past years. The application of such simple-sum aggregates in monetary policy can, however, only be justified if the component assets are perfect substitutes.

The substitutability between the main components of the Dutch harmonised M3 aggregate is the topic of chapter 5 . In order to assess whether simple-sum aggregation over these financial assets provides an adequate measure of the amount of liquidity in the economy we analyse the magnitude, significance and stability of the elasticities of substitution between these assets. The substitution approach to monetary aggregation is also founded on the decision process of a representative utility maximizing agent. The sensitivity of the estimated elasticities for the assumptions underlying a specific functional form to approximate the unknown utility (or aggregator) function of the representative agent is analysed by the application of three functional forms (the static and the dynamic Fourier function and the translog function). Basically, the substitution issue deals with the responses of demand for financial assets to relative price changes between the assets. We add to the literature by presenting an alternative normalisation of the assets' user costs, which is similar to the normalisation applied in chapter 3, to obtain homogeneous systems of demand equations. Because of the differences in portfolio behaviour of the business and the household sector, a sectoral anallysis of the substitution between financial assets, which is also included in chapter 5, may provide better insights than an investigation based solely on aggregate data.

Chapter 6 focuses on a comparison of the empirical performance of simple-sum and Divisia monetary aggregates as indicators of inflation and real growth in the Netherlands. This is the final step necessary to evaluate whether a measure of the flow of monetary services in the Netherlands can be used for policy purposes. To answer this question, St. Louis equations as well as causality tests that explicitly model short- and long-run effects are estimated for the different aggregates.

Given the fixed exchange rate between the Dutch guilder and the German mark, the indicator properties of German sum and Divisia aggregates for the Dutch economy are examined as well and are compared with the performance of the corresponding Dutch aggregates in chapter 7 .

Finally, chapter 8 contains a general summary and the conclusions of the thesis. 



\title{
THE MEASUREMENT OF MONETARY SERVICES:
}

\author{
a survey
}

\subsection{Introduction}

A large body of evidence on the correct measurement of (the flow of) monetary services is available for the USA, one of the countries which have experienced a breakdown of formerly stable demand for money functions in the early 1970 s already. This literature has developed out of interest in the causes of the observed instabilities in the demand for money. For other countries research in the area has been limited in number and in scope. Only recently can we observe an increasing interest in the topic of this thesis in other countries as well. Therefore, the present review of the empirical literature about the definition and usefulness of monetary aggregates mainly contains the results obtained for the USA, although some of the research for other countries is discussed as well. Most of the literature is based on the view that money provides positive value to utility maximising economic agents. Theoretical details, however, will be explained at greater length in the following chapters.

Section 2.2 discusses the empirical studies that focus on weak separability of monetary aggregates (the admissibility criterion for defining aggregates). In section 2.3 attention is paid to research into the issue of substitution between financial assets, which may explain the instability in the demand for money in different countries. Several functional forms have been used in this direction of research to approximate the true aggregator function over a number of financial assets. Finally, section 2.4 presents the results of empirical tests of the indicator properties of simple-sum and weighted monetary aggregates in different countries. Additionally, this section shows evidence from studies that compare the stability of the demand for simple-sum and weighted aggregates. The latter two research areas are ultimately directed at the same objective: finding a definition of money that implies a predictable influence of this money measure on the economy.

\subsection{Weak separability of monetary aggregates}

The first step in the construction of well-founded monetary aggregates (or, more precisely, of measures of the flow of monetary services) involves the selection of 
financial assets to be included in them. Barnett (1982) argues that economically meaningful monetary aggregates should be based on aggregation theory. This implies that an aggregate can only exist if it is weakly separable from other goods or assets. In that case, preferences over the individual components of the aggregate are unaffected by the excluded items.

Clearly then, the selection of financial assets for inclusion in monetary aggregates is an empirical question. In the literature, two approaches that test for weak separability can be distinguished. Both approaches are based on consumer demand theory. One approach uses nonparametric techniques to determine which components can be included in an aggregate, while the other imposes a specific functional form on the unknown aggregator function of economic agents to test the weak separability conditions.

\subsubsection{Nonparametric tests of weak separability}

The nonparametric testing procedure for weak separability has been applied frequently to monetary data after Varian (1982 and 1983) wrote the software routine to execute these tests. Swofford and Whitney $(1986,1987$ and 1988) use US data to analyse, on the one hand the consistency of demand for financial assets with utility maximisation, and weak separability of money from consumption goods and leisure on the other. Their entire data set of 11 financial assets appears consistent with utility maximisation, but subsets of assets reveal violations of consumer demand theory (Swofford and Whitney, 1986), which implies that these subsets cannot be used as separate monetary aggregates. ${ }^{1}$ In their 1987 and 1988 papers the same authors test the necessary and sufficient conditions for weak separability between monetary assets, consumption goods and leisure. Their main interest is in the separability of one or more monetary aggregates from the rest of the economy, since this is crucial for the existence of a stable relation between money and income. Using quarterly data, only narrow monetary aggregates (which include relatively liquid assets) satisfy the necessary conditions for weak separability from other goods (Swofford and Whitney, 1987 and 1988). With annual data (1988), they find that broader monetary aggregates can also be considered weakly separable from the rest of the economy. This indicates that holdings of less liquid financial assets are adjusted fairly slowly to their optimal levels.

Weak separability of financial asset groupings from other assets is considered in Belongia and Chalfant (1989) for the USA. They conclude that three weakly separable monetary aggregates can be constructed. The narrowest group consists of currency and demand deposits, which corresponds to the M1A aggregate. The other admissible aggregates are $\mathrm{M} 1$, and $\mathrm{M} 1$ plus interest-bearing checkable deposits that are part of the official M2 aggregate. Overall, the test results suggest that only

1 Similar tests for Japan indicate that demand for the broad monetary aggregate used for policy purposes (M2 + CDs) is not consistent with utility maximisation (lishida and Nakamura, 1994). 
monetary aggregates narrower than $\mathrm{M} 2$ are weakly separable groups of financial assets. In the same nonparametric tradition, Belongia and Chrystal (1991) determine weakly separable monetary aggregates in the United Kingdom. They find only two candidates: the sterling M4 aggregate and an aggregate defined over non-interest bearing sight deposits, interest-bearing retail deposits and interest-bearing building society sight deposits. Interestingly, when currency is included in any group of assets narrower than M4 the conditions for weak separability are violated. This suggests that currency has the same degree of substitution with all three components of the narrow weakly separable aggregate. The M4 components (except currency), however, have different degrees of substitution with each other.

\subsubsection{Parametric tests of weak separability}

The second approach to weak separability, which uses flexible functional forms to approximate the unknown aggregator (or utility) function over a number of financial assets, requires the estimation of a system of demand equations for the assets involved. Weak separability is tested for by considering restrictions on the estimated parameters, which makes the results of such tests sensitive to the choice of functional form.

Serletis (1987a) adopts an a priori aggregation strategy over 19 Canadian financial assets to arrive at four socalled monetary subaggregates. These subaggregates are computed using simple-sum and Divisia aggregation techniques and can be viewed as elementary goods in the representative agent's utility function. Then, starting from a translog monetary services aggregator function, a demand system consisting of the four sum aggregates is estimated. This is repeated for a system with the four Divisia aggregates. All aggregates that can be created with the four sum and four Divisia subaggregates, respectively, are checked for weak separability from the excluded subaggregate(s) by testing the appropriate parameter restrictions. The results suggest that a narrow monetary aggregate (consisting of currency, demand deposits and checkable deposits) can be used in monetary policy in Canada, since weak separability of this aggregate from the other subaggregates cannot be rejected with the simplesum approach nor with the Divisia approach. With simple-sum data, broader aggregates which include transactions-type assets also satisfy the weak separability conditions. However, when Divisia subaggregates are used, an admissible aggregate is found which indicates that currency and demand deposits should not be included in a weakly separable aggregate. The same procedure with Divisia subaggregates is applied to US data in Serletis (1987b), where the test results suggest that Divisia M1 can be expanded with other financial assets. These outcomes are supported by Serletis (1991), where the same data set is used, but now in a dynamic translog demand system. A similar analysis is also performed by Hahm and Kim (1994) for Korea. Of the monetary aggregates used for policy purposes in Korea only M2A and M2B are admissible measures of money.

With US data Hancock (1987) approaches the weak separability issue from the supply side. With a model of the behaviour of financial intermediaries in supplying money to the public the study tests whether monetary goods are weakly separable 
from non-monetary goods in the financial intermediaries" profit function, which is specified in translogarithmic form. Non-monetary goods include the usual production factors, which are used as input by the intermediaries, but also bank loans, which are part of their output. From the intermediaries ${ }^{2}$ profit function a system of demand and supply equations for non-monetary and monetary goods is derived and estimated. Weak separability (the existence of a monetary index) implies the testing of parameter restrictions. Using different functional forms for the monetary index it appears that an aggregate of cash and demand deposits is not weakly separable from nonmonetary goods. On the other hand, weak separability of a monetary index defined over cash, demand deposits and time deposits cannot be rejected.

\subsubsection{Evaluation}

The survey of the weak separability literature shows that parametric and non-parametric tests give similar results. Generally, the empirical evidence on weak separability of monetary aggregates from other financial assets indicates that narrow aggregates (including only transactions-type assets) can be considered elementary goods. It also appears that weakly separable monetary aggregates should not be defined too broadly. These results are obtained for most countries examined, although for the UK, the broad sterling M4 aggregate is also weakly separable. Weak separability tests with quarterly data are likely to show more violations of demand theory than tests performed with annual data. Since monetary policy is often based on the use of monetary aggregates that are not weakly separable from other assets, instabilities in the demand for these aggregates may be due to violations of demand theory. A more predictable relation between monetary policy and the real economy may be obtained when only weakly separable monetary aggregates are used.

In chapter 3, the non-parametric test is applied to Dutch monetary aggregates to determine whether the money measures used by the Dutch central bank behave as elementary goods. The weak separability test is extended with an adjustment for increases in the money supply over time.

\subsection{Substitution between financial assets}

Even if an aggregate as a whole is weakly separable from other goods and assets, this does not automatically mean that its elements are viewed as perfect substitutes in the public's utility or aggregator function. However, the traditional simple-sum aggregates which have been used for monetary policy purposes implicitly assume that the components are perfect substitutes. In order to measure the flow of monetary services in the economy correctly, the degree of substitution between different financial assets or between components of (weakly separable) monetary aggregates should be taken into account. This information may also be used to evaluate whether simple-sum aggregation is justified and to gain knowledge about the possible causes of instabilities in the demand for money in many countries. The degree of substitution or the 
degree of moneyness of financial assets can be determined empirically by estimating the elasticities of substitution between these assets.

\subsubsection{Single equation estimates of the degree of substitution}

To test Gurley and Shaw's (1960) hypothesis that non-bank financiall intermediaries" liabilities are close substitutes for money, Lee (1966) estimates the degree of substitution between money and near-moneys in the USA. Using single equation techniques, in which the demand for money is explained by permanent income and the interest differentials between near-moneys and narrow money, he estimates cross interest rate elasticities. A similar procedure is adopted to estimate cross interest elasticities between individual financial assets. The results suggest that there is indeed evidence of close substitution between money (whether defined narrowly or broadly) and nonbank financial intermediaries' liabilities. A more detailed survey of the early empirical evidence on the substitutability between money and near-moneys is contained in Feige and Pearce (1977).

\subsubsection{The microeconomic approach to financial substitution}

Most of the empirical literature about the degree of substitution between financial assets, however, explicitly uses microeconomic foundations to develop a portfolio model in which a representative agent chooses optimal quantities of financial assets. Here, two marginally different approaches to the substitution issue can be distinguished, which are in fact two sides of the same coin. In the utility-maximizing approach, the consumer chooses quantities of financial assets to maximize his utility from holding these assets given a budget constraint and the assets' prices. ${ }^{2}$ In the production-theoretic approach, the consumer chooses quantities of financial assets to minimize the opportunity costs of holding wealth in liquid form subject to the assets' prices and a given utility level (derived from the assets" monetary services). This implies that budget or cost minimization is dual to utility maximization.

\subsubsection{An eclectic view of the substitution between liquid assets}

Fase (1979) combines what he calls the Chicago and the Yale approach to the demand for liquid assets to determine the substitutability between these assets in the Netherlands. Both approaches are basically microeconomically oriented and can be ranked under the utility-maximizing approach to financial substitution. A system of demand equations for monetary assets is estimated, in which demand for each asset is explained by its own rate of return, the competing assets' rates of return, inflationary expectations, real income, the cyclical state of the economy and the total portfolio size. Cross interest rate elasticities are used to draw inferences about the degree of substitution between liquid assets in the Netherlands. Most elasticities show significant, but weak substitutability, whereas time deposits and savings deposits reveal an

2 The financial assets ${ }^{3}$ opportunity costs are the relevant prices. 
insignificant complementarity relationship. The latter result may be the expression of the different groups of holders of these assets.

In Fase (1978) a portfolio distribution model for liquid assets is adopted to analyse the causes of changes in the Dutch money supply in the 1970s. It appears that substitution between savings deposits, which were not included in the Dutch money measure at that time, and time deposits, which were part of the money supply, may have been responsible for misinterpretations of the actual monetary conditions in the 1970 s.

\subsubsection{The constant elasticity of substitution utility specification}

An early example of the utility-maximizing approach is Chetty (1969). He assumes a consumer who maximises a constant elasticity of substitution (CES) utility function to derive estimates of the degree of substitution between narrow money and other less liquid assets in the USA. After modification of the basic CES model, there is evidence of significant and relatively strong substitution between narrow money and nearmoneys. A possible explanation for this outcome is that Chetty does not separate the monetary and non-monetary services provided by financial assets. This drawback is mended in Husted and Rush (1984) who introduce a rental price for each asset's monetary services. Their estimates show that Chetty overestimated the degree of substitution between money and other liquid assets. Another extension of the Chetty model is presented in Moroney and Wilbratte (1976), who take into account dynamic adjustment of household portfolios for the case of the USA. In addition to the usual liquid assets, their analysis includes short-term government bonds and long-term corporate bonds. The results indicate that, in the course of one year, the degree of substitution between money and all the other assets, including long-term corporate bonds, is similar. Consequently, a meaningful monetary aggregate should also include these longer-term assets.

The basic Chetty approach is also applied to the Netherlands by Fase (1975). He reports that the elasticities between money measures on the one hand and time deposits on the other are of similar magnitude as the corresponding elasticities between money and savings deposits held with commercial banks. However, the estimated elasticities are relatively small, leading Fase to the conclusion that the Dutch definitions of the money supply can remain unchanged.

\subsubsection{The translog utility specification}

The financial substitution literature of the 1980 s largely corresponds to the parametric approach to weak separability discussed in the previous subsection. This research direction is built upon a more general framework of household preferences than the Chetty approach. Using a flexible functional form to approximate the unknown aggregator (or utility) function over a number of financial assets a system of demand equations for the assets involved can be derived. Estimation of this system allows the computation and estimation of elasticities of substitution between the different assets. In contrast to the Chetty approach, this part of the financial substitution literature explicitly derives a price for the monetary services provided by financial assets (see footnote 1 ). 
The most popular approximation of the aggregator function applied in empirical studies is the translog utility specification. Ewis and Fisher (1984) use this approximation to estimate the degrees of moneyness of various financial assets in the USA. The estimated elasticities generally indicate low substitutability between the assets. Time deposits appear as complements to $\mathrm{M1}$, but quite remarkably foreign financial assets are relatively strong substitutes for domestic near-money (non-M1) assets. This may imply that broader US money measures are not independent of foreign monetary developments. ${ }^{3}$ Different financial assets theld with one financial institution turn out as stronger substitutes than assets held with different institutions, which may be interpreted as institutional loyalty. Ewis and Fisher conclude that only narrow money definitions may be used as policy targets in the USA, but that broader aggregates should be constructed from disaggregate data.

Serletis (1987b) adopts the same approach to analyse US monetary data over the period 1970-1985. Prior to estimation he computes Divisia aggregates for M1, M2 and M3. Then, elasticities of substitution between the respective Divisia aggregates and nested financial asset categories are estimated. Nested assets are those assets which are a priori assumed to be the closest substitutes to the respective Divisia aggregates. Which assets are called nested thus depends on the level of aggregation considered. It appears that Divisia M1 and Divisia M3 are complements to most of their nested assets (or near-moneys), while Divisia M2 acts as a substitute to its nearmoneys. Estimation of a dynamic version of the translog demand system with the same data set leads to different results (Serletis, 1991). Divisia M1 now appears as substitute for small time deposits, whereas complementarity relations dominate for Divisia M2. Divisia M3 is a complement for short-term treasury securities, and a substitute for savings bonds and a Divisia index over bankers acceptances and commercial paper. Additionally, the estimated elasticities show that Divisia L (broad liquidity) is a substitute for leisure and a complement to a Divisia index over consumption goods. This comparison shows the sensitivity of the results for the exact modelling of the demand system. The above results may, however, also be affected by the high degree of a priori aggregation in the computation of the Divisia money measures.

With an application to Canada, Serletis and Robb (1986) calculate four Divisia and four simple-sum monetary subaggregates from 19 financial assets (see also Serletis, 1987a) in order to estimate the substitutability between these subaggregates. For both aggregation methods the four subaggregates appear to be weak substitutes. The degree of substitution between narrow money and checkable deposits is among the lowest in this sample. Thus, the appropriateness of broad simple-sum monetary aggregates is seriously questioned. In the same tradition, estimates of the substitution relations between liquid financial assets in the UK are provided in Drake (1992). Again, the low elasticities of substitution between the assets considered and the increase in their magnitude when a Divisia subaggregate is used, suggest that simple-

This observation corresponds to Marquez (1977) who reports that foreign monetary policies may affect domestic US monetary policy throwgh currency substitution. 
sum aggregates are unable to incorporate product innovation and differences in liquidity between financial assets.

The empirical studies discussed so far adopt the translog utility function to approximate the unknown aggregator function over a number of financiall assets, while assuming a utility maximizing consumer who chooses optimal quantities of financial assets. The cost minimizing approach is dual to this problem and contains a translog cost function instead of a translog utility function. Sims et al. (1987) use the translog cost model to reestimate the substitution relations between the same asset groups as in Chetty (1969) over a longer time period. Most of their estimated elasticities are smaller than in Chetty. Additionally, there are indications of complementarity between some near-moneys and narrow money. Gauger and Schroeter (1990) apply the Sims et al. technique to a monthly US data set, in which the "modern" financial assets money market funds and money market deposit accounts are included. These money market accounts show significant, though far from perfect, substitutability with the other monetary assets, indicating that demand for $\mathrm{Ml}$ assets is also affected by non-M1 instruments, which may explain part of the unstable demand for $M 1$ in the USA.

\subsubsection{The Fourier utility specification}

Another approximation to the unknown utility function over a range of financiall assets is provided by the Fourier flexible form. Since the Fourier specification can approximate the true utility function globally, time series of the elasticities of substitution can be estimated. Ewis and Fisher (1985) present the results of an application of this technique to roughly the same data set as in their 1984 paper. Their most important findings are that the substitution elasticities between the financial assets are variable over the sample and that the elasticities are not large enough to justify simple summation over the components. Disaggregation of M1 shows that currency and demand deposits are imperfect substitutes. Furthermore, the relation between several pairs of assets can, at times, be characterised as one of substitutability, but as one of complementarity at other times. These outcomes even throw doubt on the suitability of M1 for an effective monetary policy.

Fisher (1992) presents estimates of the degrees of substitution between three subaggregates of financial assets and one subaggregate defined over consumption of goods and services and leisure using the Fourier flexible form and Swofford and Whitney's (1987) data set. The four subaggregates are all weakly separable. An explicit comparison between the translog and the Fourier utility specification is provided in Fisher (1989), where leisure is excluded from the analysis. The timevariance in the Fourier elasticities indicates that one should be cautious in drawing conclusions from estimates of a translog demand system.

Finally, the static Fourier model analysed in Fisher (1992) is extended and compared with a dynamic formulation of the unknown utility function in Fisher and

4 A more elaborate explanation of the differences between the translog and the Fourier approximaltion is given in chapter 5 . 
Fleissig (1994). The substitution elasticities that are estimated with this dynamic utility representation show a relatively stable time path. Cash and time deposits appear as complements.

\subsubsection{Evaluation}

The above discussion shows that the empirical literature on substitution between financial assets has quickly evolved from calculating interest rate elasticities to estimating elasticities of substitution. This evolution corresponds with an increasing focus on the explicit modeling of microeconomic foundations behind the composition of financial asset portfolios. In general, it appears that estimates of the degrees of substitution between financial assets have been relatively low, indicating that the substitutability is imperfect. Even components of narrow monetary aggregates turn out to be imperfect substitutes, while some components of broader aggregates are complements. Moreover, time series estimates of the substitution elasticities show that the degree of substitution varies over time. Overall, the evidence indicates that simple-sum aggregates are inappropriate measures of the flow of monetary services. This conclusion applies irrespective of the model, the country and the time period anallysed.

Chapter 5 of this thesis adds to the empirical literature by estimating elasticities of substitution between monetary assets in the Netherlands and by analysing the sensitivity of the results for differences in the specification of the utility function over financial assets. Moreover, the degrees of substitution at the aggregate level are compared with the corresponding values in the household and the business sector.

\subsection{Simple-sum versus weighted monetary aggregates}

If the components of monetary aggregates are less than perfect substitutes, simplesum aggregation cannot provide a good measure of the flow of monetary services in an economy. It still needs to be resolved, however, which aggregation method can measure these services correctly. Even if the liquidity flow is measured with the correct aggregation method, it does not necessarily mean that such an aggregate should be used in the implementation of monetary policy.

In the end, the question which definition of the flow of monetary services in an economy is appropriate as intermediate target or indicator of monetary policy is determined by the relation of such a money measure with the ultimate policy objectives. Most research into this issue compares the empirical usefulness of simple-sum aggregates for an effective monetary policy with that of weighted aggregates, and of Divisia measures of money in particular. In this respect, two approaches can be distinguished in the literature. The first approach tests the relative performance of simple-sum and weighted monetary aggregates as policy indicators. This corresponds to a direct comparison of the relations between the respective aggregates and the rest of the economy. The second approach estimates demand for money functions for sum 
and weighted aggregates. Stability of the demand for monetary aggregates is a sufficient condition for the achievement of the ultimate monetary policy targets.

\subsubsection{The indicator properties of simple-sum and weighted monetary aggregates}

The first approach to the selection of an appropriate measure of the flow of monetary services in an economy deals with the relative merits of simple-sum and weighted aggregates as monetary indicators. One of the first empirical studies in this tradition is Barnett, Offenbacher and Spindt (1984). They use Granger causality tests and St. Louis equations to compare the performance of sum aggregates (calculated at different aggregation levels) for the USA with that of their Divisia counterparts. Divisia aggregates appear superior to the sum aggregates, especially at higher levels of aggregation. ${ }^{5}$ No aggregate, however, is superior in all of the tests performed. Similar results are obtained by Serletis (1988), who adopts Granger causality tests to investigate the effects of money on prices and real income separately. Belongia and Chalfant (1989) use St. Louis equations to compare the performance of three weakly separable monetary aggregates (defined either as sum or Divisia aggregate) as intermediate target. Divisia M1A is the most suitable of the six aggregates analysed, exhibiting an almost one-to-one relation with nominal GNP. Also for the USA, Swofford and Whitney (1991) create a weakly separable Divisia index over a number of assets having different liquidity characteristics. In an error-correction model it appears that this Divisia index forecasts inflation more accurately than the sum M1 and $\mathrm{M} 2$ aggregates.

A recent, innovative method to investigate the relation between money growth and inflation uses artificial neural networks to approximate the unknown functional form of this relation (Dorsey, 1994). The neural networks approach shows that Divisia measures of money dominate their simple-sum counterparts in forecasting inflation for the USA and Germany.

Within the framework of St. Louis type spending equations for the United Kingdom, Belongia and Chrystal (1991) use non-nested tests to compare the relative indicator performance of weakly separable Divisia aggregates and simple-sum money measures. The Divisia aggregates outperform all available sum aggregates, whereas a Divisia money measure that excludes currency is preferred to the broader Divisia M4 index. The latter index, however, shows a stable long-run relationship with real income and the price level. Fisher et al. (1993) analyse the indicator properties of aggregate as well as sectoral Divisia M4 indices for the UK. The informational content of these Divisia money measures for nominal GDP and the price level is examined in a bivariate causality framework, which incorporates money's short-run effects and any long-run demand for Divisia money relationships. The results show that the Divisia indices at the M4 aggregation level have some leading indicator properties for nominal output and the price level, but simple-sum aggregates contain similar information in this respect.

Estimates of (the stability of) denand for money functions lead to similar results. 
Additional evidence on the relative merits of simple-sum and Divisia M4 as monetary policy indicators in the UK is presented in Drake et al. (1994). The aggregates" performance is examined with a whole spectrum of testing procedures. The most important among these are St. Louis equations for nominal spending, dynamic demand for money estimates and causality tests between money, real income, prices and interest rates. In the latter two specifications, economically reasonable cointegrating vectors are included to handle the long-run relations between money and the real economy. Although the evidence is still mixed, the Divisia M4 index contains better indicator properties of inflation than sum M4.

In an earlier study, Ford et al. (1992) take into account the effects of non-meutral technological progress on different financial assets. These changes in financial technology are then incorporated in the rental prices of the individual financial assets, which enables the construction of modified Divisia aggregates. These modified Divisia aggregates, which can account for financial innovation, tend to outperform their simple-sum and unmodified Divisia counterparts as indicators of nominal GDP in the UK.

The causality between money and income in the Netherlands is analysed in Fase (1987). Based on a bivariate ARMA model, which shows that Divisia aggregates do not cause changes in income, he estimates St. Louis equations for the simple-sum monetary aggregates, which indeed appear to cause changes in nominal income, but only when seasonally unadjusted data are used. Earlier research by Fase (1985), however, shows that the socalled liquidity ratio (the ratio between a monetary aggregate and nominal income) was lower for Divisia money measures than for simplesum aggregates in the 1970s and early 1980s. Average growth rates and standard deviations of Divisia aggregates were also lower than the corresponding variables for simple-sum aggregates. Fase and Schuit (1992) compare these Dutch summary statistics with the equivalent values for Belgium and the USA. Divisia growth rates in Belgium are smaller than the sum growth rates, but standard deviations are similar for the two money definitions. For the USA, Divisia M1 has the lowest standard deviation of the aggregates considered.

Yue and Fluri (1991) find only marginal differences in the inflationary indicator properties of simple-sum and Divisia aggregates in Switzerland. Granger causality tests in Fluri and Spoerndli (1994) indicate that the narrower Divisia aggregates are preferred to their sum equivalents in predicting prices in the short run. Inclusion of the long-run effects of Swiss aggregates does not significantly alter this conclusion. In contrast, real output is better explained by narrow simple-sum aggregates. Overall however, the explanatory power of monetary aggregates is relatively low.

The study by Longworth and Atta-Mensah (1994) compares the appropriateness of simple-sum and weighted monetary aggregates as monetary indicators in Canada (using similar testing procedures as Drake et al., 1994). The weighted aggregates employed are Fisher Ideal indices of monetary services, since these can easily deal with the introduction of new financial assets. In a St. Louis context and in causality tests, the Fisher Ideal aggregates rarely dominate their simple-sum counterparts. Stable long-run demand for money relationships are obtained with all simple-sum aggregates, whereas cointegration is hardly ever found for the weighted aggregates. 
Overall, only a minority of the test statistics shows a preference for Fisher Ideal aggregates. The main conclusion from this analysis is that Canadian simple-sum aggregates are better monetary indicators than their weighted counterparts. In particular, broad aggregates are the best inflation indicators, while Ml predicts output best.

For Korean data, Hahm and Kim (1994) find that only velocity of the broader Fisher Ideal aggregates is stationary. Next, they estimate an error-correction model to explain inflation with standard lag lengths of four quarters for inflation and money growth. Relying on these estimates and on out-of-sample forecasts generated with this model, they conclude that the broader Fisher Ideal indices M2A and M2B may be appropriate inflationary indicators for Korea.

An extensive cross-country study into the indicator properties of simple-sum versus Divisia aggregates is presented in Chrystal and MacDonald (1994). They estimate St. Louis equations for nominal spending and perform multivariate causality tests between money, real income, prices and interest rates, while taking into account any cointegrating vectors between these variables. With evidence for the USA, Canada, the UK, Germany, Switzerland, Japan and Australlia, they conclude that Divisia measures of money exhibil some important advantages over their simple-sum counterparts. Especially after 1980 , the results are strongly in favour of the US Divisia aggregates. The same may be said of Australia over the whole sample investigated. The UK results confirm that Divisia M4 influences inflation significantly. The Swiss money measures do not reveal many striking differences in their role as monetary indicators, although Divisia M2 is clearly a better indicator of output than sum M2. For Germany and Japan no monetary aggregate shows informational content for output, while the Canadian aggregates harcly affect any of the variables analysed.

\subsubsection{The demand for simple-sum and weighted monetary aggregates}

The existence of a stable demand relation for a monetary aggregate is considered essential for the usefulness of such an aggregate as monetary policy indicator, although McCallum (1987, 1988 and 1989) argues that instabilities in the demand for money do not necessarily impede the adoption of monetary aggregates for policy purposes. Comparisons of the stability of demand for sum and weighted aggregates are frequently reported in the literature. Based on graphicall analysis, Barnett, Offenbacher and Spindt (1981) conclude that velocity (which is the inverse of demand for money) of the US Divisia M3 aggregate is more stable than that of sum M3.

Ishida and Nakamura (1994) estimate partial adjustment models of the demand for Japanese simple-sum and Divisia monetary aggregates. At the M1 aggregation level, the differences between the two aggregation methods are small. Demand for the broad Divisia measure (M2+CDs) appears, however, more stable than demand for its sum equivalent. Weakly separable aggregates are found to be less useful as monetary indicators, since they have been strongly affected by deregulation of time deposit interest rates.

In addition to simple-sum and Divisia aggregates, Herrmann et al. (1994) apply two other weighting schemes to construct transaction-oriented measures of the money supply. The empirical performance of the resulting four aggregates (at the M3 aggre- 
gation level) is compared for the case of Germany. They first estimate demand for money functions that incorporate both short and long run behaviour of the explanatory wariables. Additionally, the link between money and prices is analysed in a P-star framework, which is also used to forecast inflation out-of-sample. Strongest evidence of cointegrating relations between money and prices is found for sum M3, while the evidence for the weighted aggregates is somewhat weaker. All M3 aggregates possess similar forecasting properties for inflation.

Fase and Winder (1994) and Fase (1994) present comparisons of the demand for simple-sum and Divisia monetary aggregates for different sets of countries of the future Economic and Monetary Union (EMU) in Europe. The monetary aggregates for these groups of countries are calculated with different weighting schemes to convert the indiwidual country data into the same currency. Both studies adopt demand functions for monetary aggregates in which the long-run properties as well short-run adjustments to equilibrium are included. Fase and Winder (1994) estimate this type of demand for money functions only for Divisia aggregates computed for a group of ten potential EMU member countries (this group consists of the European Union members as of 1994, except Greece and Luxemburg). The results show that the behaviour of the Divisia M2 and Divisia M3 aggregates at the EMU level was similar to M1's behaviour between 1970 and 1992. Estimates of the long-run (price and income) elasticities of the demand for the Divisia aggregates are comparable with estimates obtained with simple-sum money in other research at the EMU level. For Divisia M3 price and income homogeneity is found, whereas the income elasticity of Divisia M2 is also one, but its price elasticity is smaller than one. Interest and inflation sensitivity of the Divisia aggregates are similar to the corresponding values for sum aggregates. In line with earlier research into the properties of simple-sum aggregates, the results also suggest that the demand for Divisia money at the aggregate EMU level is more stable than the demand for sum aggregates in the individual EMU countries. Finally, it appears that the applied weighting scheme for the country data affects the results only marginally.

The same kind of analysis is performed in Fase (1994) for the core EMU countries Germany, the Netherlands, Belgium, Luxemburg and France. Demand for money functions are estimated for simple-sum and Divisia aggregates. Broadly speaking, the results are similar to the outcomes in Fase and Winder (1994), although now all Divisia money measures show price and income homogeneity. Money demand functions in the individual core EMU countries reveal comparable stability, with the Netherlands showing the least stable relation. The study provides additional evidence that aggregated demand for money in a group of countries is more stable than demand in the individual countries. The differences in stability between the demand for Divisia aggregates and the demand for their simple-sum equivalents are only marginal.

Evidence for Spain (Ayuso and Vega, 1993) on the demand for different measures of money in the long run does not support the use of weighted aggregates, whether 
they are defined as Divisia or as currency-equivalent aggregates. ${ }^{6}$ No cointegrating relationships are found between weighted monetary aggregates, real income, prices and interest rates, but the sum aggregates reveal a stable relation with the final target variables of monetary policy.

Similar results are finally found in Lim and Martin (1994), who estimate long-run demand for money relations using different monetary aggregates for Australia. In contrast to Divisia aggregates, the weighted aggregates considered here are not computed as the sum of the weighted growth rates of the individual components, but as the sum of their weighted levels. The official sum aggregates reveal long-run elasticities that are in accordance with economic theory. There is no evidence of any long-run relations between weighted monetary aggregates and the real economy.

\subsubsection{Evaluation}

The studies investigating the relative performance of simple-sum and weighted monetary aggregates as indicators for real growth and/or inflation do not give rise to clearcut conclusions. The same applies to the research into the stability of demand for the various aggregates. In many countries the differences between the two aggregation methods are marginal. No single monetary aggregate consistently outperforms the other measures of money. In some countries, sum aggregates are even preferred to their weighted counterparts. Divisia indices of money, however, tend to provide advantages over their sum equivalents as inflation indicators in the USA and the UK.

Additional evidence on the relative indicator performance of simple-sum and Divisia monetary aggregates in the Netherlands is presented in chapter 6.

\subsection{Concluding summary of the empirical evidence}

The main motivation behind the empirical literature discussed in this survey has been the observation that demand for money relations have become unstable in many industrialised countries during the 1970 s and 1980 s. Since a stable demand for money is considered an important, but not a necessary condition for an effective policy of monetary targeting, these instabilities have confronted central banks with serious problems in achieving their ultimate policy objectives (mostly price stability). One explanation for these instabilities may be the occurrence of financial innovations, which include the introduction of new financial assets and changes in the characteristics of existing ones. Such innovations may cause substitution processes between new assets and more traditional ones, and may also affect substitution relations between the components of monetary aggregates. The degree of substitution between financial assets may be considered an expression of the liquidity of the different assets.

See Rotemberg et al. (1991) for an elaboration on the currency-equivalent aggregate. 
On the other hand, the observed unstable demand for money functions may be due to incorrect measurement of the flow of monetary services in the respective economies. The literature in this review evaluates the importance of these phenomena for money demand instabilities. The ultimate aim is to test whether definitions of money which provide better measures of this flow of monetary services are also appropriate as intermediate targets or indicators for monetary policy.

The general impression arising from the studies that estimate elasticities of substitution between component assets of monetary aggregates is that these liquid assets are imperfect substitutes or even complements for each other. This finding is independent of the type of model, the country and the time period analysed. Furthermore, time series evidence shows that these elasticities are not constant over time. This implies that the components of monetary aggregates possess different degrees of moneyness. Simple-sum monetary aggregates are unable to incorporate these differences. Consequently, they are unfit as measures of the flow of monetary services. Weighted. aggregates that internalise the imperfect substitution effects between their elements may be more appropriate.

An important requirement for an effective monetary targeting policy is that such a policy is based on monetary aggregates that behave as elementary goods. If this weak separability condition is violated, preferences over the individual components of the aggregates are affected by excluded items, making the aggregates' relation with the rest of the economy unstable. The few studies addressing this problem indicate that many monetary aggregates used for policy purposes cannot be considered as one good.

The last part of the empirical literature compares the relative usefulness of simplesum and weighted monetary aggregates as indicators for monetary policy. The outcomes of these tests may indicate whether measurement error is an important source of money demand instabilities. The available evidence suggests that there is no single monetary aggregate that performs best as indicator in all of the tests executed. In most countries the differences between the indicator properties of sum and weighted aggregates are minor. In addition, demand for weighted aggregates is not consistently more stable than demand for simple-surm aggregates. However, the literature suggests that Divisia aggregates have some advantages over their sum equivalents, especially in the USA and, to a lesser extent, in the United Kingdom. 



\section{DETERMINATION OF WEAKLY SEPARABLE MONETARY AGGREGATES}

\subsection{Introduction}

A theoretically proper definition of monetary aggregates is an important prerequisite for a correct assessment of the effectiveness of monetary policy. Most (simple sum) monetary aggregates used so far by central banks for policy purposes, however, have not been tested for consistency with economic theory. ${ }^{1}$ This paper uses findings from economic theory in order to construct consistent monetary aggregates by first identifying the components that should be grouped into aggregates. In the process of selecting optimal monetary aggregates this is called the existence condition (Barnett, 1982).

Consumer demand theory provides well-developed models of optimizing behav iour of individual economic agents consuming individual goods. This does not imply, however, that demand theory can be readily applied to relationships concerning aggregates of goods. Aggregation theory states that economically well-defined aggregates influence the economy only through the specified (non-linear) aggregation function. Aggregates are well-defined if they are weakly separable from the excluded goods. Accordingly, these correctly defined quantity aggregates are good approximations of the utility function over the components of the aggregates. Consequently, aggregates constructed using aggregation theory are consistent with utility maximizing behaviour of representative consumers. Aggregation theory allows us to view these aggregates as a single consumption good. The economy can then be divided into fewer composite groups of goods and/or assets (which may correspond to a monetary and a real sector) and separate analysis of the relations within such an aggregate (or within one sector) is theoretically justified. In other words, preferences within that aggregate can be analysed independently of the quantities of goods and financial assets outside the aggregate.

Applied to monetary economics, separate analysis of the monetary sector can only be justified if decisions on the consumption of financial services as a whole are weakly separable from other consumption decisions concerning goods and services. In that sense, weak separability of monetary aggregates is a necessary condition for a

1 Research shows that especially the broader monetary aggregates in the USA and the UK are inconsistent with economic theory. See e.g. Swofford and Whitney (1987) and Belongia and Chrystal (1991). 
stable demand for money. The question of weak separability of financial assets from real consumption should, therefore, be resolved before the monetary sector can be analysed in more detail. Monetary aggregates should only be broadened by including new financial assets (as happens in the European Union due to harmonisation efforts), if these newly defined aggregates are tested for weak separability first.

During the last decade some tests of weak separability have been developed and applied to various consumption and production models. In the case of monetary aggregation, weak separability means that the marginal rate of substitution between two financial assets, which are elements of a weakly separable group ${ }^{2}$ of financial assets, is unaffected by the consumption level of all other goods and financial assets not in the group. Then, it is justified to aggregate the two weakly separable assets in one measure which can be treated as one elementary good in further analysis. The size of this aggregate depends on total income and is not affected by the composition of expenditures on non-monetary goods. The elasticity of substitution between this aggregate and any good outside this measure is equal to the elasticity of substitution between that good and any good within the aggregate. ${ }^{3}$

Among the weak separability tests, parametric and non-parametric versions can be distinguished. The parametric tests are dependent on flexible functional forms, and are in fact joint tests of demand theory and of the functional form chosen for the utility (or aggregation) function. On the other hand, the non-parametric test developed by Varian (1982 and 1983), checks whether a given data set is consistent with the utility maximization hypothesis in demand theory. This test does not require specification of the functional form of the aggregator function.

This chapter adopts Varian's test to determine whether the monetary aggregates reported by the Dutch central bank (DNB) ${ }^{4}$ form weakly separable groups from consumption goods and from other financial assets. Stated differently, this chapter examines which financial assets are admissible components of a monetary aggregate defined for the Netherlands. The analysis is executed with aggregate annual data on volumes and prices of consumption goods and financial assets over the period 19701993. The use of aggregate data may, however, bias the test results towards rejection of the weak separability conditions. Taking into account as well that the concept of weak separability is founded in consumer demand theory this explains why a similar analysis is undertaken for households only. Another potential bias in the test, but now towards acceptance of weak separability, is due to the steady increase of the money stock and of income over time. To alleviate this problem a new normalisation for goods" and assets" quantities is introduced that is more appropriate to test the separate effects of relative price changes between goods and/or financial assets.

2

The group is weakly separable both from consumption goods and from other financial assets.

3

See Barnett and Choi (1989) for a proof.

4

The central bank has been reporting the stocks of the M1, M2 and harmonised M3 aggregate in its Quarterly Bulletins and Anmal Reports since 1991. 
The present chapter is organised in the following way. In the second section, the theoretical background for weak separability of utility functions is explained. This section provides a brief overview of some alternative test procedures for weak separability and discusses the procedure adopted here in more detail, including the new quantity normalisation. The following sections are of a more applied nature. Section 3.3 describes the data used and presents tests for the consistency of an aggregate as well as a household data set with the utility maximization hypothesis and for weak separability between financial assets on the one hand and consumption goods on the other, together with the test results. The fourth section tries to define aggregates of financial assets, based on tests of weak separability within the whole group of financial assets, both for data for the economy as a whole and for household data. The chapter concludes with a summary in which the main findings and the implications for monetary aggregation are presented.

\subsection{Weak separability of utility functions}

\subsubsection{Theoretical foundations}

In a demand-theoretic approach, financial assets are treated as normal consumption goods that are held because of the services they provide. Accordingly, in this chapter, consumers are assumed to allocate their available wealth among a wide range of goods and financial assets. Then, the composition of their wealth holdings is determined by the characteristics and relative prices of the individual goods and financial assets. The service flow from holding a financial asset is assumed to be proportional to that asset's stock in the representative consumer's portfolio. As a result, financial assets can be included as arguments in the consumer's utility function ${ }^{5}$ and analysis of demand for them is analogous to consumer goods demand analysis (Belongia and Chalfant, 1990). The consumer's allocation problem ${ }^{6}$ then is to maximize his total utility from holding a vector of consumption goods $(C)$ and financial assets $k\left(m_{k}\right)$ subject to the usual budget constraint:

5 Financial assets enter the utility function if we assume that they have positive value of their own; in other words, financial assets prowide their holders with services like liquidity and/or they render a positive yield.

6 Since financial assets are not only held by consumers (households), aggregate financial asset stocks are determined by the optimizing behaviour of different categor ies of asset holders. Instead of focusing on weak separability of aggregate financial asset holdings from goods ${ }^{*}$ consumption it may be more appropriate to investigate weak separability of aggregate financial asset stocks from national income. Tests of these two patterns of weak separability show, however, that the results are only marginally different (see section 3.3.2). 


$$
U=U\left(C, m_{k} ; k=1, \ldots, n\right) \quad \text { s.t. } \quad P C+\sum_{k=1}^{n} p_{k} m_{k}=Y
$$

where $P$ is a vector of consumption goods' prices, $p_{k}$ is the user cost of financial asset $k$ and $Y$ is total expendiure or the total budget avallable to the consumer.

Within a demand-theoretic framework, aggregation over a set of goods and/or assets appearing in a utility function is theoretically admissible, if the respective set is weakly separable from the other arguments in the utility function of the representative consumer. A group of goods and/or assets is called weakly separable if the consumer"s marginal rate of substitution between two goods (assets) in the group is independent of the quantities held of goods (assets) not in this group. If this condition is met, the group behaves like a single consumption good. ${ }^{7}$ Consequently, the aggregate under consideration can be integrated in the utility function of the representative consumer by writing it as a subutility function defined over the elements of the aggregate. The analytical advantage of weakly separable sets of goods and assets is quite evident in the case of a consumer allocating his available budget over consumption goods as well as financial assets. Weak separability of the consumer's utility function is a necessary and sufficient condition for considering his maximization problem as a multistage budgeting process. In the first stage, the available budget is allocated between the weakly separable groups, 8 based on total expenditure and all individual goods' prices. The second stage concerns the allocation of the resulting group expenditures (from stage one) to the individual elements within the respective groups. Consequently, two stage budgeting involves aggregation over goods and separable decision making. In empirical investigations we can then analyse the allocation within weakly separable groups ${ }^{9}$ by only considering demand for one asset $k$ (denoted by $m_{k}, k=1, \ldots, n$ ) as a function of group expenditure in the weakly separable group $\left(y_{m}\right)$ and the prices of the group elements $\left(p_{k}\right)$ (Varian, 1984):

$$
m_{k}=g_{k}\left(y_{n, k}, p_{k} ; k=1, \ldots, n\right)
$$

whete

7

On the other hand, when the weak separability condition is violated, preferences over the group are not stable. sunce variations in the relative amounts of the group"s components (but holding the aggregate level constant) will affect consumer preferences over excluded goods as well.

8

It is not necessary that more than one weakly separable group can be identified. If only one group is weakly separable from the other individual goods, the first stage decision amounts to the optimal allocation of the budget to this group and the other individual goods simultaneously.

9

For the moment we assume that monetary or financial assets are weakly separable from other consumption decisions. 


$$
y_{m}=\sum_{k=1}^{n} p_{k} m_{k}
$$

Weak separability can be analysed using either parametric or non-parametric tests. Parametric tests (using different functional form representations for the individual agent's utility function) are actually joint tests of the applicability of the respective functional forms and of consistency of the data with utility maximization and weak separability. Additionally, the parametric approach requires estimation of a model of the agent's optimizing behaviour and testing of weak separability hypotheses, usually formulated as restrictions on parameters or marginal rates of substitution. 10 Because of this joint character of parametric tests they are not suited for analyzing the compatibility of a data set with demand theory. For, if a parametric weak separability test reveals that weak separability should be rejected, we cannot decide whether this rejection is due to a violation of demand theory in general or only to misspecification of the consumer's utility function. A general test for consistency of the data with demand theory can only be executed without a priori assumptions about the specification of the utility function. The advantage of parametric tests, however, is that they are stochastic.

Weak separability can also be tested with the composite commodity theorem (Deaton and Muellbauer, 1988). If a group of prices move in parallel, the corresponding group of commodities can be treated as one single good or aggregate. The common factor in the prices can then be treated as the price of the commodity aggregate. Its quantity can be calculated by weighting the individual quantities with their respective base-period prices and then adding them together. Empirically, however, it appears to be hard to identify a common factor in prices of goods or in the user costs of two or more financial assets. 11

A hybrid test procedure is the semiparametric method, as described by Barnett and Yue (1988). Their Asymptotically Ideal Model (AIM) (consisting of a system of demand equations) is derived from the Müntz-Szatz series expansion. This series expansion is globally flexible in the sense that the model can approximate any continuous function asymptotically without specifying a parametric form. The Müntz-Szatz series partial sums can easily be forced to be globally regular (if all parameters are nonnegative) at all orders of approximation as well as in the limit. The AIM then approximates the demand functions that result from the consumer's optimization

10 A theoretical foundation for parametric tests of weak separability (using the translog functional form) is given in Denny and Fuss (1977). Empirical examples are provided by Serletis (1987a), Hahm and Kim (1994) andl Hancock (1987). These weak separability tests are formulated as restrictions on the parameters of the estimated demand equations.

11. The only exception may be the common factor in the user costs of curtency and demand deposits, which can be traced for rather long periods of time. Such a common factor can be explained by their relatively constant interest returns. This might provide an intuitive justification for aggregating these two assets in $\mathrm{M} 1$ 
problem. This is an important advantage of the AIM as opposed to parametric models which are only locally regular. The AIM can be used to test for or to impose theoretical regularity of the demand system. Weak separability can be tested with the AIM by checking restrictions on estimated parameters of the model. Nevertheless, the AIM remains an approximation to the underlying demand functions. Therefore, we will not use the AIM here, but instead apply a nonparametric test for weak separability.

\subsubsection{The nonparametric test for weak separability}

\subsubsection{Test for consistency of the data with GARP}

A nonparametric test for weak separability does not require the specification of a functional form for consumer preferences. Based on axioms of revealed preference, only data on observed quantities and prices of a set of goods are needed to perform the test. Revealed preference theory gives information on the true definition of monetary aggregates, since it analyses which grouping (or aggregator function) of financial assets has been used by money-holders (consumers of monetary services) in practice. In this chapter we use Varian's non-parametric (NONPAR) test (1982 and 1983) to check the compatibility of our data with demand theory.

First, the NONPAR test examines whether the whole data set on real consumption goods and financial assets is consistent with the utility maximization hypothesis of consumer behaviour. This step must be executed before we can test for weak separability of the data set. Here, the null hypothesis of a stable set of preferences means that variation in the observed consumption patterns over time can be completely explained by changes in relative prices and total expenditure. Acceptation of the null hypothesis implies that we can use a demand system (of any functional form) to describe consumer behaviour. Consistency of the data with utility maximizing consumer behaviour appears under the following condition (where $p^{i}$ is a vector of $r$ prices and $x^{i}$ is a vector of the $r$ associated goods" quantities) ${ }^{12}$ :

$$
\text { if } U\left(x^{i}\right) \geq U(x) \text { for all } x \text { such that } p^{i} x^{i} \geq p^{i} x, \text { for } i=1, \ldots, t
$$

there is a utility function $U(x)$ that rationalizes the set of observations $\left(p^{i}, x^{i}\right)$. In other words, if the above condition is met, the data could have been generated by a non-satiated, continuous and concave utility function. Varian (1983) shows that this condition is equivalent to the Generalized Axiom of Revealed Preferences (GARP). Consistency of the data with utility maximization will be tested using GARP, since it is easier to implement in practice. The empirical application of this axiom is executed as follows (where $R$ means revealed preferred):

12 The superscript $i$ refers to observation $i$, since the nonparametric test requires the use of time series data. 


$$
x^{i} R x^{j} \text { if } p^{i} x^{i} \geq p^{i} x^{j}, \text { for } i, j=1, \ldots, t
$$

A violation of GARP occurs if equation (3.5) holds and simultaneously $p^{j} x^{j}>$ $p^{j} x^{i}$, implying that the data cannot have been generated by a utility function that is maximized by a rational consumer subject to a budget constraint. When GARP is violated this implies that: a combination of goods $x^{i}$ chosen by the consumer is preferred to all other combinations available at that time (meaning that they are located inside the budget line when $x^{i}$ is purchased), but also that combination $x^{j}$ is revealed preferred to $x^{i}$ ( $x^{i}$ lies inside the budget line when $x^{j}$ is actually chosen). Therefore, a violation of GARP can only be explained by a shift of the indifference curves. This means that preferences (as evidenced by the observed quantities consumed) have changed over time due to changes in relative prices and that the data have not been generated by a well-behaved utility function.

\subsubsection{Examples of the GARP testing procedure}

The procedure for executing the GARP test can be explained further with some simple examples containing hypothetical data (two goods, two observations). The first example consists of the following price and quantity data respectively:

Example 1 Large income effects (no violations of GARP)

\begin{tabular}{|l|l|l|l|l|}
\hline \multirow{2}{*}{ Observations } & \multicolumn{3}{|l|}{ Prices } & Quantities \\
\cline { 2 - 5 } & Good A & Good B & Good A & Good B \\
\hline 1 & 0.2 & 0.3 & 10 & 8 \\
\hline 2 & 0.1 & 0.4 & 12 & 9 \\
\hline
\end{tabular}

The data in this example do not violate GARP. Recall that superscripts indicate the respective observations and that all variables are vectors of two goods. Before GARP can be checked the products $p^{I} x^{1}(=0.2 * 10+0.3 * 8=4.4), p^{2} x^{2}(=4.8), p^{l} x^{2}$ $(=5.1)$ and $p^{2} x^{I}(=4.2)$ must be calculated. In an iterative procedure, starting with the value 1 for both $i$ and $j$, these products are used to compare the cost of period $j$ consumption bundles at period $i$ prices with the cost of period $i$ consumption bundles at period $i$ prices. The whole testing procedure then consists of the following steps:

1) $p^{l} x^{l} \geq p^{l} x^{l} \rightarrow x^{l} R x^{l} ; \quad p^{l} x^{l}>p^{l} x^{l}:$ no, conclusion: no violation of GARP; 2) $p^{l} x^{l} \geq p^{l} x^{2} \rightarrow$ no; $\quad$ no further testing, conclusion: no violation of GARP;

3) $p^{2} x^{2} \geq p^{2} x^{l} \rightarrow x^{2} R x^{l} ; \quad p^{l} x^{l}>p^{l} x^{2}$ : no, conclusion: no violation of GARP; 4) $p^{2} x^{2} \geq p^{2} x^{2} \rightarrow x^{2} R x^{2} ; \quad p^{2} x^{2}>p^{2} x^{2}:$ no, conclusion: no violation of GARP.

The results show that $x^{2}$ is revealed preferred to $x^{l}$, and that $x^{l}$ is not revealed preferred to $x^{2}$, implying that GARP is not violated. Although the price of good B rises from period $\mathbb{1}$ to period 2 , both goods are consumed in higher quantities in 
period 2. This indicates that income effects dominate price (or substitution) effects in the first example.

Example 2 Large substitution effects (two violations of GARP)

\begin{tabular}{|c|c|c|c|c|}
\hline \multirow[t]{2}{*}{ Observations } & \multicolumn{2}{|l|}{ Prices } & \multicolumn{2}{|c|}{ Quantities } \\
\hline & Good A & Good B & Good A & Good B \\
\hline 1 & 0.2 & 0.3 & 14 & 8 \\
\hline 2 & 0.1 & 0.4 & 12 & 9 \\
\hline
\end{tabular}

In this example, the available budget falls from period 1 to period 2 , but the quantity consumed of good B rises nevertheless. Substitution effects are stronger than income effects in this case. With $p^{l} x^{1}=5.2, p^{2} x^{2}=4.8, p^{1} x^{2}=5.1, p^{2} x^{1}=4.6$, the results of the testing procedure are as follows:

1) $p^{l} x^{l} \geq p^{l} x^{l} \rightarrow x^{l} R x^{l} ; \quad p^{l} x^{l}>p^{l} x^{l}:$ no, conclusion: no violation of GARP; 2) $p^{l} x^{l} \geq p^{1} x^{2} \rightarrow x^{l} R x^{2} ; \quad p^{2} x^{2}>p^{2} x^{l}$ : yes, conclusion: violation of GARP;

3) $p^{2} x^{2} \geq p^{2} x^{1} \rightarrow x^{2} R x^{1} ; \quad p^{I} x^{1}>p^{l} x^{2}$ : yes, conclusion: violation of GARP;

4) $p^{2} x^{2} \geq p^{2} x^{2} \rightarrow x^{2} R x^{2} ; \quad p^{2} x^{2}>p^{2} x^{2}:$ no, conclusion: no violation of GARP.

Since $x^{1}$ is revealed preferred to $x^{2}$ at period 1 prices and $x^{2}$ is revealed preferred to $x^{\prime}$ at period 2 prices, two violations of GARP appear. According to equation (3.5), an observation is always revealed preferred to itself, as also becomes clear from the above examples. With the constant consumer budget in example 3, no violations of GARP are found.

Example 3 Constant consumer budget (no violations of GARP)

\begin{tabular}{|c|c|c|c|c|}
\hline \multirow[t]{2}{*}{ Observations } & \multicolumn{2}{|l|}{ Prices } & \multicolumn{2}{|c|}{ Quantities } \\
\hline & Good A & Good B & Good A & Good B \\
\hline 1 & 2 & 3 & 10 & 8 \\
\hline 2 & 3.5 & 2 & 9 & 6.25 \\
\hline
\end{tabular}

In this case, $p^{1} x^{1}=44, p^{2} x^{2}=44, p^{1} x^{2}=36.75$ and $p^{2} x^{1}=51$. In contrast to example 2 , here, the consumption of both goods falls in period 2 in response to the relative price changes of these goods. With a constant budget, the representative consumer cannot buy more of good B in period 2 in response to its lower price, because good A's own-price elasticity is relatively small. It appears that GARP is not violated in example 3 . Steps 1 and 4 of the testing procedure are not reported, because an observation is always revealed preferred to itself. The results of steps 2 and 3 are: 
2) $p^{l} x^{I} \geq p^{1} x^{2} \rightarrow x^{1} R x^{2} ; \quad p^{2} x^{2}>p^{2} x^{1}:$ no, conclusion: no violation of GARP; 3) $p^{2} x^{2} \geq p^{2} x^{l} \rightarrow$ no; $\quad$ no further testing; conclusion: no violation of GARP.

\subsubsection{Determination of weakly separable groups}

After the whole data set is tested with the GARP procedure described in sections 3.2.2.1 and 3.2.2.2, the same test procedure must be employed to determine the subsets of the data that are weakly separable from the rest. ${ }^{13}$ To summarize, the necessary conditions for weak separability are that the entire data set and each weakly separable grouping from it (the subaggregates) must satisfy GARP. If there are no violations of GARP, the data in that (sub)set are consistent with the existence of a well-behaved utility function defined over that specific group of goods. The next step in the NONPAR program can tell us which subsets of goods are weakly separable.

At this point, Varian's nonparametric test checks the sufficient condition for weak separability of the utility function in two categories. If the data are divided into two subsets of prices and quantities of goods $\left(p^{i}, x^{i}\right)$ and $\left(q^{i}, z^{i}\right) i=1,2, \ldots, t$ respectively, the utility function is weakly separable if a subutility function $V(z)$ and a macroutility function $U(x, z)$ strictly increasing in $V(z)$ can be found such that:

$$
U(x, z)=U(x, V(z))
$$

where $x$ and $z$ are vectors of quantities of goods.

The separability of the macro-utility function $U(x, z)$ into these two subsets of data can be examined by testing the consistency with GARP when the subutility functions are calculated using the following Afriat inequalities:

$$
U^{i} \leq U^{j}+\alpha^{j} p^{j}\left(x^{i}-x^{j}\right)+\left(\frac{\alpha^{j}}{\beta^{j}}\right)\left(V^{i}-V^{j}\right)
$$

and

$$
V^{i} \leq V^{\lambda}+\beta^{j} q^{j}\left(z^{i}-z^{j}\right) \text { for } i, j=1,2, \ldots, t
$$

This test checks whether utility indices $U^{i}, v^{i}>0$, and the corresponding indices of marginal utility of income $\alpha^{i}>0$ and $B^{i}>0$ can be found that satisfy the Afriat inequalities. If no solution to a specific set of Afriat inequalities can be found, the null hypothesis of weak separability of the whole data set in the respective subset is rejected. The Afriat inequalities can be tested for every possible subset of goods or financial assets. In short, the whole NONPAR program checks the compatibility of the set of observed data with the existence of a utility function that is weakly separable in some subset of the goods. The GARP test is equivalent to calcullating the Afriat numbers that satisfy the inequalities (3.7) and (3.8) (see Varian, 1982 and

13 This is the necessary condition for weak separability, whereas the second one (to be discussed in the next paragraph) is a sufficient condition (Swofford and Whitney, 1988). 
1983 for a proof). The exact procedure for determining these Afriat indices is described in Varian (1982, appendix 1). If, however, GARP is violated, the Afriat inequalities cannot be computed, since the data have not been generated by a well-behaved utility function (as in example 2). If the data are consistent with GARP the procedure for determining the Afriat numbers is an iterative process of finding positive numbers that satisfy the above inequalities in each observation of the sample. However, these positive numbers are not necessarily unique.

If the data in example 1 are weakly separable in good $\mathrm{A}$ (represented by $p^{i}$ and $x^{i}$ ) and good B (represented by $q^{i}$ and $z^{i}$ ), the inequalities (3.7) and (3.8) are satisfied with the following Afriat numbers: $100.39\left(U^{l}\right), 101\left(U^{2}\right), 99.07\left(V^{I}\right), 100\left(V^{2}\right), 1$ $\left(\alpha^{I}\right.$ and $\left.\alpha^{2}\right), 3.3\left(B^{l}\right)$ and $2.3\left(B^{2}\right)$. When $i=j$ the inequalities are satisfied for all positive numbers. Substitution of the above Afriat numbers and of the data from example 1 in inequalities (3.7) and (3.8) (for $i$ and $j$ unequal) demonstrates that these numbers indeed provide a solution to the Afriat inequalities. For $i=1$ and $j=2$ we obtain:

$$
\begin{gathered}
100.39 \leq 101+0.1 *(10-12)+\frac{99.07-100}{2.3} \\
99.07 \leq 100+2.3 * 0.4 *(8-9)
\end{gathered}
$$

The corresponding inequalities for $i=2$ and $j=1$ are:

$$
\begin{gathered}
101 \leq 100.39+0.2 *(12-10)+\frac{100-99.07}{3.3} \\
100 \leq 99.07+3.3 * 0.3 *(9-8)
\end{gathered}
$$

\subsubsection{Drawbacks and modifications of the NONPAR test}

\subsubsection{The bias towards rejection of the weak separability hypothesis}

Varian's nonparametric test has some important drawbacks. First, the test is very restrictive, because a single violation of the null hypothesis leads to a rejection of the respective hypothesis. ${ }^{14}$ No confidence intervals are available to determine whether the null hypothesis of weak separability of a set of goods must be accepted or rejected.

In order to overcome the bias in the NONPAR program of rejecting consistency of the data with GARP and of weak separability, we adopt the following decision

14 See Barnett and Choi (1989) for a comparison of the power of various tests for weak separabili-
ty. 
rule. If, with a specific data set, GARP is violated for less than $5 \%$ of the combinations tested, we assume that the rejection of GARP is not significant. Consequently, the conclusion is that these data are consistent with demand theory (the necessary condition for weak separability is not rejected). ${ }^{15}$ The question of weak separability of a subset of these data can still not be resolved, however, because the sufficient condition for weak separability can only be tested if GARP is not violated at all. In other words, even if GARP is violated in less than $5 \%$ of the observations, we are unable to determine whether the proposed weak separability pattern can be accepted. On the other hand, if a specific tested structure of weak separability is consistent with the Afriat inequalities (the sufficient condition for weak separability), the goods or assets can be aggregated in the proposed way.

A second drawback of the nonparametric test appears if the data set contains goods and/or assets that are held by different groups of economic agents (which is the case in our analysis, since we use aggregate data on household and company asset holdings). Then, the number of violations of GARP is likely to be higher than if disaggregate data are available. Therefore, data on goods' consumption and monetary asset holdings of the household sector are also analysed in the empirical part of this chapter.

\subsubsection{A new quantity normalisation in the NONPAR test}

Perhaps the most important problem with the nonparametric test for consistency of a given data set with GARP is the low power of the test when the available consumer budget increases over time. This amounts to a budget line that shifts steadily outward in consecutive periods. Then, budget lines will rarely cross. Each combination of goods chosen by the representative consumer is revealed preferred to the previous ones, since real expenditure (the goods' quantities consumed) rises over time. The effects of the rising consumer budget will dominate the total effect of relative price changes between goods. The cost of buying the same bundles at time $t$ prices that were purchased earlier at then prevailing prices will be lower than the actual expenditures in period $t$. In the case of outward shifting budget lines the probability of finding observations that are inconsistent with GARP is very low (Chalfant and Alston, 1988).

In order to resolve this objection to the GARP test and to analyse the effects of price changes separately the NONPAR program is modified as follows. For each observation in time the quantities of goods are adjusted for the consumer budget, and then compensated for the sum of the respective goods' prices, as in equation (3.9).

15 Note that the necessary condition for weak separability implies that the whole data set and the proposed subsets satisfy GARP (see page 31). Therefore, the decision rule is applied to the whole data set and to the subgroups. The necessary condition for weak separability is not rejected if GARP is not significantly violated for the whole group and for the subgroups. 


\subsection{Testing the separability of monetary assets from consumption goods}

\subsubsection{Data generation procedure}

In order to test for weak separability we use on the one hand aggregate data on guantities and prices of consumption goods, of national income and of monetary assets $^{16}$ in the Netherlands. On the other hand, however, since the theory of revealed preference assumes the existence of a representative consumer and because of the second problem with the NONPAR program mentioned in section 3.2.3.1, the weak separability tests are also performed with the corresponding data for households separately. The weak separability tests for the aggregate data are executed with annual (end of year) data over the period 1970 to 1993. With the household portfolio, the analysis focuses on the period 1974-1993. For aggregate as well as household data, we also examine the weak separability conditions over the subsample 19861993. This latter time period is one without major institutional changes in the monetary sector of the Dutch economy (after 1986 no liquid financial assets have been introduced anymore), and it also enables us to test all financial assets in the data set over the same span of time. ${ }^{17}$ This subsample thus provides a consistent time series on consumption goods and financial assets without major external shocks. A comparison of the test results for the full sample with those for the subsample may indicate whether breaks in separability patterns are due to financial innovations that were introduced in 1986 or to, for example, slow portfolio adjustment.

We use data on the value of aggregate household consumption of goods and services, since this paper focuses on the existence of weak separability of monetary assets from consumption in general, and not the reverse. The annual values of total household consumption of goods and services are taken from various National Accounts, published by the Dutch Central Bureau of Statistics (CBS). The same source provides the data on nominal national income. The Consumer Price Index (CPI) used in this chapter is taken from the OECD series provided by Datastream, with January 1986 as the base. Dividing the value of total household consumption by the CPI then gives real consumption. This real consumption series is used in the tests with the aggregate data as well as in the tests with the household data only, with the CPI as the corresponding price series. A similar procedure is adopted to construct real national income data, while the CPI is again used as the relevant price series.

16 The terms monetary assets and financial assets are used interchangeably throughou this thesis. Both refer to assets that are either money themselves or that can be transformed into money very quickly and at minor costs; in oher words, both terms are synonyms for liquid assets.

17

Data on short-term savings are only available from 1970 onward, whereas Certificates of Deposit: and Commercial Paper have only been issued in the Netherlands since 1986. 
The annual series on interest rates and stocks of financial assets are obtained from the Annual Reports and the Quarterly Bulletins of the Dutch central bank (DNB). Time series on short-term savings from 1970 onwards were made available by DNB.

The whole monetary asset portfolio considered here consists of currency*, demand deposits*, short time deposits*, foreign currency deposits*, short-term government liabilities, ${ }^{18}$ savings deposits with a maturity of less than two years*, Certificates of Deposit (CD)* and finally Commercial Paper (CP). The financial assets marked with an asterisk are components of the harmonised M3 aggregate currently used as the main money supply variable in the Netherlands. The two non-M3 financial assets are included in the analysis, because it is likely that there is some degree of substitution between the harmonised M3 components and the excluded assets. Relatively new financial assets, like Commercial Paper, can influence the separability of existing monetary aggregates through their substitution relations with individual components of these aggregates. The other monetary aggregates that will be examined in this chapter are $M 1$ (which consists of currency and demand deposits) and M2 (which contains currency, demand deposits, short-term time deposits, foreign currency deposits and CDs).

The respective interest rates on financial assets are needed in order to calculate the shadow prices (user costs) of holding financial assets. Since financial assets are assumed to provide monetary services in proportion to their stock, the shadow price of monetary services from financial asset $k\left(p_{k}\right)$ is calculated as the one period holding cost using Barnett's (1978) formula:

$$
p_{k}=\frac{\pi *\left(R-r_{k}\right)}{(1+R)}
$$

Here $\pi$ represents the level of the CPI, $R$ is the benchmark interest rate (the highest rate or yield achievable regardless of risk and maturity and measured ex-post) and $r_{k}$ is the own interest rate on financial asset $k$. The benchmark asset is a non-monetary asset with a high rate of return; usually the benchmark asset serves as a means of transferring wealth intertemporally. ${ }^{19}$ Fase (1985) uses the interest rate on private loans with a period to maturity of 20 years as a proxy for the benchmark rate. Equa-

18 These sthort-term government liabilities are the aggregate of Treasury Bills and claims on local governments, because the private sector only holds a very small stock of these assets. The interest rate on government liabilities is calculated as a quantity-weighted average of the component interest rates, although we only use the interest rate on local government liabilities from 1990 onwards (due to missing data on Treasury Bill rates).

19 If there is an inverted term structure of interest rates, the benchmark rate chosen is a short-term interest rate, such as the rate on call money. This procedure guarantees that all financial assets" wser costs are non-negative. 
tion (3.10) measures the nominal user costs because of the presence of the CPI in the formula. 20

Holdings of financial assets in the sample are deflated by the CPI in order to attain real data that can be compared with real goods' consumption. This approach comes closest to demand-theoretical restrictions, since we now have real quantities and nominal user costs of financial assets. As a result, multiplication of the quantities and prices of the individual financial assets, and subsequent summation of these products over all assets equals total nominal expenditure on this asset category (see equation (3.3)). After these transformations the whole data set can be tested for consistency with GARP and for the subutility functions providing solutions to the Afriat inequalities.

\subsubsection{Results with aggregate data}

Our aim in this subsection is to determine whether decisions on the consumption of monetary services are weakly separable from real consumption decisions and from real national income. If the NONPAR program provides evidence for this separability we can analyse the monetary sector independently of the rest of the economy. 21 The results of weak separability tests of financial asset holdings from real consumption decisions are presented in full detail below. The same tests are performed using real national income instead of real consumption. Since the test results are only marginally different for these two patterns of weak separability, we will only briefly comment on the outcomes obtained with real national income.

Results of the test between consumption of goods and services on the one hand and the total financial asset portfolio on the other (using data for the economy as a whole) are shown in table 3.1. The second and third column in this table show whether the total portfolio (consisting of the elements mentioned in column one) is consistent with GARP, using unacljusted and adjusted quantity data, respectively. In parentheses, the number of violations of GARP and the total number of combinations tested are presented. Columns four and five reveal the outcomes for the Afriat inequalities without and with normalisation imposed in the NONPAR program, respectively. The outcomes for the necessary conditions in these columns show whether the subutility functions are consistent with GARP, whereas the results for the sufficient conditions indicate whether positive numbers that satisfy the Afriat inequalities are found. The reader is reminded that, until 1986, the financial asset portfolio consists of currency, demand deposits, short-term time deposits, foreign currency deposits, short-term government liabilities and savings deposits. From 1986 onwards, Certificates of Deposit and Commercial Paper are also included in this portfolio.

20

Barnet?, Fisher and Serletis (1992) discuss the issue of real versus nominal user costs in more detail (p. 2093).

21 Implicitly, it is assumed that all real consumption can be aggregated in one measure. This is not a crucial assumption for the purpose of this paper, since we want to test for the appropriateness of modeling the demand for monetary assets separately 
Table 3.1 Results of weak separability tests of financial assets from other consumption goods (aggregate annual data, $1970 \mathrm{~m} 1993)^{22}$

\begin{tabular}{|c|c|c|c|c|c|}
\hline & \multicolumn{2}{|c|}{$\begin{array}{l}\text { Consistency of total portfolio } \\
\text { with GARP } \\
\text { (number of violations) } \\
\text { (total number of combinations } \\
\text { tested) }\end{array}$} & \multicolumn{3}{|c|}{$\begin{array}{l}\text { Satisfying the Afriat inequali- } \\
\text { ties: } \\
\text {-necessary } \\
\text {-sufficient }\end{array}$} \\
\hline & $\begin{array}{l}\text { without } \\
\text { normalisation }\end{array}$ & $\begin{array}{l}\text { with normali- } \\
\text { sation }\end{array}$ & $\begin{array}{l}\text { without } \\
\text { normalisation }\end{array}$ & $\begin{array}{l}\text { with } \\
\text { mal }\end{array}$ & tion \\
\hline $\begin{array}{l}\mathrm{U}=\mathrm{U} \text { (goods consumption. } \\
\mathrm{V} \text { (hnamcial assets }) \text { ) }\end{array}$ & $\begin{array}{l}\text { yes yes } \\
(0)(0) \\
(576) \quad(64)\end{array}$ & $\begin{array}{l}\text { yes yes } \\
(2)(0) \\
(576)(64)\end{array}$ & $\begin{array}{ll}\text {-no } & \text { yes } \\
\text {-no } & y e s\end{array}$ & $\begin{array}{l}- \text { no } \\
\text {-no }\end{array}$ & $\begin{array}{l}\text { yes } \\
\text { yes }\end{array}$ \\
\hline
\end{tabular}

Table 3.1 reveals that without normalisation the whole portfolio is consistent with GARP. With normalisation we also accept consistency with GARP, since the number of violations in the full sample is less than $5 \%,{ }^{23}$ whereas the subsample shows no violations at all. However, the necessary and sufficient conditions for weak separability of financial assets' consumption decisions from real goods' consumption decisions are only fulfilled over the period 1986-1993. If we would consider the full sample (1970-1993) the results of both versions of the nonparametric test suggest that research into the monetary sector of the economy cannot be undertaken by merely looking at this sector, since the composition of consumers' financial asset portfolios is also affected by real economic factors. ${ }^{24}$ It appears that the quantity adjustment does not significantly influence the results of weak separability between the monetary sector and real goods" consumption.

When real national income is used instead of real goods' consumption, the results of the weak separability tests without normalisation are identical to those reported in table 3.1. The main difference with table 3.1 is that, with normalised data, GARP is violated twice between 1986 and 1993. Over the periods 1970-1985 and 1987-1993, however, the necessary and sufficient conditions for weak separability of financial assets" consumption decisions from real national income are satisfied. These results indicate that the rejection of this type of weak separability is due to only one outlier in the data.

22 Results with annual data from 1986 to 1993 are shown in thalics.

23 Note that, because of the non-stochastic nature of the NONPAR program, the sufficient conditions for weak separability cannot be tested if GARP is violated. With the availlable testing procedures we can only reject weak separability then.

24 Unreported weak separability tests with quarterly data over the period 1986:1-1993:4 show results that are qualitatively similar to those for the full annual sample. 
At first sight, the outcomes in table 3.1 might suggest that the introduction of CDs and CP in 1986 has made the monetary sector more complete, in the sense that consumers have considered monetary assets as one good since then. This might explain why weak separability between the monetary and the real sector of the economy is accepted after 1986. Additional tests (with normalised as well as with unadjusted data) show, however, that this hypothesis should be rejected. From these tests, it appears that weak separability of the financial asset portfolio from goods' consumption is also accepted over the subsamples 1970-1980 and 1981-1993. The rejection of weak separability over the full sample 1970-1993 may, therefore, be caused by the fact that consumption decisions which were taken at very distant moments in time lead to violations of the weak separability conditions. This suggests that the inconsistency of the subutility functions with GARP over the full sample is mainly due to violations of the transitivity axiom of consumer preferences, which is implicitly tested in the GARP procedure. Consequently, we may cautiously conclude that financial assets as a group are weakly separable from goods' consumption, since violations of this weak separability pattern are only found in samples which cover a long span of time.

The results in table 3.1 confirm our earlier assumption that the likelihood of violations of the utility maximization hypothesis and of rejections of weak separability is higher if quantities are normalised than if the raw data are used. Table 3.1 suggests that the growth in expenditures has been an important factor for the existence of stable preferences over monetary assets and real consumption goods.

Unreported tests executed with quarterly data (1986:1-1993:4) lead us to reject this pattern of weak separability (even without quantity normalisation). This outcome may be an indication of the imperfect adjustment of financial asset holdings within one quarter (see also Swofford and Whitney, 1988), which may, in turn, be explained by the costs of prepayment on several financial assets. When quarterly data are used, research that is primarily concerned with substitution effects between monetary assets and that abstracts from relations with the real sector of the economy should, therefore, incorporate this lagged adjustment in one way or another. Otherwise, this kind of research may be inappropriate because of the rejection of weak separability between the monetary and the real sector with quarterly data.

When the same tests as in table 3.1 are performed with portfolios of financial assets consisting of only the M1, M2 and M3 components, respectively, the results with normalisation are somewhat different (see table 3.2). The interpretation of the respective columns is the same as in table 3.1. Without normalisation all three aggregates, except M2, whose subutility function violates the necessary and sufficient conditions for weak separability over the years $1970-1993,{ }^{25}$ turn out to be weakly separable from goods" consumption, irrespective of whether the full sample or the subsample is used. Identical results are obtained in the separability tests between monetary aggregates and real national income (with unadjusted quantity data).

25 More specifically, the subutility function over M2 violates the weak separability conditions between 1970 and 1985 
Table 3.2 Results of weak separability tests of M1, M2 and hamonised M3 from other consumption goods with normalisation (aggregate annual data)

\begin{tabular}{|c|c|c|c|c|}
\hline & \multicolumn{2}{|c|}{$\begin{array}{l}\text { Consistency of total portfolio } \\
\text { with GARP } \\
\text { (number of violations) } \\
\text { (total number of combinations } \\
\text { tested) }\end{array}$} & \multicolumn{2}{|c|}{$\begin{array}{l}\text { Satisfyiting the Afriat inequall- } \\
\text { ties: } \\
\text {-necessary } \\
\text {-sufficient }\end{array}$} \\
\hline & $1970-1993$ & $1986-1993$ & $1970-1993$ & $1986-1993$ \\
\hline $\mathrm{U}=\mathbb{U}(\operatorname{goods}, \mathrm{V}(\mathrm{M} 1))$ & $\begin{array}{l}\text { yes } \\
(0) \\
(576)\end{array}$ & $\begin{array}{l}\text { yes } \\
(0) \\
(64)\end{array}$ & $\begin{array}{l}\text { yes } \\
\text { yes }\end{array}$ & $\begin{array}{l}\text {-yes } \\
\text {-yes }\end{array}$ \\
\hline$U=U(g o o d s, V(M 2))$ & $\begin{array}{l}\text { yes } \\
(2) \\
(576)\end{array}$ & $\begin{array}{l}\text { yes } \\
(2) \\
(64)\end{array}$ & $\begin{array}{l}- \text { no } \\
- \text { no }\end{array}$ & $\begin{array}{l}- \text { no } \\
- \text { no }\end{array}$ \\
\hline$U=U($ goods,$V(M 3))$ & $\begin{array}{l}\text { yes } \\
(0) \\
(576)\end{array}$ & $\begin{array}{l}\text { yes } \\
(0) \\
(64)\end{array}$ & $\begin{array}{l}- \text { no } \\
\text {-no }\end{array}$ & $\begin{array}{l}- \text { yes } \\
- \text { yes }\end{array}$ \\
\hline
\end{tabular}

Note: data on CDs and CP are only available since 1986. Full sample results for M2 thus include currency, demand deposits, short-term time deposits and foreign currency deposits. Similar renarks apply to other aggregates.

With normalisation it appears that M1 satisfies the necessary and the sufficient conditions for weak separability from goods' consumption in both samples. Weak separability of harmonised M3 is accepted for the subsample (unreported results show that this is also the case between 1970 and 1980). M2 shows violations of GARP in both samples, which may indicate that it is not an admissible monetary aggregate when goods' and assets' quantities are adjusted for budget increases. Even without quantity normalisation, however, it appears that M2 is inconsistent with demand theory between 1970 and 1985 . When considering weak separability of the three monetary aggregates from real national income (with quantity normalisation), M1 and harmonised M3 appear consistent with demand theory over the full sample (and, of course, also over the subsample). M2 shows two violations of GARP over the period 1970-1985, but is weakly separable over the subsample.

Summarising the results for the economy as a whole, we may conclude, based on table 3.2, that the M1 aggregate is weakly separable from the consumption of real goods (even with quantity adjustments). The whole financial asset portfolio may also be considered a weakly separable group, for the reasons mentioned below table 3.1 . The harmonised M3 aggregate is consistent with demand theory over the subperiods 1970-1980 and 1986-1993 when quantity normalisations are imposed, indicating that the wiolations of GARP for M3's subutility function are caused by a few outliers in the data. Although weak separability of harmonised M3 from goods' consumption is rejected over the full sample, this aggregate may still be consistent with demand theory, since the normalisation adopted here may be incorrect. Moreover, when unadjusted quantity data are used, M3 appears weakly separable from goods" con- 
sumption. In addition, test results show that harmonised M3 is weakly separable from real national income. Therefore, we will as well consider harmonised M3 as a monetary aggregate that is consistent with demand theory.

\subsubsection{Results for households}

The portfolio for households consists of currency, demand deposits, short-term time cleposits, foreign currency deposits, short-term savings and consumption of goods and services. The test results in table 3.3 show that households" holdings of monetary assets are weakly separable from real consumption using annual data from 19741993, both without and with quantity normalisation. As for the aggregate portfolio, unreported test results with quarterly data (1986:1-1993:4) indicate that both the necessary and the sufficient weak separability conditions are violated, irrespective of whether the data are normalised or not.

From additional tests for households, it appears that the years 1970-1973 cause many violations of GARP for different portfolios consisting of only monetary assets. The household data generally show consistency with utility maximizing behaviour from 1974 onwards, even when quantities are adjusted for budget rises over time. This observation may be explained by slow portfolio adjustments in the early 1970 s, due to less opportunities for households to cliversify their portfolios as compared with the later period.

Table 3.3 Results of weak separability tests of monetary assets from other consumption goods (household data, 1974-1993)

\begin{tabular}{|l|l|l|l|l|}
\hline \multicolumn{2}{|l|}{} & \multicolumn{2}{|l|}{$\begin{array}{l}\text { Consistency of total portfolio } \\
\text { with GARP } \\
\text { (number of violations) } \\
\text { (total mumber of combinations } \\
\text { tested) }\end{array}$} & $\begin{array}{l}\text { Satisfying the Afriat inequali- } \\
\text { ties: } \\
\text {-necessary } \\
\text {-sufficient }\end{array}$ \\
\hline & $\begin{array}{l}\text { without } \\
\text { normalisation }\end{array}$ & $\begin{array}{l}\text { with normali- } \\
\text { sation }\end{array}$ & $\begin{array}{l}\text { without } \\
\text { normalisation }\end{array}$ & $\begin{array}{l}\text { with nor- } \\
\text { malisation }\end{array}$ \\
\hline $\begin{array}{l}U \text { (financial assets) }) \\
\text { yestion, }\end{array}$ & $\begin{array}{l}\text { yes } \\
(0) \\
(400)\end{array}$ & $\begin{array}{l}\text { yes } \\
(400)\end{array}$ & $\begin{array}{l}\text {-yes } \\
\text {-yes }\end{array}$ \\
\hline
\end{tabular}




\subsection{Weakly separable groups of financial assets}

\subsubsection{Weakly separable monetary aggregates for the economy as a whole}

According to the outcomes of the NONPAR test presented in section 3.3.2, decisions about the consumption of financial assets ${ }^{26}$ are weakly separable from real consumption when the actual and the normalised quantities of consumed goods and assets are used, at least over some subsamples (e.g. the period 1981-1993). The same may be said of the separability between the $\mathrm{M} 1$ and harmonised $\mathrm{M} 3$ monetary aggregates and real consumption. Unreported results for the assets that have existed over the full sample analysed in this chapter (1970-1993), show that the M3 aggregate (excluding CDs) was allso weakly separable during that time period when unadjusted data are used. In addition, inconsistencies of some of the monetary aggregates with GARP and/or with weak separability may also have been caused by an incorrect normalisation of the assets' and goods' quantities.

Therefore, real consumption is now excluded from the analysis. This section deals with tests whether several subsets of financial assets are weakly separable from other financial assets. The objective here is to find subsets of financial assets that can be aggregated in accordance with demand and aggregation theory. First, however, the utility maximization hypothesis is checked using GARP when the group of financial assets is broadened one by one. We start with a utility function consisting of currency $^{27}$ and demand deposists only and then extend the set until all financial assets available in our portfolio are included in this utility function. Additional combinations that have been tested for consistency with demand theory are $\mathrm{M} 1, \mathrm{M} 2$, the harmonised M3 aggregate, and an aggregate called M4 defined over currency, demand deposits, short-term time deposits and short-term savings. Table 3.4 merely shows the results of the GARP test for these four aggregates without and with quantity normalisation, respectively.

We find no violations of GARP at all for the narrow aggregate M1. The only significant violation of GARP in table 3.4 is observed for M2 over the sample 1970 1993 if asset stocks are adjusted for budget increases. In all other cases presented in table 3.4 the number of violations remains below $5 \%$. Therefore, it seems reasonable to assume that M1, harmonised M3 and M4 satisfy the necessary condition for weak separability from other financial assets. Roughly speaking, these outcomes are consistent with the results presented in section 3.3.2.

Other significant (unreported) violations of GARP only occur in the full sample with standardised asset stocks, when the assets currency, demand deposits and time deposits are aggregated, and when this aggregate is extended with foreign currency

\footnotetext{
26 These decisions are actually concerned with the consumption of services derived from holding financial assets.

27 One of Barnett's (1982) conditions for creating an admissible monetary aggregate is that currency is included in the aggregate.
} 
deposits. In the subsample 1986-1993 no violations at all result, which implies that all financial assets can appear in the representative consumer"s utility function defined over services derived from monetary assets.

Table 3.4 Monetary aggregates tested for consistency with GARP

\begin{tabular}{|l|l|l|}
\hline \multirow{2}{*}{$\begin{array}{l}\text { Combination of financial assets (without } \\
\text { normalisation) }\end{array}$} & \multicolumn{2}{|l|}{$\begin{array}{l}\text { Number of violations in } \\
\text { samples (total number of } \\
\text { combinations tested) }\end{array}$} \\
\cline { 2 - 4 } & $1970-1993$ & 1986 m 1993 \\
\hline M1 & $0(576)$ & $0(64)$ \\
\hline M2 & $5(576)$ & $0(64)$ \\
\hline M3 & $2(576)$ & $0(64)$ \\
\hline M4 & $0(576)$ & $0(64)$ \\
\hline With normalisation & & \\
\hline M1 & $0(576)$ & $0(64)$ \\
\hline M2 & $128(576)$ & $0(64)$ \\
\hline M3 & $0(576)$ & $0(64)$ \\
\hline M4 & $0(576)$ & $0(64)$ \\
\hline
\end{tabular}

See table 3.2 for notes.

The central issue in this section is whether the financial assets' utility functions that do not violate GARP can be divided into one or more subutility functions, while the data in the subutility functions are still satisfying GARP. To answer this question, the NONPAR program tests whether specified subgroups of financial assets satisfy the necessary conditions for weak separability. Next, the sufficient conditions can only be tested for those subgroups that satisfy GARP (the necessary condition). If weak separability applies, this means that positive values for the utility function as well as for the subutility functions of the representative consumer exist. In tables 3.5 and $3.6,{ }^{28}$ we show the samples in which the necessary and sufficient conditions for weak separability of the above four subgroups of financial assets from other assets apply.

28 Again, similar tests with quarterly data over the sample 1986:1-1993:4 reveall more violations of demand theory than the anmual data. 
Table 3.5 Subgroups of financial assets for which the necessary and sufficient conditions for weak separability apply (without nomalisation)

\begin{tabular}{|l|l|}
\hline $\begin{array}{l}\text { U ( V(M1), time deposits, foreign currency deposits, govern- } \\
\text { nent liabilities, savings, CDs, CP) }\end{array}$ & $1986-1993^{* *}$ \\
\hline$U(\mathrm{~V}(\mathrm{M} 2)$, government liabilities, savings, CP) & $1986-1993^{*}$ \\
\hline$U(\mathrm{~V}(\mathrm{M} 3)$, government liabilities, CP) & $1986-1993^{*}$ \\
\hline $\begin{array}{l}\mathrm{U}(\mathrm{V}(\mathrm{M} 4), \text { foreign currency deposits, government liabilities, } \\
\mathrm{CDS}, \mathrm{CP})\end{array}$ & $1986-1993^{*}$ \\
\hline
\end{tabular}

See table 3.2 for notes.

** Subsamples 1970-1980 and 1981-1993 also satisfy necessary and sufficient conditions.

* Subsample 1981-1993 also satisfies necessary and sufficient conditions.

Table 3.6 Subgroups of financial assets for which the necessary and sufficient conditions for weak separability apply (with normalisation)

\begin{tabular}{|l|l|}
\hline $\begin{array}{l}\text { U ( V(M1), time deposits, foreign currency deposits, govern- } \\
\text { ment liabilities, savings, CDs, CP) }\end{array}$ & $1986-1993^{* * *}$ \\
\hline U ( V(M2), govermment liabilities, savings, CP) & $1986-1993^{*}$ \\
\hline U ( V(M3), government liabilities, CP) & $1970-1993$ and 1986-1993 \\
\hline $\begin{array}{l}U(\mathrm{~V}(\mathrm{M} 4), \text { foreign currency deposits, government liabilities, } \\
\text { CDs, CP) }\end{array}$ & $1970-1993$ and 1986-1993 \\
\hline
\end{tabular}

See table 3.2 for notes.

* Subsamples 1970-1980 and 1981-1993 also satisfy necessary and sufficient conditions.

* Subsample 1981-1993 also satisfies necessary and sufficient conditions.

Over the period 1981-1993, as tables 3.5 and 3.6 show, the four monetary aggregates we distinguish for the Netherlands turn out to be weakly separable from the other financial assets that are included in the analysis. This result holds irrespective of whether asset stocks are normalised or not. For the other samples mentioned in the tables, the results with unadjusted asset stocks slightly differ from the ones obtained with normalised stocks. With unadjusted data, M1 shows the best performance. As both tables show, rejections of the weak separability conditions for this aggregate seem mainly due to violations of the transitivity axiom of consumer preferences (see section 3.3.2). When budget normalised asset stocks are used, harmonised M3 and M4 satisfy the conditions for weak separability over the full sample (and, of course, also over the subsamples). In both tables, M2 only appears to be weakly separable from other financial assets from 1981 onwards. The result that some of the monetary aggregates analysed in this section were inconsistent with demand theory in the 1970s may be explained by the higher adjustment costs and by limited diversification opportunities of asset portfolios during that time period. A further observation from the 
tests performed is that government liabilities are not admissible as a component of monetary aggregates.

Our assumption made earlier that a period without major institutional changes in the financial sector (1986-1993) leads to few violations of demand theory is not rejected by the results in tables 3.5 and 3.6. However, this result is not a consequence of the introduction of the financial innovations CDs and CP in 1986, because the weakly separable groups of assets can also be distinguished since the early 1980 s. Compared with this smaller sample, the sample covering the period 1970-1993 shows more violations of weak separability, which may be due to higher portfolio adjustment costs in the 1970s. Apparently, however, the introduction of new financial assets has not caused breaks in formerly existing relationships in the financiall sector. Financial innovations (especially CDs, which are included in M2 and harmonised M3) can be incorporated in the traditional monetary aggregates without causing violations of the necessary and sufficient conditions for weak separability. Formerly existing separability structures of the monetary aggregates examined in this section have not been affected by these innovations.

\subsubsection{Weakly separable monetary aggregates for households}

The results of weak separability tests for several monetary aggregates created for households are shown in table 3.7 (only with normalisation for budget increases). The samples tested are: 1974-1993 and 1986-1993.

M1 still consists of currency and demand deposits, but now only held by households. M2 includes the same assets as aggregate M2 except CDs. M4 again refers to an aggregate over currency, demand deposits, time deposits and savings. M3 is not included in the analysis since this aggregate contains all assets that are held by households; M3 for households appears to be weakly separable from goods" consumption (see section 3.3.3). M5 includes currency, demand deposits and savings, since time deposits are only a very small part of households' asset portfolios.

Table 3.7 Aggregates for households that saristy necessary and sufficient conditions for weak separability (with normalisation)

\begin{tabular}{|l|l|}
\hline $\begin{array}{l}\text { (V (M1), time deposits, foreign currency } \\
\text { deposits, savings) }\end{array}$ & $1986-1993^{*}$ \\
\hline$U(V(M 2)$, savings) & $1986-1993$ \\
\hline$U(V(M 4)$, foreign currency deposits) & $1974-1993$ and 1986 -1993 \\
\hline$U(V$ (MS), time deposits) & $1974-1993$ and 1986-1993 \\
\hline
\end{tabular}

* Total sample 1974-1993 anly violates sufficient conditions for weak separability.

Generally, the results are not significantly different from the outcomes for the economy as a whole (when the same tests for households are executed with quarterly data, we find more violations of the weak separability conditions). It appears that all aggregates (including M3, as section 3.3.3 shows) defined for households meet the 
conditions for weak separability from 1986 onwards. The two non-official aggregates M4 and M5 for households are also consistent with demand theory over the full sample. As with aggregate data, $M 2$ reveals the largest number of violations of the weak separability requirements. When asset stocks are not adjusted for budget increases similar results are obtained for household aggregates.

\subsection{Conclusion}

In this chapter, we discuss several methods for examining weak separability among financial assets in the Netherlands between 1970 and 1993. Weak separability is an important condition that should be fulfilled before small-scale economic models can be applied in empirical analysis. With respect to monetary theory this implies that separate analysis of the monetary sector can only be justified if weak separability from the real sector (goods' consumption or real national income) applies. Using Varian's nonparametric test this separability is confirmed for most monetary aggregates analysed. If, however, an adjustment for budget increases over time is imposed, the number of violations of the necessary as well as the sufficient conditions for weak separability slightly increases. This may be an indication that income effects are important factors for the result that the observed data are consistent with demand theory. However, the chosen normalisation may also be incorrect; the income elasticities may be different for the assets included in the portfolio. Overall, the results indicate that only the Dutch M2 aggregate is not an admissible monetary aggregate, since most tests show that it is not weakly separable from goods' consumption and from real national income.

Our second objective is to determine monetary aggregates that are weakly separable from other financial assets. It appears that violations of the weak separability conditions for the M1 monetary aggregate (over the full sample) are mainly due to rejections of the transitivity axiom of consumer preferences. When subsamples are considered, M1 turns out to be weakly separable from other financial assets. Since the early 1980s, hardly any monetary aggregate considered reveals inconsistencies with demand theory. Test results with budget normalised asset stocks show that harmonised M3 and an aggregate defined over M1 plus time deposits and savings meet the conditions for weak separability from other financial assets. Most violations of demand theory are, again, found for the M2 aggregate (between 1970 and 1980), which may be an additional indication that its components are not weakly separable as a group. This outcome suggests that $\mathrm{M} 2$ is either too narrow or too broad an aggregate to be considered an elementary good in wealth holders' portfolios. The composition of M2 may not be independent of the stock of savings deposits, which may explain why M2 is not weakly separable, and why harmonised M3 is considered an elementary good.

Comparison of the weak separability results over the period 1970-1.993 with the outcomes over the years 1986-1993 indicates that financial innovations have hardly affected formerly existing separability relations between financial assets. Violations of 
the weak separability conditions are mainly found in the 1970 s, probably due to relatively high adjustment costs of asset portfolios during that time period.

Additional tests with quarterly data indicate that adjustment of a portfolio in response to changes in relative prices is slow, which results in more violations of GARP and of the conditions for weak separability. This corresponds to results obtained by Swofford and Whitney (1988) for the USA.

Similar results as with a portfolio for the whole economy are obtained for asset stocks held by households only. When asset stocks are normalised, M2 only satisfies the weak separability conditions between 1986 and 1993 . The admissible components of monetary aggregates have been determined in this chapter, but additional tests are required to determine how the weakly separable monetary aggregates should be constructed in order to be in accordance with aggregation theory. This is the subject of chapter 4 . 


\section{THE CONSTRUCTION OF ECONOMIC INDICES OF MONETARY SERVICES}

\subsection{Introduction}

Monetary authorities have been using measures of the domestic money supply since many years. Information about the money supply is important for the execution and effectiveness of monetary policy, irrespective of whether monetary authorities have an interest rate or a money supply target. According to monetarist theory the demand for money (defined over the correct range of monetary assets) is stable. This motivates the monetarist policy advice of a steady growth rate of the money stock to achieve price stability (which has been the most prominent policy objective of many central banks). Therefore, direct or indirect control of the money supply (and information about it) is an important precondition for an effective monetary policy. In countries like Germany and the Netherlands, the money supply has been the main intermediate policy target ${ }^{1}$ for many years. The German Bundesbank has been announcing target growth rates for monetary aggregates since 1975. In the early years of monetary targeting in Germany the Central Bank. Money Stock was the central policy variable, ${ }^{2}$ whereas, from 1988 onwards, the broad money supply M3 has been used as intermediate target.

Until the mid 1980 s, the Dutch central bank used the socalled liquidity ratio ${ }^{3}$ as its main intermediate policy objective. Because monetary policy increasingly focused on keeping the exchange rate of the guilder pegged to the German mark, and due to the almost perfect degree of international capital mobility, the controllability of the money supply decreased significantly over time. Initially, the central bank's policy still aimed at restraining only the domestic component of M2 to support the credibility of the exchange rate policy. In its Annual Report over 1991, however, the central bank declared that it did not consider the liquidity ratio as the main policy variable

1 The main ultimate target of monetary policy has been to stabilise the price llevel.

2 The relations between several monetary aggregates and nominal income in Germany and other countries in the 1960 s and 1970 s are analysed in Dennis (1983).

3 The liquidity ratio is defined as the money supply (formerly $M 2$ and now harmonised M3) divided by GNP. 
anymore. ${ }^{4}$ The harmonised M3 aggregate is currently used as monetary indicator. The Dutch central bank can only affect M3's composition by controlling the commercial banks' domestic credit creation with e.g. non-interest bearing cash requirements. Nevertheless, even with a fixed exchange rate, the money supply can still be a reliable indicator for future inflationary pressures that may arise from monetary growth. The Dutch central bank follows the Bundesbank's policy as closely as possible by changing money market interest rates in response to changes in the German discount rate, in order to achieve its intermediate target of the fixed exchange rate with the German mark (Duisenberg, 1994). Due to the successful and credible implementation of this Dutch monetary policy, the exchange rate between the guilder and the Dmark has been almost fixed since 1983 and inflation rates in the Netherlands and in Germany have become strongly related (Berk and Winder, 1994). Additionally, disturbing capital flows between the two countries have generally been prevented. Theretore, monetary aggregates and inflation (and/or real growth) in the Netherlands may still be related.

Although monetary authorities in countries like the USA, the United Kingdom, Germany and the Netherlands have been trying to control or monitor ${ }^{5}$ the growth of one or more monetary aggregates for some years, ${ }^{6}$ policymakers in general have not always been very successful in achieving their ultimate goals of price stability and/or stabilisation of GNP. The traditional relation between monetary aggregates on the one hand and inflation and GNP, on the other, has become unstable in many countries, especially in the USA and the United Kingdom, since the early 1980s.

An important reason for the failure of achieving ultimate policy objectives through monetary targeting may be the application of inappropriate aggregation methods, especially in times when the characteristics of monetary assets change rapidly, as was

4

See De Nederlandsche Bank (1992), pp. 25-26.

5

The difference between controlling and monitoring monetary aggregates largely corresponds to the difference between using money measures as intermediate targets and as indicators of monetary policy. Intermediate target variables should be controlled directly and/or accurately by monetary authorities and serve as operational monetary policy guides. Achievement of these intermediate targets is assumed to contribute to desired outcomes for the ultimate monetary policy objectives. The role of indicator variables is to providle information about the current or future state of the economy. Indicator variables should, therefore, have a predictable effect on real and/or nominal target variables, such as inflation (see McCallum, 1989 for more details on the difference between intermediate targets and indicators).

6

For details on monetary targeting procedures in the first three countries see Dennis (1983). The official US Federal Reserve policy was to target M1 between 1979 and 1982 (McCallum, 1989). After that time, monetary aggregates (especially $\mathrm{M} 2$ ) were mainly used as indicators of the state of the economy until mid-1993 (Collins and Edwards, 1994). An extensive survey of US money supply policy is provided in Anderson and Kavajecz (1994) and Kavajecz (1994). In the UK, monetary targeting of 1 M3 was in effect between 1976 and 1986, whereas M0 and M4 have been used as indicators since September 1992 (Drake et al., 1994). Targets for monetary aggregates are still used in a number of European countries, e.g. Germany (see Herrmann et al., 1994), Switzerland (Fluri and Spoerndil, 1994) and France (Bank for International Settlements, 1994). 
the case in the 1980s. The monetary aggregates used so far for policy purposes have been obtained by simple summation over the different components. Since the main application of monetary aggregates is in anti-inflationary policy, aggregates should measure total liquidity ${ }^{7}$ in the economy. The flow of monetary services is closely related to total spending and determines, among other factors, the rate of inflation in the long run. However, the usually applied simple-sum aggregates measure the stock of money instead, treating all components of these aggregates as perfect substitutes, an assumption which is unlikely to be true in reality. In order to measure the flow of monetary services, information on the degree of moneyness of different monetary assets is required. A good proxy for the degree of moneyness is the interest foregone when people hold their wealth in liquid form. This means that theoretically welldefined monetary service flow aggregates should be calculated as weighted monetary aggregates and not as simple-sum aggregates.

Theoretical research shows that a good method of weighting financial assets ${ }^{8}$ is the use of socalled Divisia monetary aggregates. Based on microeconomic optimization decisions, such aggregate (index) is able to measure the amount of liquidity services in the economy without making assumptions about the monetary aggregator function.

This chapter analyses whether the Divisia index provides a better measure of the liquidity flow in the Dutch economy than the currently used simple-sum aggregates. Theoretically, Divisia aggregates are better able to internalise pure substitution effects between their financial asset components than the sum aggregates (Barnett, Offenbacher and Spindt, 1981 and 1984). This should result in more stable (predictable) velocity behaviour of the Divisia aggregates. Velocity of the Divisia aggregates should, for instance, be more closely related to the relevant opportunity cost measures than velocity of their sum counterparts. A comparison of these relations provides preliminary evidence on the relative usefulness of Divisia and simple-sum aggregates as measures of the liquidity flow in the Netherlands.

The structure of this chapter is as follows. Section 4.2 discusses the main reasons for the current interest in weighted monetary aggregates. The next section continues with the theoretical basis for using weighted monetary aggregates in general and Divisia aggregates in particular. Section 4.4 explains which data are used to construct Divisia indices of money for the Netherlands. The fifth section contains empirical evidence on the behaviour of simple-sum and Divisia aggregates over time and on the

7 Total liquidity refers to the flow of monetary (or transactions) services. These services are, to different extents, obtained from holding monetary assets. If an asset can be usedi as anedium of exchange, it provides monetary services. The interest yield on monetary assets, however, is treated as a non-monetary service (this refers to the store-of-value function of money). The justification for this approach is that this yield is not an argument in the consumer's utility function, but it is only part of the budget constraint.

8 The terms monetary and financial assets will be used interchangeably in this thesis, because nearly all assets considered here provide both monetary and non-monetary services. 
relations between their velocity series and the respective opportunity cost measures. The chapter ends with a summary of the main findings.

\subsection{Historical background for the current interest in weighted mo- netary aggregates}

Due to the increased influence of monetarism and the generally high inflation of the 1970 s, monetary authorities in most industrialised countries were finally convinced of the importance of a policy of monetary aggregates targeting. Traditionally, central banks have been using simple-sum monetary aggregates for this purpose. Observed shifts in the velocity of these simple-sum aggregates ${ }^{9}$ in many countries in the 1970 s and 1980s have, however, been responsible for the reduced interest in the use of monetary aggregates for policy purposes. These shifts have had a serious impact on the effectiveness of monetary targeting procedures. Judd and Scadding (1982) refer to changes in financial regulation, financial innovations, better corporate cash management techniques, and higher interest rate volatility as possible causes of instabilities in velocity, especially in the USA. Poole (1988) adds progress in communications technology and increased confidence in economic stability as explanations for these shifts. The impact of financial innovations (the introduction of new financial instruments that possess similar characteristics to existing monetary assets) on the usefulness of monetary aggregates as policy guide is further analysed in Hester (1981). Van Veen and Janssen (1990) provide a survey of the causes of financial innovations and their possible consequences for a policy of monetary targeting.

Since the velocity shifts have occurred at nearly all levels of aggregation, they cannot just be explained by the existence of financial assets that are highly substitutable for assets included in the simple-sum monetary aggregates, and that are, despite this substitutability, excluded from the official aggregates. Stated differently, the velocity shifts have not merely been caused by incorrect (or too narrow) definitions of the money supply, but inappropriate aggregation may also provide an explanation for the observed instabilities in the demand for money. Simple-sum aggregates are obtained by adding up the quantities of the monetary assets included in it, a procedure that generally is inconsistent with economic aggregation or index number theory. Simple summation over assets can only be justified theoretically if all assets are perfect substitutes. ${ }^{10}$ Only under the latter condition, substitution within simplesum aggregates will not affect any macroeconomic variables. As long as all assets included in the aggregate have a zero own rate of return, simple sum aggregation is

\footnotetext{
9 Barnett, Oftenbacher and Spindt (1984) compare velocity shifts of simple-sum and Divisia aggregates in the USA. The reasons for and extent of the shifts in the Netherlands are described in Fast (1985).
}

10

As will become clear later, the consumer"s utility function must be unweighted in that case, implying that the consumer cannot distinguish between the individual monetary assets. 
appropriate and consistent with economic theory. However, due to shifts in economic transaction technology, the degree of moneyness of financial assets included in simple-sum monetary aggregates is becoming more divergent. "Then, the issue of appropriately aggregating over a certain number of liquid financial assets in order to determine the total flow of monetary services in an economy becomes crucial. A different transaction technology may imply that the modes of payment have changed considerably due to the introduction of, for example, automated teller machines and new financial instruments. New technologies and new financial instruments spread very fast in markets that have become increasingly integrated. These phenomena may, thus, partly explain why the velocity shift is observed in many industrialised countries relatively simultaneously.

The importance of applying a theoretically correct aggregation method for an effective monetary targeting policy can further be illustrated with the effects of financial innovations (which have occurred, especially in countries like the USA, the UK and Japan since the 1980s). More specifically, the introduction of several new financial instruments that possess some degree of moneyness may have affected monetary velocity, because the monetary services they provide make the new assets possible, though imperfect, substitutes for components of the traditional monetary aggregates. Nevertheless, these new instruments have not yet been included appropriately in the monetary aggregates that are used as policy indicator so far. Additionally, many traditional monetary assets earn a non-market related rate of return, as opposed to many of the new products. Most monetary assets have also developed into hybrid assets in that they now have both transactions and investment (or savings) characteristics. Consequently, it has become difficult to distinguish between pure transactions assets (money in a narrow sense) and pure savings assets.

As an expression of the tendencies described above, empirical research ${ }^{12}$ indeed shows that substitution between monetary assets is far from perfect (substitution elasticities are relatively low). Because of this existing imperfect substitutability, simple-sum aggregates cannot distinguish between income and pure substitution effects of relative price changes within the aggregate. Aggregation theory states that a quantity index should be unresponsive to pure substitution effects, and should only measure exactly the income effects of such price changes. This implies that economically meaningful monetary aggregates should take into account the different degrees of moneyness of financial assets and should weigh these assets differently.

The use of monetary aggregates that are calculated by summation of the stocks of all component assets may, therefore, be responsible for observing a breakdown in formerly existing empirical relationships between money, on the one hand, and real

Il Simple summation implies more severe violations of economic aggregation theory when the aggregates become broader, since the characteristics of the included assets are more diverse and the substitutability gets less perfect.

12 Examples of such research results can be found in Serletis (1987). An overview of theoretical and empirical studies is provided by Barnett, Fisher and Serletis (1992) 
income and the price level on the other. This underlines the importance of using appropriate aggregation methods for an effective monetary policy.

Structural financial changes have, thus, shown that the concept of money changes continuously over time due to changes in substitution between monetary assets. In Divisia monetary aggregates this variation is automatically taken into account, because of the non-linear aggregation procedure. Such variation is revealed in fluctuations in the assets' user costs. Consequently, changes in the degree of moneyness of financial innovations can also be taken into account automatically. In some countries, such as Switzerland and the UK, the monetary authorities themselves have also been monitoring Divisia aggregates. By including formerly excluded liquid financial assets in a weighted monetary aggregate that is used as monetary policy indicator this aggregate may become a better indicator, since it is less affected by (changes in) substitution between the components of the aggregate than its simple-sum equivalent.

In countries like Germany and the Netherlands, however, that have had a relatively liberal financial regime for many years, phenomena, like financial innovation and liberalisation, have been less pronounced, since all changes have been spread over a longer period of time. In general, the financial systems of these countries have evidenced only a few significant structural changes during the 1980 s.

\subsection{The flow of liquidity measured by weighted monetary aggregates}

Economically meaningful monetary aggregates are based on consumer demand theory and aggregation theory. This means that the starting point is the representative consumer from chapter 3 who maximizes his overall utility from consumption goods and monetary assets ${ }^{13}$ subject to a budget constraint (equation (3.1)). A necessary condition for obtaining a meaningful measure of the money supply (or, alternatively, of the monetary services flow) is that this measure behaves as a stable, single variable in consumer decision-making (the weak separability condition dealt with in chapter 3). If the consumer's optimization problem is weakly separable in the monetary services of the assets, two-stage optimization can be applied. This means that consumers first allocate their expenditures among the two broad consumption categories and then decide how to spend the two available budgets within each category. The tests performed in chapter 3 show that the consumption of monetary services may indeed be considered weakly separable from the consumption of goods and services (C). Then, the overall utility function for the representative consumer can be written as:

\footnotetext{
13 We treat monetary assets as durable consumption goods and assume that the flow of services from holding an asset is proportional to the stock of that asset. Services from holding monetary assets are, for example, the availabillity of liquidity and the receipt of interest.
} 


$$
U=U(C, V(m))
$$

where $V(m)$ is the monetary services' subutility function and $m$ represents a vector of services from holding financial assets $k(k=1, \ldots, n)$. The functional monetary aggregate for the representative consumer corresponds to the subutility function defined over the individual monetary assets in the overall utility function. The utility from holding a certain amount of monetary services (the subutility function) is independent of the composition of the monetary aggregate.

$\mathrm{It}_{\mathrm{t}}$ is now possible to construct portfolios consisting of financial assets only and to create monetary aggregates in accordance with consumer and aggregation theory. The relevant decision problem facing the consumer in the second stage reduces to maximizing the services supplied by the various financial assets in his portfolio, subject to the usual budget constraint:

$$
\max _{m} V=V(m) \quad \text { s.t. } \quad \sum_{k=1}^{m} p_{k} m_{k}=y_{m}
$$

where the aggregator function $V(m)$ measures the monetary services provided by the financial assets $k$, is continuous and twice differentiable. In equation (4.2), $m_{k}$ represents the flow of services from holding financial asset $k, y_{m}$ is defined as the expenditure on the monetary services of the stock of financial assets in the consumer's portfolio (the total amount of financial assets held), and $p_{k}$ is the opportunity cost (rental price) of obtaining the monetary services from holding financial asset $k$.

To specify the nonlinear monetary services' aggregator function $V(m)$ that takes into account the imperfect substitution between its components, one may choose a functional form $^{14}$ for the representative consumer's utility function and estimate its parameters. These parameters are then used to construct weights for the quantity index, but the true aggregator function remains unknown. This may lead to misspecification errors and, consequently, to an unstable outcome for the aggregate.

Alternatively, statistical index number theory can be applied to find a solution to the specification problem of the aggregator function. The purpose of index number theory is to find higher-order approximations to the true (quantity) aggregator function. Contrary to functional quantity aggregators, index numbers are independent of parameters that have to be estimated in a functional specification. Quantity index numbers depend on both the components' quantities and prices. Additionally, the socalled exact statistical index numbers (Diewert, 1976) are based on consumers' utility maximization, where the utility function is a quantity aggregate over a group of goods or assets. A monetary quantity index is called exacl for an aggregator function $V(m)$ if it is calculated as the ratio of the value of this quantity aggregate at

14 Simple-sum aggregates are based on an implicit functional form of one-by-one addition of the component quantities. 
a certain moment $\left(V\left(m_{t}\right)\right)$ and its value in a base period $\left(V\left(m_{0}\right)\right)$, used as normalisation. This can formally be expressed as:

$$
V\left(m_{t}\right) / V\left(m_{0}\right)=Q\left(p_{0}, p_{i} ; m_{0}, m_{p}\right)
$$

where $t$ and 0 are time subscripts and $Q\left(p_{0}, p_{t} ; m_{0}, m_{t}\right)$ defines the quantity index in period $t$ and $p_{t}$ is a vector of prices for financial assets $k(k=1, \ldots, n)$. By introducing prices into index number theory the parameters required for the determination of a functional aggregator can be ignored. Therefore, statistical index numbers are preferred to functional aggregators because the index numbers are constructed without a priori assumptions about the weights of the individual monetary assets in the aggregate. Here, index numbers will be used to measure the flow of monetary services.

As Diewert (1976) has shown, the Fisher ideal and Törnquist-Divisia index (called Divisia index in the rest of the thesis) are elements of the superlative index class. He defines superlative index numbers as exact for some flexible functional aggregator, which can provide second-order local approximations to any unknown linearly homogeneous utility (or aggregator) function that is implicit in the data. Statistical index number theory states that aggregator functions should be linearly homogeneous irrespective of whether they measure price or quantity aggregates. The continuoustime Divisia index is an example of an exact index number for any properly defined aggregator function that is weakly separable in its components. This continuous-time Divisia quantity index (indicated by $Q$ ) can be calculated as the line integral of the following differential:

$$
d(\log Q)=\sum_{k=1}^{n} s_{k} d\left(\log m_{k}\right)
$$

where

$$
s_{k}=\frac{p_{k} m_{k}}{\sum_{k=1}^{n} p_{k} m_{k}}
$$

with $s_{k}$ representing asset $k$ 's expenditure share.

The continuous-time version is directly derived from the first-order conditions of microeconomic maximizing behaviour, where linear homogeneity of the aggregator function is additionally required to arrive at the Divisia index. Equation (4.4) provides the solution to the utility maximization problem described in equation (4.2). The Divisia index measures the flow of monetary services in the economy provided by a group of monetary assets. In that way, the Divisia index takes into account the different degrees of moneyness of monetary assets by giving the most liquid assets the highest weight in the aggregate. Since it is based on consumer demand theory, the Divisia monetary quantity index approximates the utility derived from the monetary service flow generated by the monetary assets included in the aggregate. The 
first-order conditions of the optimization problem $(4,2)$ show that the marginal utility of a monetary asset (the marginal service flow) is proportional to its user cost. Consequently, these user costs can be taken as a proxy for the marginal utility from holding monetary assets, and similarly as a proxy for the marginal monetary services (Thornton and Yue, 1992). Since the utility function defined over a group of monetary assets measures total utility from holding these assets, the utility derived from their non-monetary services is also included. Then, a good proxy for only the marginal monetary services of financial assets is the assets' rental price defined as the interest foregone by holding wealth in liquid form. This rental price merely approximates the price of an asset"s monetary service flow, ignoring the price of its nonmonetary services. Ideally, all characteristics of monetary assets would be assigned separate implicit prices, so that an exact rental price for monetary or transactions services could be determined. Since the Divisia index still remains an approximation to the transactions services generated by monetary assets, its relationship with macroeconomic variables may be less stable than it should be theoretically (Fisher et al., 1993). On the other hand, it should be noted that the non-monetary characteristics of monetary assets have been relatively stable, making the failure of the approximation fairly small.

Having determined what the monetary asset's user costs should measure, its precise formulation will now be discussed (in fact, this results in equation (3.10) with time subscripts appended). The user cost of monetary assets is derived from an intertemporal utility maximization problem, as described in Barnett $(1978,1980 \mathrm{a}$ and 1981). ${ }^{15}$ In this model, the representative consumer maximizes his utility subject to a single wealth constraint for his whole planning horizon. This budget constraint shows that the current-period (indicated by the subscript $t$ ) user costs of monetary services from asset $k$ can be represented as:

$$
p_{k, t}=\frac{\pi_{t} *\left(R_{t}-r_{k, t}\right)}{\left(1+R_{t}\right)}
$$

where $\pi_{t}$ indicates the level of the Consumer Price Index, $R_{t}$ is the benchmark yield (the highest yield achievable regardless of risk and maturity) and $r_{k, t}$ is the own rate

15 Alternatively, the user cost of monetary assets can be derived analogously to the rental price of at durable good (Donovan, 1978 and Fisher et al., 1993). 
of return on monetary asset $k^{16}$ The benchmark asset is a non-monetary asset with a high rate of return; the benchmark asset is a means of transferring wealth intertemporally.

Combining the above expression for the monetary assets' user costs with the respective quantities we can define the discrete-time Divisia index, which is an approximation of the continuous-time version. Since the latter version belongs to the superlative class of index numbers, the discrete-time Divisia index is also an element of this class. In order to calculate a Divisia index, both quantities and prices of monetary assets are required, regardless of the fact whether a quantity or a price index is computed. The discrete-time version of the Divisia index is used because monetary quantity data are only observed at discrete time intervals. A major advantage of the Divisia index is that it is constructed in such a way that imperfect substitution between components of a monetary aggregate is taken into account. As a result, internal substitution caused by changes in opportunity costs, will not affect the level of the Divisia aggregate.

The discrete-time version of the Divisia quantity index $Q_{t}$ (which is equal to the aggregator function $V\left(m_{t}\right)$ ) over the components $m_{k}$ for period $t$ is computed in the following way.

$$
\log Q_{t}=\log Q_{t-1}+\sum_{k=1}^{n} s_{k, t}^{*}\left(\log m_{k, t}-\log m_{k_{t} t-1}\right)
$$

where $t$ and $t-1$ are time subscripts and $s_{k, t}{ }^{*}$ (the average expenditure share of asset k) is defined in equation (4.8):

$$
s_{k, t}^{*}=0.5\left(s_{k, t}+s_{k, t-1}\right)
$$

and $s_{k_{s} t}$ and $s_{k, t-1}$ are as defined in equation (4.5) for periods $t$ and $t-1$ respectively. ${ }^{17}$

16 As opposed to Bannett (1981), we do not take into account the after-tax interest earnings, because interest receipts from all financial assets in our sample are, by assumption, treated equally by the tax system. If we had used after-tax interest receipts, equation (4.6) would have been:

$$
p_{k, t}=\frac{\pi_{t} *\left(1-\tau_{t}\right)\left(R_{t}-r_{k, t}\right)}{\left(\mathbb{1}+R_{i}\left(1-\tau_{t}\right)\right)}
$$

where $\pi_{t}$ is the marginal tax rate. The only exception is currency, which does not pay interest, but which is always available at no cost at all. The other assets have low costs (due to a penalty fee) when they are used for payment purposes. Therefore (following the literature) we consider our equation (4.6) a good proxy for the after-tax opportunity costs of financial assets.

17 In periods in which fimancial innovations take place, Fisher's Ideal Index is used as weighted monetary aggregate, because the Divisia index cannot take into account these new assets immediately after their introduction (see chapter 6 for further details). 
The growth rate of the Divisia quantity index can be seen to be a weighted average of the growth rates of the components with the expenditure shares $s_{k}$ reflecting the weights. Corresponding to the above index is a price (opportunity cost) index $\left(P_{t}\right)$. According to Fisher's weak factor reversal test (as described in Diewert, 1976) the product of a Divisia quantity and a Divisia price index $\left(P_{i}\right)$ equals the expenditure ${ }^{18}$ ratio in two consecutive periods:

$$
Q_{t} P_{t}=\frac{\sum_{k=1}^{n} p_{k, t} m_{k, t}}{\sum_{k=1}^{n} p_{k, t-1} m_{k, t-1}}
$$

When applying discrete-time Divisia aggregation to observed price and quantity data some data normalisations are imposed. The Divisia quantity index is normalised so that its value equals 100 in the first observation of a sample (the base period). The Divisia quantity index is computed using equation $(4.7)$; the price index then results from Fisher's weak factor reversal test:

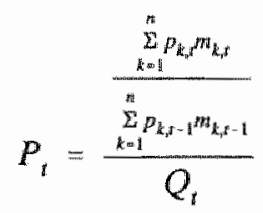

Another way of determining weighted monetary aggregates is the construction of a Currency-Equivalent aggregate (CE) (Rotemberg et al., 1991). This CE aggregate measures the total stock of currency required to provide the same amount of monetary services that all monetary assets together generate. Contrary to the Divisia index, the $\mathrm{CE}$ aggregate is a measure of the stock of money in that it calculates a weighted average of the levels of the monetary asset components. ${ }^{19}$ Although there is a close link between both of these weighted aggregates, we will use the Divisia index here to measure the flow of monetary services. This flow may be a more important determinant of total spending and inflation in the economy than the stock of money.

\footnotetext{
18 In the present example this is total expenditure on the monetary service flow generated by the component monetary assets included in these indices.
}

The weights do not sum to one in case of the CE aggregate. 


\subsection{Data description}

The monetary aggregates in this chapter are calculated using quarterly data on monetary asset quantities and their respective user costs for the period 1962-1993. The financial assets used in our analysis consist of currency, demand deposits, short-term time deposits with a maturity of less than two years (since the introduction in 1986 also including Certificates of Deposit), foreign currency deposits held in banks located in the Netherlands, short-term claims on Dutch central or local government institutions, savings deposits with a maturity of less than two years, Certificates of Deposit (CD) and Commercial Paper (CP). ${ }^{20}$ Generally, these assets are risk-free (with a minor exception for $\mathrm{CP}$ ), which means that different returns should reflect differences in liquidity. Quarterly data on quantities and interest rates of the financial assets are mostly taken from the Quarterly Bulletins published by "De Nederlandsche Bank" (DNB). ${ }^{21}$ In DNB's statistical publications CDs are included in the quantity of short-term time deposits. The stock of short-term time deposits is, therefore, corrected for the guantity of CDs issued. Our sample covers the years 1962 to 1993 for M1 and M2,22 and 1970 to 1993 for harmonised M3 because data on short-term savings ${ }^{23}$ are only available from the last quarter of 1970 onwards. Currency and demand deposits together constitute the Dutch monetary aggregate M1. Harmonised M3 is the main monetary policy indicator for the Dutch central bank since October 1992 in order to facilitate international comparison across EU-countries. ${ }^{24}$ At these three aggregation levels, we calculate a simple-sum and a Divisia money measure.

20 CDs and CP have been allowed to be issued in the Netherlands since January 1986.

21 Data on the quantities of M2 and harmonised M3 components are taken from table 3.1 Quarterly Bulletin. Quantities of $\mathrm{CD}$ and $\mathrm{CP}$ issued in the market are obtained from table 8.3. Interest rates on M2 and harmonised M3 assets and the benchmark interest rate are found in table 9.2 of the Quarterly Bulletin. Interest tates on $\mathrm{CDS}$ and $\mathrm{CP}$ were made available by $\mathrm{ABN}-\mathrm{AMRO}$ Bank, Amsterdam. For reasons of simplicity we use the 6 month interest rate on these two assets.

22 Although M2 may not be a weakly separable monetary aggregate (see chapter 3), it is still included in the anilysis of this thesis in order to show the differences between the simple summation and the Divisia aggregation method at various levels of aggregation.

23 Before the revision of the M2 aggregate by the Netherlands" Bank in January 1991 savings were separated into real savings and pseudo-sawings, according to their velocity of circulation. Pseudosavings were part of the old M2 measure. Nowadays all savings deposits with a maturity shorter than wo years are considered one liquid asset (near-money) and are part of the new harmonised M3 aggregate.

24 Harmonised M3 includes currency, demand deposits, time deposits, foreign currency deposits, savings deposits and CDs. From October 1992 onwards M2 is defined as harmonised M3 minus savings deposits. Between January 1991 and October $1992 \mathrm{M} 2$ consisted of currency, demand deposits, time deposits, foreign currency deposits, short-term government liabilities and CDs. In this thesis the $\mathrm{M} 2$ series according to the current definition is used. 
For a good understanding of the results of our empirical research it is necessary to make some additional remarks about the assets we consider and about the assumptions we make. The stock of claims on government institutions is calculated by adding outstanding Treasury Bills and claims on municipalities. The corresponding interest rate is a quantity-weighted rate of the rates on the two components. However, in the third quarter of 1990 the time series on Treasury Bill interest rates ends, because short-term Treasury Bills have not been issued anymore since that period. For the remaining quarters, the interest rate on local government liabilities is used.

The benchmark interest rate used for the construction of Divisia aggregates is the highest yield among the following: the yield on long-term government bonds, call money, local government liabilities, euroguilder deposits, or three month AIBOR plus $0.25 \%$ (used as a proxy for short-term notes issued by the private sector). As can be seen from this list, a short interest rate is sometimes considered the benchmark rate. This rate is used in periods in which the yield curve is downward sloping; if we had used a long-term interest rate user costs would have been negative for some monetary assets. Since we consider the euroguilder yield as a proxy for the yield on foreign currency deposits, the user costs of foreign currency deposits are zero in those observations in which this yield serves as benchmark. In our sample this happens only twice (in the third and fourth quarter of 1969). Figure 4.1 shows the highly volatile behaviour of the benchmark rate over the sample-period. The monetary assets" user costs, however, are more stable, because their interest rates move partly in parallel with the benchmark rate.

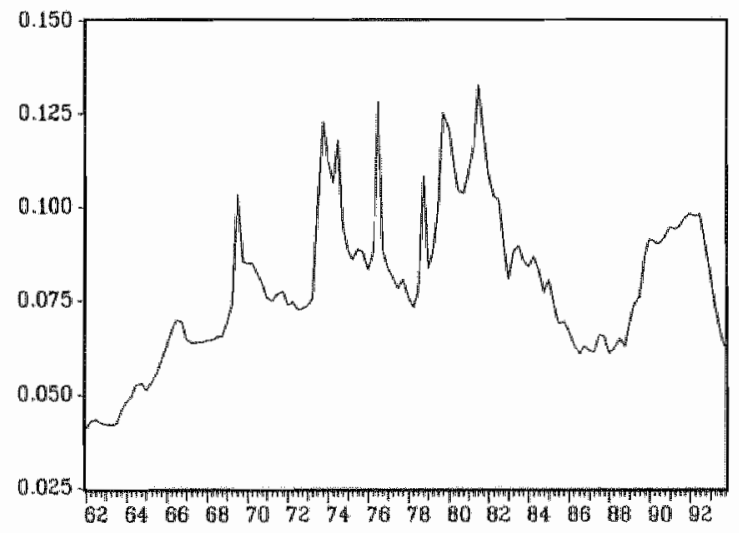

Figure 4.1 Benchmark interest rate, 1962:1-1993:4

Since quarterly data are used the opportunity costs of monetary services from financial asset $k$ (which is the interest foregone by holding wealth in a monetary asset) are computed according to the following modification of equation (4.6): 


$$
p_{k, t}=0.25 \pi_{i} * \frac{\left(R_{t}-r_{k, q}\right)}{\left(1+R_{l}\right)^{0.25}}
$$

Furthermore, in order to calculate the income velocity of the different monetary aggregates, data on nominal net national income over the same time-period are used, obtained from $\mathbb{D N B}^{\prime}$ 's Quarterly Bulletins (table 3.1). Seasonally adjusted data are used in the analysis. As a measure of the opportunity costs of the Divisia monetary aggregates dual Divisia price indices are used, computed according to equation (4.10). For simple-sum aggregates (which imply perfect substitutability between the component assets) the minimum user cost among the component assets is considered the correct opportunity cost measure (Barnett, 1983). If assets are perfect substitutes, only the least expensive asset will be held by consumers.

\subsection{Empirical results}

In this section we compare the empirical behaviour of simple-sum monetary aggregates with that of their Divisia counterparts in the Netherlands over the basic sample 1962:1-1993:4. After adding up the quantities of the different component assets the resulting time series of the respective aggregates are seasonally adjusted. Divisia quantity indices are determined according to equation (4.7), with the first quarter of 1962 chosen as the base period for M1 and M2 (1970:4 is the base period for harmonised M3).

Figure 4.2 reveals that the mean shares of the eight monetary assets are considerably different for a simple-sum and a Divisia aggregation procedure over all these assets. ${ }^{25}$ The simple-sun aggregate over these eight assets is called M4, with Divisia M4 as its weighted counterpart. The simple-sum shares (depicted as category 1 in figure 4.2) are simply the quantity shares of the respective assets in the M4 aggregate, whereas the Divisia M4 shares are computed as expenditure shares according to equation (4.5) (category 2).

As can be seen clearly in figure 4.2 , the shares of currency and demand deposits in the M4 portfolio are larger when this aggregate is calculated as a Divisia index, because of the higher degree of moneyness (represented by higher user costs) relative to other assets. Other assets, such as time and savings deposits, get a lower weight when their degree of moneyness is taken into account in the Divisia M4 index. This suggests that the latter two monetary assets are imperfect substitutes for the MI components. The new financial products, CDs and CP, have only minor weights in both aggregate measures, but the Divisia M4 shares are smaller than the sum M4 shares. These new assets may also be less than perfect substitutes for narrow money.

25 The mean shares for the eight assets are calculated over the sample 1986:1-1993:4, since CDs and CP have been issued only during that time-period. 


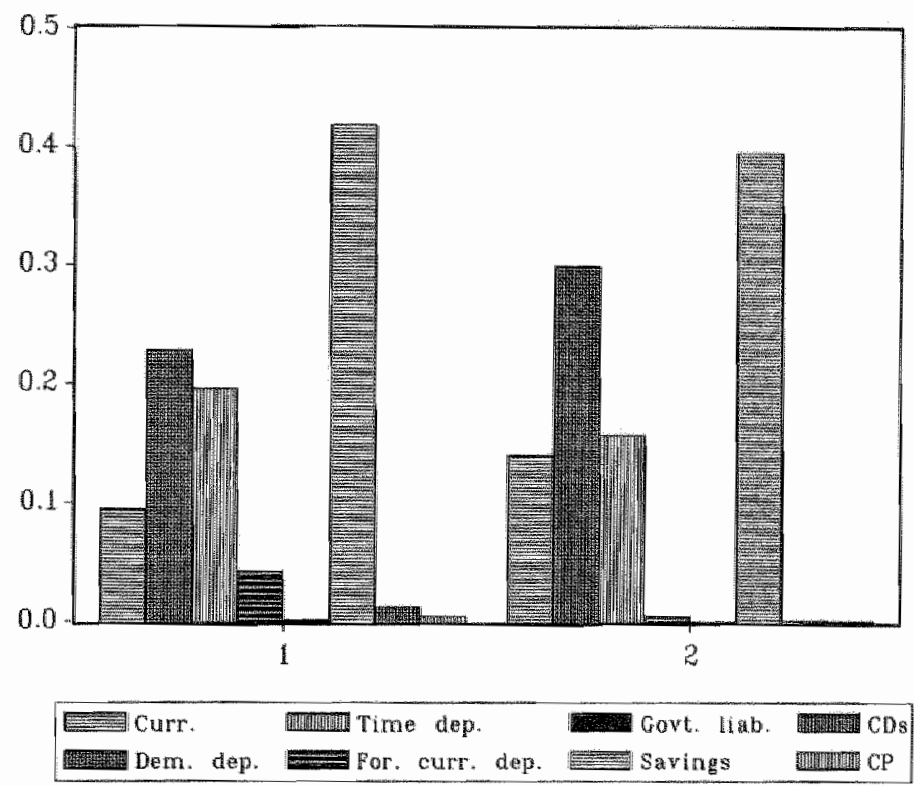

Figure 4.2 Mean financial asset shares, 1986:1-1993:4 (1: sum M4: 2: Divisia M4)

\subsubsection{Growth rates of simple-sum and Divisia monetary aggregates}

Table 4.1 presents the mean and standard deviation of the annual growth rates of M1, M2, M3 and their Divisia counterparts. It appears that the mean annual growth rate and its standard deviation for Divisia $\mathrm{M} 2$ are lower than the corresponding values for sum M2. The same applies to the M1 aggregation level, although the differences between the two aggregation methods are negligibly small. At the M3 aggregation level, the mean growth rates are almost identical, whereas sum M3 shows the smallest standard deviation. ${ }^{26}$ Overall, simple-sum M3 has the lowest mean growth rate (together with Divisia M3) and the lowest standard deviation, although the reader should note that the sample for harmonised M3 is shorter due to data availability. 27

The figures 4.3 through 4.5 show the annual growth rates of the Divisia and simple-sum versions of the aggregates $M 1$ through harmonised $M 3$ in the Netherlands. In line with the results in table 4.1 , figure 4.3 shows that the M1 growth rates

26 The results in table 4.1 are not as clearly in favour of Divisia aggregates as the outcomes for the Netherlands in Fase and Schuit (1992). However, they use a shorter sample and definitions of the aggregates which are slightly different from the ones adopted in this thesis

27 The relatiwe performance of the six aggregates does not change when the statistics in table 4.1 are measured over the period 1971:4-1993:4. 
are almost identical. This may be due to the constancy of the relative opportunity costs of currency and demand deposits (the components of M1). ${ }^{28}$

Table 4.1 Descriptive statistics for annual growth rates of monetary aggregates (1963:1-1993:4)

\begin{tabular}{|l|l|l|}
\hline & Mean & Standard deviation \\
\hline Sum M1 & 0.0788 & 0.0456 \\
\hline Divisia M1 & 0.0778 & 0.0440 \\
\hline Surn M2 & 0.0921 & 0.0397 \\
\hline Divisia M2 & 0.0865 & 0.0324 \\
\hline Sum M3 (1971:4-1993:4) & 0.0701 & 0.0185 \\
\hline Divisia M3 (1971:4-1993:4) & 0.0701 & 0.0204 \\
\hline
\end{tabular}

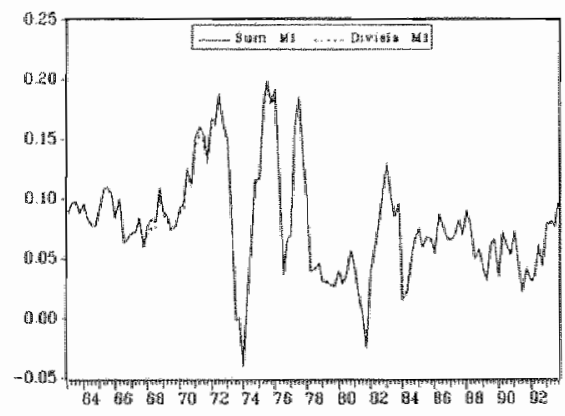

Eigure 4.3 Annual growth rates of sum and Divisia M1, 1963:1-1993:4

Similar results for M1 are found for Belgium (Fase and Schuit, 1992) and Japan (Ishida and Nakamura, 1994). Since it is hard to distinguish the two versions of the narrow monetary aggregate in the Netherlands, one may ask whether narrow money alone can give the right measure for the flow of monetary services in the economy. On the one hand, Divisia M1 may be discarded as a correct money measure, because it excludes a large spectrum of financial assets which also possess some degree of moneyness. On the other, the monetary service flow provided by the M1 components may dominate the monetary services provided by other, non-Ml assets in such a way that all broader Divisia aggregates closely resemble the M1 aggregates, because the weights of these non-M1 components in the broader Divisia aggregates will be very low. Figure 4.2 , however, shows that, of the non-Ml components, especially savings

28 Currency and demand deposits respectively earn no interest at all and a nearly fixed one, since the interest rate on demand deposits is adapted to market rates infrequently. 
are an important part of the Divisia M4 aggregate. This indicates that savings provide considerable monetary services and that broader Divisia aggregates may be more appropriate money measures than Divisia or sum M1. A definite appraisal of this issue can only be given after the empirical performance of the different aggregates as monetary policy indicators is compared.

At the higher aggregation levels, the differences between the growth rates of the sum and Divisia aggregates are more pronounced, as would be expected on theoretical grounds (see Barnett, Offenbacher and Spindt, 1984, who find that the broader US Divisia aggregates perform better than the sum equivalents). The differences in the M2 and the corresponding harmonised M3 aggregates' behaviour, however, are relatively small, especially since about 1986 (see figures 4.4 and 4.5). The M3 aggregates show slightly smaller growth rates than the equivalent M2 aggregates over most of the common sample (see also table 4.1 ), which may be caused by the moderate growth rate of savings deposits. We observe from figure 4.4 that simple-sum M2 grows faster than Divisia M2 during most of the sample and that sum M2 fluctuates more heavily than its Divisia counterpart. It appears that the larger fluctuations in the Divisia M3 growth rate relative to those of the sum M3 growth rate are mainly caused by the large swings in the Divisia growth rate in the first half of the 1970 s.

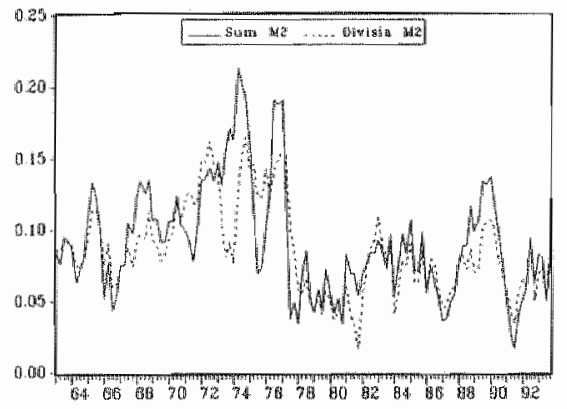

Figure 4.4
Annual growth rates of sum and Divisia M2, 1963:1-1993:4

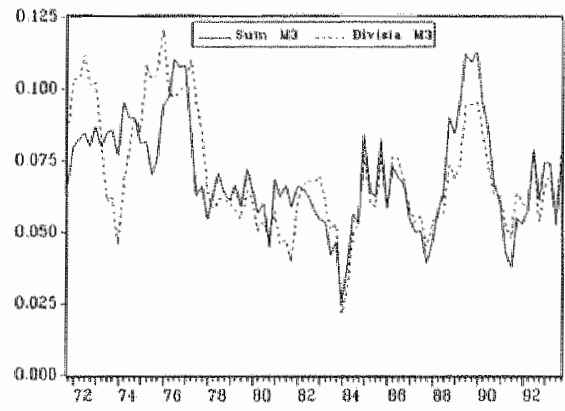

Figure 4.5 Annual growth rates of sum and Divisia M3, 1971:4-1993:4

Theoretically, Divisia aggregates are affected by interest rate changes in two opposite ways. A higher benchmark interest rate leads, ceteris paribus, to a rise in opportunity costs for the individual monetary assets. On the one hand, this may induce a fall in demand for the asset components of Divisia aggregates. On the other, higher user costs increase the weights of the component assets of Divisia aggregates, ceteris paribus. In other words, the demand effect of changes in the benchmark rate leads to lower weights, whereas the relative price effect gives rise to higher weights of the assets in the Divisia aggregates (see equation (4.5)). The exact magnitudes of these effects on all elements of the Divisia aggregates determine the final response of such aggregates to changes in the benchmark interest rate.

This theoretical insight may explain why the harmonised sum M3 aggregate grows more smoothly in the early 1970 s than Divisia M3. The expenditure share of savings 
deposits fluctuated sharply in this period, mainly caused by the unstable user costs for savings. At the same time, savings were the most important asset in the M3 aggregate. The instabilities in the savings deposits' expenditure share may have determined the overall growth path of Divisia M3.

The growth rates of the two broad Divisia aggregates may have been more modest than their sum equivalents' growth rates in the 1980 s, because of the stabilising influence that opportunity costs can have on demand for Divisia aggregates. In the 1980s, interest rates on short-term time deposits have become relatively closely related to market interest rates, which causes time deposits' user costs to be among the lowest of the M2 and M3 components. The more attractive interest rate on time deposits may explain why they have been important determinants of the growth of the broad Dutch monetary aggregates in the 1980s (see de Haan et al., 1992 and 1994). Although less pronounced, interest rates on savings deposits have also followed market interest rates rather well. Because of this considerable interest-earning capacity of time and savings deposits, the total stock of these assets may be determined both by transactions and investment (or savings) characteristics. Overall, these two asset categories have been largely responsible for the growth in simple-sum monetary aggregates in the 1980s. The low user costs for these monetary assets make their weights in the Divisia aggregates smaller than in the corresponding simple-sum aggregates (see figure 4.2 ), which may explain the observed lower and more stable growth rates of Divisia aggregates since the 1980s. As stated before, Diwisia aggregates are designed to give a better view of the flow of transactions money (or monetary services) than simple-sum aggregates. Despite some differences in the sum and Divisia aggregates' behaviour over time, the results for the Netherlands are not as pronounced as they are for the US situation (Thornton and Yue, 1992).

\subsubsection{Velocity behaviour of simple-sum and Divisia monetary aggregates}

The velocity behaviour of the different aggregates, together with their opportunity cost measures, is depicted in figures 4.6 through 4.11 . Velocity is defined as the ratio between net national income and the respective monetary aggregate (both in nominal terms). ${ }^{29}$ Each velocity series is normalised to unity in the first quarter of the respective series. Dual Divisia price indices are used as the relevant opportunity cost measures for the Diwisia aggregates, whereas for simple-sum aggregates the minimum user cost among their component assets is considered the correct opportunity cost measure. Assuming that these series indeed represent the relevant opportunity costs for the respective monetary aggregates, velocity of a monetary aggregate should increase when its user costs rise, because demand for money falls when its rental price rises. In addition to the graphical evidence, table 4.2 shows the correlation coefficients between velocity of the six monetary aggregates we distinguish and the respective user cost measures.

This implies that velocity is the inverse of the liquidity ratio. 
Table 4.2 Correlation coefficients bewween velociry of monetary aggregates and relevant user costs

\begin{tabular}{|l|l|}
\hline & correlation coefficient \\
\hline Sum M1 & 0.12 \\
\hline Divisia M1 & 0.21 \\
\hline Sum M2 & 0.02 \\
\hline Divisia M2 & 0.45 \\
\hline Sum M3 & 0.39 \\
\hline Divisia M3 & 0.42 \\
\hline
\end{tabular}

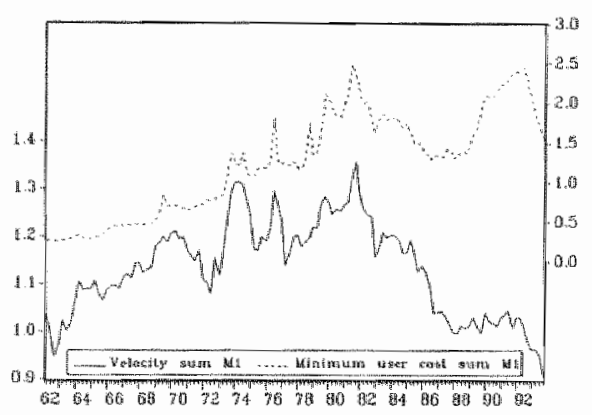

Figure 4.6 Velocity and user cost sum M1

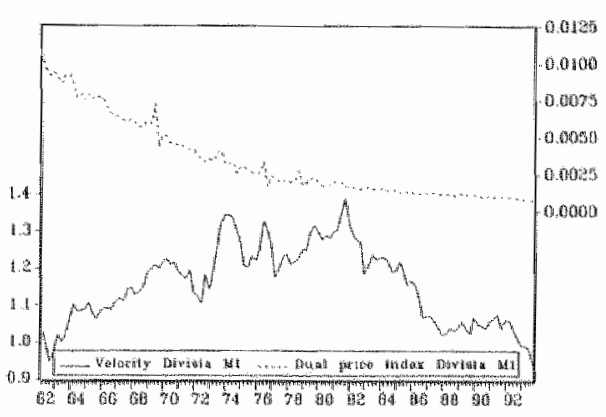

Figure 4.7 Velocity and user cost Div. MI

Overall, the velocity pattern is similar for the simple-sum and the corresponding Divisia aggregates, with the two M1 velocity series showing the greatest volatility. The downward trend in velocity for the M2 and harmonised M3 aggregates depicted in figures 4.8 through 4.11 corresponds to the rising liquidity ratio observed in the Netherlands since the early 1980 s.

At the M1 level (see figures 4.6 and 4.7 ), one can observe an upward trend in both velocity series until the early 1970s. During most of the 1970 s velocity for the two M1 aggregates fluctuates wildly, but still tends to go upwards, whereas the 1980 s and 1990 s reveal a downward trend with some stabilisation between 1988 and 1991. The highly variable velocity behaviour of sum M1 closely corresponds to the time path of its opportunity cost measure. A similar, close relation between M1 velocity and the Aaa bond yield in the USA is reported in Poole (1988). Divisia M1 velocity, however, appears to be negatively correlated with its dual user cost.

As McCallum (1987, 1988 and 1989) shows, shifts in velocity of monetary aggregates do not necessarily disqualify such aggregates for use in monetary policy. He states that a policy of intermediate targeting should take into account longer term trends in monetary aggregates' velocity. If an aggregate's velocity is unstable, but predictable with interest rates, for example, that money measure may still be useful for monetary policy. However, this requires that the relation between the aggregate"s 
velocity and interest rates is also considered in the implementation of monetary policy. Applied to our evidence at the M1 aggregation level, this suggests that sum Ml can serve as a measure of the flow of monetary services in the Dutch economy, even though its velocity series shows some important trend breaks. Sum M1 velocity is, however, relatively closely related with its opportunity cost measure.

The picture for the M2 series (figures 4.8 and 4.9 ) indicates that velocity was relatively constant until 1972 and between 1974 and 1982, although at a lower level then. Since 1982 velocity as measured by the two M2 aggregates clearly trends downward. Velocity for Divisia M2 is higher than the corresponding variable for sum M2, which can be attributed to the lower Divisia growth rates in the 1960 s and 1970 s. Table 4.2 reveals that Divisia M2 velocity is relatively closely and positively correlated with its dual user cost, in contrast to sum M2 velocity. Divisia M2's velocity behaviour may, therefore, be more predictable than that of sum $\mathrm{M} 2$, which may also imply that Divisia M2 is more useful as a measure of the flow of monetary services in the Netherlands than its sum equivalent.

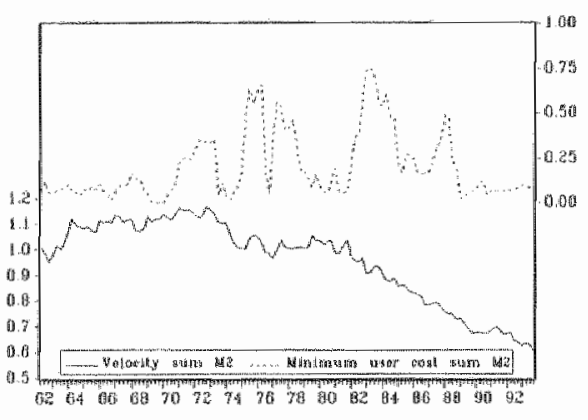

Figure 4.8 Velocity and user cost sum M2

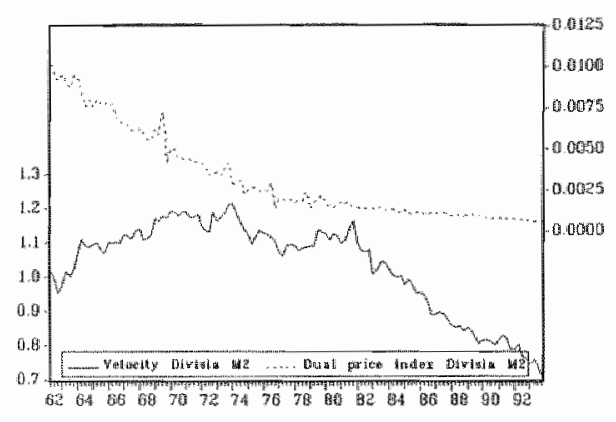

Figure 4.9 Velocity and user cost Div. M2

Finally, figures 4.10 and 4.11 show a slightly divergent velocity pattern for sum M3 and Divisia M3, with sum M3 velocity steadily increasing until 1980, and Divisia M3 velocity increasing less clearly in this period, probably caused by the higher Divisia growth rates in the early 1970 s. Similar to the results for the M2 aggregates, velocity of the harmonised M3 aggregates is downward trending after 1982. Sum M3 velocity falls more heavily than Divisia M3 velocity during this time-period, due to sum M3's higher growth rate. Divisia M3 velocity is slightly stronger correlated with its opportunity cost measure than sum M3 velocity. 


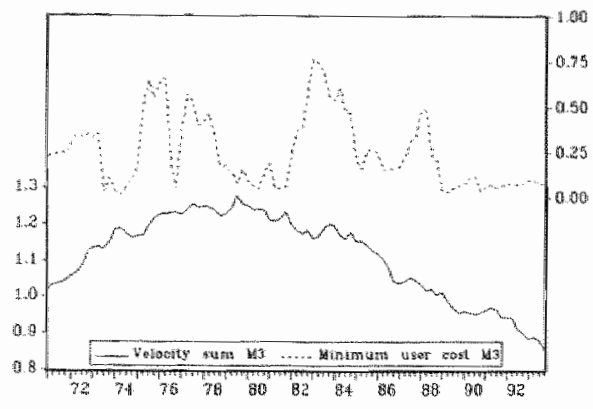

Figure 4.10 Velocity and user cost sum M3

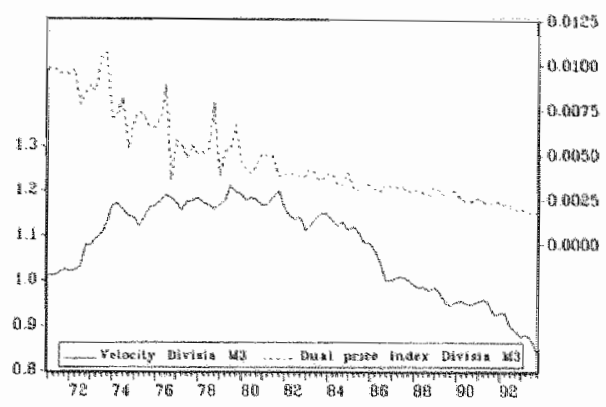

Figure 4.11 Velocity and user cost Div. M3

Based on the above graphical analysis and the correlation coefficients in table 4.2 , we may conclude that Divisia aggregates reveal similar shifts in velocity as their simplesum counterparts over the past three decades. However, Divisia M2, sum M3 and Divisia $\mathrm{M} 3$ velocity (and, to a smaller extent, sum $\mathrm{M} 1$ velocity) show a relatively strong correlation with their respective opportunity costs, and may, consequently, be more predictable than velocity for the other aggregates. This suggests that Divisia M2, sum M3 and Divisia M3 internalise pure substitution effects between their asset components relatively well. These aggregates may, therefore, be appropriate measures of the flow of monetary services in the Netherlands. However, the evidence obtained so far does not allow us to decide clearly in favour of the Divisia aggregation method. Generally, since the correlation of Divisia and simple-sum aggregates" velocity with their respective user costs is not overwhelmingly different, the evidence obtained so far is less in favour of Divisia aggregates for the case of the Netherlands than it is for the USA. ${ }^{30}$

An explanation for these findings in the Netherlands may be that the chosen user cost measure does not consider any bank charges connected with the use of many financial assets. A true opportunity cost measure should not only include the returns on financial assets, but also their costs. These bank charges, however, are not proportional to the stock of financial assets, which means that it remains an arbitrary decision how to measure such charges. Furthermore, the degree of financial innovation in the Netherlands has been relatively modest with only few structural changes compared with the USA. This might imply that the differences in the degree of moneyness between several financial assets may increase in the future when more bank charges are imputed and when financial innovations have become a more familiar element of the Dutch financial system as well. Then, the advantages of Divisia monetary aggregates may also become more pronounced.

30 Similar ambiguous results in favour of Divisia aggregates are reported for the UK (Fisher et al., 1993 ) and for Spain (Ayuso and Vega, 1993). 


\subsection{Conclusion}

In this chapter the differences between simple-sum monetary aggregates and a weighted aggregate, such as the Divisia index, are analysed for the case of the Netherlands. This kind of research has become relevant in recent years due to the unstable behaviour of demand for the traditional monetary aggregates, especially the broader ones. Combining economic theory with index number theory it appears that Divisia index aggregates are based on consumer maximizing behaviour without making assumptions about the underlying monetary aggregator function. On the other hand, simple-sum aggregates assume that all monetary assets are perfect substitutes and provide the same degree of liquidity to its users. Differences in the degree of moneyness of monetary assets are likely to be influenced by financial innovations, such as the introduction of Certificates of Deposit and Commercial Paper. Additionally, the responsiveness of monetary assets' own interest rates to changes in market interest rates is an important factor in this respect.

The empirical evidence for the USA shows that weighting financial assets with the Divisia index method generates a better measure of the flow of monetary services. For many other countries, however, it appears that the advantages of Divisia monetary aggregates are only marginal compared with their sum equivalents. The above analysis for the Netherlands shows that Divisia aggregates have mostly grown at a lower rate than their simple-sum counterparts, although the differences are only marginal. It also appears that there is a relatively strong correlation between velocity of Divisia M2, sum M3 and Divisia M3 and the respective opportunity costs, indicating that these aggregates internalise pure substitution effects between their components relatively well. Velocity for these aggregates may be more predictable than velocity for other aggregates. This suggests that the above three monetary aggregates can provide appropriate measures of the flow of monetary services in the Netherlands. So far, however, it is not possible to choose a single monetary aggregate as the best measure, nor can we decide clearly in favour of the Divisia aggregation method.

The minor differences between the simple-sum and Divisia monetary indices may be caused by the relatively low degree of financial innovation in the Netherlands (and in Europe in general). As the speed and scale of financial innovation increase in the Netherlands, the advantages of Divisia aggregates may become more clear. A more thorough analysis of the behaviour of the different monetary aggregates in the Netherlands is needed, however, before any conclusions can be drawn with regard to their usefulness as monetary indicator. 


\section{SUBSTITUTION BETWEEN \\ THE COMPONENTS OF HARMONISED M3 \\ IN THE NETHERLANDS}

\subsection{Introduction}

As discussed in chapter 4 , monetary authorities in many industrialised economies have experienced serious problems in the use of monetary policy to attain their ultimate policy objectives in terms of inflation and economic activity since the early 1980s. The predictive power of the traditional monetary aggregates for inflation and real income growth has considerably deteriorated. This may be partly explained by instabilities in the demand for money in the $1980 \mathrm{~s}$. A frequently mentioned source of this instability is the occurrence of structural changes in the international financial system, due to financial deregulation, innovation, international integration and higher exchange rate and interest rate volatility, which have important consequences for the transmission of monetary policy to the real economy. ${ }^{2}$ Naturally, this process has differed across countries.

The search for the underlying factors of the perceived instability in the demand for money and the corresponding demise of effective monetary policy has increasingly focused on the issue of substitutability between the components of narrow money (currency and demand deposits) and other liquid financial assets (near-monies). Especially in the USA and Canada the amount of empirical research ${ }^{3}$ on this issue has grown rapidly (see section 2.3). The degree of substitution between financial assets is important for several aspects of the monetary transmission process. Substitution between liquid assets affects the appropriate definition of the money supply and influences the stability of the demand for the traditional monetary aggregates. Also, monetary authorities can influence the degree of substitutability between assets with their policy instruments, for instance through interest rate regulation.

For an overview of money demand siudies see Boughton (1991 and 1992). Judd and Scadding (1982) contains a discussion of money demand instabilities in the $1970 \mathrm{~s}$.

2 A more detailed analysis of causes and effects of financial imovation and deregulation is given in Porter êt al. (1979) and Blundell-Wignall et all. (1990).

3 Examples of research in this area are Ewis and Fisher (1984 and 1985). Serletis and Robb (1986) and Serletis (1987b), who adopt a similar approach to the one we use in this chapter. 
In chapter 4 it is argued that, theoretically, traditional simple-sum monetary aggregates do not provide a good measure of the amount of monetary services available in an economy. Such aggregates assume that financial assets that are included are perfect substitutes for one another, while there is no substitution at all between assets included and assets excluded. In practice, however, the use of this dichotomy is far from obvious. The private sector can easily substitute alternative excluded financiall assets for assets that are included in some simple-sum monetary aggregate. Moreover, moving from components of narrow money to those of broader aggregates is generally characterised by a gradual and continuous decline in liquidity, not by a one time jump.

Consequently, central banks should be cautious in treating a monetary aggregate consisting of different components as homogeneous for monetary policy purposes. Taking into account the imperfect substitutability of financial assets within one aggregate, the widespread application of simple-sum monetary aggregates may have contributed to the decreased effectiveness of monetary policy in the 1980s. If, despite its shortcomings, simple-sum aggregation is performed over assets that are imperfect substitutes, the weight of each of these financial assets in the monetary aggregate is different from its actual economic importance in terms of supplying monetary services to the public. Consequently, that aggregate will overstate the amount of monetary services provided by these assets. Simple sum aggregation only provides a good economic measure of the amount of monetary services, if the components possess identical moneyness or liquidity. In that case, the elasticities of substitution between the components are infinitely high.

Imperfect substitution thus may be responsible for the observed instability of the demand for the traditional monetary aggregates. Chapter 4 shows that, by creating monetary aggregates, such as Divisia indices, which take into account these substitution relationships, the flow of monetary services in the economy may be measured more precisely and the instability of the demand for these aggregates may be lower than for the traditional aggregates. If the monetary authorities would use this newly defined monetary aggregate as an important indicator for the stance of monetary policy, their ability to control the real economy might increase.

The substitution approach to monetary aggregation is founded on the decision process of a representative utility maximizing agent, just like Divisia indices of monetary services are. In this chapter, we adopt the substitution approach to empirically analyse the magnitude, significance and stability of elasticities of substitution between the main components of the Dutch harmonised M3 aggregate; currency, demand deposits, time deposits and savings. The first two elements together constitute narrow money M1. The results in chapter 3 show that these four financial assets may be considered. weakly separable from other assets available in the Netherlands. The analysis is performed using quarterly data for the economy as a whole over the period from 1972:1 to 1993:4.

The present chapter differs from the conventional literature about substitution between financial assets in three respects. First, this chapter tests the sensitivity of the estimated elasticities for the assumptions underlying the functional form chosen to approximate the unknown utility function over the financial assets. This sensitivity 
analysis is performed by comparing the results obtained with three different specifications for the utility function (the static and the dynamic Fourier form and the translog formulation). Second, we add to the existing literature on substitution between financial assets by introducing an alternative normalisation of the assets" user costs, which is similar to the normalisation of asset stocks applied in chapter 3 . With this new normalisation we are able to derive and estimate homogeneous systems of demand equations. Finally, because of the likely differences in portfolio behaviour of the business and the household sector, the substitution elasticities between the main M3 components are analysed at the sectoral level as well.

Moreover, the estimated time series of own- and cross-substitution elasticinies will be related to the observed trend break in both M1 and M3 velocity in the Netherlands in the early eighties, and to the occurrence of financial innovations over the sample. Imperfect -and possibly time-varying- substitution between components of M3, even if as a whole weakly separable from other financial assets, may lead to the conclusion that the simple-sum M3 aggregate is an inadequate measure of the money supply and as such unfit as an indicator or intermediate objective for monetary policy. A similar procedure can be adopted for M1.

The chapter is set up as follows. Section 5.2 deals with the theoretical specification of the model. The data and the estimation procedures are discussed in section 5.3. In the fourth section of this chapter, we present and discuss the results of our empirical work at the aggregate levell. Section 5.5 deals with the corresponding results for the business and the household sector and briefly comments on the monetary policy implications of our findings. The last section contains a summary and the main conclusions from chapter 5 .

\subsection{The theoretical model}

\subsubsection{General framework}

The financial substitution literature distinguishes two approaches. The utility-maximizing approach was first developed by Chetty (1969) and extended by Ewis and Fisher (1984) and Serletis (1987b), who made the model applicable for empirical research. The second approach uses production theory and was applied by Sims et al. (1987) and Gauger and Schroeter (1990). The differences between the two approaches are only marginal, since both analyse the substitutability question as an optimization problem for the consumer. ${ }^{4}$ In the utility-maximizing approach, the consumer chooses quantities of financial assets to maximize his utility from holding these assets

Here, a consumer is a holder of financial assets, irrespective of the fact whether the holder is a lhousehold, a corporation or a non-money creating financial institution, who consumes financial assets' money services. 
given a budget constraint and the assets' prices." In the production-theoretic approach, the consumer chooses quantities of financial assets to minimize the opportunity costs of holding wealth in liquid form subject to the assets' prices and a given utility level (derived from the assets" monetary services). This implies that budget or cost minimization is dual to utility maximization. From the solution of the optimization problem in either approach, asset demand functions can be derived.

Here, we use the utility maximizing approach to estimate the degrees of substitutability between various financial assets. We approximate a consumer's indirect utility function with two different flexible forms; a Fourier flexible form representation (see Gallant, 1981), which is capable of globally approximating the true indirect utility function, and a translog utility specification, which only provides a local approximation. Applying results from duality theory, a system of asset demand equations is derived and estimated. The results yield time series of own- and cross-substitution elasticities.

Since the weak separability tests in chapter 3 indicate that decisions about the composition of the monetary services budget are made independently of the consumption decisions on real goods and services, we assume a two-stage optimization process for the representative consumer. ${ }^{6}$ In the second stage, this consumer maximizes the services supplied by the various financial assets in his portfolio, subject to the usual budget constraint (equation (4.2), which is repeated in equation (5.1) for the reader"s convenience):

$$
\max _{m} V=V(m) \quad \text { s.t. } \quad \sum_{k=1}^{n} p_{k} m_{k}=y_{m}
$$

where $m$ represents a vector of services from holding financial assets $k$. An explanation of the other symbols in equation (5.1) is given below equation (4.2). The opportunity cost of financial asset $k(k=1, \ldots, n)$ is computed according to equation (4.11).

Solving equation (5.1) leads to a system of demand functions in which demand for financial assets depends on the opportunity costs of all assets and on total monetary service expenditure. To derive this set of asset demand functions, we use the dual approach and approximate the indirect monetary services aggregator function. In this approach, the indirect utility of holding financial assets is expressed as a function of the ratios of the prices of the different financial assets to the budget. The derived indirect utility function thus corresponds to the maximum attainable (direct) utility from monetary asset services at their given prices $\left(p_{k}\right)$ and at the given budget $y_{m}$. For reasons of data availability and for estimation purposes, it is convenient to use financial asset stocks instead of the services from these stocks. Multiplying both sides of the budget restriction in equation $(5.1)$ by the total flow of financial services $\Sigma m_{k}$

As in the rest of the thesis the financial assets" prices are opportunity cosits.

See Serletis (1987b) for a detailed description of this two-stage budgeting procedure. 
and dividing them by the budget $y_{m}$, gives the indirect monetary services' utility function $g(v)$ corresponding to the maximization problem (5.1):

$$
g(\boldsymbol{w}) \equiv \max _{m}\left[V(\boldsymbol{m}): \sum_{k=1}^{n} v_{k} m_{k}=\sum_{k=1}^{n} m_{k^{*}} m_{k} \geq 0\right]
$$

where $y$ denotes the vector of $v_{k}(k=1, \ldots, n)$, which, in turn, represents the normalised opportunity costs of asset $k$ as defined in equation (5.3):

$$
v_{k}=\frac{p_{k} \sum_{k=1}^{n} m_{k}}{y_{m}}
$$

In the literature on systems of demand equations $v_{k}=p_{k} / y_{m}$ is usually taken as the normalisation. Without any additional restrictions, however, homogeneity of degree zero in prices $\left(p_{k}\right)$ and quantities $\left(m_{k}\right)$ of the system is not ensured. Therefore, we will normalise the assets' opportunity costs as in equation (5.3) when using a Fourier specification for the unknown utility function. Then, the resulting denand system is homogeneous of degree zero in prices and quantities. In the case of a translog utility function (which will be discussed in more detail later) the usual normalisation does not cause estimation problems.

Instead of the indirect utility function $g(v)$, however, it is more convenient to use a reciprocal indirect utility function $h(v) \equiv 1 / g(v)$ to approximate the direct monetary services utility function (Diewert, 1974). A duality exists between $V(m)$ and $h(v)$; given one function, the other is uniquely determined, and also, if one is maximized $(f(m))$, the other $(h(v))$ has to be minimized in order to reach the same result. From this reciprocal indirect utility function (which corresponds to a monetary services' aggregator function) a system of asset demand equations can easily be derived.

\subsubsection{The Fourier flexible form}

As the first functional form to approximate the reciprocal indirect monetary services' utility function $h(v)$ we choose Gallant's (1981) Fourier Flexible Form specification:

$$
h(v, \theta)=a_{0}+b^{\prime} v+\frac{1}{2} v^{\prime} C y+\sum_{\alpha=1}^{A} \sum_{j=-J^{\prime}}^{J} a_{j \alpha} e^{i j K_{\alpha^{\prime}}{ }^{\nu}}
$$

in which

$$
C=-\sum_{a x=1}^{A} a_{0 \alpha \alpha} K_{\alpha x} K_{a}^{\prime} \text { and } a_{j \alpha}=\bar{a}_{-j \alpha}
$$

and $a_{0}, q_{0 \alpha}$ and $b$ are real valued. The bar indicates the complex conjugate of $a_{j \alpha}, i$ is the imaginary unit and $K_{\alpha}^{\prime}$ is a vector of multi-indices of length $(n \times 1)$ with elements equal to zero or unity. These multi-indices determine the partial derivatives of the indirect utility function $h(w)$ with respect to the normalised user costs. 


\section{CHAPTER 5}

The Fourier flexible form is used because it provides a global approximation to the unknown indirect utility function. Additionally, the Fourier transformation is capable of approximating the first derivatives of the utility function. This feature is very useful for our purposes since we differentiate the Fourier form in order to arrive at the financial assets' expenditure shares. With these expenditure share expressions (and due to the global approximation of the indirect utility function) we can generate time series of elasticities of substitution between several financial assets (Barnett, Fisher and Serletis, 1992).

As Gallant (1.981) shows, the sine/cosine formulation of the Fourier demand system is equivalent to the exponential form in equation (5.4). Since the sine/cosine form is more convenient to use in empirical applications, the demand system is specified as in equation (5.6):

$$
h(v, \theta)=u_{0}+b^{\prime} v+\frac{1}{2} v^{\prime} C v+\sum_{\alpha=1}^{A}\left(u_{0 \alpha}+2 \sum_{j=1}^{J}\left[u_{j \alpha} \cos \left(j K_{\alpha}^{\prime} v\right)-w_{j \alpha}^{\prime} \sin \left(j K_{\alpha}^{\prime}{ }_{\alpha} v\right)\right]\right)
$$

in which

$$
C=-\sum_{\alpha=1}^{A} u_{0 \alpha} K_{\alpha} K_{\alpha}^{\prime}
$$

Differentiation of equation (5.6) with respect to the normalised user costs $v_{k}$ and application of Roy's identity ${ }^{7}$ leads to the following system of expenditure shares:

$$
s_{k}(v, \theta)=\frac{v_{k} b_{k}-\sum_{\alpha=1}^{A}\left(u_{0 \alpha} v^{\prime} K_{\alpha}+2 \sum_{j=1}^{j} j\left[u_{j \alpha} \sin \left(j K_{\alpha}^{\prime} v\right)+w_{j \alpha} \cos \left(j K_{\alpha \alpha}^{\prime} v\right)\right]\right) K_{k \alpha} v_{k}}{b^{\prime} v-\sum_{\alpha=1}^{A}\left(u_{0 \alpha} v^{\prime} K_{\alpha}+2 \sum_{j=1}^{J} j\left[u_{j \alpha} \sin \left(j K_{\alpha \alpha}^{\prime} v\right)+w_{j \alpha} \cos \left(j K_{\alpha}^{\prime} v\right)\right]\right) K_{\alpha}^{\prime} \nu}
$$

for $k=1, \ldots, n$ financial assets and the expenditure share for asset $k\left(s_{k}\right)$ is defined as (compare equation (4.5)):

Roy"s identity implies that the solution to the reciprocal indirect utility minimization problem is:

$$
m m_{k}(v)=\frac{\frac{\partial h(v)}{\partial v_{k}}}{\Sigma v_{k} \frac{\partial h_{k}(v)}{\partial v_{k}}}
$$

See Diewert (1974), pp. 124-128. 


$$
s_{k}=\frac{p_{k} m_{k}}{y_{m}}
$$

This version of the Fourier flexible form is static in nature and can be used for estimation purposes. The respective share equations (5.8) sum to one, which implies that we do not need any restrictions in order to estimate the system.

However, consumption decisions generally exhibit lagged adjustment patterns. This certainly applies to the consumption of monetary services, since several financial assets can only be disposed of (without costs) at maturity. Therefore, a better approximation of the consumer's indirect utility function may be a dynamic version of the Fourier transformation. As an extension of the static Fourier function, we adopt a dynamic version in which normalised opportunity costs lagged one period are allowed to affect current consumption decisions directly through the utility function (see also Fisher and Fleissig, 1994). This means that current utility depends on current as well as lagged user costs.

Then, analogously to equation (5.6), the dynamic sine/cosine representation of the Fourier form is written as:

$$
f(z, \theta)=u_{0}+b^{\prime} z+\frac{1}{2} z^{\prime} C z+\sum_{\alpha=1}^{A}\left(u_{0 \alpha}+2 \sum_{j=1}^{j}\left[u_{j \alpha} \cos \left(j K^{\prime}{ }_{\alpha} z\right)-w_{j \alpha} \sin \left(j K_{\alpha}^{\prime} z\right)\right]\right)
$$

in which

$$
C=-\sum_{\alpha=1}^{A} u_{0 \alpha} K_{\alpha} K_{\alpha}^{\prime}
$$

and $z$ is a vector of current and one-period lagged normalised opportunity $\cos t s v_{t}$ and $v_{s-1}$. The vector $K_{n}$ now represents multi-indices of length $(2 n \times 1)$, since we use a one-period lag. The expenditure shares are derived by applying Roy's identity to equation (5.10) which gives us:

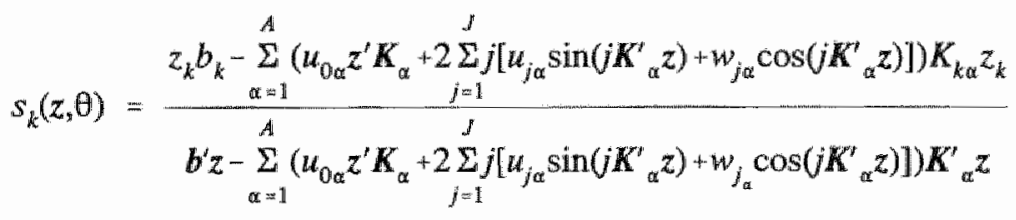

where $k=1, \ldots, n$. As in the static Fourier version, the share equations sum to one.

\subsubsection{The translog functional form}

The third specification for the representative consumer's indirect monetary services' utility function investigated here is the translog functional form. In contrast to the Fourier formulation, the translog form can only approximate the unknown indirect utility function locally. Away from the point of approximation, the translog specifica- 
tion does not provide a reliable estimate of the true utility function. The advantage of the translog utility function ${ }^{8}$ is that it requires fewer parameters to be estimated than the Fourier form.

With a translog specification the indirect utility function $h(v)$ becomes:

$$
h(v)=a_{0}+\sum_{k=1}^{n} a_{k} \ln v_{k}+\frac{1}{2} \sum_{k=1}^{n} \sum_{m=1}^{m} b_{k m} \ln v_{k} \ln v_{m}
$$

where we now take the common normalisation for asset $k$ 's user costs $v_{k}=p_{k} / y_{m}$. Furthermore, $b_{k j n}=b_{i n k}$ for all $k_{*} m$ and $\Sigma_{k} b_{k m n}=0$ for all $m(k, m=1, \ldots, n)$.

Applying Roy's identity to equation $(5.13)$ yields the system of demand functions (5.14):

$$
m_{k}=\frac{a_{k}+\sum_{m=1}^{n} b_{k m} \ln v_{m}}{v_{k}\left(\sum_{k=1}^{n} a_{k}+\sum_{k=1}^{n} \sum_{m=1}^{n} b_{k m} \ln v_{m}\right)} \quad k=1, \ldots, n
$$

Since $\Sigma_{k} \Sigma_{m} b_{k m}$ ln $v_{m}(k, m=1, \ldots, n)$ is zero by definition, the system of equations (5.14) can be written in expenditure share form as:

$$
s_{k}=a_{k}+\sum_{m=1}^{n} b_{k m} \ln v_{m} \quad k=1, \ldots, n
$$

where the normalisation $\Sigma_{k} a_{k}=1(k=1, \ldots, n)$ is imposed. Just like the Fourier system, the translog expenditure share system is homogeneous of degree zero in prices and quantities, but now the reason for this homogeneity is that $\Sigma_{m} b_{k m}=0$ $(k, m=1, \ldots, n)$.

\subsubsection{Determining substitution elasticities}

Having discussed the respective functional forms of the representative consumer's indirect utility function and the resulting expenditure share systems that will be used for estimation purposes, the next step in our analysis is the computation of elasticities of substitution between monetary assets.

Generally, the procedure runs as follows. For each of the three functional forms that we distinguish the respective system of expenditure share equations (equation $(\mathbf{5 . 8}),(5.12)$ or $(\mathbf{5 . 1 5})$ ) is estimated simultaneously and the resulting parameters, together with the data, are used to calculate substitution elasticities between pairs of

\footnotetext{
8. Many researchers have used the translog form to estimate substitution elasticities between financial assets, e.g. Ewis and Fisher (1984), Serletis (1987b) and Drake (1992). Section 2.3.2.3 of this thesis contains a discussion of the evidence reported in this literature.
} 
financial assets. Such a substitution elasticity measures the percentage change in the (income-compensated) demand for asset $k$ in response to a one percent change at the price of asset $m$.

The price elasticities are defined in equation $(\mathbf{5 . 1 6}):^{9}$

$$
\eta_{k m}=\frac{\partial m_{k}}{\partial p_{m m}} \cdot \frac{p_{m}}{m_{k}} \quad \text { for all } k \text { and } m
$$

where $\eta_{k m}$ represents the cross-price elasticity of demand for asset $k$ with respect to the price of asset $m$ and $\eta_{k k}$ represents the own-price elasticity of demand for asset $k$. Similarly, the income elasticity $\left(E_{k y}\right)$ is derived as:

$$
E_{k y^{\prime}}=\frac{\partial m_{k}}{\partial y_{m}} \cdot \frac{y_{m}}{m_{k}} \quad \text { for all } k
$$

Formally, the elasticities of substitution (or, more exactly, the income-compensated own- and cross-price elasticities) between assets $k$ and $m\left(\sigma_{k m}\right)$ can be derived by using the own- or cross-price elasticity and the Slutsky equation:

$$
\eta_{k m}=\sigma_{k m}-s_{m} E_{k y} \quad \text { for all } k \text { and } m
$$

With the translog specification the own- $\left(\sigma_{k k}\right)$ and cross- $\left(\sigma_{k m}\right)$ elasticities of substitution can easily be calculated as follows:

$$
\begin{gathered}
\sigma_{k k}=\frac{b_{k k}-s_{k}+s_{k}^{2}}{s_{k}} \\
\sigma_{k m t}=\frac{b_{k m}}{s_{k}}+s_{m}
\end{gathered}
$$

Since $\Sigma_{m} b_{k s m}=0(k, m=1, \ldots, n)$ in equation (5.15), all financial assets have unitary income elasticities when the translog approach is used. A similar procedure can be applied to the Fourier demand system, but for the sake of brevity the resulting expressions for the elasticities of substitution are not reproduced here.

Overall, assets $k$ and $m$ are considered substitutes if $\sigma_{k m}>0$ and complements if $\sigma_{k m}<0$. That is, two assets are substitutes when the (income-compensated) demand for asset $k$ increases when the opportunity costs of asset $m$ rise (or, equivalently the interest rate on asset $m$ falls c.p.). Substitutability between a pair of assets implies that these assets provide similar services to private depositors. Assets $k$ and $m$ are

9 The exact expressions for the price elasticities can be derived from the respective share equations. 
called complements if demand for asset $k$ falls, when the opportunity costs of asset $m$ rise. ${ }^{10}$ Note that the use of simple-sum monetary aggregation theoretically requires elasticities of substitution between the components of the aggregate to be infinitely high.

\subsection{Estimation procedure}

\subsubsection{Method of estimation}

\subsubsection{The static and dynamic Fourier demand system}

Both in the static and the dynamic version of the Fourier demand system we first estimate the parameters of the respective share equations (5.8) and (5.12) with seemingly unrelated regressions. "The parameters of $n-1$ demand equations can be directly estimated, whereas the parameters of the $n$th equation are inferred from these estimates using the adding-up restriction of the expenditure shares. Because of serial correlation in the residuals of these estimated equations, we include the one-period lagged expenditure share of asset $k$ in the respective share equations (5.8) and (5.12). These lagged shares account for the costs of adapting the consumer's portfolio in response to relative price changes. Assuming that there is no autocorrelation across the share equations the autocorrelation coefficients are the same in all equations (Berndt and Savin, 1975), thus satisfying the adding-up restriction.

In this chapter, the four main components of Dutch M3 are used in estimation. A similar analysis is performed at a disaggregate level for households and companies. In these sectoral samples the portfolios consist of three assets. This requires us to specify different multi-indices $\boldsymbol{K}_{\alpha}$ that are employed in the Fourier expenditure share equations for the static and the dynamic version and for a portfolio of four and three financial assets. In the static and the dynamic version with four assets the multiindices $\boldsymbol{K}_{\mathrm{\alpha}}$ are analogous to Fisher and Fleissig (1994). More specifically, in the static version $A=4$ and $J=1$, whereas $A=8$ and $J=1$ in the dynamic version:

$$
K_{1}=\left(\begin{array}{l}
0 \\
0 \\
1 \\
1
\end{array}\right), K_{2}=\left(\begin{array}{l}
1 \\
0 \\
1 \\
0
\end{array}\right), K_{3}=\left(\begin{array}{l}
0 \\
1 \\
0 \\
1
\end{array}\right), K_{4}=\left(\begin{array}{l}
1 \\
1 \\
1 \\
0
\end{array}\right)
$$

\footnotetext{
10 Although economically hard to interpret in the case of financial assets, empirically, complementarity between pairs of assets is a common result. Financial assets may be complements, if, e.g., one has more transactions and the other more investment characteristics.
}

In all estimations the coefficient $b_{n}$ is set to -1 for normalisation (Gallant, 1981). 


$$
K_{1}=\left(\begin{array}{l}
1 \\
0 \\
1 \\
0 \\
0 \\
0 \\
0 \\
0
\end{array}\right), K_{2}=\left(\begin{array}{l}
0 \\
1 \\
1 \\
0 \\
0 \\
0 \\
0 \\
0
\end{array}\right), K_{3}=\left(\begin{array}{l}
1 \\
0 \\
1 \\
1 \\
0 \\
0 \\
0 \\
0
\end{array}\right), K_{4}=\left(\begin{array}{l}
0 \\
0 \\
0 \\
1 \\
0 \\
0 \\
0 \\
0
\end{array}\right), K_{5}=\left(\begin{array}{l}
0 \\
0 \\
0 \\
0 \\
1 \\
0 \\
0 \\
1
\end{array}\right), K_{6}=\left(\begin{array}{l}
0 \\
0 \\
0 \\
0 \\
0 \\
1 \\
1 \\
0
\end{array}\right), K_{7}=\left(\begin{array}{l}
0 \\
0 \\
0 \\
0 \\
0 \\
0 \\
1 \\
1
\end{array}\right), K_{8}=\left(\begin{array}{l}
0 \\
0 \\
0 \\
0 \\
0 \\
1 \\
1 \\
1
\end{array}\right)
$$

In expression (5.22) the first four indices represent the current-period normalised prices and the last four indices the lagged prices. The first element of this multi-index refers to the first element in vector $z$ (which is $v_{1,1}$ ).

When the number of assets is three (in the sectoral samples) the static and dynamic multi-indices are, respectively;

$$
\begin{gathered}
K_{1}=\left(\begin{array}{l}
1 \\
1 \\
0
\end{array}\right), K_{2}=\left(\begin{array}{l}
1 \\
0 \\
1
\end{array}\right), K_{3}=\left(\begin{array}{l}
0 \\
1 \\
1
\end{array}\right) \\
K_{1}\left(\begin{array}{l}
1 \\
1 \\
0 \\
0 \\
0 \\
0
\end{array}\right), K_{2}=\left(\begin{array}{l}
1 \\
0 \\
1 \\
0 \\
0 \\
0
\end{array}\right), K_{3}=\left(\begin{array}{l}
0 \\
1 \\
1 \\
0 \\
0 \\
0
\end{array}\right), K_{4}=\left(\begin{array}{l}
0 \\
0 \\
0 \\
1 \\
0 \\
0
\end{array}\right), K_{5}=\left(\begin{array}{l}
0 \\
0 \\
0 \\
0 \\
1 \\
0
\end{array}\right), K_{6}=\left(\begin{array}{l}
0 \\
0 \\
0 \\
0 \\
0 \\
1
\end{array}\right)
\end{gathered}
$$

Subsequently, time series of the own- and cross-elasticities of substitution are computed using the estimated parameters of the two Fourier systems of asset demand equations. In calculating these elasticities, four-period moving averages of the respective shares and normalised prices as well as of the budget are used as data, instead of the raw quarterly data. The latter are heavily affected by seasonal effects and other transitory shocks. This results in noisy time series for the estimated substitution elasticities. Alternatively, we have included seasonal dummies in the asset demand system with only marginally different results.

Standard errors of the estimated substitution elasticities are obtained from a linearisation of the elasticities around their parameter estimates and the subsequent use of the standard formulas for the variance and covariance of linear functions of random variables.

\subsubsection{The translog demand system}

Here, the same estimation procedure is applied as with the Fourier specification of the asset demand system. The main difference, however, is that the elasticities of substitution in the translog system can only be evaluated at the mean sample values of 
the assets' expenditure shares. The translog utility representation can only approximate the true utility function locally.

Since estimates of indirect utility (or cost) functions may fail to meet the curvature requirements, parameter restrictions are imposed in order to obtain local concavity of the translog indirect utility function (for details see Wiley et al., 1973). This technique ensures that the matrix of substitution elasticities is negative semi-definite. An important drawback of this technique, however, is that it worsens the flexibility of the translog function to approximate any unknown indirect utility function locally.

\subsubsection{Data}

Quarterly data covering the time-period 1972:1-1993:4 are used. ${ }^{12}$ Holdings of financial assets in the sample are deflated by the CPI to obtain real stocks.

The financial assets used in the analysis for the aggregate economy consist of four components of the current Dutch harmonised M3 aggregate. From October 1992 onwards harmonised $\mathrm{M} 3$ is officially reported and treated as the main monetary policy indicator in the Netherlands to facilitate international comparison across EUcountries, see van Wersch (1992). This M3 measure includes currency, demand deposits, short-term time deposits with a maturity of less than two years (since the introduction in 1986 also including Certificates of Deposit), foreign currency deposits held in banks located in the Netherlands and savings deposits. In this chapter we use a portfolio consisting of currency, demand deposits, short-term time deposits (corrected for the stocks of Certificates of Deposit issued) and savings deposits to assess their substitutability. Foreign currency deposits -only available as an overall aggregate of deposits of different foreign currency denomination- are not taken into account both because of their relatively small share and the difficulty in choosing a correct opportunity cost variable. All assets under consideration are risk-free, which means that different returns should reflect differences in \iquidity. The interest rate on currency is zero; interest rates for the other three assets are given in table 9.2 in DNB's Quarterly Bulletins. Together, the four financial assets analysed in this chapter may be considered a weakly separable group ${ }^{13}$ within the whole class of financial assets monitored by the Dutch central bank. That is, the elasticities of substitution between the four assets are unaffected by other excluded financial assets.

The sectoral analysis of the elasticities of substitution between financial assets is performed for the business sector and for households separately, again over the sample 1972:1-1993:4. For each of these sectors the portfolio under investigation consists of three assets: currency, demand deposits and short-term time deposits for the business sector, and currency, demand deposits and savings with a maturity of

12. The data sources of financial asset stocks and user costs are discussed in more detail in section 4.4 (most data are obtained from table 3.1 and table 9.2 in the Quarterly Bulletins published by De Nederlandsche Bank (DNB)).

13 This separability is the result of the NONPAR test developed by Varian (1982 and 1983), see section 3.4 . 
less than two years for the household sector. Data on asset stocks held in these sectors are taken from de Haan et al. (1992) and table 2.1.3 in DNB's Quarterly Bulletins.

Figures 5.1 through 5.10 show the time series behaviour of the expenditure shares and the normalised user costs (using the normalisation method (5.3)) of the different assets at the aggregate, business and household level, respectively. It appears that for many assers the shares and the user costs move together over a large part of the sample, which may be caused by the common trend in the individual asset stocks and in the total flow of financial services in the portfolio $\left(2 m_{k}\right)$. This pattern is especially evident for currency and demand deposits at the aggregate level, for time deposits in the business sector, and for demand deposits and savings in the household sector. Clearly, the expenditure share of currency in the aggregate economy and in both sectors drops sharply after 1988, when the time-paths of these shares and their respective normalised user costs become more divergent (see figures 5.1, 5.5 and 5.8). Figure 5.6 shows that the business sector's holdings of demand deposits (measured as expenditure share) have fallen steadily over the sample in response to rising user costs; a relation which is in line with what would theoretically be expected. Time deposits have increased their share in the business sector's portfolio steadily until they formed half of this portfolio in the 1990s (see also de Haan et al., 1992 and 1994), despite an increase in their normalised user costs. A similar picture appears at the aggregate level since 1988 , because the majority of time deposits are held by companies. The household sector's portfolio mainly consists of savings (figure 5.10). At the aggregate level, the normalised user costs of savings move roughly in line with time deposits" user costs. After a downward trend until about 1986, savings" expenditure share has been relatively stable in the whole economy's portfolio (figure 5.4).

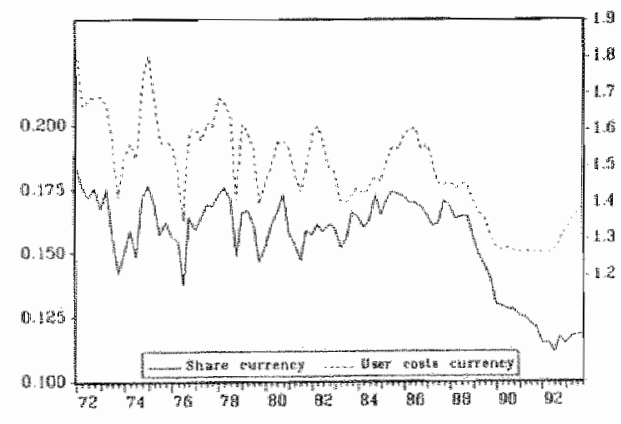

Figure 5.1 Currency (aggregate)

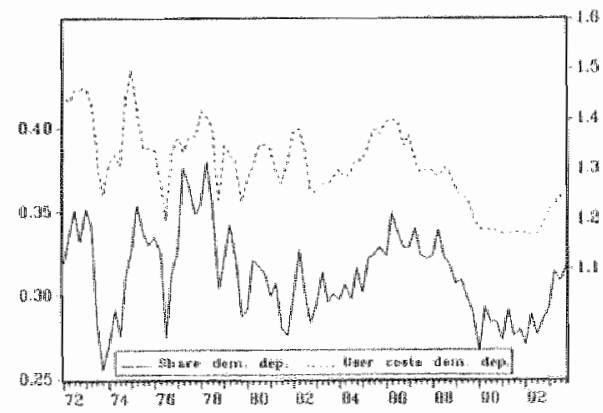

Figure $\mathbf{5 . 2}$ Demand deposits (aggregate) 


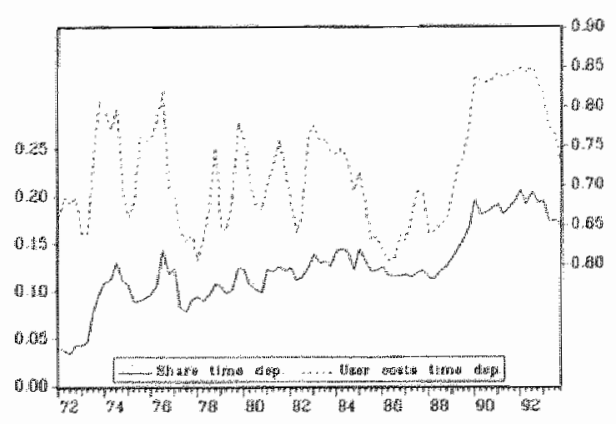

Figure 5.3 Time deposits (aggregate)

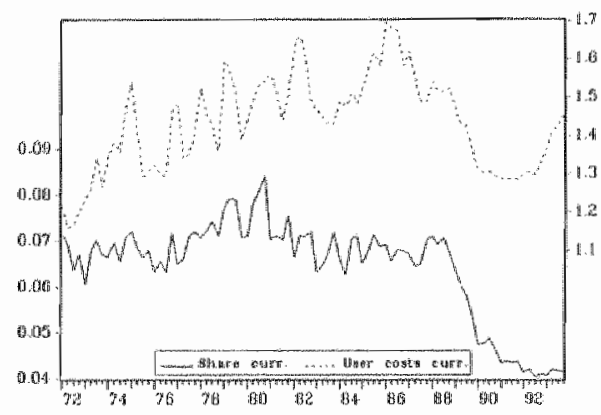

Figure 5.5 Currency (business)

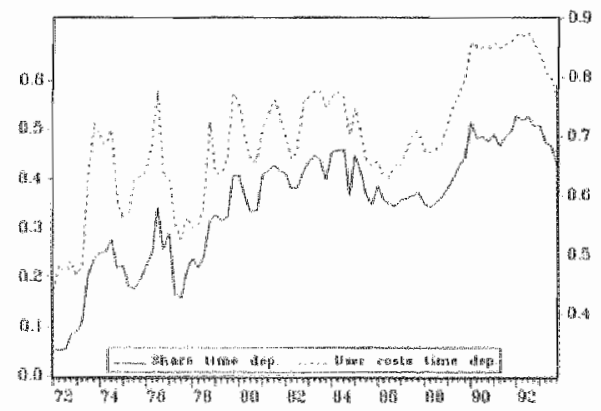

Pigure 5.7 Time deposits (business)

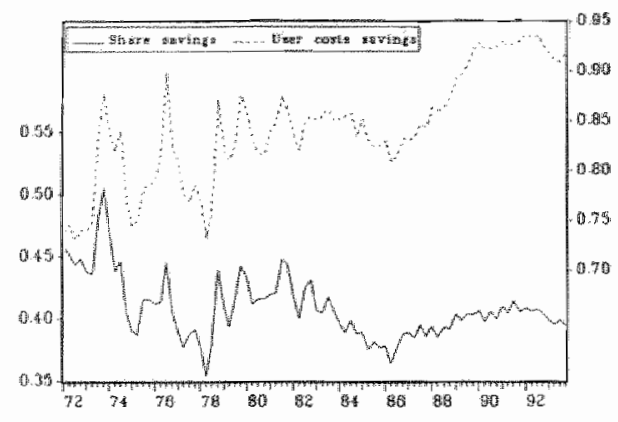

Figure 5.4 Sawings (aggregate)

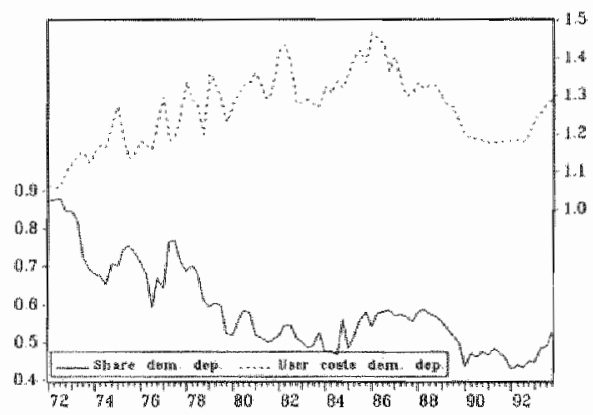

Fïgure 5.6 Demand dep. (business)

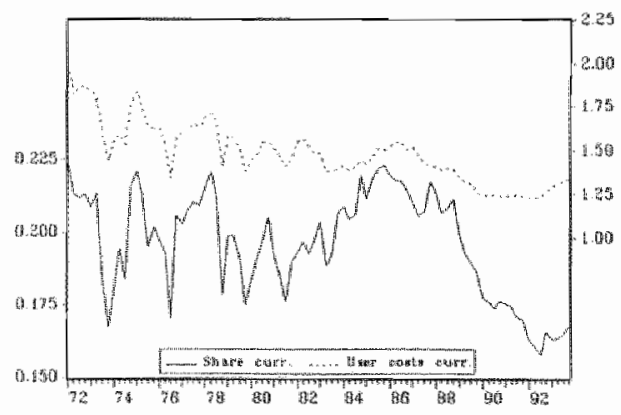

Figure 5.8 Currency (households) 


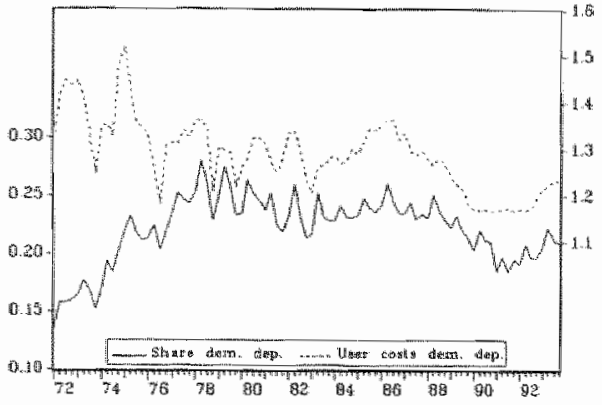

Figure 5.9 Demand dep. (households)

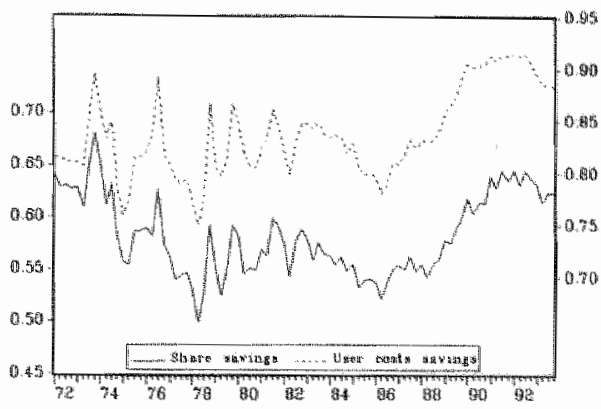

Figure 5.10 Savings (households)

\subsection{Empirical results and interpretation at the aggregate level}

\subsubsection{Fourier model}

Estimation of the derived Fourier systems of asset demand equations results in time series of own- and cross-elasticities of substitution for the period 1972-1993, that are displayed in figures 5.11 through 5.20. Both the estimated magnitude of the coefficients and their respective statistical significance (evaluated at the 5 percent level) over time is depicted. If the line indicating significance contains missing values this means that the elasticity in question is not significant at these observations.

Figures 5.11 and 5.12 (static Fourier) and 5.16 and 5.17 (dynamic Fourier) shed light on the behaviour of the own-elasticities of substitution. Theoretically, we would expect them to be negative. Demand theory states that a higher opportunity cost of asset $k$ normally should lead to a lower demand for that asset. Overall, the evidence shows significantly negative own-elasticities for currency, demand deposits and savings, although in the dynamic Fourier system demand deposits reveal a small, but significant positive elasticity. The only exception is the elasticity of time deposits (TD) which is significantly positive, but quickly decreasing, over most of the sample in both versions of the Fourier specification. In both Fourier versions currency appears to have the largest negative own-elasticity. Furthermore, in the static Fourier system, all four own-elasticities are trending downwards over the whole sample, indicating a less stable behaviour of these elasticities than when the dynamic version is used (three of the four elasticities are relatively stable then). 


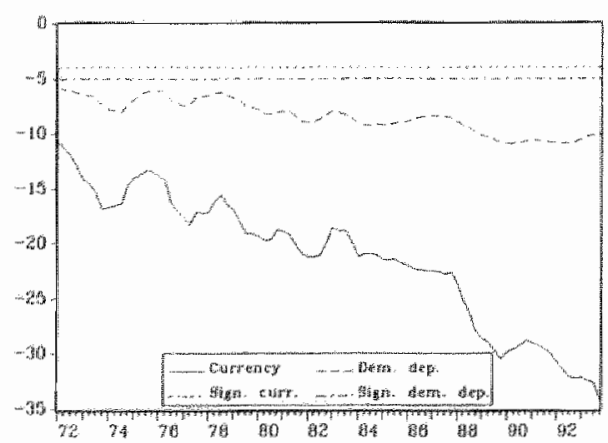

Figure 5.11 Own elastictices aggregate (static)

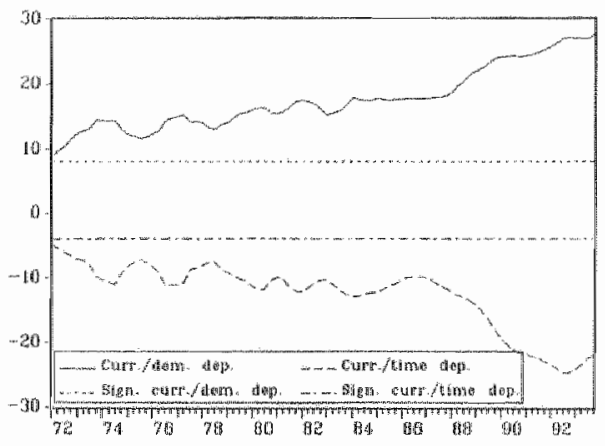

Figure 5.13 Cross elasticities aggregate (static)

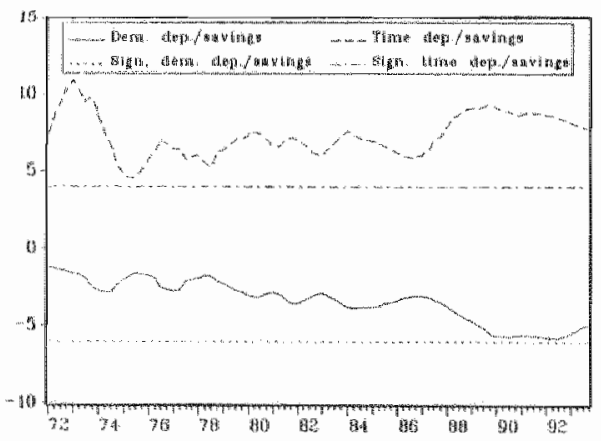

Figure \$.15 Cross elasticities aggregate (static)

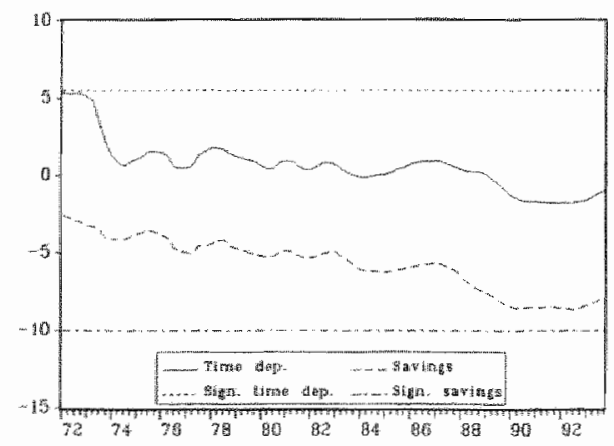

Figure 5.12 Own elasticities aggregate (static)

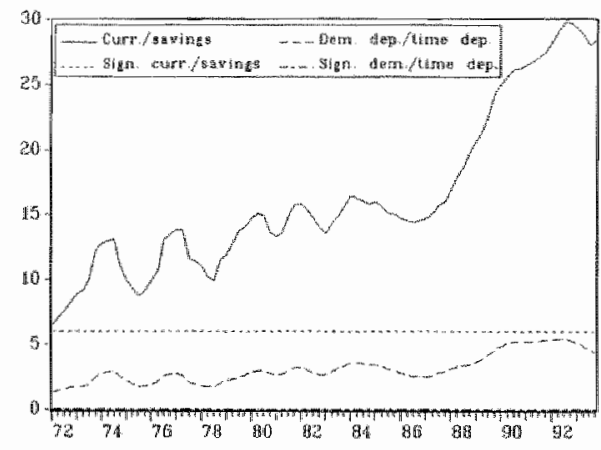

Figure 5.14 Cross elasticities aggregate (static)

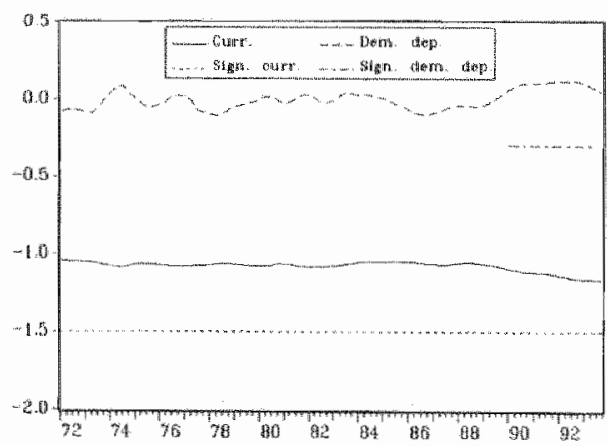

Figure 5.16 Own elasticities aggregate (dynamic) 


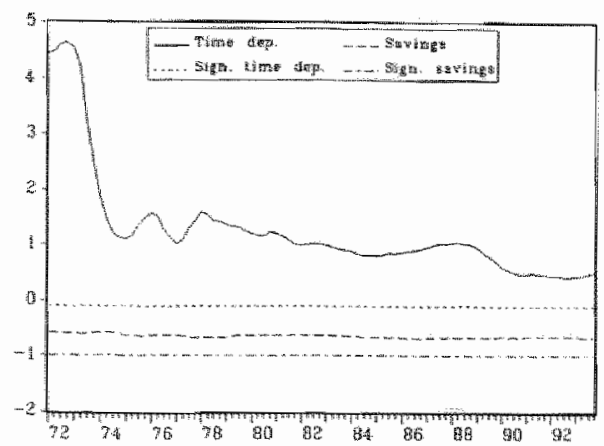

Figure 5.17 Own elasticities aggregate (dynamic)

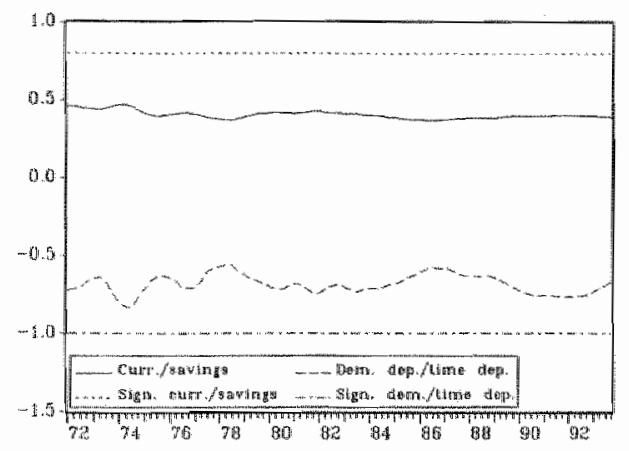

Figure 5.19 Cross elasticities aggregate (dynamic)

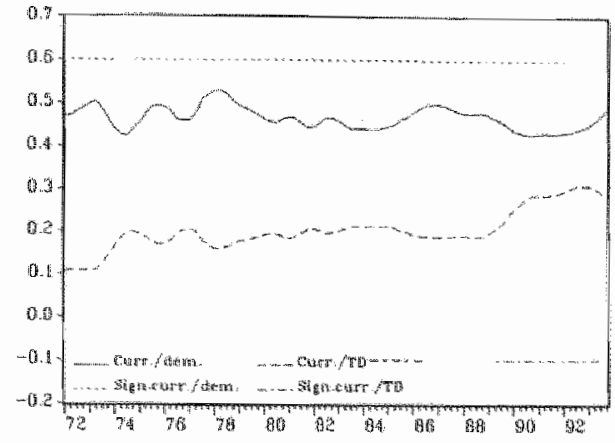

Figure 5.18 Cross elasticities aggregate (dynamic)

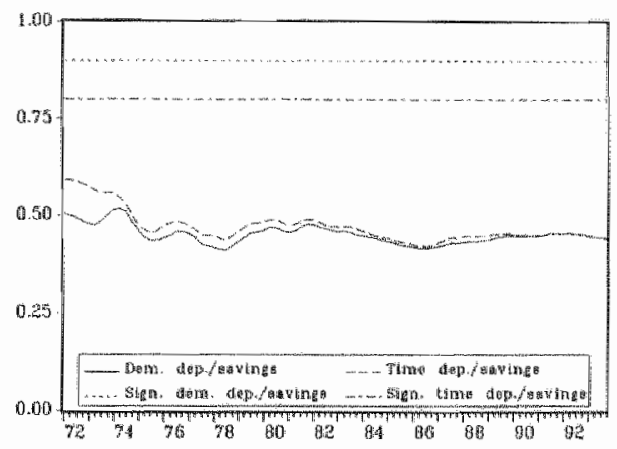

Figure 5.20 Cross elasticities aggregate (dynamic)

Figures $5,13,5.14$ and 5.15 show the cross-elasticities of substitution in the static Fourier version, whereas figures $5.18,5.19$ and 5.20 depict these values in the dynamic version. According to demand theory we should expect positive values for the estimated elasticities. Then, different assets are substitutes. Negative elasticities suggest that assets are complements. The results indeed point to a dominance of substitution relationships. Furthermore, the observed elasticities are low, relatively stable and most of them are similar in absolute magnitude over the sample period when estimated in a dynamic Fourier framework, but they are higher and much more volatile in the static model.

Using the static Fourier demand system we observe that the elasticities between currency and demand deposits and between currency and savings are the largest and are nearly the same over most of the sample. Significant complementarity is found between currency and time deposits and between demand deposits and savings. The complementarity between two assets may imply that consumers use these assets in 
combination, possibly because of diversification motives. E.g., if the user costs of demand deposits (which are an important source of funds for transactions purposes) fall, demand deposit balances increase, but, in order to keep the consumers' utility level constant, income-compensated demand for savings accounts also increases. Recall that the estimated substitution elasticities measure the change in income-compensated demand for asset $k$ in response to a one percent change in asset $m^{*} s$ price.

In the dynamic Fourier model the single most important substitution effect is found between currency and demand deposits. It is significantly positive over almost the entire period and the magnitude of the elasticity is between 0.4 and 0.5 . Other significant substitution effects are observed between currency and savings, demand deposits and savings, and between time deposits and savings. ${ }^{14}$ Significant substitution between currency and time deposits is only found between 1984 and 1986 and after 1989. Significant complementarity can be observed between demand and time deposits over the full. sample.

When we compare the overall estimation results obtained with the static and the dynamic version of the Fourier approach using aggregate data it appears that the static model shows some common trend movements in the elasticities. Most crosselasticities between assets that are substitutes tend to move upward (the combination time deposits/savings being the exception), especially after 1988 . In addition, the estimated elasticities are larger in magnitude in the static model compared with the dynamic version.

\subsubsection{Translog model}

After imposing the theoretically required curvature restrictions, the translog asset demand system is estimated, and, subsequently, the elasticities of substitution between our four financial assets are determined. Table 5.1 shows the estimated elasticities at the mean expenditure shares, together with their t-statistics, for the aggregate portfolio. The results can be interpreted as follows. By definition, all financial assets now have negative own-elasticities, which are all significant. This theoretical elegance, however, destroys part of the flexibility of the translog functional form to approximate any unknown utility function locally. Most assets are substitutes, whereas currency and savings and demand and time deposits are complements, atthough the latter relation is insignificant. The cross-elasticities between savings on the one hand and demand deposits and time deposits on the other are remarkably high compared with the elasticity between currency and demand deposits. These contraintuitive results may be caused by our imposition of curvature restrictions on the translog indirect utility function and by different portfolio behaviour of the business and the household sector.

14. The latter result is in line with substitution relations between time deposits and savings, as reported in Fase (1975 and 1978). However, Fase (1979) concludes that time deposits and savings are insignificant complements. 
In order to compare the results of the translog demand system directly with those of the static and dynamic Fourier model, table 5.2 shows the estimated elasticities at the mean expenditure shares, together with their t-statistics, for the latter two functional forms. Overall, the mean elasticities for the two Fourier specifications are consistent with the time series results in section 5.4.1. Both Fourier models are estimated without imposing curvature restrictions. It appears that the mean elasticities estimated with the dynamic Fourier model are similar to the corresponding results obtained with the translog model. The differences between the static Fourier system and the transllog model are, however, more pronounced.

Table 5.1 Elasticities of substitution for aggregate portolio evaluated at the mean with translog specification ( $[-$ statistics in parentheses)

\begin{tabular}{|l|l|l|l|l|}
\hline & currency & demand deposits & time deposits & savings \\
\hline currency & $\begin{array}{c}-0.27 \\
(-2.19)\end{array}$ & - & - & - \\
\hline demand deposits & $\begin{array}{c}0.41 \\
(4.06)\end{array}$ & $\begin{array}{l}-1.11 \\
(-2.96)\end{array}$ & - & - \\
\hline time deposits & $\begin{array}{c}0.12 \\
(1.15)\end{array}$ & $\begin{array}{c}-0.07 \\
(-0.53)\end{array}$ & $\begin{array}{c}-2.85 \\
(-7.63)\end{array}$ & - \\
\hline Savings & -0.26 & 0.98 & 2.87 & $(5.61)$ \\
\hline
\end{tabular}

Table 5.2 Elasticities of substitution for aggregate portfolio evaluated at the mean with static and dynamic Fourier specification (t-statistics in parentheses)

\begin{tabular}{|c|c|c|c|c|}
\hline & currency & demand deposits & time deposits & savings \\
\hline currency & $\begin{array}{ll}-21.84 & -1.13 \\
(-2.87) & (-3.09)\end{array}$ & - & - & - \\
\hline demand deposits & $\begin{array}{rr}14.99 & 0.52 \\
(2.74) & (1.95) \\
\end{array}$ & $\begin{array}{cc}-7.97 & -0.10 \\
(-3.57) & (-0.45)\end{array}$ & - & - \\
\hline time deposits & $\begin{array}{cc}-11.35 & 0.24 \\
(-3.64) & (1.69)\end{array}$ & $\begin{array}{cc}1.64 & -0.88 \\
(2.82) & (-5.06)\end{array}$ & $\begin{array}{c}0.64 \quad 1.08 \\
(2.28)(2.23)\end{array}$ & -. \\
\hline savings & $\begin{array}{cr}15.48 & 0.37 \\
(3.28) & (2.76)\end{array}$ & $\begin{array}{cc}-2.60 & 0.36 \\
(-2.05) & (2.67)\end{array}$ & $\begin{array}{cc}9.39 & 0.42 \\
(3.30) & (2.25)\end{array}$ & $\begin{array}{cc}-4.83 & -0.48 \\
(-3.74) & (-3.06)\end{array}$ \\
\hline
\end{tabular}

\subsection{Empirical results and interpretation at the sectoral level}

Portfolio behaviour of the business sector is likely to be different from that of households. Additionally, the two sectors hold different financial assets. Short-term time deposits (TD) are mainly held by companies, while savings are only present in the 
households" portfolio. This may, for example, explain why we find a relatively high elasticity between time deposits and savings in the translog model. Kuipers and Boertje (1988) investigate this phenomenon, estimating both overall and sectoral money demand functions. They conclude that the demand for money is significantly different for businesses and households, respectively, so that an aggregation bias may exist in estimating an economy-wide demand for money. Fase and Winder (1990) also estimate sectoral and aggregate demand for money functions. They argue that the demand for money has been relatively stable, especially when a wealth variable is included in the specification. However, their results also indicate that businesses are more sensitive to inflation and interest rates than households. Thus, these observations suggest that an analysis based solely on aggregate data, as in section 5.4, may be sensitive to misspecification and may not be useful to obtain insight into the elasticities between the components of harmonised M3 in the Netherlands. Therefore, it may be more appropriate to reestimate the above calculated elasticities of substitution at a disaggregated level.

\subsubsection{Fourier model}

\subsubsection{The business sector}

Using the multi-indices $K_{\alpha}$ described in section 5.3.1.1 we obtain estimates of elasticities of substitution in the business sector as shown in figures 5.21 through 5.24. Most elasticities are larger when lagged normalised user costs are included in the business sector"s utility function than when these costs are excluded, as in the static version. In the static Fourier model, only two elasticities appear to be significant over part of the sample, whereas the dynamic version shows that all estimates are significantly different from zero.

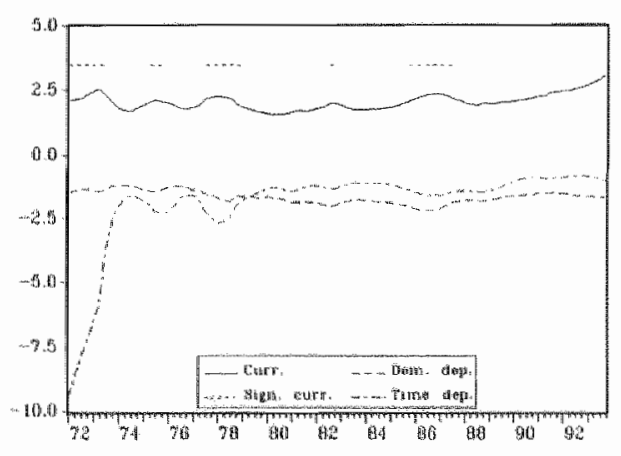

Figure 5.21 Own elmsticities business (static)

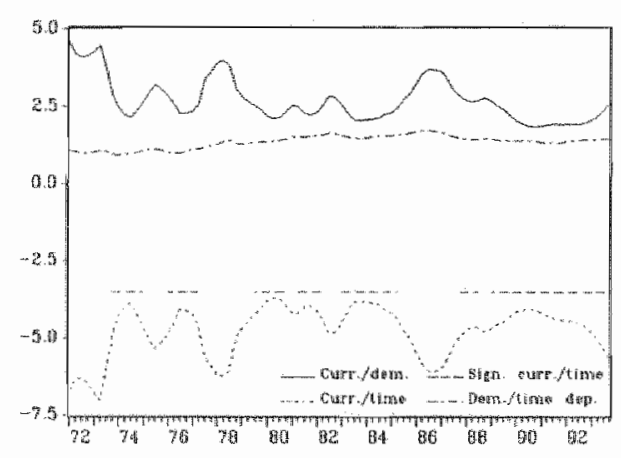

Figure 5.22 Cross elasticities business (sta(iic) 


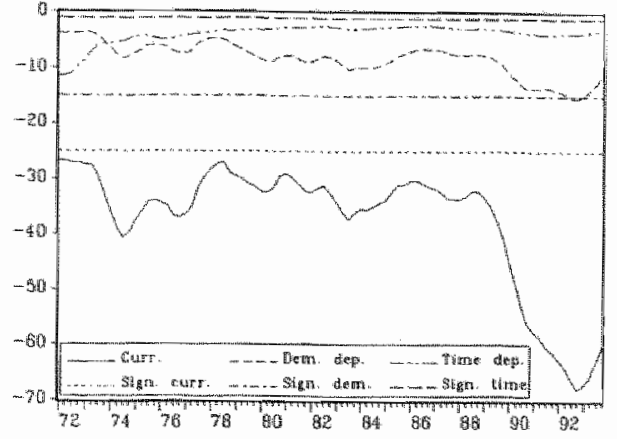

Figure 5.23 Own elasticities business (dynamic)

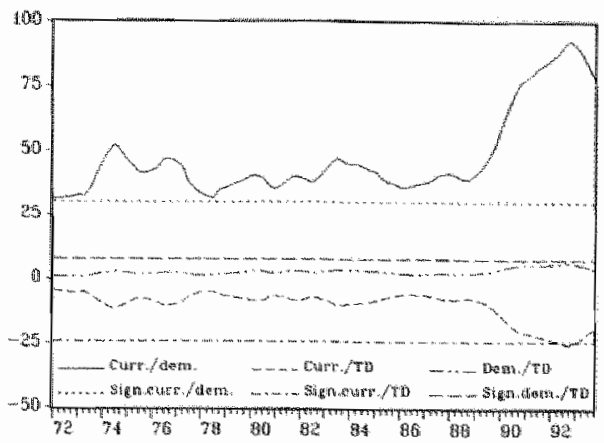

Figure 5.24 Cross elasticities business (dy. namic)

All own-elasticities have the correct (negative) sign, except the one for currency in the static Fourier model (which is significant in part of the sample). This positive own-elasticity of currency may be explained by the special character of currency as a buffer for transactions and precautionary motives. Then, the stock of currency may depend on the business sector's current payments and/or profits (see also de Haan et al., 1992 and 1994). In the dynamic version, however, currency has the highest ownprice responsiveness, which rises in absolute magnitude after 1988. This corresponds to the time series behaviour of currency's expenditure share as displayed in figure 5.5. The other two own-elasticities display a similar behaviour in both versions of the Fourier model, except that the absolute magnitude of demand deposits' elasticity is larger in the dynamic approach. In figures 5.21 and 5.23 we observe that time deposits" own-elasticity has decreased in absolute size and become relatively stable since the early 1980s. In 1991, the Dutch central bank performed a large survey among businesses to shed light on the motives for holding various liquid assets, see de Haan et al. $(1992,1994)$. These studies report that firms have considerably built up their liquidity holdings in the eighties to restore previously eroded liquidity and solvency ratios, to facilitate internal finance, and for precautionary reasons. At the same time, the interest rate (or, the differential between the short- and the long-term interest rate) has become a less important determinant of companies" liquidity holdings in general and of their stock of time deposits in particular. Our results concerning the own-elasticities seem in line with these observations.

Looking at the estimated cross-elasticities in figures 5.22 and 5.24 it appears that currency and demand deposits and demand and time deposits (TD) are substitutes, whereas currency and time deposits are complements. This complementarity may be explained by the fact that currency does not pay any interest, while time deposits earn a rate close to the money market rate. The highest degree of substitutability is found between currency and demand deposits, as one would normally expect. Additionally, the own-elasticities of currency and demand deposits and the elasticity between these two financial assets reveal an increase in absolute magnitude around 
1989. This coincides with considerable breaks in the expenditure shares of these assets in the business sector"s portfolio (see figures 5.5 and 5.6). Overall, our results suggest that the dynamic Fourier approximation of the true indirect utility function provides a better picture of the business sector's portfolio behaviour with respect to the main components of M3 than the static model.

\subsubsection{The household sector}

The main differences between the static and dynamic Fourier versions at the household level are that the estimated elasticities are generally more stable and smaller in the dynamic Fourier model, although they are often insignificant. The results in figure 5.25 show that all own-elasticities are in accordance with economic theory in the static version. In the dynamic version (figure 5.27), currency has a significant positive own-elasticity, which may again be motivated by the specific characteristics of currency as a non-interest bearing financial asset.

Both versions reach roughly the same conclusions with respect to the question of substitutability or complementarity between financial assets held by households (figures 5.26 and 5.28). Currency and demand deposits and demand deposits and savings are shown to be substitutes, although currency and demand deposits are almost independent assets when estimated with a dynamic specification. The two figures reveal that currency and savings are complements, possibly for the same reason why currency and time deposits are complements in the business sector.

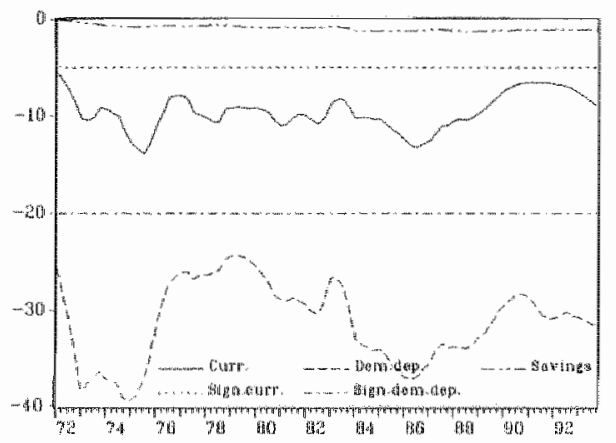

Figure 5.25 Own elasticities households (static)

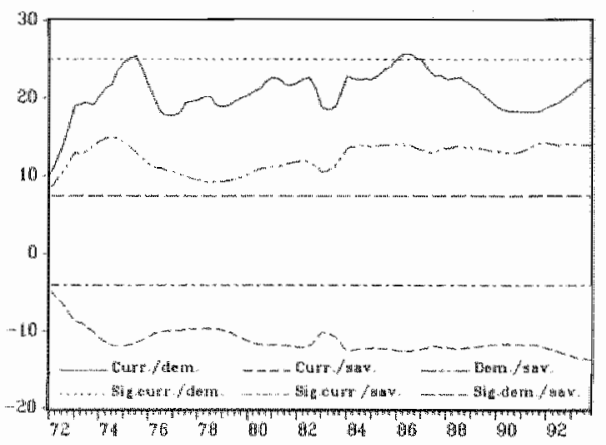

Figure 5.26 Cross elasticities households (static) 


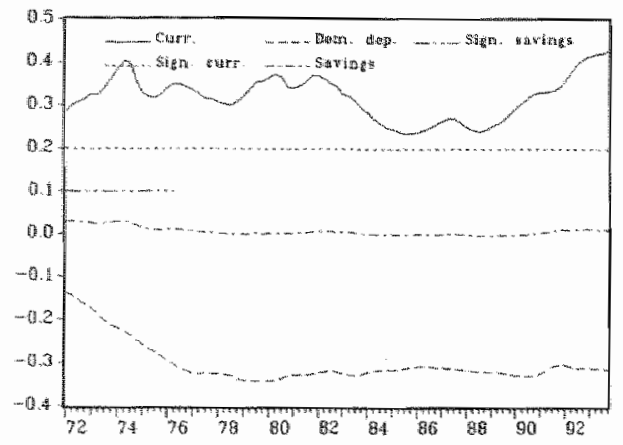

Figure 5.27 Own elasticities households (dynamic)

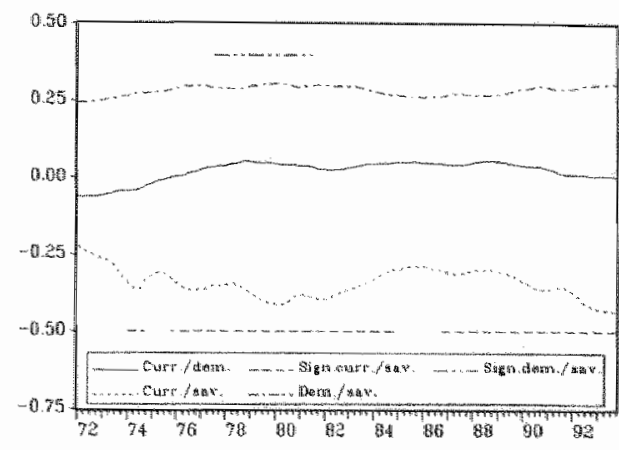

Figure 5.28 Cross elasticities households (dynamic)

The results obtained with the dynamic model for households are, however, economically implausible, mainly because of the resulting elasticity between the two components of ML, which is close to zero. The static model seems better interpretable, because currency and demand deposits are relatively strong substitutes and the ownelasticities of substitution are all negative. In the 1990s we observe some small changes in the magnitude of currency's and demand deposits' own-elasticity and of the elasticity between these two assets. This may be related to the falling share of currency in the households" portfolio, which in turn may be due to the increased use of automated teller machines.

\subsubsection{Translog model}

When we use the translog specification to approximate the true utility function locally and also impose curvature restrictions, results as presented. in tables 5.3 and 5.4 are obtained for businesses and households, respectively.

Table 5.3 Elasticities of substitution in the business sector evaluated at the mean with translog specification (t-statistics in parentheses)

\begin{tabular}{|l|l|l|l|}
\hline & currency & demand deposits & uime deposits \\
\hline currency & -0.42 & - & - \\
& $(-0.85)$ & & \\
\hline demand deposits & 1.70 & -4.56 & - \\
& $(3.01)$ & $(-8.14)$ & \\
\hline time deposits & -1.28 & 4.38 & -7.19 \\
& $(-7.08)$ & $(8.13)$ & $(-8.13)$ \\
\hline
\end{tabular}


Table 5.4 Elasticities of substitution in the household scctor evaluated at the mean with translog specification ([-statistics in parentheses)

\begin{tabular}{|l|l|l|l|}
\hline & currency & demand deposits & savings \\
\hline currency & $\begin{array}{c}-0.23 \\
(-6.33)\end{array}$ & - & - \\
\hline demand deposits & $\begin{array}{c}0.11 \\
(8.64)\end{array}$ & $\begin{array}{c}-0.15 \\
(-1.57)\end{array}$ & - \\
\hline savings & 0.12 & $\begin{array}{c}0.05 \\
(0.51)\end{array}$ & -0.06 \\
$(3.14)$ & $(-1.53)$ \\
\hline
\end{tabular}

The tables reveal that the elasticities in the business sector are generally higher than in the household sector. ${ }^{15}$ For the business sector, only the own-elasticity of currency is insignificant. Our earlier result (in the Fourier models) of complementarity between currency and time deposits in the business sector is confirmed with the translog specification. The elasticity between demand deposits and time deposits is higher in absolute terms than that between currency and time deposits. In the household sector we only find substitution relations, although the magnitudes are very small. In contrast to the results reported for the Fourier models, currency and savings are now substitutes.

The corresponding mean elasticities estimated with the static and dynamic Fourier model are presented in tables 5.5 and 5.6 for the business and the household sector, respectively. With respect to the issue of substitutability or complementarity between pairs of assets, the results from the translog model and the dynamic Fourier model are quite similar for the business sector (although the absolute magnitudes are very different). For households, however, the differences between the results from the translog system and the two Fourier versions are somewhat larger.

Table 5.5 Elasticities of substitution in the business sector evaluated at the mean with static and dynamic Fourier specification (t-statistics in parentheses)

\begin{tabular}{|c|c|c|c|c|c|c|}
\hline & \multicolumn{2}{|c|}{ currency } & \multicolumn{2}{|c|}{ denand deposits } & \multicolumn{2}{|c|}{ time deposits } \\
\hline currency & $\begin{array}{c}2.62 \\
(1.85)\end{array}$ & $\begin{array}{l}-37.99 \\
(-4.34)\end{array}$ & - & & 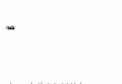 & \\
\hline demand deposits & $\begin{array}{c}3.43 \\
(1.15)\end{array}$ & $\begin{array}{l}40.86 \\
(4.39)\end{array}$ & $\begin{array}{c}-2.10 \\
(-0.86)\end{array}$ & $\begin{array}{c}-3.91 \\
(-5.47)\end{array}$ & - & \\
\hline time deposits & $\begin{array}{c}-5.60 \\
(-1.85)\end{array}$ & $\begin{array}{c}-5.75 \\
(-4.99)\end{array}$ & $\begin{array}{c}1.79 \\
(1.32)\end{array}$ & $\begin{array}{c}0.94 \\
(17.37)\end{array}$ & $\begin{array}{c}-2.34 \\
(-1.28)\end{array}$ & $\begin{array}{c}-1.23 \\
(-29.66)\end{array}$ \\
\hline
\end{tabular}

15 Fase and Winder (1990) also find that long-term interest ellasticities are higher for the business sector than for households. 
Table 5.6 Elasticities of substitution in the household sector evaluated all the mean with static and dynamic Fourier specification (i-statistics in parentheses)

\begin{tabular}{|c|c|c|c|c|c|c|}
\hline & \multicolumn{2}{|l|}{ currency } & \multicolumn{2}{|c|}{ demand deposits } & \multicolumn{2}{|l|}{ savings } \\
\hline currency & $\begin{array}{c}-9.47 \\
(-25.49)\end{array}$ & $\begin{array}{c}0.30 \\
(2.34)\end{array}$ & - & & - & \\
\hline demand deposits & $\begin{array}{r}19.09 \\
(22.76) \\
\end{array}$ & $\begin{array}{c}0.11 \\
(0.97)\end{array}$ & $\begin{array}{r}-28.40 \\
(-13.79) \\
\end{array}$ & $\begin{array}{r}-0.29 \\
(-0.46) \\
\end{array}$ & - & \\
\hline savings & $\begin{array}{c}-9.78 \\
(-4.50)\end{array}$ & $\begin{array}{c}-0.41 \\
(-4.14)\end{array}$ & $\begin{array}{l}11.64 \\
(5.11)\end{array}$ & $\begin{array}{c}0.29 \\
(2.05)\end{array}$ & $\begin{array}{c}-0.63 \\
(-0.23)\end{array}$ & $\begin{array}{l}-0.01 \\
(-1.65)\end{array}$ \\
\hline
\end{tabular}

\subsubsection{Policy implications}

The preceding analysis clearly demonstrates that an aggregate analysis of substitution elasticities between the main components of the Dutch harmonised M3 aggregate may" be seriously biased. Such an analysis should, therefore, not be used to obtain information about the likely implications for monetary policy.

A disaggregated analysis of the elasticities in the business and the household sector may provide more useful insights. However, as our results show, the relations found between financial assets at the sectoral level are semsitive to the specification of the representative consumer's indirect utility function. Nevertheless, we are able to draw some conclusions. Overall, substitution relations dominate in both sectors. Complementarity relations are found between currency and time deposits in the business sector and between currency and savings in the household sector. This may be explained by the similar roles that time deposits and savings play in the business sector's and the household sector's portfolios, respectively. For the business sector, the economically best results are obtained with the dynamic Fourier model, ${ }^{16}$ whereas the results in the static Fourier version for the household sector are to be preferred. This would imply that companies also take into account past behaviour of financial assets' user costs, while households base their decisions only on present user costs. An explanation of this result for the business sector may be that companies only adjust their portfolio after relative interest rate changes have shown to be of a more permanent character.

Overall, the role of time deposits seems crucial. As reported by de Haan et al. $(1992,1994)$ the share of time deposits in the simple sum M3 aggregate has gradual ly increased, especially in the 1980s. This is clearly related to firm behaviour, as most of the decrease in velocity comes from liquidity accumulation by the business sector. This sector holds approximately fifty percent of its total liquidity holdings in the form of time deposits, so both an absolute and a relative rise of time deposits is consistent with the overall rise in firms' liquidity holdings.

16 The mean elasticities obtained with the translog model for the business sector lead to similar conclusions with respect to substitutability or conplementarity between pairs of financial assets. 
Unreported results, moreover, show that, while the guilder share of time deposits in harmonised $M 3$ (at the aggregate level) rises in the eighties, opportunity-costweighted shares, as defined in equation (5.9), remain stable between 1982 and 1987 (see figure 5.3). Apparently, the interest rate on time deposits became more attractive (higher) relative to that of the other assets in harmonised M3 in that period.

In 1986, Certificates of Deposits (CD) and Commercial Paper (CP) were introduced in Dutch financial markets. Over our sample, the quantitative magnitude of these new markets remained small. The relatively large denominations prevented the entry of households and small firms in the market. Van Ees et al. (1989) conclude that the introduction of these assets did not influence overall money demand. Our results do not show strong breaks around 1986 either.

Overall, most estimated elasticities are as expected by demand theory. It is clear, though, that the hypothesis of perfect substitution within one simple sum aggregate, be it M1 or harmonised M3, has to be rejected. Thus, our findings throw additional doubt on the use of simple-sum aggregates.

\subsection{Summary and conclusions}

In this chapter, we have analysed the behaviour of the components of Dutch harmonised M3 in relation to their relative prices over the period 1972-1993 with quarterly data at the aggregate and sectoral level. Although monetary authorities, in general, use simple sum aggregates as indicators for monetary policy, both theoretical work and empirical observations over the past decades have cast doubt on the appropriateness of this practice (see chapter 4).

Theoretically, summing different financial liquid assets into one aggregate is allowed only if this group of assets is weakly separable from the rest of the available portfolio choices and if the included assets are perfect substitutes. These conditions often are not met in practice. The empirical money demand literature, on the other hand, has documented instabilities for many countries and for different demand for money specifications. throwing douht on the reliahility of the relation hetween money growth, inflation and real income growth.

Alternatively, as shown in chapter 4, Divisia indices may be used, which try to measure the flow of monetary services provided by different liquid assets. In Divisia aggregates, included assets are weighted with their relative opportunity costs, therefore.

In this chapter, we investigate the time path of substitution elasticities of the harmonised M3 components currency, demand deposits, time deposits and savings, using utility maximization of consumers who, within their budget constraint, choose quantities of financial assets to maximize the flow of monetary services. The utility function is approximated by three flexible functional forms: the static Fourier, the dynamic Fourier and the transllog function. This allows derivation and estimation of a system of asset demand equations. As a result, time series of own- and crosssubstitution elasticities are computed and discussed. The analysis is performed for the economy as a whole and for the business and the household sector separately. 
The results show a dominance of substitution relationships between the M3 component assets at the aggregate and the sectoral level. The aggregate results may be biased, because of differences in portfolio behaviour between companies and households. The sectoral analysis shows that only currency and time deposits and currency and savings are complements. The estimated elasticities are relatively stable over the period 1972-1993. The substitution elasticities, however, clearly indicate that the M3 assets are imperfect substitutes. The results suggest that the static Fourier function estimates household portfolio behaviour in a satisfying way, while the dynamic Fourier gives a good view of the business sector's behaviour.

The most important financial innovation in the Netherlands in the 1980s, in our view, has been the liberalisation and subsequent introduction of CDS and CP in 1986. No significant changes in the magnitude of substitution elasticities of older financial assets are found around that period, however. Probably, the size and number of participants in these markets is yet too small.

Overall, the estimated elasticities are as expected by demand theory. It is clear, though, that the hypothesis of perfect substitution within one simple sum aggregate, be it M1 or harmonised M3, has to be rejected. The stability of the estimated elasticities may also explain the similar behaviour of Dutch simple-sum and Divisia monetary aggregates, as reported in chapter 4 . Changes in relative prices between the M3 components do not seem to have been responsible for instabilities in money demand in the Netherlands. In the business sector, however, the elasticities show down- or upward trends after 1988 (in the dynamic Fourier version). This suggests that the differences between the two aggregation methods may be more pronounced when monetary aggregates are calculated at the sectoral level. Generally, our findings throw additional doubt on the use of simple-sum aggregates and call for a disaggregated monetary analysis. 



\section{SUM AND WEIGHTED MONETARY AGGREGATES AS INDICATORS FOR THE NETHERLANDS}

\subsection{Introduction}

At least since the 1970s, the heyday of monetarism, the fact that "money matters" has become incorporated into mainstream macroeconomics. It was generally recognised that shocks to the money supply formed an important - if not the single most important - source of business cycle fluctuations and that excessive money growth caused inflation in the intermediate run. As a consequence, many central banks switched to a policy of targeting growth rates of monetary aggregates to control inflation. Prime examples are the United States, Switzerland and Germany.

As discussed in chapter 4 , over the past years, however, most central banks in the industrialised world have again abandoned monetary targeting although inflation control or even price stability remains their dominant policy objective. Central banks now resort to either manipulating short-term interest rates or direct inflation-targeting through discretionary policy. In this context, the degree of independence and accountability of central banks have become important institutional issues. ${ }^{1}$

An important reason for the current lack of interest in the development of monetary aggregates appears to be the breakdown of money demand functions in many countries. Structural breaks in the trend path of velocity are considered serious impediments to the effective use of monetary targeting. ${ }^{2}$ The observed money demand instabilities are often attributed to the occurrence of innovations in financial markets and to the existence of severe measurement error. Simple-sum aggregates are just not appropriate to measure the flow of monetary services when the component assets of these aggregates are imperfect substitutes (see chapter 5). Such measurement error is especially obvious during periods of financial innovations when the relative moneyness of various financial assets within and outside monetary aggregates is due

1 See Fase (1992), De Long and Summers (1992), and Pollard (1993) for an overvicw and analysis of the relation between central bank independence, inflation and the real economy.

2 See Judd and Scadding (1982), and Boughton (1991 and 1992) for an overview of the literature on money demand instability. Nelson (1994), on the other hand, correctly argues that the ability to exploit the money-income relation for monetary policy is not necessarily destroyed by the nonstationarity of velocity. 
to change. Weighted aggregates that are based on index number theory may be more robust in this respect. Chrystal and MacDonald (1994) provide an extensive crosscountry overview of the relative performance of simple-sum and weighted monetary aggregates as indicators ${ }^{3}$ of future inflation and real growth. Their evidence points to a marginal superiority of weighted aggregates.

Closely related to the observed (imperfect) substitution processes between financial assets are the problems encountered by monetary authorities in defining monetary aggregates properly. This definition issue may be an additional reason for the currendly minor role of monetary aggregates in monetary policy.

In this chapter, we add to the existing literature by presenting new empirical evidence on the relative performance of simple-sum and weighted (Divisia) monetary aggregates in the Netherlands over the period 1965-1993 with quarterly data. At the M2 and harmonised M3 aggregation level, the indicator properties of sum and Divisia money measures are compared, whereas sum M1's behaviour is also analysed. Divisia $M 1$ is not included in the investigation, because the difference with sum M1 is only minor. So far, hardly any work in this direction is done with Dutch data. ${ }^{4}$

Although the results in chapter 5 indicate that a disaggregated monetary analysis may provide better insights into the role of money in the Dutch economy, the present chapter examines money measures only at the aggregate level. The objective in this chapter is to identify whether weighted monetary aggregates are better indicators of inflation and real growth in the Netherlands than sum aggregates. Future research may be concerned with a similar analysis at a disaggregated level. Such a disaggregated investigation may, however, be troublesome, because the implications of the different portfolio behaviour of the business and the household sector are hard to incorporate appropriately into a model of the indicator properties of money measures.

This chapter applies several testing procedures to examine the usefulness of simple-sum and Divisia aggregates as monetary policy indicators in the Netherlands. Following Chrystal and MacDonald (1994), we first use a modified version of the St. Louis equation to investigate the indicator properties of various monetary aggregates. This traditional aggregate spending equation is adopted to test whether monetary aggregates (defined as simple-sum and as Divisia money measures), in addition to government spending and exports of goods and services, contain information about the behaviour of nominal and real income and the price level. Then, cointegration and univariate regression techniques are used to test for causality between money growth, real growth, inflation and interest rates. Short- and long-run dynamic effects between the growth rates of the different monetary aggregates and the other three

3

A good monetary policy indicator should be closely and predictably related to the ultimate target variables of monetary policy, inflation and real growth. Additionally, it may be advantageous if the indicator's value is controllable by the monetary authorities to some extent. Here, we focus on the link between indicator and ultimate target.

4

Fanse (1985 and 1987) is an exception. 
variables can now be examined simultaneously. ${ }^{5}$ Even if monetary aggregates provide no short-run information at all about inflation and/or real growth, there may be a long-run equilibrium relationship between money, real income, prices and interest rates. In addition to these univariate regressions we test for causality in a parsimonious multivariate framework, which takes into account possible correlation between the residuals of the different equations.

Next, the stability of the estimated relations between, on the one hand, the growth of monetary aggregates, and inflation and real growth in the Netherlands, on the other, is investigated. We compare the out-of-sample forecasts of Dutch inflation and real growth using the different monetary aggregates.

The chapter is organised as follows. In section 6.2 we give a short overview of Dutch monetary policy over the past decades. Section 6.3 briefly discusses the data. In the fourth section, we present and discuss the results from the St. Louis equation for Dutch monetary aggregates. In section 6.5 long-run dynamics are also taken into account in the causality test using simple-sum and Divisia monetary aggregates. Section 6.6 presents out-of-sample forecasts of inflation and real growth obtained with the various monetary aggregates. Section 6.7 contains a summary and conclusions.

\subsection{Dutch monetary policy: an overview}

From an institutional point of view, the Dutch central bank (DNB) is not absolutely independent, because the so-called 'Bank-law' points out that the minister of Finance has the right to give directions to DNB with respect to policy. However, exercising this right would entail a very arduous procedure in which the government has to justify its decision to give directions to DNB in parliament. The Dutch minister of Finance has never exercised this right so far. De facto, therefore, the Dutch central bank may be regarded as one of the most independent central banks in the world. Its policy, though taking into account real developments, is primarily oriented at inflation control. Dutch inflation has been among the lowest in the world for many years.

In a small. open economy like the Netherlands, the nominal and real effects of domestic monetary policy, of course, significantly depend on the prevailing exchange rate system. Under the Bretton Woods system of fixed but adjustable exchange rates, domestic output stabilisation was the main internal policy goal for monetary authorities in most countries, including the Netherlands. Stabilisation of the exchange rate of the guilder was achieved by foreign exchange market interventions. The Dutch central bank usually imposed (relatively successfully) direct credit restrictions on the banking system in order to control domestic money creation. Monetary aggregates were used as indicators of real economic growth.

After the breakdown of the Bretton Woods system the guilder entered a period characterised by unstable exchange rates, although the fluctuations with respect to

The St. Louis method only tests for short-run effects of monetary aggregates. 
European currencies were relatively small due to the snake arrangement. Domestic monetary policy in this period was formulated in terms of the planned rate of growth of a broad monetary aggregate (M2). Indirect credit restrictions were used to obtain the target, while the liquidity ratio (defined as the broad money supply (M2) divided by nominal GNP) served as the main policy indicator both for inflation and real growth. Interest rates were not used as policy instruments, but resulted from the policy aimed at stabilising the liquidity ratio (Fase, 1985). A stable liquidity ratio (or, money growth proportional to real economic growth) may be interpreted as an indication of the absence of inflationary pressures caused by monetary policy. However, the Dutch central bank was not very successful in achieving its objectives during the 1970 s. High inflation and low economic growth resulted.

Since the beginning of the European Monetary System in 1979, the Dutch central bank's primary intermediate policy objective has been to keep the exchange rate of the guilder fixed to the German mark by using interest rates. The reason behind this specific policy is that price stability (which by now has become the single domestic monetary policy objective) in a small country like the Netherlands can best be achieved by keeping the exchange rate credibly fixed to the currency of a country where the inflation rate is low (Svensson, 1994).

During the early eighties, DNB has continued to use the liquidity ratio as monetary policy indicator. Recognising the essential endogeneity of the money supply under fixed exchange rates and (almost) perfect capital mobility, DNB initially aimed at restraining the domestic component of M2 through credit controls to support the credibility of the exchange rate policy. Both the increased magnitude of international capital flows and the observed trend breaks in the liquidity ratio in the eighties ${ }^{6}$ have led DNB to give ever more priority to the objective of exchange rate stability per se. See Kool (1995) for a more elaborate overview.

In 1992, the harmonised M3 monetary aggregate was adopted as monetary indicator in the context of the coordination of monetary policy in Europe. This indicator is currently monitored to contribute to the maintenance of the exchange rate of the guilder.

Even though the Dutch money supply is largely endogenous because of the fixed exchange rate, however, it is still possible that Dutch monetary aggregates serve as an indicator of inflation or future economic activity. This may be true, especially because of the Dutch policy of adapting the discount rate almost immediately in response to changes in the German discount rate. In the empirical part, we test for the appropriateness of Dutch simple-sum and Divisia money measures as indicators for real growth and/or inflation in the Netherlands. Short-term interest rates are strongly affected by the discount rate in the Netherlands. Because of this important

6 These two points may be related. In the 1980 s the structure of international financial markets changed markedly. Currency substitution, portfolio adjustments and the liberalization of international capital flows may be determinants of money demand instabilities in the Netherlands. Within the Netherlands, markets for commercial paper (CP) and certificates of deposic (CD) have been introduced in 1986 
role of interest rates in Dutch exchange rate policy, their indicator properties for inflation and real growth are examined as well.

\subsection{Description of the data}

The monetary aggregates (M1, M2, and harmonised $\left.\mathrm{M}_{3}\right)^{7}$ are calculated using quarterly data on monetary asset quantities and their respective user costs in the Netherlands over the period 1962-1993 (harmonised M3: 1970-1993), according to the definitions adopted by the Dutch central bank since 1992. The data sources and the definitions of these aggregates are discussed in section 4.4 .

Furthermore, data on nominal net national income are obtained from DNB's Quarterly Bulletins (table 3.1), and the same source provides data on central government expenditures, the government budget deficit (both in table 5.1) and Dutch exports of goods and services (table 6.2), which are used in the St. Louis equations. The Dutch Consumer Price Index (in the rest of the chapter referred to as CPI, taken from the OECD series in Datastream), with January 1986 as the base, is adopted as the price deflator. Until the third quarter of 1990, the short-term interest rate used in our causality tests is the three month Treasury Bill rate. After that period short-term Treasury Bills have not been issued over the counter anymore. From 1990:4 onwards, the rate on three month local government liabilities is used as the shortterm interest rate. All series are seasonally adjusted before we use them in the empirical part of this chapter.

The Divisia aggregates $\left(Q_{t}\right)$ are constructed according to equation (4.7) with $1962: 1$ as the base quarter for Divisia M2 and 1970:4 as the base for Divisia M3. Opportunity costs (see equation (4.11)) and expenditure shares of the individual asset components of the Divisia aggregates are calculated as in chapter 4.

\footnotetext{
$7 \mathrm{MI}$ and harmonised M3 may be considered weakly separable aggregates from other monetary assets, but M2 shows more wiolations of demand theory. For details on the outcomes, see section 3.4.1.

8 Divisia $\mathrm{Ml}$ is not analysed in this chapter, because the difference between sum and Divigia M1 is minor, due to the constancy of the relative opportunity costs of the two components of M1 (sce also section 4.5.1). Unreported test results, moreover, show that both aggregates behave similarly as monetary indicators.
} 
In periods in which new financial assets are introduced, Fisher's Ideal index $\left(Q_{t}^{F}\right)$ is used instead of the Divisia index. This index is computed with the following equation:

$$
Q_{t}^{F}=Q_{t-1}\left[\frac{\sum_{k=1}^{W} p_{k, t} m_{k, t} \sum_{k=1}^{n} p_{k, t-1} m_{k, t}}{\sum_{k=1}^{n} p_{k, t} m_{k, t-1} \sum_{k=1}^{n} p_{k, t-1} m_{k, t-1}}\right]^{0.5}
$$

where $t$ is a time subscript, $n$ refers to the number of assets before the introduction of new assets and $W$ is the number of assets after this introduction. The Divisia index cannot be used to take into account new assets, because it adds the weighted growth rates of individual financial assets. In the period following the introduction of new assets, we again use the Divisia index (equation (4.7)). Then, $Q_{t-1}$ is replaced by the Fisher index from the previous period $\left(Q_{t-1} F\right)$. With this procedure, new assets can easily be incorporated into the Divisia aggregate time series without causing serious breaks. ${ }^{9}$ As Barnett (1980a and 1981) shows, the difference between the Fisher Ideal index and the Divisia index is only in the third decimal. Both indices belong to the class of superlative indices (see Diewert, 1974).

\subsection{The performance of simple-sum and Divisia aggregates in the $\mathrm{St}$. Louis model}

The Quantity Theory of Money hypothesises a proportional relationship between money growth and inflation in the long run, assuming velocity growth of monetary aggregates and real income growth (or better, potential output growth) are stationary series. In the short run, however, real national income varies considerably, which may be partly caused by money growth. Testing the relation between money growth on the one hand, and real income growth and inflation on the other, may provide useful insights into the role of money in the determination of nominal income.

\subsubsection{The St. Louis modell}

Despite the well-known problems associated with the St. Louis model, we use that simple approach as a first pass through the data to test the indicator properties of different monetary aggregates. The standard equation allows for a straightforward comparison of the relative performance of various simple-sum monetary aggregates

\footnotetext{
9 We also calculated a reservation price for financial innovations in the period prior to their introduction, using Diewert's (1980) approach. However, since the stock of financial innovations is very small relative to the other assets included in the monetary aggregates, this hardly affects the magniude of the Fisher Ideal index. Therefore, we did not include these reservation prices in our computations of the Fisher index.
} 
and its Divisia counterparts in the money/nominal income relationship. More specifically, the St. Louis aggregate spending equation is adopted to test whether monetary aggregates, in addition to government spending and exports of goods and services, contain short-run information about the behaviour of nominal and real income and the price level.

The first difference $(\Delta)$ of the logarithm of nominal national income $(Y)$ is taken as the dependent variable in the simplest form of the St. Louis equation to be tested:

$$
\Delta Y_{i}=c+\sum_{i=0}^{r} \delta_{i} \Delta G_{t-i}+\sum_{i=0}^{s} \omega_{i} \Delta M_{t-i}+\sum_{i=0}^{x} \xi_{i} \Delta X_{t-i}
$$

where $c$ is a constant, $G$ indicates the logarithm of central government expenditures, $M$ refers to the logarithm of the monetary aggregate analysed (which is either a simple-sum or a Divisia measure) and $X$ represents the logarithm of exports of goods and services. ${ }^{10}$ The latter variable is included in the St. Louis equation as a proxy for the openness of the Dutch economy. Equation (6.2) thus amounts to an expression in quarterly growth rates.

The lag lengths $r$ and $s$ are determined in a pre-testing procedure in the following way (Judge et al., 1988). We specify a maximum lag length of 12 quarters for each variable and use an F-test to test the significance of the longest lag included. We start with a test of the null hypothesis $\left(\mathrm{H}_{0}\right)$ that the coefficient $\|$ for the longest lag of a variable (in our test 12 ) is zero. If $\mathrm{H}_{0}$ is not rejected, we assume that it is true in the second test. The second $H_{0}$ is that $\beta_{11}$ is zero, given that $B_{12}$ is zero. The respective null hypotheses are tested until the null hypothesis is rejected for the first time at a 5 $\%$ significance level; this is the lag length adopted in our St. Louis equations. This procedure is repeated for each variable appearing in the St. Louis equations separately, including the dependent variable. Other possible lag-length selection criteria are discussed in Thornton and Batten (1985). They find that the FPE (final prediction error) criterion ${ }^{11}$ performs best in their Granger causality tests between money and nominal income. Since the FPE criterion requires a large number of calculations in the case of more than two variables, we employ the F-test as the lag length selection criterion here. $^{12}$

10 In the tradition of the original St. Louis equation central government expenditures are included in our versions of the model. Of course, it would be better if negative government spending impulses (taxation) were also taken into account. However, unreported experiments show that, if we substitute the government budget deficit for government expenditures, this does not alter the conclusions reached in section 6.4 .2 significantly.

11 The FPE-criterion was introduced by Akaike and later adapted by Hsiao (1979).

12 Additionally, we performed some umeported tests with the FPE criterion indicating that this criterion does not select lag llengths very different fron the ones chosen with our F-test. When standard lag lengths of four quarters are employed for all wariables, the conciusions obtained are not significantly different. 
The relative performance of a simple sum monetary aggregate and its Divisia equivalent in the St. Louis equation is tested in four ways: with a likelihood ratio test ${ }^{13}$, the Davidson and MacKinnon J-test, the Fisher and McAleer JA-test, and an F-test.

The J-test provides t-statistics for the rejection of one model over the other (one monetary aggregate over the other) and vice versa (Davidson and MacKinnon, 1993) and is implemented as follows. First, we estimate the St. Louis equation (6.2) for model 1 (e.g. the model including simple-sum M2 as the money measure, and the other variables from equation (6.2)). Then, the estimated parameters on each of the lags of M2 are used to calculate the fitted value of all lags of M2 together. This fitted value is entered as an additional explanatory variable in the St. Louis equation for the other model (in this example the one including Divisia M2). The null hypothesis is that the parameter $\alpha$ for the fitted value is zero, implying that the model with Divisia M2 is not rejected over the one with sum M2. Analogously, the reverse hypothesis can be tested.

The JA-test involves a testing procedure similar to the one for the J-test. Again, the St. Louis equation (6.2) for model 1 (e.g. sum M2) is estimated and the fitted value of M2 is computed. In the next step, the fitted values of M2 are used as the dependent variable instead of the first difference of nominal income in the St. Louis equation for Divisia M2. A regression of this equation gives the estimated parameters on each of the lags of Divisia M2, which are used to calculate the fitted value of Divisia M2. Finally, this fitted value of Divisia M2 is included as an additional explanatory variable in the conventional St. Louis equation for simple-sum M2. The null hypothesis tested is that the parameter $\alpha$ for the fitted value is zero, implying that the model with sum M2 is not rejected over the one with Divisia M2. The test is symmetrically applied in both directions. Following Chrystal and MacDonall (1994), the t-statistics for the respective parameters for the fitted values are called indeterminate if neither model rejects the other and inconclusive if both specifications reject each other.

An F-test is used to test whether all lags of the monetary aggregate under consideration may be excluded from the specification. It allows for inferences about the importance of each concept of money for the determination of nominal income.

In addition to the tests with the conventional St. Louis equation, we present equivalent test statistics for an extended version of equation (6.2) with lags of the dependent variable included. Since the indicator properties of monetary aggregates can be divided into nominal and real effects, we also employ the St. Louis method with real income growth and inflation as the dependent variable, respectively. The other variables are as defined in equation (6.2), but sometimes with a different number of lags. The subsequent test procedure is identical to the one for nominal income.

13 This is equivalent to the Akaike Information Criterion, since the number of free parameters is the same in the St. Louis equations for the two money measures. 


\subsubsection{Results}

Table 6.1 contains the test results for the St. Louis equation with nominal income growth as the dependent variable. In each equation lags $0-6$ of central government expenditures and lags 0-7 of exports are included, whereas nominal income appears with lags 1-12 if it is added as lagged dependent variable. The number of lags for the monetary aggregate is mentioned in the table. The lag length is the same for a simple sum aggregate and its Divisia equivalent. The sample basically covers the period 1962:1-1993:4 (1970:4-1993:4 for harmonised M3, see section 6.3), but depending on the number of lags included we lose some observations. For M1, we only report the $\log$ likelthood of the model containing simple-sum M1 and the results of the Ftests.

Table 6.1 St. Louis equation: nominal income growth

\begin{tabular}{|c|c|c|c|c|}
\hline $\begin{array}{l}\text { Excl. lagged no- } \\
\text { minal income } \\
\text { (Y) }\end{array}$ & $\begin{array}{l}\text { LR-test: } \\
\text { log likelihood of } \\
\text { sum minus log } \\
\text { lik. of Div. ag- } \\
\text { gregate }\end{array}$ & $\begin{array}{l}\text { J-test } * \\
\alpha \text { for sum ag- } \\
\text { gregate }=0, \alpha \\
\text { for Divisia }=0\end{array}$ & $\begin{array}{l}\text { JA-test*: } \\
\alpha \text { for sum ag- } \\
\text { gregate }=0, \alpha \\
\text { for Divisia }=0\end{array}$ & $\begin{array}{l}\text { F-test: } \\
\text { Exclusion of } \\
\text { sum aggregate } \\
\text { Exclusion of } \\
\text { Divisia aggrega- } \\
\text { te }\end{array}$ \\
\hline M1 (lags 0-9) & 411.25 & - & - & $2.71(0.0059)$ \\
\hline M2 (lags $0-6)$ & $\begin{array}{l}-3.71 \\
\text { favours DM2 }\end{array}$ & $\begin{array}{l}0.16,2.84 \\
\text { favours DM2 }\end{array}$ & $\begin{array}{l}-0.66,1.83 \\
\text { favours } \mathrm{DM} 2\end{array}$ & $\begin{array}{l}1.59(0.1470) \\
2.58(0.0176)\end{array}$ \\
\hline M3 (lags $0-4)$ & $\begin{array}{l}-3.38 \\
\text { favours DM3 }\end{array}$ & $\begin{array}{l}0.19,2.48 \\
\text { fayours DM3 }\end{array}$ & $\begin{array}{l}-0.22,2.10 \\
\text { favours DM3 }\end{array}$ & $\begin{array}{l}2.14(0.0710) \\
3.38(0.0088)\end{array}$ \\
\hline \multicolumn{5}{|l|}{ Incl. lagged $Y$} \\
\hline M1 (lags $0-9$ ) & 450.83 & - & $=$ & $3.08(0.0024)$ \\
\hline M2 (lags 0-6) & $\begin{array}{l}-4.97 \\
\text { favours DM2 }\end{array}$ & $\begin{array}{l}-0.59,3.12 \\
\text { favours DM2 }\end{array}$ & $\begin{array}{l}-1.28,2.37 \\
\text { favours DM2 }\end{array}$ & $\begin{array}{l}0.85(0.5461) \\
1.96(0.0704)\end{array}$ \\
\hline M3 (lags 0-4) & $\begin{array}{l}-8.86 \\
\text { favours DM3 }\end{array}$ & $\begin{array}{l}-1.30,4.15 \\
\text { favours DM3 }\end{array}$ & $\begin{array}{l}-1.57,3.65 \\
\text { favours DM3 }\end{array}$ & $\begin{array}{l}1.09(0.3766) \\
4.14(0.0026)\end{array}$ \\
\hline
\end{tabular}

* The $y$-and JA-test statistics mentioned in the table are t-statistics (at a (wo-tail significance llevel) for the rejection of the Divisia model over the simple-sum model and the reverse rejection. The numbers in parentheses in the last column are probability values.

Both Divisia M2 and Divisia M3 are preferred above their simple-sum counterparts according to all test-statistics in tabie 6.1 .14 When lagged nominal income is excluded, the F-tests show all money measures, except sum M2, to be significant at a $10 \%$ significance level. Only for sum M3 does this significance disappear when

14 This result is in contrast to Fase (1987), who uses a bivariate ARMA model which shows that growth of Divisia aggregates does not cause changes in nominal income in the Netherlands. 
lags of nominal income are included. The sharp drop in significance for the broader sum aggregates (M2 and M3) may be explained by the presence of reverse causation from nominal income to these monetary aggregates. Overall, the M1 aggregate yields the lighest log likelihood.

Similar test results for real income growth are shown in table 6.2. Only contemporaneous government expenditures are included, plus lags $0-4$ for exports and the lag length for the dependent variable is four. As before, lag selection tests are used to determine the optimal lags.

Table 6.2 St. Louis equation: real income growth ${ }^{*}$

\begin{tabular}{|c|c|c|c|c|}
\hline $\begin{array}{l}\text { Excl lagged } \\
\text { real income }\left(Y_{i}\right)\end{array}$ & LR-test & $J$-test & JA-test & F-test \\
\hline M1 (lags 0-4) & 382.72 & 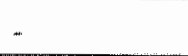 & - & $2.40(0.0415)$ \\
\hline M2 (tags 0-6) & $\begin{array}{l}-3.57 \\
\text { favours DM2 }\end{array}$ & $\begin{array}{l}0.41,2.75 \\
\text { favours DM2 }\end{array}$ & $\begin{array}{l}-0.75,2.48 \\
\text { favours } \mathrm{DM} 2\end{array}$ & $\begin{array}{l}1.35(0.2360) \\
2.36(0.0280)\end{array}$ \\
\hline M3 (lags 0-6) & $\begin{array}{l}-2.33 \\
\text { favours DM3 }\end{array}$ & $\begin{array}{l}0.40,2.40 \\
\text { favours DM3 }\end{array}$ & $\begin{array}{l}-0.48,1.74 \\
\text { favours DM3 }\end{array}$ & $\begin{array}{l}1.28(0.2727) \\
1.92(0.0780)\end{array}$ \\
\hline \multicolumn{5}{|l|}{ Ind lagged $Y_{r}$} \\
\hline M1 (lags 0-4) & 401.15 & - & - & $1.74(0.1317)$ \\
\hline M2 (lags 0-6) & $\begin{array}{l}-1.26 \\
\text { favours DM2 }\end{array}$ & $\begin{array}{l}0.24,1.64 \\
\text { favours DM2 }\end{array}$ & $\begin{array}{l}-0.15,1.39 \\
\text { andeterminate }\end{array}$ & $\begin{array}{l}1.00(0.4355) \\
1.33(0.2432)\end{array}$ \\
\hline M3 (lags 0-6) & $\begin{array}{l}-2.10 \\
\text { favours DM3 }\end{array}$ & $\begin{array}{l}0.36,2.27 \\
\text { favours DM3 }\end{array}$ & $\begin{array}{l}-0.65,1.46 \\
\text { indeterminate }\end{array}$ & $\begin{array}{l}0.81(0.5827) \\
1.34(0.2470)\end{array}$ \\
\hline
\end{tabular}

* See table 6.1 for an explanation of the test-statistics.

In general, Divisia aggregates are seen to outperform the corresponding simple-sum aggregates as indicators of real income growth. In none of the above tests can we decide in favour of a simple-sum aggregate. The JA-test appears to be the least powerful and gives indeterminate results when lagged real income growth is included. The F-tests reveal that $M 1$ and the two Divisia aggregates matter in an equation without lags of real national income, whereas their explanatory power gets insignificant when these lags are included. Tables 6.1 and 6.2 show quite similar results, though the level of significance is mostly higher in table 6.1.

Table 6.3 reports the corresponding test results for the inflation equation. The lag selection test leads us to include lags 0-7 for government expenditures, lags 0-11 for exports and lags 1-10 for inflation itself. The F-tests show that monetary aggregates contain no information about future inflation, with the exception of sum and Divisia M2 when lagged inflation is excluded and of sum M2 when the dependent variable is part of the estimated St. Louis equation. Only sum M2 is clearly preferred to its Divisia alternative. 
The insignificance of most monetary aggregates for the explanation of inflation may be the result of the nearly fixed exchange rate of the guilder, which prevents an independent monetary policy. Additionally, the inclusion of exports of goods and services in the St. Louis equations may prevent a strong impact from monetary aggregates on aggregate spending in the Netherlands. At the M3 level, half of the test statistics give indeterminate results, giving rise to the observation that the difference between these two monetary aggregates in explaining inflation is only marginal.

Table 6.3 St. Louis equation: inflation *

\begin{tabular}{|c|c|c|c|c|}
\hline $\begin{array}{l}\text { Excl. lagged in- } \\
\text { flation }(\pi)\end{array}$ & LR-test & $J$-test & $\int A$-test & F-test \\
\hline MI (lags 0-7) & 448.52 & - & - & $0.60(0.7760)$ \\
\hline M2 (lags 0-7) & $\begin{array}{l}3.77 \\
\text { favours M2 }\end{array}$ & $\begin{array}{l}2.55,0.32 \\
\text { favours } \mathrm{M} 2 \\
\end{array}$ & $\begin{array}{l}2.35,0.03 \\
\text { favours M2 }\end{array}$ & $\begin{array}{l}2.79(0.0085) \\
1.93(0.0652) \\
\end{array}$ \\
\hline M3 (lags 0-7) & $\begin{array}{l}0.77 \\
\text { favours M3 } \\
\end{array}$ & $\begin{array}{l}1.57,0.93 \\
\text { indeterminate } \\
\end{array}$ & $\begin{array}{l}0.46,-0.1 \mathrm{j} \\
\text { indeterminate }\end{array}$ & $\begin{array}{l}1.19(0.32117) \\
1.04(0.4197) \\
\end{array}$ \\
\hline \multicolumn{5}{|l|}{ Incl. lagged $\pi$} \\
\hline M1 (lags 0-7) & 455.11 & - & - & $0.37(0.9325)$ \\
\hline M2 (lags 0-7) & $\begin{array}{l}4.25 \\
\text { favours M2 }\end{array}$ & $\begin{array}{l}2.56,-0.04 \\
\text { lavours M2 } \\
\end{array}$ & $\begin{array}{l}2.26,-0.37 \\
\text { favours } \mathrm{M} 2 \\
\end{array}$ & $\begin{array}{l}2.33(0.0268) \\
1.49(0.1760) \\
\end{array}$ \\
\hline M3 (lags 0-7) & $\begin{array}{l}3.32 \\
\text { favours M3 }\end{array}$ & $\begin{array}{l}2.47,0.33 \\
\text { favours M3 }\end{array}$ & $\begin{array}{l}1.00,-0.85 \\
\text { indeterminate }\end{array}$ & $\begin{array}{l}1.27(0.2805) \\
0.70(0.6862)\end{array}$ \\
\hline
\end{tabular}

* See table 6.1 for an explanation of the test-statistics.

The results for inflation are consistent with those for nominal and real income growth presented above. Monetary aggregates, except sum M2, contain no additional information about future inflation in the Netherlands when exports of goods and services are also taken into account. M1 and the two Divisia measures do have a role as indicators of real income growth when the dependent variable is excluded from the analysis. In combination, the results suggest that the monetary aggregates" impact on real income growth dominates their effect on inflation, since nominal income growth also appears to be explained well by M1, Divisia M2 and Divisia M3. The outcomes in tables 6.1 through 6.3 indicate that shocks to the growth rate of (especially the latter three) monetary aggregates have a significant effect on nominal income growth, but their impact on real income growth and inflation is much weaker. This suggestis that monetary shocks have a time-varying impact on real growth and inflation, whine the total effect of money growth on nominal income growth is more stable over time. Income velocity of sum M1, Divisia M2 and Divisia M3 may, therefore, be relatively stable (see also section 4.5.2). The general impression arising from tables 6.1 through 6.3 is that the JA-test only has low discriminatory power in many instances. 
The likelihood ratio test and the $J$-test, however, can be adopted to draw some inferences about the relative performance of simple sum and Divisia aggregates.

\subsection{Causality tests and long-run dynamics}

In this section, we modify the pure aggregate spending analysis of the St. Louis model. Abstracting from the influence of exports on the Dutch economy we further investigate the causality between money (defined either as simple-sum or Divisia aggregates), prices, income and interest rates. Explicit account is taken of both shortrun and long-run dynamic characteristics of the data, in contrast to the St. Louis model, which focuses on short-run relations only. Interest rates are included in the analysis for their important role in Dutch exchange rate policy. The Dutch central bank can control short-term interest rates to some extent with the discount rate. If short interest rates are also closely related to the state of the economy, they may serve as an alternative indicator of future inflation or real growth in the Netherlands. If, e.g. the German Bundesbank raises the discount rate because of inflationary pressures, the Dutch discount rate will usually be raised as well. Short interest rates in the Netherlands are also likely to rise. In turn, these higher interest rates may lead to less inflation in the future, which explains why interest rates may be used as indicator variables. Section 6.5 .1 contains the unit root and cointegration tests, which are needed for the causality tests in section 6.5.2. Sub-period results for the sample 1979-1993 are presented in section 6.5.3.

\subsubsection{Unit root and cointegration tests}

To investigate the (short-run) causal relations between the monetary and the real sector of the economy, we have to take into account the time series properties of the individual variables and any long-run relationships between them. First, the variables in the causality vectors should be stationary. Furthermore, a test on cointegration between the variables should determine whether any error correction terms have to be added to the causality vectors in order to incorporate some longer run information that is present in the variables.

The stationarity of the variables included in the causality tests is examined by testing for unit roots in each variable separately, using the ADF-statistic (see Dickey and Fuller, 1979). The results from these tests are also used to decide on the correct order of differencing of the variables in the cointegration tests. Specifically, the following regression is estimated for the variables in the causality vectors:

$$
\Delta x_{t}=\mu+\rho T+\pi x_{t-1}+\sum_{i=1}^{q} \gamma_{i} \Delta x_{i-i}+u_{t}
$$

where $x$ is the variable under consideration, $\mu$ is a constant, $T$ is a time trend and $u$ denotes the error term. With this representation the unit root test is a t-test of the null hypothesis $\pi=0$, whereas the alternative hypothesis of stationarity implies that $\pi$ is 
significantly negative. The lag length $q$ of the first difference of the dependent variable is chosen such that the error terms are serially uncorrelated. Starting with a lag length $q$ of four for the first differences of all variables we reduce the number of lags by deleting insignificant lags. Table 6.4 shows the estimated $t$-statistics for the coefficient $\pi$ in equation (6.3) and whether a variable is stationary in levels, in first or in second differences. All variables, except the interest rate, are in natural logarithms and the number of lags $q$ is given in parentheses. Critical values for a unit root test including a trend term are taken from Fuller (1976).

Table 6.4 Unit root tests (i-statistics on $\pi=0$ ) including time trend

\begin{tabular}{|l|l|l|l|}
\hline & Levels & $\begin{array}{l}\text { First dif- } \\
\text { ference }\end{array}$ & $\begin{array}{l}\text { Second dif- } \\
\text { ference }\end{array}$ \\
\hline $\begin{array}{l}\text { Short interest rate } \\
(3)\end{array}$ & $-3.48^{*}$ & $-5.55^{* *}$ & $-8.94^{* *}$ \\
\hline CPI (4) & -0.79 & $-3.04^{*}$ & $-8.02^{* *}$ \\
\hline Real income (2) & -2.17 & $-6.53^{* *}$ & $-11.89^{* *}$ \\
\hline Sum M1 (4) & -1.57 & $-4.76^{* *}$ & $-6.86^{* *}$ \\
\hline Sum M2 (4) & -1.17 & $-3.88^{* *}$ & $-6.43^{* *}$ \\
\hline Divisia M2 (3) & -0.27 & $-3.65^{* *}$ & $-11.49^{* *}$ \\
\hline Sum M3 (3) & -2.22 & $-3.47^{* *}$ & $-9.09^{* *}$ \\
\hline Divisia M3 (3) & -2.52 & $-3.27^{*}$ & $-9.50^{* *}$ \\
\hline
\end{tabular}

* silgnificant at the $10 \%$ level

* significant at the $5 \%$ level

Only the short-term interest rate is stationary in levels. At the $10 \%$ significance level, all other variables contain a unit root. The Dutch CPI and harmonised Divisia M3 are borderline cases. Depending on the significance level used, they may be classified as either I(1) or I(2). Chrystal and MacDonald (1994) obtain similar results for other countries. We assume these series to be I(1) from now on. 
Next, we focus on the existence of cointegrating vectors among real national income, the price deflator, a monetary aggregate (all in logarithms), and the level of the short-term interest rate. In total, we have to analyse the cointegrating properties for five cases (since we distinguish five money measures). The variables appearing in the respective vectors should be I(1) or $\mathbb{I}(0)$ processes (see Johansen, 1988 and 1991 and Johansen and Juselius, 1990). According to table 6.4, this condition is marginally fulfilled (at the $10 \%$ significance level). The presence of any cointegration vectors among the four variables in the analysis is determined with a multivariate version of equation (6.3):

$$
\Delta X_{t}=\mu+\Pi X_{t-h}+\sum_{i=1}^{h-1} \Gamma_{i} \Delta X_{t-i}+\varepsilon_{i}
$$

where all symbols are as defined in equation (6.3) and $h$ indicates the lag length in the Vector Auto Regression (VAR) system for the levels of the four variables. $\Gamma_{i}$ and $\Pi$ are matrices of coefficients on, respectively, the first differences and the levels of the variables appearing in $X_{t}$. The matrix $\Pi$ contains information about the cointegration between the four variables in the vector $X_{t}$. Since all variables in $X_{t}$ are integrated of order 1 or less, equation (6.4) can only be stationary if the components of $\Pi X_{t-h}$ are stationary. Therefore, we need to know the rank (r) of the matrix $\Pi$. When the rank is zero, equation (6.4) reduces to a VAR in first differences and no series in $X_{t}$ can be written as a linear combination of the other series, indicating that there is no long-run relationship between the four variables. If, however, $r$ is equal. to $n$ (the number of series in $X_{t}$ ) a VAR analysis in levels is appropriate. If $0<\mathbb{}$ " $<$ n there are ( $\mathrm{n} \times \mathrm{r}$ ) matrices $\alpha$ and $\beta$ such that $\Pi=\alpha \beta$ '. For $\mathbb{I} X_{t-h}$ to be stationary there must be vectors $B^{\prime} X_{t-h}$. The matrix $B$ contains the cointegrating vectors and $\alpha$ contains the adjustment vectors (or error-correction terms).

The test statistics used to evaluate the number of cointegrating vectors are the trace statistic which tests the null hypothesis that there are at most $r$ cointegrating relationships against the alternative of $n(=4)$ vectors, and the maximum eigenvalue test statistic $\left(\lambda_{\max }\right)$ which tests the null hypothesis of $r$ cointegrating vectors against the alternative of $r+1$ vectors.

Table 6.5 gives the results of the Johansen-Juselius (1990) test on cointegration for the sample 1965:1-1993:4, using $h=4$. Critical values are taken from Osterwald-Lenum (1992). We conclude that, in the five cases analysed, either one or two cointegrating vectors exist that have to be incorporated in the causality tests. 
Table 6.5 Trace and $\lambda_{\max }$ statistics (M1, M2: 1965:1-1993:4; M3: 1972:4-1993:4)

\begin{tabular}{|c|c|c|c|c|c|c|}
\hline \multicolumn{7}{|c|}{ Trace } \\
\hline $\begin{array}{l}\text { Null hypo- } \\
\text { thesis }\end{array}$ & $\begin{array}{l}5 \% \\
\text { crifical } \\
\text { value }\end{array}$ & Sum MI & Sum M2 & Div. M2 & $\begin{array}{l}\text { Sum } \\
\text { My }\end{array}$ & Div. M3 \\
\hline $\mathbf{r} \leq 3$ & 9.24 & 0.25 & 0.00 & 0.04 & 1.09 & 0.57 \\
\hline$r \leq 2$ & 19.96 & 11.04 & 10.49 & 12.31 & 9.07 & 9.20 \\
\hline$r \leq 1$ & 34.91 & $37.22^{*}$ & $35.85^{*}$ & $41.63^{*}$ & 21.05 & 21.45 \\
\hline$r=0$ & 53.12 & $71.40^{*}$ & $66.14^{*}$ & $74.89 *$ & $64.77 *$ & $65.16 \%$ \\
\hline \multicolumn{7}{|c|}{$\lambda_{\max }$} \\
\hline $\begin{array}{l}\text { Null by- } \\
\text { pothesis }\end{array}$ & $\begin{array}{l}5 \% \\
\text { critical } \\
\text { value } \\
\end{array}$ & Sum Ml & Sum M2 & Div. M2 & $\begin{array}{l}\text { Sum } \\
\mathrm{M} 3\end{array}$ & Div. M3 \\
\hline$r=3 ? r=4$ & 9.24 & 0.25 & 0.00 & 0.04 & 1.09 & 0.57 \\
\hline$r=2 ? r=3$ & 15.67 & 10.79 & 10.49 & 12.27 & 7.98 & 8.63 \\
\hline$r=1 ? r=2$ & 22.00 & $26.18^{*}$ & $25.36^{*}$ & $29.32^{*}$ & 11.97 & 12.26 \\
\hline$r=0 ? r=1$ & 28.14 & $34.18 \%$ & $30.29 *$ & $33.26 *$ & $43.73^{*}$ & $43.71 *$ \\
\hline
\end{tabular}

* significant at 5 level

\subsubsection{Causality test results, 1965-1993}

The Granger causality tests are carried out with a vector consisting of real national income growth, inflation, the growth rate of a monetary aggregate, and the shortterm interest rate. In this set-up, the monetary effects on real income growth and inflation can be examined separately. Short- and long-run dynamics are incorporated in the following causality analysis.

In the previous section evidence in favour of one or two cointegrating vectors was found. In the case of only one cointegrating vector this vector is determined by regressing the level of one variable (the short-term interest rate, the natural logarithm of real income, of the CPI or of a monetary aggregate) on a constant and the levels of the other three variables. Next, the resulting vector is tested for stationarity. If there are two cointegrating vectors the same procedure is performed with one linear restriction imposed on each cointegrating vector (see Rasche, 1994). The resulting cointegrating vectors may for example be interpreted as money demand relations in which the price or income elasticity is close to one. Alternatively, such vectors may indicate the long-run determination of the interest rate, the price level or real income by the other variables. E.g. the interest rate may depend negatively on the money stock and positively on real income and the price level. The latter relation may be interpreted as an implicit reaction function of the monetary authorities who raise the discount rate (which is usually followed by an increase in short-term interest rates) in 
response to higher prices. At the M2 and harmonised M3 aggregation levels we find small differences between the cointegration vectors corresponding to simple-sum or Divisia aggregates. The residuals from the cointegration vector(s) reflect the (meanreverting) deviation from long-run equilibrium and are incorporated in the causality analysis.

We use the results of the unit root tests to make sure that all variables in the causality vectors are stationary; consequently, real income growth, inflation, growth of a monetary aggregate and the short-term interest rate level are included in the causality vector. Causality then is analysed by testing the null hypothesis that all lags of a variable can be excluded from the regression. The variance-covariance matrix of the estimated coefficients is adjusted for heteroskedasticity. Linear Wald statistics, which have a central chi-squared distribution, are presented in table 6.6 , with pvalues in parentheses. ${ }^{15}$ Additionally, variables can have a long-run effect through the error-correction (ECM) terms. Because the error correction mechanisms differ only because of the different monetary aggregates included, variation in their significance may be attributed to the monetary aggregates used. Table 6.6 also gives Waldstatistics and p-values for the exclusion of the ECMs. Our interest is mainly in the relative performance of simple-sum and Divisia monetary aggregates as indicators of monetary policy, and in the interest rate's performance.

The information in table 6.6 is not directly comparable with our findings from the St. Louis equations, since the latter include exports and government expenditures, whereas the causality regressions consist of the four variables mentioned in the former paragraph and one or two error-correction terms. In table 6.6, no monetary aggregate appears to have a significant short-run impact on the future consumer price level in the Netherlands at a $10 \%$ confidence level. Only M1 and Divisia M2 affect inflation via the error correction terms in a marginally significant way. Real income is well explained by Divisia M3 in the short-run, and by M1 and the two Divisia indices through their error-correcting mechanisms.

Monetary aggregates, except M1, are only affected by short-run variables, and not by the error-correction terms. Especially lagged money growth, the short-term interest rate and the inflation rate have a significant impact on the monetary aggregates' growth rates, although these factors do not significantly influence all five aggregates. Money growth is not significantly affected by real income growth.

Interest rates, on the one hand, and M1 and Divisia M2 on the other, appear to be closely interrelated. Short-term interest rates are influenced by growth in the monetary aggregates, with sum M2 growth as the exception, and also by the error-correction terms for all money measures. The Divisia aggregates have a more significant influence on the short interest rate than their sum equivalents.

15 The interest rate is indicated by $R, Y_{r}$ means real national income, $P$ is the consumer price deflam tor, ECM is the error-correction term, sum aggregates are abbreviated as SM2, e.g., and Divisia aggregates as DM2. The Wald statistics for the ECMs are the result of a test of the joint significance of either one or two cointegrating vectors, depending on the number of cointegrating vectors for the respective monetary aggregates. 
Table 6.6 Exclusion tests in causality regressions (M1 and M2: 1965:1-1993:4; M3: 1972:4$1993.4)^{*}$

\begin{tabular}{|c|c|c|c|c|}
\hline & $\mathrm{Y}_{\mathrm{r}}$ & SMI & $\mathbb{P}$ & $\mathbb{R}$ \\
\hline $\mathrm{SMI}$ & $8.52(0.1297)$ & $18.59(0.0009)$ & $6.08(0.6379)$ & $93.19(0.0000)$ \\
\hline $\mathrm{Y}_{\mathrm{r}}$ & $41.76(0.0000)$ & $0.35(0.5543)$ & $70.08(0.0000)$ & $0.87(0.6476)$ \\
\hline $\mathrm{p}$ & $106.97(0.0000)$ & - & $85.09(0.0000)$ & - \\
\hline $\mathbf{R}$ & $12.84(0.0016)$ & $58.25(0.0000)$ & - & $45.83(0.0000)$ \\
\hline \multirow[t]{2}{*}{$\mathrm{ECM}$} & $9.20(0.0100)$ & $4.96(0.0836)$ & $4.64(0.0981)$ & $12.63(0.0018)$ \\
\hline & $\mathrm{Y}_{\mathrm{r}}$ & $\mathrm{SM} 2$ & $\mathbb{P}$ & $\mathbb{R}$ \\
\hline $5 \mathrm{M} 2$ & $4.45(0.7270)$ & $25.50(0.0013)$ & $8.82(0.3576)$ & $8.32(0.3053)$ \\
\hline$Y_{\mathbb{I}}$ & $41.99(0.0000)$ & $1.08(0.2979)$ & $51.70(0.0000)$ & $0.26(0.8773)$ \\
\hline $\mathrm{P}$ & $97.19(0.0000)$ & $15.30(0.0536)$ & $79.43(0.0000)$ & - \\
\hline $\mathrm{R}$ & $8.04(0.0179)$ & $7.27(0.1225)$ & - & $131.86(0.0000)$ \\
\hline \multirow[t]{2}{*}{$\mathrm{ECM}$} & $3.83(0.1476)$ & $2.07(0.3549)$ & $3.92(0.1412)$ & $6.86(0.0324)$ \\
\hline & $\mathrm{Y}_{\mathrm{r}}$ & DM2 & $\mathrm{P}$ & $\mathrm{R}$ \\
\hline DM2 & $5.71(0.5745)$ & $34.39(0.0000)$ & $9.65(0.2904)$ & $16.17(0.0236)$ \\
\hline $\mathrm{Y}_{\mathrm{r}}$ & $39.87(0.0000)$ & $1.67(0.1967)$ & $56.27(0.0000)$ & $0.35(0.8386)$ \\
\hline $\mathrm{p}$ & $94.52(0.0000)$ & $14.77(0.0638)$ & $74.75(0.0000)$ & - \\
\hline $\mathrm{R}$ & $10.17(0.0062)$ & $9.92(0.0418)$ & - & $57.53(0.0000)$ \\
\hline \multirow[t]{2}{*}{$\mathrm{ECM}$} & $6.49(0.0390)$ & $2.88(0.2370)$ & $4.60(0.1002)$ & $11.94(0.0025)$ \\
\hline & $Y_{r}$ & SM3 & $\mathrm{P}$ & $\mathrm{R}$ \\
\hline SM3 & $8.36(0.3018)$ & $22.50(0.0010)$ & $4.27(0.8316)$ & $10.33(0.0665)$ \\
\hline $\mathrm{Y}_{\mathrm{t}}$ & $43.68(0.0000)$ & $11.85(0.2955)$ & $134.25(0.0000)$ & $0.36(0.5485)$ \\
\hline $\mathrm{P}$ & $13.24(0.0003)$ & $21.39(0.0062)$ & $313.16(0.0000)$ & $16.11(0.0132)$ \\
\hline $\mathrm{R}$ & $15.43(0.0004)$ & $3.06(0.5484)$ & $\sim$ & $139.82(0.0000)$ \\
\hline $\mathrm{ECM}$ & $1.16(0.2808)$ & $0.09(0.7601)$ & $0.69(0.4073)$ & $5.43(0.0198)$ \\
\hline
\end{tabular}


Table 6.6 (continued)

\begin{tabular}{|l|l|l|l|l|}
\hline & $Y_{\mathrm{r}}$ & $\mathrm{DM}$ & $\mathrm{P}$ & $\mathrm{R}$ \\
\hline DM3 & $15.74(0.0276)$ & $19.09(0.0040)$ & $6.02(0.6455)$ & $17.72(0.0033)$ \\
\hline$Y_{r}$ & $50.43(0.0000)$ & $11.89(0.2922)$ & $137.60(0.0000)$ & $3.05(0.0809)$ \\
\hline $\mathrm{P}$ & $17.84(0.0000)$ & $21.89(0.0051)$ & $283.85(0.0000)$ & $25.95(0.0002)$ \\
\hline $\mathbb{R}$ & $15.86(0.0004)$ & & & $170.08(0.0000)$ \\
\hline ECM & $3.59(0.0583)$ & $0.02(0.8759)$ & $1.23(0.2669)$ & $5.55(0.0184)$ \\
\hline
\end{tabular}

* Column headings indicate the dependent variable. Entries are Wald statistics with probability values in parentheses. The symbol "-" indicates that lags of this variable are not included in the regression because of insignificance.

Most variables are primarily explained by their own past. The differences in indicator properties of the five aggregates are relatively small. Overall, the error-correction term is significant in about $50 \%$ of the regressions. Real income growth has a direct impact on its own future and on inflation, no matter which monetary aggregate is used as money measure. No lags of the interest rate are included in the causality regressions for inflation, because these lags turn out to be insignificant; the same applies to lagged inflation in the regressions for the interest rate at the $\mathrm{M} 1$ and $\mathrm{M} 2$ level.

The same causality tests are performed in a parsimonious multivariate framework, in which correlation between the residuals of the equations explaining the dependent variables' behaviour is taken into account. The main differences with the test results for the univariate regressions are that sum and Divisia M2 growth now show significant short-run explanatory power for inflation (compare table 6.3), whereas sum M1 and Divisia M3 are marginally significant in this respect. In addition, inflation is significantly influenced by $\mathrm{M} 1$ and the two M2 money measures via the error-correction terms. Sum M1 and Divisia M3 appear to have a significant short-run impact on real income (in line with the results in the upper half of table 6.2). Finally, all aggregates, except sum M3, affect real income via their error-correction terms.

\subsubsection{Causality test results, 1979-1993}

Since 1979 the European Monetary System, in which the exchange rate between guilder and mark has been almost completely fixed, has been operating. Moreover, capital mobility in the eighties was considerably higher than in the decades before. Therefore, we now investigate the stability of our previous results by re-estimating the causality relations between money, prices, income and interest rates over the period 1979-1993. The number of lags chosen for the variables is determined by the lag selection criterion explained before. Table 6.7 shows that there is again evidence of one or two cointegrating relationships for the five vectors of four variables. For most individual nonetary aggregates the number of cointegrating vectors over the subsample is, however, different from the number over the total sample (compare 
tables 6.5 and 6.7 ). This also suggests that the causality relations over the two samples are different.

Table 6.7 Trace and $\lambda_{\max }$ statistics (subsample: 1979:4-1993:4)"

\begin{tabular}{|l|l|l|l|l|}
\hline \multicolumn{5}{|c|}{ Trace } \\
\hline Sum M1 & Sum M2 & Div. M2 & Sum M3 & Div. M3 \\
\hline 0.21 & 0.26 & 0.00 & 0.37 & 0.88 \\
\hline 12.23 & 9.62 & 10.12 & 9.68 & 10.62 \\
\hline $44.03^{*}$ & 29.74 & 34.43 & 34.48 & 34.78 \\
\hline $92.00^{*}$ & $72.52^{*}$ & $64.35^{*}$ & $74.21^{*}$ & $76.73^{*}$ \\
\hline & & $\lambda_{\max }$ & & \\
\hline Sum M1 & Sum M2 & Div. M2 & Sum M3 & Div. M3 \\
\hline 0.21 & 0.26 & 0.00 & 0.37 & 0.88 \\
\hline 12.02 & 9.36 & 10.12 & 9.30 & 9.74 \\
\hline $31.80^{*}$ & 20.12 & $24.30^{*}$ & $24.80^{*}$ & $24.16^{*}$ \\
\hline $47.96^{*}$ & $42.78^{*}$ & $29.92^{*}$ & $39.72^{*}$ & $41.95^{*}$ \\
\hline
\end{tabular}

* For an explamation of the respective test statistics and critical values, see table 6.5 .

Table 6.8 Chow test on stability of cointegration vector over full sample

\begin{tabular}{|l|l|}
\hline Monetary aggregate & Chow test $1979: 4^{*}$ \\
\hline Sum M1 & $50.16(0.0000)$ \\
\hline Sum M2 & $64.89(0.0000)$ \\
\hline Divisia M2 & $59.82(0.0000)$ \\
\hline Sum M3 & $111.81(0.0000)$ \\
\hline Divisia M3 & $9.36(0.0000)$ \\
\hline
\end{tabular}

* F-statistics on structural break in 1979:4 with probability values in partentheses.

In addition, table 6.8 shows the results of Chow tests on the stability of the estinated cointegration vectors over the full sample. For each monetary aggregate the stability of one vector is analysed. We test whether there is a structural break in these vectors in 1979:4. It appears that stability of the estimated cointegration vectors over the full sample must be rejected and that the causality relations should be reestimated over the sample 1979:4 1993:4 for all monetary aggregates.

The causality test results in table 6.9 are, indeed, different from the ones obtained for the larger sample. Again, however, in about half of the number of regressions over 
the EMS-period there is evidence of the cointegrating vectors affecting the short-run dynamics between the four variables.

Table 6.9 Exclusion tests in causality regressions (1979:4-1993:4)*

\begin{tabular}{|c|c|c|c|c|}
\hline & $Y_{r}$ & $\mathrm{SMI}$ & $\mathrm{P}$ & $\mathrm{R}$ \\
\hline SMI & $15.71(0.0279)$ & $11.20(0.0244)$ & $23.36(0.0095)$ & $37.18(0.0001)$ \\
\hline$Y_{f}$ & $41.43(0.0000)$ & $7.71(0.1732)$ & $61.15(0.0000)$ & $19.47(0.0347)$ \\
\hline$P$ & $20.76(0.0000)$ & $26.15(0.0001)$ & $86.71(0.0000)$ & $13.33(0.2060)$ \\
\hline $\mathrm{R}$ & $0.06(0.8131)$ & $70.56(0.0000)$ & $5.99(0.0144)$ & $45.44(0.0000)$ \\
\hline \multirow[t]{2}{*}{ ECM } & $11.40(0.0033)$ & $8.61(0.0135)$ & $11.71(0.0029)$ & $2.92(0.2325)$ \\
\hline & $\mathrm{Y}_{\mathrm{r}}$ & $5 \mathrm{M} 2$ & $\mathrm{p}$ & $\mathrm{R}$ \\
\hline SM2 & $7.90(0.3419)$ & $22.00(0.0025)$ & $3.35(0.3406)$ & $5.66(0.2258)$ \\
\hline$Y_{i}$ & $28.73(0.0000)$ & $2.88(0.7180)$ & $62.12(0.0000)$ & $18.22(0.0514)$ \\
\hline $\mathrm{P}$ & $41.74(0.0000)$ & $4.18(0.5238)$ & $88.60(0.0000)$ & $9.21(0.5122)$ \\
\hline $\mathrm{R}$ & $6.55(0.0105)$ & $6.67(0.1544)$ & $4.61(0.0318)$ & $45.46(0.0000)$ \\
\hline \multirow[t]{2}{*}{$\mathrm{ECM}$} & $0.57(0.4503)$ & $0.04(0.8478)$ & $0.19(0.6630)$ & $3.40(0.0652)$ \\
\hline & $\mathrm{Y}_{\mathrm{r}}$ & $D M 2$ & $\mathrm{P}$ & $\mathbb{R}$ \\
\hline DM2 & $33.74(0.0000)$ & $11.78(0.0190)$ & $17.96(0.0216)$ & $3.51(0.4757)$ \\
\hline$Y_{r}$ & $50.33(0.0000)$ & $15.46(0.0791)$ & $89.69(0.0000)$ & $14.75(0.1415)$ \\
\hline $\mathrm{P}$ & $49.33(0.0000)$ & $13.70(0.0177)$ & $82.54(0.0000)$ & $19.51(0.0343)$ \\
\hline $\mathrm{R}$ & $4.94(0.0262)$ & $14.27(0.0065)$ & $0.01(0.9067)$ & $13.14(0.1072)$ \\
\hline \multirow[t]{2}{*}{ ECM } & $15.10(0.0001)$ & $0.03,(0.8669)$ & $6.69(0.0097)$ & $0.05(0.8305)$ \\
\hline & $\mathrm{Y}_{\mathrm{T}}$ & SM3 & $\mathrm{P}$ & $\mathrm{R}$ \\
\hline SM3 & $3.75(0.8086)$ & $33.28(0.0000)$ & $13.15(0.1067)$ & $17.96(0.0356)$ \\
\hline $\mathrm{Y}_{\mathrm{U}}$ & $30.22(0.0000)$ & - & $94.11(0.0000)$ & $21.29(0.0192)$ \\
\hline$p$ & $38.36(0.0000)$ & $17.25(0.0277)$ & $109.34(0.0000)$ & $12.82(0.1710)$ \\
\hline $\mathbf{R}$ & $3.88(0.0489)$ & $4.81(0.3070)$ & $4.89(0.0270)$ & $35.35(0.0000)$ \\
\hline $\mathrm{ECM}$ & $6.72(0.0347)$ & $1.87(0.3922)$ & $12.18(0.0023)$ & $4.08(0.1301)$ \\
\hline
\end{tabular}


Table 6.9 (continued)

\begin{tabular}{|l|l|l|l|l|}
\hline & $Y_{r}$ & $D M 3$ & $P$ & $R$ \\
\hline$D M 3$ & $5.83(0.5593)$ & $18.51(0.0099)$ & $20.39(0.0001)$ & $13.26(0.2094)$ \\
\hline$Y_{r}$ & $34.49(0.0000)$ & $5.94(0.4298)$ & $113.41(0.0000)$ & $19.41(0.0354)$ \\
\hline$P$ & $35.66(0.0000)$ & $22.87(0.0004)$ & $83.84(0.0000)$ & $6.35(0.7854)$ \\
\hline$R$ & $1.53(0.2163)$ & $14.07(0.0071)$ & $12.06(0.0005)$ & $31.24(0.0001)$ \\
\hline$E C M$ & $8.25(0.0161)$ & $1.49(0.4737)$ & $12.80(0.0017)$ & $6.77(0.0338)$ \\
\hline
\end{tabular}

* See table 6.6 for an explanation of the lay-out and symbols of this table.

As in the whole sample, lags of the dependent variable are highly significant in explaining each variable's behaviour, with the exception of a marginally significant short-term interest rate when Divisia M2 is used as the money measure.

Table 6.9 shows that the growth rates of sum M1 and Divisia M2 have significant short-run explanatory power for real income growth. Via the error-correction terms real income is affected by all monetary aggregates, except sum M2. Growth rates of M1 and the Divisia monetary aggregates now are highly significant in the inflation equations as well, both in the short-run and through their cointegrating vectors (sum M3 growth also affects inflation in a significant way via its error-correction term and marginally in the short-run). In general, Divisia measures outperform their simplesum equivalents in this respect. Thus the evidence may be interpreted as being in favour of the use of Divisia monetary aggregates as indicators of inflation. In this respect, the behaviour of the Divisia indices is quite similar to Ml's performance. This might suggest that the non-M1 components included in the broader Divisia aggregates provide only a small amount of monetary services, and that the monetary service flow from the $\mathrm{M} 1$ components dominates them (see the discussion in section 4.5.1).

Table 6.10 Summary statistics for quarterly growth rates of monetary aggregates (1979:41993:4)

\begin{tabular}{|l|l|l|}
\hline & Mean & Standard deviation \\
\hline Sum M1 & 0.0152 & 0.0206 \\
\hline Divisia M2 & 0.0176 & 0.0197 \\
\hline Divisia M3 & 0.0158 & 0.0113 \\
\hline
\end{tabular}

On average, however, the growth rates of the broader Divisia aggregates have been slightly higher, but less volatile than M1"s growth rate over the EMS-period, as table 6.10 shows. Apparently, changes in the stocks and in the degrees of moneyness of the non-M1 components have contributed to the observed time-paths of Divisia money measures. As mentioned in section 4.5.1, the non-M1 components (which possess some degree of moneyness) have been responsible for most of the growth in 
the broad simple-sum aggregates in the Netherlands. This explains why the Divisia M2 and Divisia M3 aggregates have grown at a higher rate than sum M1. It also indicates that a monetary aggregate consisting solely of the M1 components currency and demand deposits does not measure the total flow of monetary services appropriately. Over time then, M1 underestimates the growth and overstates the variation of the monetary service flow in the economy. Nevertheless, the test results in table 6.8 show that the MI components are the main sources of liquidity in the Netherlands, and that they are important determinants of inflation.

The short-term interest rate is affected by several of the other variables included in the causality tests, depending on the money measure used. The sum M3 aggregate and M1 do affect the interest rate directly, whereas sum M2 and Divisia M3 exert their influence on the interest rate only via the error-correction terms. The interest rate has a direct impact on real income growth in all equations, except the ones where M1 and Divisia M3 are the monetary aggregates. In addition, the cointegrating vectors are significant in explaining real income growth in all cases, except with sum M2. It appears that the interest rate now explains inflation, either via its short-run effect or via the error-correction term, in contrast to the total sample results. This may indicate that the interest rate has become a useful indicator of inflation since the beginning of the EMS-period. When inflationary expectations rise, short-term interest rates also tend to go up through the Fisher effect. Together with the central bank's policy of using the discount rate to stabilise the exchange rate of the guilder this may explain why short-term interest rates are closely related to inflation. Finally, we can also detect a significant effect of the interest rate on all money measures, except surm $\mathrm{M} 2$ and sum M3.

In addition to the univariate causality tests performed before, table 6.11 presents the results of exclusion tests when the four dependent variables are estimated with a VAR system in which possible correlation between the residuals of the different equations is taken into account. In order to arrive at a parsimonious VAR system we use the results of the univariate regressions to ensure that only lags of the different variables with a t-statistic larger than one are included in the VAR regressions. Of course, this leads to a bias of rejecting the null hypothesis that all lags of a certain variable can be excluded from the regression. Most results of the exclusion tests appear to be significantly different from zero.

An important difference with the univariate test results is that the error-correction terms are now significant in all regressions, except in the inflation equation with surn M2 as the money measure. Furthermore, all monetary aggregates, except sum M3, now turn out to be good indicators of real income growth via the short-run (all errorcorrection terms for real growth are significant as well). Inflation is significantly influenced by all aggregates, except sum M2. Overall, the indicator properties of the respective monetary aggregates are very similar in this VAR system; only sum M2 appears unfit as indicator of inflation. 
SUM AND WEIGHTED MONETARY AGGREGATES AS INDICATORS FOR THE NETHERLANDS

Table 6.11 Exclusion rests in VAR causallity ragressions (1979:4-1993:4)

\begin{tabular}{|c|c|c|c|c|}
\hline & $\mathrm{Y}_{\mathrm{r}}$ & $5 \mathrm{Ml}$ & $\mathrm{p}$ & $\mathrm{R}$ \\
\hline SMI & $14.22(0.0066)$ & $19.80(0.0002)$ & $20.73(0.0139)$ & $10.01(0.0185)$ \\
\hline $\mathbb{Y}_{r}$ & $83.54(0.0000)$ & $9.49(0.0087)$ & $81.47(0.0000)$ & $3.49(0.3221)$ \\
\hline $\mathrm{P}$ & $35.53(0.0000)$ & $22.95(0.0000)$ & $140.98(0.0000)$ & $0.45(0.8004)$ \\
\hline $\mathrm{R}$ & - & $66.59(0.0000)$ & $9.74(0.0018)$ & $244.67(0.0000)$ \\
\hline \multirow[t]{2}{*}{$\mathrm{ECM}$} & $13.32(0.0013)$ & $21.38(0.0000)$ & $27.88(0.0000)$ & $5.56(0.0619)$ \\
\hline & $\mathrm{Y}_{\mathrm{r}}^{\prime}$ & SM2 & $\mathrm{P}$ & $\mathrm{R}$ \\
\hline$S M 2$ & $9.31(0.0095)$ & $37.31(0.0000)$ & $1.51(0.2198)$ & $9.94(0.0069)$ \\
\hline$Y_{i}$ & $61.81(0.0000)$ & $10.64(0.0049)$ & $164.31(0.0000)$ & $0.18(0.9123)$ \\
\hline $\mathrm{P}$ & $53.09(0.0000)$ & $18.71(0.0003)$ & $120.57(0.0000)$ & $1.48(0.6857)$ \\
\hline $\mathrm{R}$ & $5.21(0.0225)$ & $18.43(0.0004)$ & $3.70(0.0546)$ & $434.93(0.0000)$ \\
\hline \multirow[t]{2}{*}{ ECM } & $4.22(0.0400)$ & $10.49(0.0012)$ & $0.64(0.4232)$ & $19.44(0.0000)$ \\
\hline & $\mathrm{Y}_{\mathrm{I}}$ & $\mathrm{DM} 2$ & $\mathrm{P}$ & $\mathrm{R}$ \\
\hline DM2 & $21.98(0.0012)$ & $16.22(0.0010)$ & $10.91(0.0276)$ & $2.38(0.1230)$ \\
\hline$Y_{\mathrm{r}}$ & $98.54(0.0000)$ & $26.60(0.0002)$ & $151.89(0.0000)$ & $5.99(0.1121)$ \\
\hline $\mathrm{P}$ & $54.10(0.0000)$ & $34.97(0.0000)$ & $230.37(0.0000)$ & $11.61(0.0205)$ \\
\hline $\mathrm{R}$ & $5.74(0.0166)$ & $52.85(0.0000)$ & - & $226.88(0.0000)$ \\
\hline \multirow[t]{2}{*}{$\mathrm{ECM}$} & $23.61(0.0000)$ & $18.84(0.0000)$ & $27.72(0.0000)$ & $8.08(0.0045)$ \\
\hline & $\mathrm{Y}_{\mathrm{r}}$ & $\mathrm{SM} 3$ & $\mathrm{P}$ & $\mathrm{R}$ \\
\hline $\mathrm{SM} 3$ & $2.45(0.1174)$ & $47.90(0.0000)$ & $16.79(0.0021)$ & $7.05(0.3162)$ \\
\hline $\mathrm{Y}_{\mathrm{r}}$ & $80.40(0.0000)$ & - & $108.26(0.0000)$ & $0.04(0.9798)$ \\
\hline $\mathrm{P}$ & $52.32(0.0000)$ & $19.48(0.0001)$ & $162.71(0.0000)$ & $1.65(0.6473)$ \\
\hline $\mathbb{R}$ & $4.74(0.0294)$ & $8.29(0.0403)$ & $898(0.0027)$ & $236.22(0.0000)$ \\
\hline $\mathrm{ECM}$ & $18.24(0.0001)$ & $32.10(0.0000)$ & $25.33(0.0000)$ & $11.87(0.0026)$ \\
\hline
\end{tabular}


Table 6.11 (continued)

\begin{tabular}{|l|l|l|l|l|}
\hline & $Y_{\mathrm{I}}$ & $\mathrm{DM}$ & $\mathrm{P}$ & $\mathrm{R}$ \\
\hline $\mathrm{DM} 3$ & $5.54(0.0626)$ & $23.55(0.0006)$ & $18.50(0.0003)$ & $291(0.9834)$ \\
\hline $\mathrm{Y}_{\mathrm{r}}$ & $77.50(0.0000)$ & $0.64(0.4231)$ & $98.13(0.0000)$ & $2.65(0.6181)$ \\
\hline $\mathrm{P}$ & $51.84(0.0000)$ & $20.02(0.0002)$ & $134.69(0.0000)$ & $0.32(0.5696)$ \\
\hline $\mathrm{R}$ & $3.52(0.0606)$ & $6.48(0.0109)$ & $14.89(0.0001)$ & $271.48(0.0000)$ \\
\hline ECM & $11.98(0.0025)$ & $21.10(0.0000)$ & $18.94(0.0001)$ & $8.47(0.0145)$ \\
\hline
\end{tabular}

* See table 6.6 for an explanation of the lay-out and symbols of this table.

Over the EMS-period, the causality test results obtained with univariate and mulivariate regression techniques may give rise to the following monetary policy implications. Short-term interest rates may be used as main indicator of inflation, due to the Fisher effect. On the other hand, the Dutch central bank can control short-term interest rates relatively easily with the discount rate. Since interest rates are affected both by inflationary expectations and by the discount rate, the exact relation between short interest rates and inflation may be ambiguous. If the Fisher effect dominates, interest rates and inflation will move in the same direction. But if DNB's control over short-term interest rates dominates, an increase in the discount rate will cause short interest rates to rise as well. In turn, this may lead to less inflation in the future. In addition, the ambiguous relation between short interest rates and inflation may be a consequence of the feedback from inflation to the discount rate. Because of the Bundesbank's tight anti-inflationary policy, higher inflationary pressures in Germany may cause the Bundesbank to raise the discount rate. The close relation between the German and the Dutch inflation rate (see Berk and Wincler, 1994) will usually imply that, in such circumstances, Dutch inflation is higher as well. ${ }^{16}$ In order to stabilise the guilder/Dmark exchange rate (and to reduce inflation) the Dutch discount rate will be raised as well, and short term interest rates will rise. In the furure, these higher interest rates may reduce inflation (assuming that the anti-inflationary policy is effective). Then, short-term interest rates are also useful indicators of future inflation. Of course, the credibility of DNB's policy in keeping the exchange rate fixed (and, consequently, in fighting inflation) is a crucial factor in the final relation between the discount rate and inflation. If short interest rates are relatively easily controllable wia the discount rate, and if these interest rates are, on the other hand, closely related to inflation, using these interest rates as indicators of future inflation contributes to the effectiveness of DNB's anti-inflationary monetary policy.

The results in tables 6.9 and 6.11 also show that interest rates, which are primarily used to stabilise the exchange rate of the guilder, have affected (demand for)

16 The higher (expected) inflation rate in the Netherlands may be observed in higher short interest rates. 
all monetary aggregates in the EMS period. Especially the Divisia monetary aggregates could be adopted as additional indicators of inflation. Of these, Divisia M3 might be preferred, because it has very good indicator properties for inflation and also appears to be a reasonable indicator for real income growth according to the VAR system results. We do not like to choose Divisia M2 as inflationary indicator, since weak separability tests have thrown some doubt on the appropriateness of using M2 as a monetary aggregate (see section 3.4 .1 ). ${ }^{17} \mathrm{M} 1$ could also be used as real and/or nominal indicator of monetary policy, but, as already mentioned before, M1 does not measure the flow of monetary services appropriately (see section 4.5 .1 and page 120). For simplicity, it should also be preferred to use as few monetary indicators as possible. Furthermore, Divisia M3, in contrast to M1, does not affect the short-term interest rate, which may be caused by the lower variation in Divisia M3. This implies that, for Divisia M3, the relation between short interest rates and inflation is not disturbed by an effect of liquidity growth (of Divisia M3) on these interest rates. When $\mathrm{Ml}$ is used as indicator of inflation, M1's effect on short interest rates may affect their controllability with the discount rate. This additional effect on interest rates may also impair their usefulness as indicator of inflation, since it is unclear whether short interest rate movements are caused by changes in M1, by inflationary expectations, or by changes in the discount rate. Summarisingly, short-term interest rates could be used as the primary nominal indicator and Divisia M3 as additional nominal and primary real indicator. Although Divisia $\mathrm{M} 3$ and the short-term interest rate do not have good indicator properties for inflation before the EMS-period, their indicator performance has considerably improved since the late 1970 s.

\subsection{Out-of-sample forecasts of inflation and real income growth}

As an additional test on the relative performance of simple-sum and Divisia monetary aggregates we analyse the stability of the estimated relations between, on the one hand, the growth of the respective monetary aggregates, and inflation and real growth in the Netherlands, on the other. This section presents one-period and eight-period ahead out-of-sample forecasts for Dutch inflation and real income growth applying the same univariate regressions of inflation and real income growth as in table 6.9. Using rolling regressions the inflation and real income equations are first reestimated over the sample 1979:4-1985:4. Then we forecast one period (1986:1) and eight periods (1987:4) ahead. In the eight-period ahead forecasts of inflation and real growth we use forecasted values for the first seven lags of the respective dependent variable. After these first forecasts, the initial sample is extended with one observation and the same procedure is repeated until the last forecasts are obtained. With this method, we have 32 one-period ahead forecasts and 25 eightmeriod ahead forecasts for inflation and real income growth in the Netherlands for each monetary aggregate.

\footnotetext{
17 Especially if financial asset stocks are adjusted for budgef increases over time the NONPAR test reweals significant violations of weak separability of $\mathrm{M} 2$ from the other financial assets.
} 
The relative performance of the aggregates is evaluated in tables 6.12 and 6.13 by the root mean square forecast error (RMSE) and the mean absolute forecast error (MAE).

In general, it is clear that the forecast errors increase with the forecast horizon, although M1 and Divisia M3 forecast inflation better over a longer horizon than just one quarter ahead. According to the RMSE the same applies to real growth forecasts obtained with Divisia M2. The differences in forecasting performance of the monetary aggregates is relatively small. Concerning real income growth, our results from previous estimations are confirmed in that the Divisia aggregates show smaller forecast errors than their simple-sum equivalents. Overall, Divisia M2 shows the smallest forecast errors for real income at both intervals. These findings are consistent with the results in section 6.5.3 where Divisia M2 is the best real indicator and where Divisia aggregates perform marginally better than their sum equivalents. Mostly, sum M1 forecasts real growth and inflation with larger errors than the two Divisia aggregates (only the short-run forecast errors of real growth are smaller with M1 than with Divisia M3). This may be another indication that M1 does not measure the flow of monetary services appropriately.

Table 6.12 Forecast errors of Durch real income growth in percentages (initial estimation sample: 1979:4-1985:4)

\begin{tabular}{|l|l|l|l|l|}
\hline & \multicolumn{2}{|l|}{ one-period ahead } & \multicolumn{2}{l|}{ eight-periods alhead } \\
\hline & RMSE & MAE & RMSE & MAE \\
\hline Dutch M1 & 0.7500 & 0.5985 & 0.9360 & 0.7919 \\
\hline Dutch M2 & 0.8613 & 0.6738 & 0.9026 & 0.7479 \\
\hline Dutch Divisia M2 & 0.6195 & 0.4831 & 0.6039 & 0.4905 \\
\hline Dutch M3 & 0.8323 & 0.6349 & 0.9806 & 0.7658 \\
\hline Dutch Divisia M3 & 0.7923 & 0.6454 & 0.9170 & 0.6764 \\
\hline
\end{tabular}

With respect to inflation, Divisia M3 has the overall best performance at both forecasting horizons. This confirms our view that Divisia M3 should be used as indicator of inflation (section 6.5.3). Sum M3 has the worst inflation forecasting ability at longer horizons. The generally better forecasting properties of Divisia M3 compared with those of sum M3 suggest that velocity for Divisia M3 has been more stable than velocity for sum M3 over the EMS-period.

Simple-sum M2 predicts inflation slightly better than Divisia M2, an outcome that contradicts the results obtained before. This may be an indication that, over the EMS-period, the relation between Divisia M2 growth and inflation is not as stable as the relation between sum M2 growth and inflation. Alternatively, these ambiguous results at the M2 aggregation level may be caused by the inappropriateness of M2 as a weakly separable aggregate. 
Tablle 6.13 Forecast errors of Dutch inflation in percentages (initial estimation sample: $1979: 4$ 19854 )

\begin{tabular}{|l|l|l|l|l|}
\hline & \multicolumn{2}{|l|}{ one-period ahead } & \multicolumn{2}{l|}{ eight-periods ahead } \\
\hline & RMSE & MAE & RMSE & MAE \\
\hline Dutch M1 & 0.7367 & 0.4636 & 0.6122 & 0.4565 \\
\hline Dutch M2 & 0.4715 & 0.3863 & 0.4628 & 0.3954 \\
\hline Dutch Divisia M2 & 0.4904 & 0.4051 & 0.5826 & 0.5209 \\
\hline Dutch M3 & 0.5239 & 0.4273 & 0.7723 & 0.6086 \\
\hline Dutch Divisia M3 & 0.4565 & 0.3260 & 0.3853 & 0.3151 \\
\hline
\end{tabular}

\subsection{Conclusion}

Inflation control or even price stability has been an important policy objective in many industrialised countries since the 1970s. Although explicit monetary targeting by now has become obsolete in most countries, the development of monetary aggregates is still generally perceived to convey important information about the future course of both real growth and inflation. An important issue in this respect is the way money should be measured.

In this chapter we focus on the relative performance of simple-sum and Divisia monetary aggregates as indicators of future real growth and inflation in the Netherlands. First, conventional (reduced form) St. Louis equations are estimated. Then, long-run considerations are taken into account as well. Unit root and cointegration tests lead to the inclusion of error correction terms that capture deviations from longrun equilibrium. Because of the importance of the short-term interest rate for the stabilisation of the exchange rate of the guilder to the German mark, the interest rate is included as a potential monetary indicator as well.

For the full sample 1965-1993 (1972-1993 for harmonised M3), the results are generally disappointing. The outcomes for Dutch monetary aggregates suggest that sum M1 and Divisia M3 are appropriate indicators for real growth. Both M2 aggregates are significant determinants of inflation in a multivariate causality system and in a St. Louis equation. In general, monetary aggregates matter for future inflation and real growth via their error-correction terms. The EMS period 1979-1993 is investigated separately, because of the possibility of structural breaks. Now all monetary aggregates, except sum M2, show a significant inpact on inflation. Divisia aggregates' growth rates outperform their simple-sum equivalents as indicators of real growth and inflation. In addition, the interest rate explains inflation well. Divisia M3 remains the preferred indicator for real growth.

In terms of forecasting ability the Divisia aggregates show smaller forecast errors of real growth than their sum counterparts, with Divisia M2 performing best. Weak separability tests in chapter 3, however, indicate that M2 may not be consistent with demand theory. Divisia M3 has the overall best performance in forecasting inflation, 
whereas Divisia M3's velocity also seems more stable than sum M3's velocity. Thus, the results for the EMS period suggest that the short term interest rate may be the preferred indicator of inflation in the Netherlands. Additionally, Divisia M3 could be monitored as well because of its relevance for inflation and real growth.

Overall, the evidence obtained is in favour of using Divisia aggregates as indicators of inflation and real growth, although not as strongly as might theoretically be expected. One explanation for this observation is the low and gradual degree of financial innovation in the Netherlands. We do observe, though, that monetary aggregates have become more informative about future inflation, in particular in the period 1979-1993, than was the case in the earlier part of our sample. This may be due to the increased importance attached to price stability since the late seventies. 


\section{DO GERMAN MONETARY AGGREGATES MATTER FOR THE DUTCH ECONOMY?}

\subsection{Introduction}

Over most of the period investigated in chapter 6, the Netheriands has had a fixed exchange rate with Germany. According to the monetary theory of the balance of payments for small open economies, this makes the Dutch money supply endogenous. " Due to the openness of the Dutch economy and the almost fixed exchange rate between the Dutch guilder and the German mark, real economic growth and inflation in the Netherlands are also heavily affected by foreign developments. Under fixed exchange rates, a country's long-run equilibrium price level should mainly be determined by the anchor country"s price level (Kool and Tatom, 1994). They show that the Dutch long-run equilibrium price level and inflation rate are dominated by German price developments, which, presumably, are mainly determined by the Bundesbank's monetary policy. Although trade with foreign countries is an important determinant of the Dutch economic performance, it might additionally be argued that German monetary aggregates (simple-sum or Divisia) are more appropriate indicators for inflation (and real growth) in the Netherlands than their Dutch counterparts. This may especially be true for inflation, since the German Bundesbank has been using monetary targeting for many years in order to achieve price stability.

In this chapter we, therefore, include German simple-sum and Divisia aggregates in our analysis as potential indicators of Dutch inflation and real growth. Causality between German aggregates and the Dutch economy is tested with cointegration, univariate and multivariate regression techniques. Since Dutch exports of goods and services are also included in the causality analysis, we can examine whether German money growth provides incremental explanatory power for Dutch inflation and real income growth. This is the subject of section 7.2. As a test of the stability of the estimated relations between German monetary aggregates, and inflation and real growth in the Netherlands, we present out-of-sample forecasts of Dutch inflation and real growth using the German sum and Divisia aggregates in section 7.3. In the fourth section of this chapter, the aggregate spending environment of the St. Louis equation for an open economy is used to test explicitly the relative importance of equivalent Dutch and German (simple-sum and Divisia) monetary aggregates in determining inflation and real income growth in the Netherlands. Finally, section 7.5

1 See Kool (1995) for an overview and analysis 
contains a summary of the German monetary aggregates" influence on the Dutch economy.

\subsection{Impact of German monetary aggregates on the Dutch economy}

In this section we test the indicator properties of German monetary aggregates for Dutch inflation and real income growth. In a fixed exchange rate system, like the EMS, the equilibrium domestic price level in a small country is determined by the ratio between, on the one hand, the product of the nominal exchange rate (in domestic currency units per unit of foreign currency) and the foreign price level, and the equilibrium revil exchange rate on the other, see Kool and Tatom (1994). Since the nominal exchange rate is fixed, the main determinant of the long-run domestic price level then is the foreign price level. As a consequence of the pegging of the exchange rate, the domestic money stock in a small country becomes endogenous (demanddetermined). Dewiations of domestic prices from their equilibrium level are corrected by changes in the money supply due to arbitrage in goods and capital markets.

Theoretically, equilibrium price levels and inflation in the smaller EMS member countries will, among other factors, be primarily determined by price developments in Germany. The German Bundesbank has been using monetary targeting for many years in order to achieve domestic price stability. This policy has contributed to the relatively close link between money and prices (and inflation) in Germany. Since the Bundesbank determines monetary policy in the European Monetary System, it is likely that economic developments -and especially inflation- in other countries participating in the EMS will be closely related to the German money supply as well. Kool and Tatom (1994) use the $\mathbb{P}^{*}$-approach to show that German monetary conditions have a more important impact on inflationary pressures in the surrounding small countries than monetary conditions within these countries. This holds in particular for Austria and the Netherlands. Berk and Winder (1994) show that the Dutch inflation rate has been very closely related to the German inflation rate since the establishment of the EMS.

The Netherlands has followed the German lead almost perfectly in the 1980 s. Only in 1983, a two percent devaluation of the guilder took place. Due to the exchange rate agreement, the Dutch central bank uses interest rates to stabilise the exchange rate, causing the money supply to be largely endogenous. Since the economies of Germany and the Netherlands are so closely integrated and the Bundesbank adheres to an anti-inflationary policy of monetary targeting, German monetary aggregates may be good indicators of Dutch inflation and real growth. A crucial factor for this relation to be present is the credibility of the fixed exchange rate policy of the Dutch central bank. ${ }^{2}$ Data for German simple-sum and Divisia aggregates are avail-

2 See Svensson (1994) for a discussion of the importance of credibility in maintaining a fixed exchange rate systern. 
able for the period 1975-1993. ${ }^{3}$ We investigate causality relations between the growth rates of German monetary aggregates and Dutch real income growth, inflation, and the short-term interest rate ${ }^{4}$ over the EMS period 1979:4-1993:4. First differences of Dutch exports of goods and services are also included in the analysis because of their important role for the Dutch economy. This also enables us to investigate the additional explanatory power of German monetary aggregates when the openness of the Dutch economy is already taken into account via these exports.

Table 7.1 Trace and $\lambda_{\max }$ statistics with Geman monetary aggregates (sample: 1979:4-1993:4)

\begin{tabular}{|c|c|c|c|}
\hline \multicolumn{4}{|c|}{ Trace } \\
\hline Sum $M 2$ & Divisia M2 & Sum M3 & Divisia M3 \\
\hline 0.46 & 0.00 & 387 & 0.16 \\
\hline 13.50 & 11.54 & 8.42 & 6.86 \\
\hline 26.98 & 23.65 & 25.76 & 25.30 \\
\hline 52.10 & 45.36 & $55.68 *$ & 50.22 \\
\hline $103.93^{*}$ & $99.37^{*}$ & $106.12 *$ & $107.85^{*}$ \\
\hline \multicolumn{4}{|c|}{$\lambda_{\max }$} \\
\hline Sum M2 & Divisia M2 & Sum M3 & Divisia M3 \\
\hline 0.46 & 0.00 & 3.87 & 0.16 \\
\hline 13,04 & 11.54 & 4.55 & 6.70 \\
\hline 13.48 & 12.10 & 17.34 & 18.44 \\
\hline 25.12 & 21.72 & $29.92 *$ & 24.92 \\
\hline $51.82 *$ & $54.01 *$ & $50.44 *$ & $57.63^{*}$ \\
\hline
\end{tabular}

* For an explanation of symbols, test statistics, and critical values see table 6.5 .

In table 7.1 , the results of cointegration tests between German monetary aggregates (sum and Divisia M2 and M3) and the Dutch real income, price level, short-term interest rate and exports are shown. It appears that there is generally evidence of one cointegration relationship over the sample 1979:4-1993:4, although with sum M3 two cointegrating vectors are found.

3 We are indebted to Alec Chrystal and Hermann et al. (1994) for making these series available to us. German monetary unification is incorporated as it Hermann et al (1994). In the subsequent analysis, German monetary aggregates have been converted into Dutch guilders using the actual guilder/Dmark exchange rate.

The sources of the Dutch data are discussed in section 6.3 . 
Table 7.2 displays the results of causality tests when the role of various German aggregates and Dutch exports for the Dutch economy is taken into account. Lag selection tests lead us to include long lag lengths for German monetary aggregates and for exports in the equations for Dutch real income growth, inflation and the short interest rate. This indicates that the Dutch economy reacts more slowly to German monetary conditions and foreign demand than to the corresponding domestic developments. The results in table 7.2 show that German monetary aggregates generally have a significant effect on Dutch real income growth. The effect of German Divisia M3 is only marginally significant. German sum aggregates explain real income better than the corresponding Divisia aggregates. The two German M3 aggregates have a significant impact on Dutch short-term interest rates, either via a short-run effect or via the error-correction term. Since monetary targets in Germany are expressed in terms of the growth rates of M3 and the Dutch central bank uses short-term interest rates to stabilise the exchange rate of the guilder, it should not be surprising that we find evidence of a close relation between both German M3 aggregates and the Dutch interest rate.

Dutch inflation, on the other hand, is only indirectly affected by the German M2 money supply measures (via the error-correction terms). Exports of goods and services appear significant in explaining Dutch inflation in all four cases. Additionally, these exports also determine Dutch real growth (in the short-run or via the cointegrating relations), except when Divisia M2 is used as money measure. Both the results for inflation and for real growth give a clear indication of the openness of the Dutch economy. It appears that German monetary aggregates have low additional explanatory power for Dutch inflation when Dutch exports are included in the univariate analysis. Unreported results show that the impact of German monetary aggregates on the Dutch economy is much higher when exports are neglected.

Table 7.2 Exclusion tests in causality regressions between German monetary aggregates and the Dutch real economy $(1979: 4-1993: 4)^{*}$

\begin{tabular}{|l|l|l|l|}
\hline & $Y_{r}$ & $P$ & $R$ \\
\hline SGM2*** & $34.35(0.0002)$ & $14.53(0.1503)$ & $13.08(0.2192)$ \\
\hline$Y_{r}$ & $43.88(0.0000)$ & $19.51(0.0015)$ & $14.14(0.1666)$ \\
\hline$P$ & $48.93(0.0000)$ & $65.91(0.0000)$ & $33.43(0.0002)$ \\
\hline$R$ & $0.73(0.3921)$ & $3.43(0.0640)$ & $26.40(0.0009)$ \\
\hline$X$ & $15.13(0.1273)$ & $18.42(0.0483)$ & $2.61(0.9779)$ \\
\hline ECM & $4.23(0.0398)$ & $6.88(0.0087)$ & $0.05(0.8256)$ \\
\hline
\end{tabular}


Table 7.2 (continued)

\begin{tabular}{|c|c|c|c|}
\hline & $Y_{r}$ & $\mathrm{p}$ & $\mathbb{R}$ \\
\hline $\mathrm{DGM} 2 *$ & $18.94(0.0410)$ & $4.29(0.2320)$ & $8.63(0.5679)$ \\
\hline $\mathrm{Y}_{\mathrm{r}}$ & $47.76(0.0000)$ & $60.15(0.0000)$ & $16.29(0.0916)$ \\
\hline $\mathrm{P}$ & $23.27(0.0000)$ & $101.39(0.0000)$ & $8.78(0.5533)$ \\
\hline $\mathrm{R}$ & $0.01(0.9083)$ & $8.20(0.0042)$ & $17.84(0.0225)$ \\
\hline $\mathrm{X}$ & $12.82(0.2337)$ & $40.19(0.0000)$ & $5.76(0.7638)$ \\
\hline ECM & $0.80(0.3722)$ & $5.39(0.0203)$ & $1.18(0.2767)$ \\
\hline z & $\mathrm{Y}_{\mathrm{r}}$ & $\mathrm{P}$ & $\mathbb{R}$ \\
\hline SGM3 & $41.51(0.0000)$ & $12.26(0.2680)$ & $53.68(0.0000)$ \\
\hline $\mathrm{Y}_{\mathrm{r}}$ & $69.40(0.0000)$ & $28.03(0.0000)$ & $21.14(0.0201)$ \\
\hline $\mathbb{P}$ & $36.56(0.0000)$ & $54.00(0.0000)$ & $20.22(0.0272)$ \\
\hline $\mathbb{R}$ & $9.92(0.0016)$ & $0.60(0.4397)$ & $42.80(0.0000)$ \\
\hline$x$ & $56.10(0.0000)$ & $17.03(0.0736)$ & $24.15(0.0041)$ \\
\hline \multirow[t]{2}{*}{$\mathrm{ECM}$} & $2.13(0.1447)$ & $0.08(0.7823)$ & $2.57(0.1087)$ \\
\hline & $\mathrm{Y}_{\mathrm{r}}$ & $\mathrm{p}$ & $\mathbf{R}$ \\
\hline DGM3 & $5.91(0.1159)$ & $0.65(0.8859)$ & $3.53(0.6196)$ \\
\hline$Y_{p}$ & $44.95(0.0000)$ & $54.71(0.0000)$ & $12.21(0.2712)$ \\
\hline $\mathrm{P}$ & $21.96(0.0000)$ & $74.65(0.0000)$ & $9.36(0.4980)$ \\
\hline$R$ & $4.26(0.0390)$ & $7.34(0.0067)$ & $48.45(0.0000)$ \\
\hline$X$ & $33.53(0.0002)$ & $39.35(0.0000)$ & $5.12(0.8240)$ \\
\hline $\mathrm{ECM}$ & $1.46(0.2275)$ & $1.05(0.3057)$ & $3.01(0.0827)$ \\
\hline
\end{tabular}

* See table 6.6 for an explanation of the lay-out and symbols of this table.

* SGM2 and DGM2 refer to German sum and Divisia M2, respectively.

Due to the long lag lengths for especially the four German monetary aggregates in the univariate regressions many shorter lags of these aggregates are included in the above analysis, although they are insignificant individually. This may seriously affect the results obtained. Therefore, the same causality regressions are performed for German aggregates with a VAR system over the period 1979:4-1993:4, the results of which are shown in table 7.3. Starting from the univariate regression results, only lags of variables with a t-statistic larger than one are included in the VAR system.

A comparison of tables 7.2 and 7.3 shows some interesting differences. Overall, significant results dominate in the VAR system. All error-correction terms are now (highly) significant, except in the equations for real income growth and inflation 
when Divisia M3 is included. Thus, there is generally evidence of the cointegrating vector affecting the short-run dynamics between German money and the Dutch economy. As in the univariate causality tests, all four German aggregates have an impact on Dutch real income, but their significance is usually higher. Dutch interest rates are still well explained by the two $\mathrm{M} 3$ aggregates (both through a direct and an indirect channel), however, sum M2 now plays a similar role.

Table 7.3 Exclusion tests in VAR causality regressions between German monetary aggregates and the Dutch real economy $(1979: 4-1993: 4)^{\text {i* }}$

\begin{tabular}{|l|l|l|l|}
\hline & $Y_{r}$ & $P$ & $R$ \\
\hline SGM2 & $35.02(0.0000)$ & $37.07(0.0000)$ & $186.02(0.0000)$ \\
\hline$Y_{r}$ & $113.77(0.0000)$ & $45.13(0.0000)$ & $41.47(0.0000)$ \\
\hline$P$ & $85.09(0.0000)$ & $191.47(0.0000)$ & $85.07(0.0000)$ \\
\hline$R$ & - & $23.76(0.0000)$ & $12.70(0.0017)$ \\
\hline$X$ & $28.27(0.0001)$ & $60.25(0.0000)$ & - \\
\hline ECM & $18.73(0.0000)$ & $31.37(0.0000)$ & $52.86(0.0000)$ \\
\hline & $Y_{r}$ & $P$ & $R$ \\
\hline DGM2 & $23.15(0.0000)$ & $2.21(0.1373)$ & $0.65(0.4197)$ \\
\hline$Y_{r}$ & $67.41(0.0000)$ & $243.71(0.0000)$ & $1.74(0.6278)$ \\
\hline$P$ & $54.26(0.0000)$ & $149.96(0.0000)$ & $0.82(0.8441)$ \\
\hline$R$ & & $10.19(0.0014)$ & $223.79(0.0000)$ \\
\hline$X$ & $35.84(0.0000)$ & $54.37(0.0000)$ & $0.12(0.7290)$ \\
\hline$E C M$ & $12.95(0.0003)$ & $7.68(0.0056)$ & $25.79(0.0000)$ \\
\hline & $Y_{r}$ & $P$ & $R$ \\
\hline SGM3 & $42.85(0.0000)$ & $12.45(0.0060)$ & $51.89(0.0000)$ \\
\hline$Y_{r}$ & $157.91(0.0000)$ & $173.85(0.0000)$ & $0.91(0.6356)$ \\
\hline$P$ & $82.68(0.0000)$ & $167.98(0.0000)$ & $8.53(0.0363)$ \\
\hline$R$ & $18.59(0.0000)$ & - & $295.74(0.0000)$ \\
\hline$X$ & $57.89(0.0000)$ & $13.61(0.0035)$ & $9.47(0.0504)$ \\
\hline$E C M$ & $4.20(0.0403)$ & $4.09(0.0431)$ & $16.70(0.0000)$ \\
\hline
\end{tabular}


Table 7.3 (continued)

\begin{tabular}{|l|l|l|l|}
\hline & $Y_{r}$ & $P$ & $R$ \\
\hline$D G M 3$ & $7.66(0.0217)$ & $1.46(0.2263)$ & $10.89(0.0043)$ \\
\hline$Y_{r}$ & $95.15(0.0000)$ & $182.02(0.0000)$ & $6.68(0.0829)$ \\
\hline$P$ & $42.18(0.0000)$ & $11.49(0.0000)$ & $3.59(0.3087)$ \\
\hline$R$ & $4.05(0.0443)$ & $6.71(0.0096)$ & $225.93(0.0000)$ \\
\hline$X$ & $21.23(0.0034)$ & $48.98(0.0000)$ & - \\
\hline ECM & $2.28(0.1309)$ & $1.45(0.2290)$ & $17.89(0.0000)$ \\
\hline
\end{tabular}

* See table 6.6 for an explanation of the lay-out and symbols of this table. The symbol "-" indicates that lags of this variable are not included in the regression because of insignificance.

Another important difference with table 7.2 is that all German monetary aggregates, except Divisia M3, appear as significant determinants of Dutch inflation (Divisia M2 is only marginally significant). With regard to the error-correction terms, there is hardly any difference in explanatory power of these three German aggregates for Dutch inflation. This confirms the theoretical view that the Dutch inflation rate is determined by German monetary policy through long-run equilibrium restoring tendencies. With respect to the (short-run) indicator properties of German aggregates for Dutch inflation the two simple-sum aggregates dominate their Divisia counterparts. This outcome is consistent with the results obtained for sum M3 in Germany in Hermann et al. (1994). The role of exports for the Dutch economy is similar to the one found with univariate regressions. Overall, the VAR system results for German monetary aggregates indicate that these foreign money measures, in addition to Dutch exports, contain important information about the behaviour of Dutch inflation and real income growth.

As in the univariate system, we find evidence that interest rates significantly influence inflation, except when German sum M3 is the explanatory money stock. Consequently, these short-term interest rates may have become useful inflationary indicators after the founding of the EMS. This confirms the results from the casality tests with Dutch monetary aggregates (tables 6.9 and 6.11 ) where the short-term interest rate also turns out to be a good indicator of inflation. In combination, the significant influence of German simple-sum monetary aggregates and of the Dutch short-term interest rate on Dutch inflation may be due to the credible Dutch policy of stabilising the guilder/Dmark exchange rate with short-term interest rates. It may also be an indication that the relative weight of price stability in the objective function of the Dutch central bank has increased over the sample. 


\subsection{Out-of-sample forecasts of Dutch inflation and real income growth with German monetary aggregates}

This section presents one- and eight-period ahead forecasts of Dutch inflation and real income growth using the respective univariate regressions from table 7.2 , which contain, among others, Dutch exports of goods and services and German monetary aggregates as explanatory variables. The forecasting procedure is identical to the one applied in section 6.6. In general, the magnitude of the forecast errors obtained with German monetary aggregates is similar to the errors with Dutch aggregates. At the one-period horizon, Divisia M3 forecasts Dutch real income growth best of all four German aggregates (table 7.4). The German sum aggregates forecast real growth better at the longer horizon than just one period ahead. As a result, German sum aggregates outperform their Divisia counterparts as real income growth indicators at this longer forecast horizon.

Table 7.4 Fioreast errors of Dutch real income growth in percentages (initial estimation sample: 1979:4-1985:4)

\begin{tabular}{|l|l|l|l|l|}
\hline & \multicolumn{2}{|l|}{ one-period ahead } & \multicolumn{2}{l|}{ eight-periods ahead } \\
\hline & RMSE & MAE & RMSE & MAE \\
\hline German M2 & 0.8867 & 0.7011 & 0.7909 & 0.6496 \\
\hline German Divisia M2 & 1.0624 & 0.7697 & 1.1901 & 0.9933 \\
\hline German M3 & 0.8850 & 0.6739 & 0.8077 & 0.6268 \\
\hline German Divisia M3 & 0.8177 & 0.6509 & 0.9242 & 0.7722 \\
\hline
\end{tabular}

Table 7.5 Forecast errors of Dutch inflation in percentages (initial estimation sample: 1979:41985:4)

\begin{tabular}{|l|l|l|l|l|}
\hline & \multicolumn{2}{|l|}{ one-period ahead } & \multicolumn{2}{l|}{ eight-periods ahead } \\
\hline & RMSE & MAE & RMSE & MAE \\
\hline German M2 & 0.5104 & 0.3952 & 0.7958 & 0.5215 \\
\hline German Divisia M2 & 0.3896 & 0.3454 & 0.4746 & 0.4041 \\
\hline German M3 & 0.6786 & 0.4670 & 0.9287 & 0.5758 \\
\hline German Divisia M3 & 0.4061 & 0.3319 & 0.4872 & 0.3995 \\
\hline
\end{tabular}

Table 7.5 shows that the German Divisia aggregates always forecast Dutch inflation with smaller errors than their simple-sum equivalents. This observation is in contrast with the results provided by the causality tests (see tables 7.2 and 7.3 ), where German sum aggregates appear as better indicators of Dutch inflation. The relation between the German Divisia aggregates and Dutch inflation seems more stable than the corresponding relation for German sum aggregates. According to the RMSE, 
German Divisia M2 performs even better than the Dutch aggregates at the one-period horizon.

\subsection{The relative performance of Dutch and German monetary ag- gregates}

The multivariate causality analysis in section 7.2 shows that German simple-sum aggregates have become significant indicators of Dutch inflation after the founding of the EMS and that all German aggregates contain information about future real growth in the Netherlands (see table 7.3). Within the framework of causality tests, an explicit test of whether German aggregates outperform Dutch ones or the other way round must take into account the combined effect of short-run money growth and any long-run error-correction terms. The forecasts made in the former section and in section 6.6 can be viewed as a formal test of the stability of the estimated relations explaining real income growth and inflation in the Netherlands with, among other variables, the growth rates of various German and Dutch monetary aggregates, respectively. Here, we return to the more simple St. Louis method for a quantitative test of the aggregates" performance in a (short-run) aggregate spending framework. More specifically, the real and nominal indicator properties of the Dutch sum M2, Divisia M2, sum M3 and Divisia M3 aggregates are compared with the properties of the corresponding German aggregates. The sample covers the period 1979:4-1993:4.

The St. Lowis method is applied as described in section 6.4.1. This implies that the explanatory variables are government expenditures, exports of goods and services and a monetary aggregate (either Dutch or German). In a pre-testing procedure we determine the lag lengths of the different variables to be included in the St. Louis regressions (F-test). The only difference with the testing procedure adopted earlier is that we now use the Akaike Information Criterion (AIC) instead of the likelihood ratio test, because the number of parameters in the regressions containing Dutch aggregates can differ from the number of parameters when German aggregates are

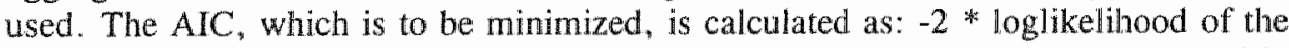
model $+2 *$ number of parameters of the model. The AIC test statistic reported in tables 7.6 and 7.7 is calculated as the difference between the AIC for a Dutch aggregate and the AIC for an equivalent German aggregate. Analogously to tables 6.1 through 6.3, the results for J-tests, JA-tests, and an F-test are given. For this latter test, probability values are given in parentheses. The results for real income growth are in table 7.6, and for inflation in table 7.7.

Generally, the picture arising from tables 7.6 and 7.7 is consistent with earlier results in that the differences between Dutch and German monetary aggregates are generally marginal, though now a direct comparison is possible. The J- and IA-teststatistics are the least powerful of the test-statistics and very often give indeterminate or inconclusive results. The results of the F-tests reveal that the two Dutch M2 aggregates, Germany"s sum M3 and its two Divisia aggregates are significant for the determination of real income in the Netherlands. Only German sum M2 affects Dutch 
inflation in a highlly significant way (irrespective of whether the respective dependent variable is excluded from or included in the St. Louis equation). No Dutch monetary aggregate affects inflation significantly.

Table 7.6 St. Louis equation: real income growth

\begin{tabular}{|c|c|c|c|c|}
\hline $\begin{array}{l}\text { Excl. lagged } \\
\text { real income }\left(Y_{P}\right)\end{array}$ & $\begin{array}{l}\text { AlC-test: } \\
\text { AlC Dutch } \\
\text { aggregalte minus } \\
\text { AlC German } \\
\text { aggregate }\end{array}$ & $\begin{array}{l}\text { J-test*: } \\
\text { a for Dutch ag- } \\
\text { gregate }=0, \alpha \\
\text { for German } \\
\text { aggregate }=0\end{array}$ & $\begin{array}{l}\text { JA-lest : } \\
\alpha \text { for Dutch ag- } \\
\text { gregatte }=0, \alpha \\
\text { for German } \\
\text { aggregate }=0\end{array}$ & $\begin{array}{l}\text { F-test: } \\
\text { Excl. of Dutch } \\
\text { aggregate } \\
\text { Excl. of Ger- } \\
\text { man aggregate }\end{array}$ \\
\hline Sum M2 & $\begin{array}{l}-18.34 \\
\text { favours M2 }\end{array}$ & $\begin{array}{l}3.95,2.87 \\
\text { inconclusive }\end{array}$ & $\begin{array}{l}1.53,-0.50 \\
\text { indeterminate }\end{array}$ & $\begin{array}{l}2.41(0.0458) \\
0.74(0.7027)\end{array}$ \\
\hline Divisia M2 & $\begin{array}{l}24.93 \\
\text { favours DGM2 }\end{array}$ & $\begin{array}{l}2.13,5.75 \\
\text { inconclusive }\end{array}$ & $\begin{array}{l}0.34,1.64 \\
\text { fawours DGM2 }\end{array}$ & $\begin{array}{l}1.90(0.1069) \\
3.85(0.0030)\end{array}$ \\
\hline Sum M3 & $\begin{array}{l}8.47 \\
\text { favours SGM3 }\end{array}$ & $\begin{array}{l}2.99,3.82 \\
\text { inconclusive }\end{array}$ & $\begin{array}{l}0.40,1.41 \\
\text { indeterminate }\end{array}$ & $\begin{array}{l}1.61(0.1736) \\
2.76(0.0302)\end{array}$ \\
\hline Divisia M3 & $\begin{array}{l}7.71 \\
\text { favours DGM3 }\end{array}$ & $\begin{array}{l}2.43,2.03 \\
\text { inconclusive }\end{array}$ & $\begin{array}{l}1.71,0.51 \\
\text { favours DMB }\end{array}$ & $\begin{array}{l}1.21(0.3288) \\
3.16(0.0378)\end{array}$ \\
\hline \multicolumn{5}{|l|}{ Ind lagged $Y_{\mathrm{r}}$} \\
\hline Sum M2 & $\begin{array}{l}-14.87 \\
\text { favours M2 } \\
\end{array}$ & $\begin{array}{l}4.00,3.30 \\
\text { inconclusive }\end{array}$ & $\begin{array}{l}0.43,-0.96 \\
\text { indeterminate } \\
\end{array}$ & $\begin{array}{l}1.91(0.1126) \\
0.68(0.7511) \\
\end{array}$ \\
\hline Divisia M2 & $\begin{array}{l}15.26 \\
\text { favours DGM2 }\end{array}$ & $\begin{array}{l}2.56,4.49 \\
\text { inconclusive }\end{array}$ & $\begin{array}{l}1.13,1.00 \\
\text { indeterminate }\end{array}$ & $\begin{array}{l}1.72(0.1525) \\
2.48(0.0384)\end{array}$ \\
\hline Sum M3 & $\begin{array}{l}22.03 \\
\text { favours SGM3 }\end{array}$ & $\begin{array}{l}1.38,3.51 \\
\text { favours SGM3 }\end{array}$ & $\begin{array}{l}0.60,0.81 \\
\text { indeterminate }\end{array}$ & $\begin{array}{l}0.46(0.8523) \\
2.55(0.0457)\end{array}$ \\
\hline Divisia M3 & $\begin{array}{l}18.50 \\
\text { favours DGM3 }\end{array}$ & $\begin{array}{l}1.24,2.72 \\
\text { favours DGM3 }\end{array}$ & $\begin{array}{l}0.07,1.80 \\
\text { favours DGM3 }\end{array}$ & $\begin{array}{l}0.67(0.6970) \\
4.07(0.0161)\end{array}$ \\
\hline
\end{tabular}

* The $J$ - and $J A$-test statistics mentioned in the table are $t$-statistics (at a two-tail significance level) for the rejection of the German aggregate over the Dutch aggregate and the reverse rejection.

With some caution because of the high number of indeterminate or inconclusive test results, it appears that German Divisia M2, sum M3 and. Divisia $\mathrm{M}^{5}$ money measures have better indicator properties for real income in the Netherlands than the corresponding Dutch aggregates during the EMS era. Only Dutch sum M2 turns out to be more useful than the German counterpart as real indicator.

5 The JA-test at the Divisia M3 level (without lagged real income) shows that Dutch Divisia M3 is to be preferred above the German equivalent, but the other test statistics clearly prefer the German aggregate. 
Table 7.7 St. Louis equation: inflation*

\begin{tabular}{|c|c|c|c|c|}
\hline $\begin{array}{l}\text { Excl lagged in- } \\
\text { fation (\%) }\end{array}$ & AIC-test: & J-test: & JA-test: & F-test: \\
\hline Sum M2 & $\begin{array}{l}17.70 \\
\text { favours SGM2 }\end{array}$ & $\begin{array}{l}0.49,5.68 \\
\text { favours SGM2 }\end{array}$ & $\begin{array}{l}-0.65,1.33 \\
\text { indeterminate }\end{array}$ & $\begin{array}{l}1.48(0.2398) \\
2.16(0.0539)\end{array}$ \\
\hline Divisia $\mathbf{M} 2$ & $\begin{array}{l}-9.53 \\
\text { favours DM2 }\end{array}$ & $\begin{array}{l}4.62,1.48 \\
\text { favours DM2 }\end{array}$ & $\begin{array}{l}-0.85,-2.57 \\
\text { favours DGM2 }\end{array}$ & $\begin{array}{l}1.54(0.1897) \\
0.36(0.7803)\end{array}$ \\
\hline Sum M3 & $\begin{array}{l}-7.75 \\
\text { favours M3 }\end{array}$ & $\begin{array}{l}5.43,5.04 \\
\text { inconclusive }\end{array}$ & $\begin{array}{l}-1.41,-2.49 \\
\text { favours SGM3 }\end{array}$ & $\begin{array}{l}1.47(0.2129) \\
0.85(0.6042)\end{array}$ \\
\hline Divisia M3 & $\begin{array}{l}-3.52 \\
\text { favours DM3 }\end{array}$ & $\begin{array}{l}1.99,1.21 \\
\text { favours DM } 3\end{array}$ & $\begin{array}{l}1.58,0.07 \\
\text { indeterminate }\end{array}$ & $\begin{array}{l}1.55(0.2215) \\
0.82(0.4950)\end{array}$ \\
\hline \multicolumn{5}{|l|}{ Incl lagged $\pi$} \\
\hline Sum $\mathrm{M} 2$ & $\begin{array}{l}47.91 \\
\text { favours SGM2 }\end{array}$ & $\begin{array}{l}0.25,7.90 \\
\text { favours SGM2 }\end{array}$ & $\begin{array}{l}-0.64,1.03 \\
\text { indeterminate }\end{array}$ & $\begin{array}{l}1.06(0.3823) \\
3.83(0.0052) \\
\end{array}$ \\
\hline Divisia M2 & $\begin{array}{l}-11.56 \\
\text { favours DM2 }\end{array}$ & $\begin{array}{l}3.71,0.37 \\
\text { favours DM2 }\end{array}$ & $\begin{array}{l}0.25,-0.87 \\
\text { indeterminate }\end{array}$ & $\begin{array}{l}1.36(0.2658) \\
0.22(0.8787)\end{array}$ \\
\hline Sum M3 & $\begin{array}{l}7.31 \\
\text { favours SGM3 }\end{array}$ & $\begin{array}{l}2.61,4.95 \\
\text { inconclusive }\end{array}$ & $\begin{array}{l}-1.10,0.03 \\
\text { indeterminate }\end{array}$ & $\begin{array}{l}0.90(0.5364) \\
1.10(0.4144)\end{array}$ \\
\hline Divisia M3 & $\begin{array}{l}1.82 \\
\text { fawours DGM3 }\end{array}$ & $\begin{array}{l}1.13,1.40 \\
\text { indeterminate }\end{array}$ & $\begin{array}{l}0.69,-0.02 \\
\text { indeterminate }\end{array}$ & $\begin{array}{l}0.49(0.6946) \\
0.79(0.5082)\end{array}$ \\
\hline
\end{tabular}

* For explanation of test-statistics and notes see table 7.6.

The conclusion from table 7.7 is that growth of the German sum M2 aggregate explains Dutch inflation better than growth of the corresponding Dutch aggregate. We may also cautiously conclude that Dutch Divisia M2 outperforms the German equivalent as indicator of inflation. At the other aggregation levels, no unambiguous conclusions can be reached, since the test-statistics give contradictory results for the St. Louis equations with and without lagged inflation. In general, the above presented St. Louis tests do not give rise to any clearcut results as to whether Dutch or German monetary aggregates are better indicators of the Dutch real and nominal growth path.

\subsection{Conclusion}

Because the Dutch central bank has been targeting the exchange rate with Germany during the seventies and eighties to ensure price stability, this chapter analyses whether German simple-sum and Divisia indices of money are potential indicators of Dutch inflation and/or real growth.

German monetary aggregates are used over the EMS-period 1979-1993. Dutch short-term interest rates are well explained by the two German M3 aggregates and by sum M2. All German aggregates, except Divisia M3, appear as significant determi- 
nants of Dutch inflation in the short-run. Additionally, for these three German aggregates, there is evidence of the Dutch inflation rate being also determined by German monetary policy through long-run equilibrium restoring tendencies. German simplesum aggregates dominate their Divisia counterparts as indicators of Dutch inflation. All four German aggregates explain real income growth in the Netherlands similarly well.

At short time intervals, German Divisia M2 provides even better out-of-sample forecasts of Dutch inflation than Dutch money measures. Real income growth forecast errors are mostly smaller for German sum aggregates than for their Divisia equivallents. Overall, the differences in indicator performance of the German aggregates for the Dutch economy are only marginal.

A direct comparison of the performance of Dutch and German monetary aggregates in a St. Louis framework does not give clearcut results for the period 1979-1993. The information content of Dutch and German aggregates for the Dutch economy is quite similar, probably due to the exchange rate policy of the Dutch central bank which in effect makes the Dutch money supply an endogenous variable, closely responding to developments in German monetary conditions. Since Dutch exports of goods and services are also included in the analysis of this chapter, we may conclude that most German money measures provide incremental information about Dutch inflation and real income growth. In other words, German monetary aggregates matter for the Dutch economy. 


\section{SUMMARY AND CONCLUSIONS}

\subsection{Summary and evaluation}

This thesis takes the currently widely accepted view that money matters as a starting point. More specifically, it has become generally recognised in modern macroeconomics that money supply shocks are important determinants of business cycle fluctuations and that excessive money growth leads to inflation in the intermediate term. This explains why central banks in many industrialised economies have, since the 1970 s, adhered to a policy of targeting the growth rates of monetary aggregates to achieve their ultimate policy objective of price stability. Instabilities in the demand for money during the 1970s and 1980s, however, have led many central banks to abandon this policy in the past few years. Monetary policy is now frequently implemented through manipulation of short-term interest rates and via direct inflation targeting.

With an application to the case of the Netherlands, this thesis analyses whether these observed instabilities in the demand for the traditional monetary aggregates have been caused by measurement errors as to what comprises money. An important source of measurement error may be the substitutability between the components of monetary aggregates and other liquid financial assets. This substitution affects the appropriate definition of money and, additionally, the (stability of the) demand for monetary aggregates. Consequently, the usefulness of monetary aggregates as indicators for monetary policy is also influenced. Such measurement errors may be reflected in the traditional simple-sum monetary aggregates, because these assume that their component assets are perfect substitutes and that there is no substitution at all with financial assets outside the aggregates. These conditions are unlikely to be met in practice, since a whole spectrum of financial assets with different characteristics is available to the public nowadays.

The importance of measurement error for instabilities in the demand for these simple-sum aggregates is investigated along two lines. First, this study examines how a theoretically correct definition of the flow of monetary services should be constructed and whether the theoretical conditions for simple-sum aggregation in the Netherlands are fulfilled. The second objective of the thesis is to analyse whether a theoretically correct measure of money that takes into account the potential imperfect substitutability between financial assets is an appropriate indicator of the state of the economy in the Netherlands. The relative usefuness of simple-sum and weighted monetary aggregates as monetary policy indicators, and in particular as indicators of 
inflation, may be interpreted as an indication of the relative stability of demand for the respective money measures.

The thesis shows that a correct measure of the flow of monetary services in an economy (which is what monetary aggregates should deal with) should be founded on microeconomic consumer demand theory and on index number theory. Chapter 2 provides a survey of the international empirical literature on the measurement of monetary services. It appears that many monetary aggregates, which have traditionally been used for policy purposes, are not in accordance with theoretical considerations. Furthermore, the components of such aggregates are imperfect substitutes, or even complements, indicating that simple-sum aggregation over these components is inappropriate. The evidence for different countries shows that theoretically correct (weighted) monetary aggregates, however, do not clearly outperform their simplesum equivalents as inflation and real growth indicators.

In chapter 3 the underlying microeconomic theory for consistent aggregation is explained in more detail. It is shown that optimizing behaviour of economic agents determines whether an aggregate defined over a number of goods or assets is considered as an elementary good. An aggregate is assumed to behave as an elementary good if preferences over its components are independent of goods or assets which are excluded from the aggregate. The necessary condition for consistent aggregation over a group of goods or assets is called weak separability. Weak separability should be fulfilled before small-scale economic models can be applied in empirical analysis. With respect to monetary theory it implies that separate analysis of the monetary sector can only be justified if it appears weakly separable from the real sector. Using Varian's (1982 and 1983) nonparametric test this first type of separability is confirmed for most monetary groups analysed with annual Dutch data. The test is adjusted in order to correct for the effect of budget increases over time. Without this adjustment, the results of weak separability tests may seriously be affected by this income effect dominating pure substitution effects between the aggregates" components. In general, the adjusted test shows more violations of the weak separability conditions than the unadjusted test.

My objective in chapter 3 is to define monetary aggregates in such a way that they are weakly separable from other financial assets. It appears that violations of weak separability are frequently found when a long period of time is analysed. This suggests that the violations are mainly caused by inconsistency with demand theory for observations which are far apart in time, and that, essentially, only the transitivity axiom of consumer preferences is violated. An explanation for these violations may be found in the early $1970 \mathrm{~s}$ when adjustment costs of asset portfolios were relatively high compared with the 1980s. Moreover, the necessary conditions for weak separability of various monetary aggregates are mostly violated in less than $5 \%$ of the total number of combinations tested. The relatively small number of violations suggests that the rejections of weak separability are not significant.

In general, taking into account the $5 \%$ decision rule, the tests indicate that the Dutch M1 and the harmonised M3 aggregate, and an aggregate defined over M1 plus time deposits and savings may be considered weakly separable from other financial assets. The M2 aggregate, however, reveals more violations of demand theory than 
the other three definitions of money, especially when asset stocks are adjusted for budget increases. After $1981 \mathrm{M} 2$ also appears weakly separable from other financial assets. According to the outcomes of the nonparametric weak separability tests, there are still some doubts whether the M2 aggregate may be considered an elementary good. Similar results as with a portfolio for the whole economy are obtained for asset stocks held by households only. Again, M2 reveals many violations of demand theory.

After the admissible components of monetary aggregates have been determined in chapter 3 , chapter 4 provides the microeconomic and index number theory for the determination of the correct aggregation method over these components. Monetary aggregates should measure liquidity (or the flow of monetary services) in an economy, since liquidity is an important determinant of total spending and inflation. It is argued that a proper monetary aggregate should, therefore, take into account the different degrees of liquidity of financial assets, which are comparable to durable goods. The usually applied simple-sum aggregates measure the stock of money instead of the flow of monetary services, while all components of these aggregates are treated as perfect substitutes with the same degree of moneyness. A good proxy for the degree of liquidity of financial assets is the interest foregone when people hold their wealth in liquid form. Consequently, theoretically well-defined monetary aggregates can be calculated as weighted monetary aggregates and not as simple-sum aggregates. Theoretical research shows that such a weighted aggregate is the Divisia index, which is founded in microeconomic optimization decisions. The Divisia aggregate approximates the unknown utihity (or aggregator) function of economic agents over a whole spectrum of financial assets. Chapter 4 also presents some preliminary evidence of the differences between simple-sum monetary aggregates and their Divisia counterparts constructed for the Netherlands. Mostly, the Divisia aggregates' growth rates have been lower than the rates for the simple-sum aggregates, but the differences are only marginal. Velocity of Divisia M2, Divisia M3 and sum M3 is relatively closely related to the respective opportunity cost measures. This may be an indication that Divisia aggregates internalise pure substitution effects between their component assets rather well.

Chapter 5 uses price and quantity data for the main components (currency, demand deposits, short-term time deposits and savings) of the Dutch harmonised M3 aggregate to test whether these financial assets possess the same degree of moneyness and are, as a result, perfect substitutes. Stated differently, chapter 5 tests whether simple-sum aggregation over the main M3 component assets is allowed. Three different functional forms that can approximate the public's unknown utility (or aggregator) function over financial assets are used to derive systems of asset demand equations and estimate elasticities of substitution between the M3 components. The static and the dynamic Fourier function are global approximations, which allow the computation of time series of own- and cross-substitution elasticities between these financial assets. The translog utility specification, however, only provides a locall approximation to the unknown utility function and allows estimates of average elasticities. Since portfolio behaviour of the household sector differs substantially from the business sector's behaviour, the analysis is performed for the economy as a whole and for the 
two sectors separately. An inmovation to the existing literature is that our normalisation of fmancial assets' user costs leads to a homogeneous system of demand equations.

Overall, the estimated elasticities are as expected by demand theory. Substitution relationships between the $M 3$ component assets dominate, both at the aggregate and the sectoral level. The sectoral analysis shows that only currency and time deposits (in the business sector) and currency and savings (in the household sector) are complementary assets. These complementarity results are obtained with all three functional forms: the only exception is the translog specification, which shows that currency and savings are substitutes. In general, however, the translog utility function does not give reasonable estimates of the magnitudes of the substitution elasticities. The contra-intuitive results provided by the translog demand system may be caused by the local approximation of the consumer"s unknown utility function and the imposition of curvature restrictions, which affects the flexibility of the approximation.

The magnitudes and time-paths of the estimated elasticities are different for the static and the dynamic Fourier function, but the conclusions about substitutability or complementarity between assets are not affected by the choice of the global approximation to the utility function. Overall, the time series evidence obtained with the two Fourier specifications reveals that the estimated elasticities are relatively stable over the period 1972-1993. In the business sector, however, the elasticities show down- or upward trends after 1988 (in the dynamic Fourier version). These trends may be explained by observed changes in the expenditure shares of the assets in the business sector's portfolio in this time period. The results indicate that the dynamic Fourier function gives a good view of portfolio behaviour in the business sector, whereas the static Fourier estimates household behaviour in a satisfying way.

The hypothesis of perfect substitution within one simple sum aggregate, be it M1 or harmonised M3, clearly has to be rejected. Consequently, the analysis into the degree of substitution between the main components of harmonised M3 shows that simple-sum aggregates in the Netherlands do not measure the flow of monetary services appropriately. Since Divisia monetary aggregates are more suitable to incorporate differences in the degree of moneyness of various financial assets, breaks in income velocity may be avoided with Divisia money measures. The stability of the estimated elasticities, however, may explain why Dutch simple-sum and Divisia. monetary aggregates show a similar behaviour over time. This stability indicates that changes in relative prices between the M3 components have not been responsible for instabilities in money demand in the Netherlands. Portfolio behaviour in the business sector seems to have been the main source of money demand instability in the Netherlands. On the other hand, the differences between the two aggregation methods may be more pronounced when monetary aggregates are calculated at the sectoral level. Generally, our findings throw additional doubt on the use of simple-sum aggregates and call for a disaggregated monetary analysis.

The results so far show that simple-sum aggregates are unable to measure the flow of monetary services in the Netherlands properly. In theory it is clear, by now, that waighted aggregates are to be preferred in this respect, since these can better incorporate the imperfect substitution between the different financial assets. The 
above findings do not imply, however, that weighted (Divisia) aggregates are also better indicators for monetary policy in general, and for inflation in particular. To answer this question, chapter 6 compares the relative performance of simple-sum and Divisia monetary aggregates as indicators of inflation and real growth in the Netherlands.

As a first test, conventional St. Louis equations, that take into account the openness of the Dutch economy, are estimated. Causality tests, in which short-run effects and deviations from long-run equilibrium are included, provide additional evidence on the indicator properties of simple-sum and Divisia aggregates. Because of the importance of the short-term interest rate for the stabilisation of the exchange rate of the guilder to the German mark, the interest rate is included as a potential monetary indicator as well. Finally, out-of sample forecasts are used to tesc the relative stability of the different money measures.

Only over the EMS period do all monetary aggregates, except sum M2, show a significant impact on inflation. Divisia growth rates tend to outperform their simplesum equivalents as indicators of real growth and inflation. The results for the EMS period suggest that the short term interest rate may be the preferred inflation indicator in the Netherlands. Additionally, Divisia M3 could be monitored as well because of its relevance for inflation and especially real growth. In addition, Divisia M3 has the overall best performance in forecasting inflation out-of-sample. The results suggest that Divisia M3's velocity has been more stable than sum M3's velocity since 1979.

Overall, the evidence in chapter 6 is in favour of using Divisia aggregates as indicators of inflation and real growth, although not as strongly as might theoretically be expected. Especially at the harmonised M3 aggregation level, it appears that the Divisia money measure generally has better indicator properties for inflation and real income growth than its simple-sum counterpart. One explanation for the observation that Divisia indices do not consistently dominate their simple-sum equivalents is the low and gradual degree of financial innovation in the Netherlands. When the speed of financial innovation increases, the advantages of Divisia aggregates may become clearer. Although the evidence in favour of one of the two aggregation methods is mixed, we do observe that monetary aggregates have become more informative about future inflation, in particular in the period 1979-1993, than was the case in the period from 1965 onwards. This may be due to the increased importance attached to price stability since the late seventies.

Because the Dutch central bank has been targeting the exchange rate with Germany during the seventies and eighties to ensure price stability, chapter 7 analyses whether German simple-sum and Divisia indices of money are potential indicators of Dutch inflation or real growth. The results show that German aggregates contain additional information about real growth, inflation and interest rates in the Netherlands. In contrast to the evidence with Dutch aggregates, German simple-sum aggregates dominate their Divisia counterparts as indicators of Dutch inflation. Chapter 7 also shows that the information content of Dutch and German aggregates for the Dutch economy is quite similar. This outcome is probably due to the exchange rate policy of the Dutch central bank which in effect makes the Dutch money supply an 
endogenous variable closely responding to developments in German monetary conditions.

In conclusion, we can state that a theoretically correct definition of the flow of monetary services in the Netherlands is clearly provided by Divisia aggregates. Their relevance for monetary policy is, however, not as evident as theory suggests, since the empirical advantages of Divisia aggregates over simple-sum aggregates are relatively small in terms of their usefulness as indicators of inflation and real growth. Nevertheless, it may be appropriate to use Divisia monetary aggregates (and Divisia $\mathrm{M} 3$ in particular) as additional indicators in monetary policy, since these money measures can easily deall with changes in the characteristics of financial assets, which are likely to occur at higher frequencies in the future. Furthermore, since Divisia aggregates are designed to measure transactions money in the economy, these indices should, at least in the longer run, be closely related to nominal spending.

\subsection{Directions for future research}

The advantages of weighted monetary aggregates as opposed to simple-sum aggregates may, however, still be underestimated due to misspecification of these weighted measures of money. Future research into the substitution between financial assets may be directed at finding a better measure of the assets' user costs. The rental prices used in this thesis are constructed taking into account only the return side of financial assets, computing the rental price as the difference between two interest rates. Recently, however, holders of several financial assets have been confronted with the imputation of bank charges on the use of these assets. An example of this tendency is the charge on the use of checks if more than a specified number of checks are drawn on a demand deposit. Another important, but unresolved, problem in this direction of research concerns the modelling of the dynamics in asset demand systems. How should we incorporate adjustment costs in a portfolio model of an optimizing economic agent? Our dynamic formulation of the Fourier demand system in chapter 5 is an attempt to shed more light on this issue.

Other directions of possibly fruitful further analysis concern the inclusion of the effects of technological progress on different financial assets. The approach by Ford et al. (1992) seems a promising first step in this direction. The effects of technological improvements on financiall assets are important for both the substitutability issue between assets and for the correct determination of the flow of monetary services.

As our sectoral analysis in chapter 5 shows, portfolio behaviour of the business sector is clearly different from that of households. Since the subject of the correct measurement of monetary services is founded in microeconomic behaviour of economic agents, a sectoral analysis may be used to construct sectoral money indices and, as such, to improve the quality of the existing weighted aggregates.

Finally, future research could try to integrate the demand and the supply side of the market for monetary services in order to improve monetary authorities' control opportunities of inflation (see Barnett, Hinich and Weber, 1986 and Hancock, 1987). 
Anderson, R.G. and K.A. Kavajecz (1994), A. Historical Perspective on the Federal Reserve"s Monerary Aggregates: Definiton, Construction and Targeting, Federal Resene Bank of St. Low Review (Proced dings of the Eighteenth Annual Economic Policy Conference "Money Stock Measurement: History, theory and Implications"), vol. 76, no. 2, pp. 1-31.

Ayuso, J. and J.L. Vega (1993). Weighted Monetary Aggregates: ha Spanush Case. Documento de Trabajo no. 9303, Banco de España. Madrid.

Bank for Intemational Settements (1994), 64th Ammal keport, Basle.

Barnett, W.A. (1978), The user cost of money, Econonics Letters, 1, pp. 145-149.

Barnett, W.A. (1980a), Economic Monetary Aggregates, An Application of Index Number and Aggregation Theory, Journal of Econonetrics, vol. 14 , pp. 11-48.

Barnett. W.A. (1980b), Economic Monetary Aggregates - Reply, Journal of Econometrics, vol. 14, Pp. 57.59 .

Bamett, W.A. (1981), Consumer Denand and Labor Supply: Goods, Monetary Assets, and Thme, North-Holland, Ansterdam

Barmet, W.A. (1982), The Optimal Level of Monetary Aggregation, Journot of Money, Credit, and Banking, wol. 14, no. 4, pp. $687-710$.

Barnet, W.A. (1983), New Indices of Money Staply and the Hexible Laurent Demand System. Joumal of Business and Economic Sratistics, wol. 1, no. 1. pp. 7-23.

Barnet, W.A. (1984), Recen Monetary Policy and the Divisia Monetary Aggregates, The Anertcan Statistician, vol. 38, no. 3 , pp. $165-172$.

Barnet, W.A. and S. Choi (1989), A Monte Carlo Study of Tests of Blockwise Weak Separability. Jounal of Business and Economic Starisrics, vol. 7, no. 3, pp. 363-377.

Barnet, W.A., D. Fisher and A. Serletis (1992). Consumer Theory and the Demand for Money, Jounnal of Economic Literante, vol. 30, pp. 2086-2119.

Barnett, W.A., M.I. Hind and W.E. Weber (1986), The Regulatory Wedge between the DemandSide and Supply-Side Aggregation-Theoretic Monetary Aggregates, Journal of Econometrics, vol. 33, pp. $165-185$.

Barnett, W.A. E.K. Offenbacher and P.A. Spindt (1981), New Concepts of Aggre-gated Money, Journal of Finance, vol. 36, no. 2, pp. 497-505.

Barnett, W.A., E.K. Offenbacher and P.A. Spindr (1984), The New Divisia Mone-tary Aggregates, Joumal of Political Economy, vol. 92, no. 6, pp. 1049-1085.

Barnett, W.A. and P. Yue (1988), Semiparametric estimation of the asymptotically ideal model: the AM demand system, in: G.F. Rhodes and T.B. Fomby, Advances in Econometric: Nonparametric and Robiast inference, vol. 7, pp. 229-251.

Belongia, M.T. and J.A. Chaltant (1989), The Changing Empirical Definition of Money: Some Estimates from a Model of the Demand for Money Substitutes, Journal of Polidical Erconomy. vol. 97, no.2, pp. 387-397.

Belongia. M.T. and J.A. Chalfane (1990), Alternative Measures of Monxy as Indicators of Inflation: A Survey and Some New Evidence, Federal Reserve Bank of St. Louis Revew, vol. 72, no. 6 , pp. 20-33.

Belongia, M.T. and K.A. Chrystal (1991), An Admissible Monetary Aggregate for the United Kingdom, Review of Economics and Statistics, vol. 73, pp. 497-503.

Berk, I.M. and C.C.A. Winder (1994), Price movements in the Netherlands and Germany and the guilder-Dmatk peg, De Economist, voll. 142, no. 1, pp. 63-74.

Berndt, E.R. and N.E. Savin (1975), Estimation and Hypothesis Testing in Singular Equation Systems with Autoregressive Disturbances, Econonetrica, wol, 43, no. 5-6, pp. $937-957$.

Blundell-Wignal1, A., F. Browne and P. Manasse (1990), Monetary Polloy in the Wake of Financial Liberalisation, OECD Working Papers, no. 77.

Boughton, J.M. (1991). Long-run money demand in large industrial countries, MF staff Papers, 38 , pp. 1.32 . 
Boughton, J.M. (1992), Internarional comparisons of money demand: a review essay, MF Working Papers.

Chalfant, J.A and J.M. Alston (1988). Accounting for Changes in Tastes, Joumal of Political Economy, vol. 96, no. 2, pp. $391-410$.

Chetty, V.K. (1969), On Measuring the Nearness of Near-Moneys, American Econ-omic Review, vol. 59, no. 3, pp. $270-281$.

Chrystal, K.A. and R. MaeDonald (1994), Empirical Evidence on the Recent Beha-vior and Usefulness of Simplesum and Weighted Measures of the Money Stock, Federal Reserve Bank of St. Louis Review (Proceedings of the Eighteenth Annual Economic Policy Conference "Money Stock Measurement: History, Theory and Implications"), vol. 76, no. 2, pp. 73-109.

Clements, K.W. and P. Nguyen (1980), Economic Monetary Aggregates - Comment, Joumal of Econometrics, vol. 14, pp. $49-53$.

Collins, S. and C.L. Edwards (1994), An Alternative Monetary Aggregate: M2 Plus Household Holdings of Bond and Equity Mutual Funds, Federal Reserve Bank of St. Louis Review, vol. 76, no. 6, pp. 7-29.

Davidson, R. and J,G. Mackinnon (1993), Estimation and Inference in Econometrics, Oxford Universily Press, New York, Oxford.

Deaton, A. and J. Muellbauer (1988), Economics and consumer behawior, reprint, Cambridge University Press, Cambridge.

De Long, J.B. and L.H. Summers (1992), Macroeconomic Policy and Long-Run Growth, in: Policies for Long-Run Economic Growh, Symposium Federal Reserve Bank of Kansas City, Jackson Hole, Wyoming, pp. $93-128$.

De Nederlandsche Bank, Anmual Report, various issues, Amsterdan.

De Nederlandsche Bank, Quarterly Bulletin, various issues, Amsterdam.

Dennis, G.E.J. (1983), Monetary aggregates and economic activity: evidence from five industrial countries, BLS Economic Papers, no. 7, Basle.

Denny, M. and M. Fuss (1977), The Use of Approximation Analysis to Test for Separability and the Existence of Consistent Aggregates, Americcon Economic Review, vol. 67, no. 3, pp. 404-418.

Dickey, D.A. and W.A. Fuller (1979), Distribution of the estimators for autore-gressive time series with a unit root, Joumal of the American Statistical Association, vol. $74, \mathrm{pp} .427-431$.

Diewert, W.E. (1974), Applications of duality theory, in: M.D. Intriligator \& D.A. Kendrick (eds.), Frontiers of Quantitative Economics, Volume II, NorthuHolland Publishing Company, pp. 106176.

Diewert, W.E. (1976), Exact and Superlative Index Numbers, Journal of Econometrics, vol. 4, pp. $115-145$.

Diewert, W.E. (1980), Aggregation Problems in the Measurement of Capital, in: $\mathbb{D}$. Usher. The Measurement of Capital. Studies in Income and Wealth, vol. 45. University of Chicago Press, Chicago, pp. 433-538.

Donovan, D.J. (1978), Modeling the Demand for Liquid Assets: An Application to Canada, IMF Staff Papers, 25 . pp. 676-704

Drake, L. (1992). The substitutability of financial assets in the U.K. and the implications for monetary aggregation. The Monchester School, wol. 60 (3), pp. 221-248.

Drake, L., K.A. Chrystal and J. Binner (1994), Weighted Monetary Aggregates for the UK, paper presented at Conference "Divisia Monetary Aggregates: Right in Theory - Useful in Practice?", organised by the University of Mississippi, Oxford, USA, October.

Duisenberg, W.F. (1994), Prijsstabiliteit en woelige financiele wateren, ESB, vol. 79, no. 3983, pp. 984.987.

Ees, H. wan, E. Sterken, D. Wansink and A.A.T. Wesseling (1989), Gevolgen van tinanciële innovatie in Nederland, in: J. de Haan and L.H. Hoogduin (eds.), De gevolgen van financiële innowate en integratie voor het montaire beleid, NIBE, Amsterdam, pp. 60-93.

Ewis, N.A. and D. Fisher (1984), The Translog Utility Function and the Demand for Money in the United States, Journal of Money, Credit, and Banking, vol. 16, no. 1, pp. 34-52. 
Ewis, N.A. and D. Fisher (1985), Toward a Consistent Estimate of the Demand for Monies: An Application of the Fourier. Flexible Form, Jounal of Macroeconomics, vol. 7, no. 2, pp. 151174.

Fase, M.M.G. (1975), Verruiming of werschraling, Een poging her liquiditeitsbegrip empirisch af te bakenen, Selecte Studies, Rabobank, pp. 7-31.

Fase, M.M.G. (1978), Een verdeelmodel voor liquide activa, De overheveling als vootbeeld van toegepaste economie, ESB, pp. 215-218.

Fase, M.M.G. (1979), The Demand for Financial Assets, Time Series Evidence for The Neherlands: 1963-II-1975:IV, European Economic Review, vol. 12, pp. 381-394.

Fase, M.M.G. (1985), Monetary Control: The Dutch Experience, in: C. van Ewijk and J.J. Kant (eds.), Monetary Conditions for Economic Recovery. Financial and Monetary Policy Studies, 11. Martinus Nijhoff Publishers, Dordrecht etc., pp. 95-125.

Fase, M.M.G. (1987), Geld en inkomen: een macro-economisch debat van 25 jaar, in: H.W.J. Bosman and J.C. Brezet, Sparen en Investeren, Geld en Banken, Stenfert Kroese, Leiden/Ant werpen, pp. $187-214$.

Fase, M.M.G. (1992), Over geld en monetair beleid in Nederlands en Europees perspectief, Mededelingen wan de Afleling Letterkunde. Nieuwe Reeks, Koninklije Nederlandse Academie van Wetenschappen, Amsterdam, vol. 55, no. 7.

Fase, M.M.G. (1994), Divisia Measures and the Dernand for Money in the Hard Core of EMU, paper presented at Conference "Divisia Monetary Aggregates: Right in Theory - Useful in Practice?", organised by the Uniwersity of Mississippi, Oxford, USA, October.

Fase, M.M.G. and M.E.J Schuit (1992), Monetaire aggregatie en de Divisia-index, Machdschrift Economie, vol. 56, pp. 434-449.

Fase, M.M.G. and C.C.A. Winder (1990), The Demand for Money in The Nether-lands Revisited, De Economist, vol. 138, no. 3, pp. 276-301

Fase, M.M.G. and C.C.A. Winder (1994), De geldhoeveelheid in de EMU: een analyse met de Diwisia-maatstaf, Kwartaalberich, September, De Nederlandsche Bank, Amsterdam, pp. $27-58$.

Feige, E.L. and D.K. Pearce (1977), The Substitutability of Money and Near-Monies: A Survey of the Time-Series Evidence, Journal of Economic Literature, vol. 15, pp. 439-469.

Feldstein, M. (1993), The Recent Failure of U.S. Monetary Policy, De Economist, vol. 141, no. 1, pp. $29-42$.

Fisher, D. (1989), Money Demand and Monetary Policy. Harwester Wheatsheaf, New York.

Fisher, D. (1992), Money-Demand Variability: A Demand-Systems Approach, Journal of Business and Economic Statistics, vol. 10, no. 2, pp. 143-151.

Fisher, D. and A. Fleissig (1994), Money Demand in a Flexible Dymanic Fourier Expenditure System, Federal Reserve Bank of St. Louis Review (Proceedings of the Eighteenth Annual Economic Policy Conference "Money Stock Measurement: History, Theory and Implications"), vol. 76, no. 2, pp. 117-128.

Fisher, P., S. Hudson and M. Pradlhan (1993), Divisia Indices for Money: An Appraisal of Theory and Practice, working paper no. 9, Bank of England, London.

Fluri, R. and E. Spoerndli (1994), Simple Sum vs. Divisia Money in Switzerland: Some Empirical Results, paper presented at Conference "Divisia Monetary Aggregates: Right in Theory Useful in Practice?", organised by the University of Mississippi, Oxford, USA, October.

Ford, J.L, W.S. Peng and A.W. Mullineux (1992), Financial Innovation and Divisia Monetary Aggregates, Oxford Bulletin of Economics and Statistics, vol. 54, no. 1, pp. 87-1.02.

Fuller, W. A. (1976), Introduction to Statistical Time Series, Wiley, New York.

Gallant, A.R. (1981), On the Bias in Flexible Functional Forms and an Essentially Unbiased Form, Journal of Econometrics, vol. 15, pp. $211-245$.

Gauger, J, and H.A. Black (1991), Asser Substitution and Monetary Volatility Journal of Money, Credit, and Banking, vol. 23, no. 4, pp. 677-691.

Gauger, J.A. and J.R. Schroeter (1990), Measuring the Nearness of Modern Near-Monies: Evidence from the 1980s, Journal of Macroeconomics, vol. 12, no. 2, pp. $247-261$. 
Gurley, J.G. and E.S. Shaw (1960), Money in a Theory of Finance, Brookings Insintute, Washington, D.C.

Haan, L, de, C.G. Koedijk and J.EJ. de Vrijer (1992), De stijging wan het liquidictsbezit in de jaren tachtig. Monetaire Monografieen 12. De Nederlandsche Bank, Amsterdam.

Haan, L. de, C.G. Koedijk and J.E.J. de Vrijer (1994), Buffer stock money and pecking order financing: Results from an interview study among Dutch firms, De Economist, vol. 142 (3). pp. 287-305.

Hahm, J.H and J.T. Kim (1994), The Signals from Divisia Money in a Rapidly-Growing Economy, paper presented at Conference "Divisia Monetary Aggregates: Right in Theory - Useful in Practice?" "organised by the Uniwersity of Mississippi, Oxford, USA, October.

Hancock, D. (1987), Aggregation of monetary goods: a production model, in: W.A. Barnett and KJ. Singleton (eds.), New Approaches to Monetary Economics, Proceedings of the second international symposium in economic theory and econometrics, Cambridge University Press, Cambridge etc., pp. $200-218$.

Hermann, H., H.-E. Reimers and K.H. Toedter (1994), Weighted Monetay Aggregates for Germany, paper presented at Conference "Divisia Monetary Aggregates" Right in Theory Useful in Practice?", organised by the University of Mississippi, Oxford, USA, October.

Hester, D.D. (1981), Innovations and Monetary Control, Brookings Papers on Economic Activity, no. 1, pp. 141-189.

Hsiao, C. (1979), Causality Tests in Econometrics, Journal of Economic Dynawics and Control, vol. 1, pp. $321-346$.

Husted, S. and M. Rush (1984), On Measuring the Nearness of Near-Moneys, Joumal of Monetary Economics, vol. 14, pp. $171-181$.

Ishida, K. and K. Nakamura (1994), Broad and Narrow Monetary Aggregates for Japan, paper presented it Conference "Divisia Monetary Aggregates: Right in Theory - Usefull in Practice?", organised by the University of Mississippi, Oxford, USA, October.

Janssen, N.G.J. and C.J.M. Kool (1994). The Components of M3. Substitution Elasticiries in the Netherlands, 1972-1992, Research Memorandum, University of Limburg, Maastricht.

Janssen, N.G.J. and A.P. van Veen (1990), Financiële innovaties: achtergrond en betekenis, ESB, vol. 75 , no. 3769 , pp. $728-732$.

Johansen, S. (1988), Statistical Analysis of Cointegration Vectors, Joumal of Economic Dynamics and Control, vol. 12, pp. 231,-254.

Johansen, S. (1991), Estimation and Hypothesis Testing of Cointegration Vectors in Gaussian Vector Autoregressive Models, Econontetrica, vol. 59, no. 6, pp. 1551-1580.

Johansen, S. and K. Juselius (1990), Maximum Likelihood Estimation and Inference on Cointegration - with Applications to the Demand for Money, Oxford Bulletin of Econonics and Statistics, vol. 52, no. 2, pp. 169-210.

Judd, J.P. and J.L Scadding (1982), The search for a stable money demand function, Journal of Economic Literature, 20 , pp. $993-1023$.

Judge, G.G., R.C. Hill, W.E. Griffiths, H. Läkepohl and T-C. Lee (1988), Introduction to the Theory and Practice of Econometrics, second edition, Wiley, New York.

Kaln, G.A. (1992), Policies for Long-Run Economic Growth: A Summary of the Bank's 1992 Symposium, Economic Review, Federal Reserve Bank of Kansas City, wol. 77, no. 4, pp. 31-40.

Kavajecz, K.A. (1994), The Evolution of the Federal Reserve's Monetary Aggre-gates: A Timeline, Federal Reserve Bank of St. Lowis Review (Proceedings of the Eighteenth Annual Economic Policy Conference "Money Stock Measurement: History. Theory and Implications"), vol. 76, no. 2, pp. 32-66.

Kool, C.J.M. (1995), The Case for Targeting Domestic Money Growth under Fixed Exchange Rates: Lessons from the Nether]ands. Belgium, and Austria: 1973-1992, forthooming in De Econonist.

Kool, C.J.M. and J.A. Tatom (1994), The P-Star Model in Five Small Economies, Federal Reserve Bank of St. Louis Review, vol. 76, no. 3, pp. 11-29. 
Kuipers, $S . K$, and $B$. Boertie (1988), On the causes of the rise in the liquidity ratio in the Netherlands during the early eighties, De Economist, vol. 136, no. 1, pp. 50-90.

Laidler, D. E.W. (1985). The Demand for Money, Theories, Evidence, and Problems third edition. Harper and Row, New York.

Lee, T.H. (1966), Substitutability of Non-Bank Intermediary Liabilities for Money: The Empirical Ewidence, Journal of Finance, vol. 21, pp. $441-457$.

Lee, T.H. (1972), On Measuring the Nearness of Near-Moneys: Comment, Amterican Economic Review, wol. 62, no. 1, pp. 217-220.

Lim, G.C. and V.L. Martin (1994), Weighted Monetary Aggregates: Empirical Evidence for Australia. paper presented at Conference "Divisia Monetary Aggregates: Right in Theory - Useful in Practice?", organised by the University of Mississippi, Oxford, USA, October.

Longworth. D. and J. Atta-Mensah (1994), The Canadian Experience with Weighted Monetary Aggregates, paper presented at Conference "Divisia Monetary Aggregates" Right in Theory Useful in Practice?", organised by the University of Mississippi, Oxford, USA, October.

Loo, P.D. van (1983), A sectoral andysis of the Dutch financial system, Stenfert Kroese, Leiden/ Antwerpen.

Marquez, J. (1987), Money demand in open economies: a Divisia application to the U.S. case, in: W.A. Barnett and K.J. Singleton (eds.), New Approaches to Monetary Economics, Proceedings of the second international symposium in economic theory and econometrics, Cambridge University Press, Cambridge etc., pp. 183-199.

McCallum, B.T. (1987). The Case for Rules in the Conduct of Monetary Policy: A Concrete Example, Weltwirtschaftiches Archiv, 123, pp. 415-429.

McCallum, B.T. (1988), Robustness Properties of a Rule for Monetary Policy, Carnegie-Rochester Conference Series on Public Policy, 29, pp. 173-203.

McCallum, B.T. (1989), Targets, lidicators, and Instruments of Monetary Policy, NBER working. paper, no. 3047 .

Milboume, R. (1986), Financial Innovation and the Demand for Liquid Assets, Joumal of Money, Credit, and Banking, vol. 18, no. 4, pp. 506-511.

Nelson, C.R. (1994), Commentary, Federal Reserve Bonk of St. Louis Review (Proceedings of the Eighteenth Anmual. Economic Policy Conference "Money Stock Measurement: History, Theory and Implications"), vol. 76, no. 2, pp. 110-116.

Offenbacher, E.K. (1980), Economic Monetary Aggregates - Comment, Joumal of Econometrics, vol. 14, pp. $55-56$.

Osterwald-Lenum, M. (1992), A Note with Quantiles of the Asymptotic Distribution of the Maximum Likelihood Cointegration Rank Test Statistics, Oxford Bulletin of Economics and Staristics, vol. 54, no. 3, pp. 461-472.

Pollard, P.S. (1993), Central Bank Independence and Economic Performance, Federat Reserve Bank of St. Louis Review, vol. 75, no. 4, pp. 21-36.

Poole, W. (1988). Monetary Policy Lessons of Recent Infation and Disinflation, Joumal of Econ omic Perspectives, vol. 2, no. 3, pp. 73-100.

Porter, R.D., T.D. Simpson and E. Mauskopf (1979). Financial Innovation and the Monetary Aggregates, Brookings Papers on Economic Activity, no. 1, pp. 213-229.

Rasche, R.H. (1994), Money Demand and the Term Siructure: Some New Ideas on an Old Problem, paper presented at the Konstanz Seminar on Monetary Theory and Monetary Policy, May $24-27$.

Rasche R.H. and J.M. Johannes (1987), Controlling the Growth of Monetary Aggregates, Rochester Siudies in Managerial Economics and Policy, Kluwer, Boston, etc.

Rotemberg, J.J., J.C. Driscoll and J.M. Poterba (1991), Money, Owtpu and Prices: Evidence From a New Monetary Aggregate, NBER working paper, no. 3824.

Serletis, A. (1987a), Monetary asset separability tests, in: W.A. Barnett and K.J. Singleton (eds.), New Approaches to Monetary Economics, Proceedings of the second international symposium in economic theory and ecomometrics, Cambridge University Press, Cambridge etc., pp. 169-182. 
Serletis, A. (1987b), The Demand for Divisia M1, M2, and M3 in the United States, Joumal of Macroeconomics, vol. 9, no. 4, pp. 567-591.

Serletis, A. (1988), The Empirical Relationship Between Money, Prices, and Income Revisited, Journat of Business and Economic Statistics, vol. 6, no. 3, pp. 35\$-358

Serletis, A. (1991). The Demand for Divisia Money in the United States: A Dynamic Flexible Demand System, Joumal of Money, Credit, and Banking, vol. 23, no. 1, pp. 35-52.

Serletis, A. and A.L. Robb (1986), Divisia Aggregation and Substitutability among Monetary Assets, Journal of Money, Credit, and Banking, vol. 18, no. 4, pp. 430-446.

Sims, G.E., A. Takayama and C. Chao (1987), A Dual Approach to Measuring the Nearness of Near-Monies, Review of Economics and Statistics, vol. 69, pp. 118-127.

Svensson, L.E.O. (1994), Fixed exchange rates as a means to price stability: What have we learned?, European Economic Review, vol. 38, pp. 447-468.

Swofford, J.L and G.A. Whitney (1986), Flexible Functional Forms and the Utility Aproach to the Demand for Money: A Nonparametric Analysis, Joumal of Money, Credit, and Barking, wol. 18 , no. 3, pp. 383-389.

Swofford, J.L and G.A. Whitney (1987). Nonparametric tests of utility maximization and weak separability for consumption, leisure and money, Review of Economics and Statistics, vol. 69, pp. 458-464.

Swofford, J.L and G.A. Whitney (1988), A Comparison of Nonparametric Tests of Weak Separability for Annual and Quarterly Data on Consumption, Leisure, and Money, Journal of Business and Economic Statistics, vol. 6, no. 2, pp. 241-246.

Swofford, J.L and G.A. Whitney (1990), Bounding an Economic Aggregate Under Nonhomothetic Preferences, Journal of Business and Economic Sratistics, vol. 8, no. 1, pp. 137-141.

Swofford, J.L and G.A. Whitney (1991), The Composition and Construction of Monetary Aggregates, Economic Inquiry, wol. 29, pp. 752-761.

Sijben, J.J. (1979), Rationele verwachtingen en de monetaire politiek, Stenfert Kroese, Leiden.

Thornton, D.L. and D.S. Batten (1985), Lag-Length Selection and Tests of Granger Causality between Money and Income, Journal of Money, Credit, and Banking, vol. 17, no. 2, pp. 164178.

Thornton, D.L. and P. Yue (1992), An Extended Series of Divisia Monetary Aggregates, Federal Reserve Bank of St. Louis Review, vol. 74, no. 6, pp. $35-52$

Varian, H.R. (1982), The nonparametric approach to demand analysis, Econometrica, 50, pp. 945973.

Varian, H.R. (1983), Non-parametric Tests of Consumer Behaviour, Review of Economic Siudies, 50. pp. $99-110$.

Varian, H.R. (1984), Microeconomic Analysis, second edition, Norton, New York, London.

Veen, A.P. van and N.G.J. Janssen (1990), Nieuwe Financiele Instmumenten, Over NIF, RUF, FRA, FRN, Swaps: Achtergrond en Betekenis, Research Memorandum, University of $\mathbb{L i m b u r g}$, Maastricht.

Wersch, M.P.F.M. van (1992), M3H: Het nieuwe Europese geldbegrip, Kwataalbericht, no. 3, De Nederlandsche Bank, Ansterdam, pp. 47-54.

Yue, P. and R. Fluri (1991), Divisia Monetary Services Indexes for Switzerland: Are They Useful foi Monetary Targeting?, Federal Reserve Bank of St. Lowis Review. vol. 73, no. 5, pp. 19-33. 


\section{SAMENVATTING}

Het uitgangspunt van dit proefschrift is dat geld de economische ontwikkeling in een land kan beinvloeden. De huidige macroeconomische theorie erkent dat schokken in het geldaanbod belangrijke fluctuaties in de conjunctuurcyclus veroorzaken en dat een excessieve groei van de geldhoeveelheid op termijn tot inflatie leidt. Sinds de jaren ' 70 zijn centrale banken in veel geïndustrialiseerde landen overgegaan op een beleid van doelzones voor de groei van monetaire aggregaten om zodoende hun uiteindelijke doelstelling van prijsstabiliteit te bereiken. Instabiliteiten in de vraag naar geld in de jaren ' 70 en ' 80 hebben er toe geleid dat veel centrale banken deze beleidslijn in de afgelopen jaren weer hebben verlaten. Tegenwoordig houdt monetaire politiek veelal in dat centrale banken de korte termijn interestwoet veranderen en door middel van directe doelzones de inflatie trachten te bestrijden.

In dit proefschrift wordt voor Nederland onderzocht of instabiliteiten in de vraag naar de traditionele monetaire aggregaten zijn veroorzaakt door fouten in de afbakening van het geldbegrip. Substitueerbaarheid tussen de componenten van monetaire aggregaten en andere liquide financiële activa kan een belangrijke bron van meetfouten vormen. Een dergelijke substitutie beïnvloedt de correcte definitie van het geldbegrip en bovendien de (stabiliteit van de) vraag naar monetaire aggregaten. Bovendien wordt de bruikbaarheid van monetaire aggregaten als indicator voor monetaire politiek door substitutie beïnvloed. Genoemde meetfouten komen in het bijzonder tot uitdrukking in de traditionele ongewogen (sommatie) aggregaten. Deze laatste aggregatiemethode veronderstelt dat de componenten van monetaire aggregaten perfecte substituten zijn en dat er geen substitutie naar andere financiële activa (buiten de aggregaten) optreedt. De praktijk komt slechts zelden met deze veronderstellingen overeen, aangezien het publiek tegenwoordig over een heel spectrum van financiële activa met uiteenlopende kenmerken kan beschikken.

Het belang van meetfouten voor instabiliteiten in de vraag naar sommatie aggregaten wordt op twee manieren geanalyseerd. In de eerste plaats wordt in deze studie onderzocht hoe een theoretisch correcte definitie van de monetaire dienstenstroom in een economie kan worden geconstrueerd. In de tweede plaats wordt nagegaan of een dergelijke correcte geldmaatstaf een bruikbare indicator voor de Nederlandse economische situatie vormt. Daarbij kan het verschil in bruikbaarheid van de sommatie en de gewogen monetaire aggregaten als indicatoren voor monetair beleid worden geïnterpreteerd als een indicatie voor de relative stabiliteit van de vraag naar deze aggregaten.

Het proefschrift toont aan dat een correcte maatstaf voor de monetaire dienstenstroom in een economie (monetaire aggregaten zouden in feite deze stroom moeten meten) gebaseerd dient te zijn op microeconomische principes en op de theorie van indexcijfers. Hoofdstuk 2 geeft een overzicht van de internationale empirische literatuur over de meting van monetaire diensten. Uit dit overzicht blijkt dat de (ongewogen) monetaire aggregaten die worden gebruikt voor beleidsdoeleinden niet voldoen 
aan de genoende theoretische uitgangspunten. De componenten van deze aggregaten zijn imperfecte substituten of zelfs elkaars complement.

In hoofdstuk 3 wordt de microeconomische theorie omtrent consistente aggregatie gedetailleerd besproken. Aggregaten van goederen of financiële activa gedragen zich als één goed indien preferenties over de afzonderlijke componenten onafhankelijk zijn van de consumptie van andere goederen of activa. Dergelijke aggregaten worden zwak scheidbalar genoemd. Uit het empirische gedeelte van dit hoofdstuk blijkt dat de Nederlandse monetaire aggregaten MI en M3 zwak scheidbaar zijn van de consumptie van goederen en van andere financiële activa. De gebruikte niet-parametrische toets geeft echter aan, dat M2 zich niet geheel conform de microeconomische vraagtheorie gedraagt.

Hoofdstuk 4 behandelt de theorie van de indexcijfers en enkele aspecten van de microeconomische theorie die noodzakelijk zijn om de correcte aggregatiemethode over de componenten van (zwak scheidbare) monetaire aggregaten te bepalen. Monetaire aggregaten dienen de liquiditeit (m.a.w. de monetaire dienstenstroom) in een economie te meten, aangezien liquiditeit een belangrijke determinant van bestedingen en inflatie vormt. Een geschikt monetair aggregaat dient rekening te houden met de verschillen in liquiditeit tussen financiële activa. Ongewogen sommatie aggregaten beschouwen alle elementen als perfecte substituten met dezelfde mate van liquiditeit. Een benadering voor de mate van liquiditeit van financiële activa wordt gevormd door de alternatieve interestkosten die mensen maken als ze hun vermogen in liquide vorm aanhouden. Derhalve zijn gewogen aggregaten wel in overeenstemming met de microeconomische uitgangspunten. Een dergelijk gewogen aggregaat is het Divisia aggregaat, dat elke onbekende nutsfunctie over een aantal financiële activa kan benaderen. De empirische analyse in hoofdstuk 4 geeft aan dat Divisia aggregaten pure substitutie-effecten tussen hun componenten goed kunnen internaliseren.

In hoofdstuk 5 wordt onderzocht of de belangrijkste elementen van het Nederlandse geharmoniseerde M3 geldbegrip (chartaal geld, giraal geld, kortlopende termijndeposito's en kortlopende spaartegoeden) dezelfde mate van liquiditeit bezitten. Dit gebeurt door substitutie-elasticiteiten tussen de financiële activa te schatten. De onbekende nutsfunctie (of aggregatiefunctie) over deze financiële activa wordt benaderd door 3 functionele wormen: de statische en de dynamische Fourier specificatie en de translog specificatie. De analyse wordt zowel uitgevoerd voor de gehele Nederlandse economie als voor bedrijven en gezinnen afzondlerlijk. Substitutierelaties tussen de componenten van M3 overheersen, op geaggregeerd en op sectoraal niveau, hoewel enkele combinaties van activa complementen blijken.

De geschatte tijdreeksen van substitutie-elasticiteiten blijken redelijk stabiel over de periode 1972-1993. De hypothese van perfecte substitutie tussen de componenten van het geharmoniseerde M3 geldbegrip dient echter te worden verworpen. Voorts bestaan er aanzienlijke verschillen in portefeuillegedrag van bedrijven en gezinnen. Ongewogen sommatie over de componenten van M3 geeft dan ook geen correct beeld van de monetaire dienstenstroom in de Nederlandse economie.

In hoofdstuk 6 worden de resultaten van een empirisch onderzoek naar de indicatoreigenschappen van ongewogen en Divisia monetaire aggregaten in Nederland besproken. Onderzocht wordt in hoeverre ongewogen en Divisia aggregaten kunnen 
fungeren als indicatoren voor inflatie en reële groei in Nederland. Hierbij worden St. Louis vergelijkingen en causaliteitstoetsen gebruikt, zodat de korte en de lange termijn effecten van geldgroei op inflatie en reelle groei kunnen worden geanalyseerd. Sinds het begin van het EMS blijken alle monetaire aggregaten, behalve het ongewogen M2 aggregaat, een significante invloed op de inflatie uit te oefenen. Groei in de Divisia aggregaten blijkt een betere voorspelling op te leveren van inflatie en reële groei in Nederland dan groei in de ongewogen aggregaten. Het Divisia M3 aggregaat lewert de beste voorspelkracht op voor inflatie.

De resultaten wat betreft de indicatoreigenschappen van ongewogen en Divisia aggregaten zijn niet zo duidelijk in het voordeel van Divisia aggregaten als theoretisch is te verwachten. Een verklaring hiervoor zou het lage innovatietempo in het Nederlandse financiële systeem kunnen zijn.

Hoofdstuk 7 bevat een vergelijkbare analyse als hoofdstuk 6 , maar nu worden de indicatoreigenschappen van Duitse ongewogen en Divisia monetaire aggregaten voor de Nederlandse inflatie en reèle groei onderzocht. De reden voor deze analyse is dat het beleid van De Nederlandsche Bank er sinds de jaren '70 op gericht is geweest de wisselkoers tussen de gulden en de DM te stabiliseren. Uit de analyse van hoofdstuk 7 blijkt dat Duitse en Nederlandse monetaire aggregaten vergelijkbare informatie bevatten over Nederlandse inflatie en reële groei.

De conclusie van dit proefschrift luidt dat Divisia monetaire aggregaten tot een theoretisch correcte definitie van de monetaire dienstenstroom in Nederland leiden. Het belang van Divisia aggregaten voor het Nederlandse monetaire beleid is echter nog niet zo groot, aangezien de empirische voordelen van Divisia aggregaten als indicator voor inflatie en/of reële groei vooralsnog beperkt zijn. 



\section{Curriculum Vitae}

Norbert Janssen (9 November 1964, Heerlen) attended Grammar School at the Bernardinuscollege in Heerlen between 1977 and 1983. From 1983 to 1988 he was studying Economics at Tilburg University, where he obtained his Master's degree. Between 1989 and 1991 the author was employed as a teaching assistant professor in Economics at the Faculty of Economics and Business Administration of the University of Limburg in Maastricht. He wrote his $\mathrm{Ph} . \mathrm{D}$. thesis while he was a research assistant (AIO) at this faculty between 1991 and 1995. Since 1 May 1995 Norbert Janssen has been employed at the Bank of England's Monetary Analysis Division as a Specialist Contractor. 


\section{ERRATUM}

p. 59: the right-hand side of equation (4.9) should be normalised to total expenditure on the monetary service flow in the period used as the base for the calculation of the Divisia quantity index. Equation (4.10) changes analogously. The dual Divisia price indices are now normalised to 0.01 in the base period for the respective series.

Consequently, the user cost series (dual price indices) for the Divisia aggregates in figures $4.7,4.9$ and 4.11 show a different behaviour over time. To illustrate how the new specification of the dual Divisia price index affects the relation between the velocity of Divisia aggregates and their user costs, the following figure shows this relation for Divisia M1. At the other aggregation levels the figures change analogously.

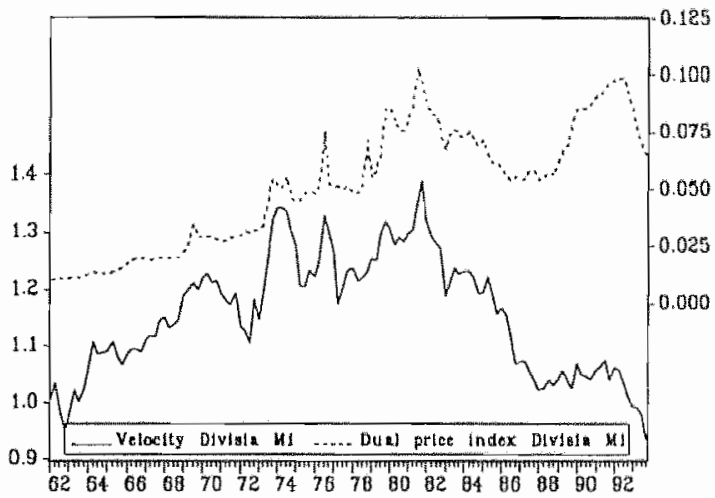

Figure 4.7 Velocity and user cost Div.M1

The time-series behaviour of the dual price indices for all three Divisia aggregates closely corresponds to that of sum Ml's minimum user cost, because all dual Divisia price indices measure the opportunity cost of monetary services (or, of holding transactions money). The relations between the two M1 velocity measures and their respective user costs appear to be very similar, although the correlation for Divisia M1 is slightly stronger than for sum M1.

At the M2 and M3 aggregation levels, the conclusions on pages 68 and 69 hardly change. Divisia M2 and Divisia M3 show marginally stronger correlations with their dual price indices than their sum counterparts. However, the relations between these Divisia aggregates and their user costs seem to have broken down in the mid 1980s.

Overall, Divisia aggregates seem slightly better predictable with their respective opportunity cost variables than sum aggregates.

Other parts of the thesis are not affected by the misspecification of equation (4.9). 